Alternativas Cuadernos de trabajo social

$\mathrm{N}^{\mathrm{o}} 22 \cdot 2015$ 
Alternativas. Cuadernos de Trabajo Social

No 22. Año 2015

\section{Dirección}

Ma Asunción Martínez-Román

masun.martinez@ua.es

Secretaria

Yolanda Domenech López

yolanda.domenech@ua.es

Comité Editorial/Editorial Board*

Andrés Arias Astray. Universidad Complutense de Madrid

Antonio Gorri Goñi. Universidad Pública de Navarra

Antonio López Peláez. Universidad Nacional de Educación a Distancia

Carmen Alemán Bracho. Universidad Nacional de Educación a Distancia

Carmen Barranco Expósito. Universidad de La Laguna

Cristóbal Torres Albero. Universidad Autónoma de Madrid

Fernando Casas Mínguez. Universidad de Castilla-La Mancha (Cuenca)

Jorge Garcés Ferrer. Universitat de València

María Asunción Martínez Román. Universidad de Alicante

Natividad de la Red Vega. Universidad de Valladolid

Octavio Vázquez Aguado. Universidad de Huelva

Víctor M. Giménez Bertomeu. Universidad de Alicante

Yolanda Domenech López. Universidad de Alicante

María Felicidad Tabuenca Cuevas. Universidad de Alicante (editora de inglés)

Consejo Científico Asesor/Advisory Board

Carmina Puig Cruells. Universitat Rovira i Virgili. Tarragona

Clarisa Ramos Feijóo. Universidad de Alicante

Daniel La Parra Casado. Universidad de Alicante

Enrique Pastor Seller. Universidad de Murcia

Esther Villegas Castrillo. Universidad de Alicante

Fernando de Lucas y Murillo de la Cueva. Universidad Complutense

Francisco Javier Domínguez Alonso. Universidad de Alicante

Hortensia Redero Bellido. Universidad de Alicante

José Luis Sarasola-Sánchez Serrano. Universidad Pablo de Olavide. Sevilla

José Manuel Barbero García. Universitat de Girona

Josefa Cardona Cardona. Universitat de les Illes Balears

Josefina Fernández Barrera. Universidad de Barcelona

Luís Enrique Alonso Benito. Universidad Autónoma de Madrid

María Carmen Pérez Belda. Universidad de Alicante

María de las Olas Palma García. Universidad de Málaga

María Jesús Uriz Pemán. Universidad Pública de Navarra

María Luisa Setién Santamaría. Universidad de Deusto

Marta Llobet Estany. Universidad de Barcelona

Miguel Ángel Mateo Pérez. Universidad de Alicante

Roberto Mohedano Menéndez. Universidad de Alicante

Santa Lázaro Fernández. Universidad Pontificia de Comillas

Teresa Facal Fondo. Universidad de Santiago de Compostela

Consejo Científico Asesor Internacional/International Advisory Board

Agnes Koon Chui Law. Center for Social Work Eduation and Research. Sun Yat-sen University. Guangzhou, China.

Alberto Acosta Espinosa. Facultad Latinoamericana de Ciencias Sociales, (FLACSO- Ecuador). Quito, Ecuador.

Annamaria Campanini. Università degli Studi di Milano-Bicocca. Milán, Italia.

Darja Zavirsek. University of Ljubljana. Ljubljana, Slovenia.

Göran Therborn. Göteborg University. Göteborg, Sweden.

John Gal. Paul Baerwald School of Social Work and Social Welfare. Hebrew University of Jerusalem. Jerusalem, Israel.

Johan Galtung. Transcend. Peace University. A Peace and Development Network.

Jorge M. L. Ferreira. ISCTE-Instituto Universitario de Lisboa. Lisboa, Portugal.

José Paulo Netto. Universidade Federal do Rio de Janeiro. Rio de Janeiro, Brasil.

Mona Fransehn. Göteborg University. Göteborg, Sweden.

Nino Zganec. University of Zagreb. Zagreb, Croatia.

Philip Mendes. Monash University. Melbourne, Australia.

\footnotetext{
* El Comité Editorial tiene las siguientes funciones. Asistir al editor de la revista, especialmente, en el seguimiento de los trabajos: recepción, evaluación, aceptación y decisión final sobre la publicación del trabajo. Asimismo es responsable del estilo, definición de las normas de presentación de trabajos y de establecer la estructura de la revista.
} 


\section{ALTERNATIVAS \\ Cuadernos de Trabajo Social}




\section{BASES DE DATOS}

ISOC. Base de Datos Bibliográficos de Ciencias Sociales y Humanidades del Centro Superior de Investigaciones Cientificas (CSIC): http://bddoc.csic.es:8080/

Latindex (Catálogo y directorio). Sistema Regional de Información en Línea para Revistas Científicas de América Latina, el Caribe, España y Portugal: http://www.latindex.unam.mx/

PSICODOC. http://www.psicodoc.org/

DIALNET. http://dialnet.unirioja.es/

COMPLUDOC. Base de datos de artículos de Revistas: http://www.ucm.es/BUCM/complu/menu.htm

ULRICHSWEB. Base de Datos de publicaciones periódicas internacionales: http://ulrichsweb.serialssolutions.com/

\section{PLATAFORMAS DE EVALUACIÓN DE REVISTAS}

DICE. Difusión y calidad editorial de las revistas españolas de Humanidades y Ciencias Sociales y Jurídicas:

http://dice.cindoc.csic.es/index.php

CIRC. Clasificación Integrada de Revistas Científicas: http://epuc.cchs.csic.es/circ/

RESH. Revistas Españolas de Ciencias Sociales y Humanas: http://epuc.cchs.csic.es/resh/

MIAR. Matriu d'Informació d'Avaluació de Revistes: http://miar.ub.es/

IN-RECS. Índice de impacto de las revistas españolas de Ciencias Sociales: http://ec3.ugr.es/in-recs/

\section{REPOSITORIOS}

RUA. Repositorio institucional de la Universidad de Alicante: http://rua.ua.es/

Hispana. Directorio y recolector de recursos digitales del Ministerio de Educación: http://hispana.mcu.es/

DRIVER. Digital Repository Infrastructure Vision for European Research: http://search.driver.research-

infrastructures.eu/

OAIster. The OAIster database: http://oaister.worldcat.org/

OpenDOAR. The Directory of Open Access Repositories: http://www.opendoar.org/

RECOLECTA. Recolector de ciencia abierta: http://www.recolecta.net

Scientific Commons. http://en.scientificcommons.org/

Google Académico. http://scholar.google.es/

\section{CATÁLOGOS DE BIBLIOTECAS UNIVERSITARIAS}

Catálogo de la Universidad de Alicante. http://gaudi.ua.es/

Catálogo de la Red de Bibliotecas Universitarias españolas (REBIUN). http://www.rebiun.org/

Catàleg Col-lectiu de les Universitats de Catalunya (CCUC). http://ccuc.cbuc.cat

Catálogo del Consorcio de Bibliotecas Universitarias de Andalucía (CBUA). http://catcbua.cbua.es/

\section{DIRECCIÓN POSTAL}

Alternativas. Cuadernos de Trabajo Social. Universidad de Alicante

Departamento de Trabajo Social y Servicios Sociales. Ap. Correos 99 (03080) Alicante

dtsss@ua.es

http://rua.ua.es/dspace/handle/10045/5269/

Información estadística relativa al No 22. Año 2015

\begin{tabular}{|l|c|}
\hline Número total de trabajos recibidos / Total number of submissions & 29 \\
\hline Número de trabajos aceptados (\%) / Total number of submissions accepted & $11(37,93 \%)$ \\
\hline$\%$ de trabajos rechazados / \% of submissions rejected & $11(37,93 \%)$ \\
\hline Trabajos en proceso de revisión y evaluación (\%) / Submissions in review process (\%) & $7(24,14 \%)$ \\
\hline Número medio de revisores por artículos / Average number or reviewers per article & 2,07 \\
\hline Demora media recepción-revisión / Average time reception-review & 20,09 \\
\hline Demora media aceptación-publicación / Average time acceptance-publication & 102,91 \\
\hline Demora media recepción-publicación / Average time reception-publication & 200,55 \\
\hline$\%$ de trabajos que comunican resultados de investigación originales / & $(10 / 11)$ \\
$\%$ works reporting results of original research & $90,9 \%$ \\
\hline$\%$ de autores externos al Comité Editorial / & $(24 / 24)$ \\
$\%$ of external authors (Editorial Board) & $100 \%$ \\
\hline $\begin{array}{l}\% \text { de autores externos a la organización editora de la revista / } \\
\% \text { of external authors (Publishing Organisation) }\end{array}$ & $(23 / 24)$ \\
\hline$\%$ de autores extranjeros / & $95,8 \%$ \\
\hline Foreign authors & $(1 / 24)$ \\
\hline$\%$ de trabajos financiados por organismos públicos o privados de investigación / \\
$\%$ works funded by public/private reseach organisation & $4,2 \%$ \\
\hline
\end{tabular}

El número 22 de la revista Alternativas. Cuadernos de trabajo social, correspondiente a 2015, se editó en diciembre de 2015. 


\section{ALTERNATIVAS \\ Cuadernos de Trabajo Social}

N. ${ }^{\circ}$ 22. Año 2015

DEPARTAMENTO DE TRABAJO SOCIAL Y SERVICIOS SOCIALES

UNIVERSIDAD DE ALICANTE 
La publicación de este número ha sido posible gracias a la obtención de una ayuda del Vicerrectorado de Investigación, Desarrollo e Innovación de la Universidad de Alicante.

TITULO: ALTERNATIVAS. CUADERNOS DE TRABAJO SOCIAL

ISSN: 1133-0473

ISSN electrónico: 1989-9971

EDITOR: Departamento de Trabajo Social y Servicios Sociales. Universidad de Alicante PERIODICIDAD: Anual

FECHA DE INICIO: 1992

WEB: http://dtsss.ua.es/es/alternativascuadernostrabajosocial/

CORREO ELECTRÓNICO: dtsss@ua.es

http://publicaciones.ua.es/publica/revistas.aspx?Cod=11

RUA: http://rua.ua.es/dspace/handle/10045/5269

TITLE: ALTERNATIVAS. CUADERNOS DE TRABAJO SOCIAL

ISSN: 1133-0473

Electronic ISSN: 1989-9971

PUBLISHER: Department of Social Work and Social Services, University of Alicante, Spain

PERIODICITY: Annual

START DATE: 1992

WEB: http://dtsss.ua.es/es/alternativascuadernostrabajosocial/

EMAIL: dtsss@ua.es

http://publicaciones.ua.es/publica/revistas.aspx?Cod=11

RUA: http://rua.ua.es/dspace/handle/10045/5269

Publicaciones de la Universidad de Alicante

Campus de San Vicente s/n

03690 San Vicente del Raspeig

Publicaciones@ua.es

http://publicaciones.ua.es

Teléfono: 965903480

() de la presente edición: Universidad de Alicante

ISSN: 1133-0473

ISSN electrónico: 1989-9971

Depósito legal: A 974-2015

Diseño de portada: candela ink

Composición: Marten Kwinkelenberg

Los contenidos están bajo una licencia Creative Commons Reconocimiento 3.0 España.

Los contenidos pueden copiarse, distribuirse o comunicarse públicamente, bajo las siguientes condiciones generales: Reconocimiento. Debe reconocerse los créditos de la obra de la manera especificada por el autor o el licenciador (pero no de una manera que sugiera que tiene su apoyo o apoyan el uso que hace de su obra). Los términos de la licencia disponibles on-line en: http://creativecommons.org/licenses/by-nc/3.0/es/ 


\section{ÍNDICE}

1. El juego como adicción social: crónica de una patología anunciada

Gambling as a social addiction: chronicle of a pathology foretold.... 9

Pilar Blanco Miguel, Mercedes GonzÁlez Vélez, Cinta Martos

SÁNCHEZ

2. Sistematización y generación de conocimientos en trabajo social.

Aportes metodológicos a la formación profesional

Systematization and generation of knowledge in social work.

Methodological contributions to vocational training

PATRICIA CASTAÑEDA MENESES

3. Diversidad familiar: una experiencia docente en el grado de trabajo social

Family diversity: a teaching experience in social work degree

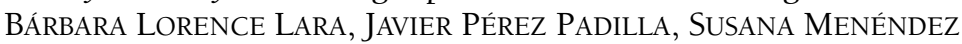

ÁlVAREZ-DARDET, IVÁN RODRÍGUEZ PASCUAL

4. Regulación del espacio público: impacto de las ordenanzas

municipales en el ejercicio de la prostitución desde la voz de las trabajadoras del sexo

Regulation of public space: the impact of municipal bylaws in the pursuit of prostitution from the voices of sex workers.

CELIA PÉREZ MARTín

5. Acogimiento residencial y producción de subjetividades: identidades

y trayectorias ciudadanas de los niños y niñas en protección

Child residential care and the production of subjectivity: children's

indentities and citizenship trajectories

JULIA RAMIRO

6. Servicios Sociales en la Comunitat Valenciana: el actual 'modelo valenciano' y una nueva agenda de construcción de un modelo de derechos sociales

Social Services in the region of Valencia: the current 'Valencian model' and a new set of ideas for the construction of a model of social rights

FRANCESC XAVIER UCEDA I MAZA, FRANCISCO JAVIER DOMÍNGUEZ

Alonso, LuCía MartínEZ-MartínEZ

7. Validación del Cuestionario de Actitudes ante las Intervenciones

Asistidas por Perros (CAINTAP) en Estudiantes Universitarios del

Sur de España: Beneficios y Temores Percibidos

Validation of the Questionnaire on Attitudes Towards Dog Assisted

Interventions (CAINTAP) among Southern Spanish college students:

perceived benefits and fears

Javier lópez-Cepero Borrego, María A. Perea-Mediavilla, ARCADio Tejada RoldÁn, José Luis SARASOla-SÁnCHEZ-SERRANO 
8. Calidad en los Servicios Sociales de acogimiento familiar

The quality of specialized family placement social services

MARÍA Victoria OCHANDO RAMÍREZ, ANNA RUCABADO SALA, ANA

RAQUEL ORTEGA MARTÍNEZ

9. ¿Cómo afecta la crisis económica al contexto de la prostitución de calle?

How does the economic crisis affect the context of street prostitution?

CARMEn MENESES Falcón, LAURA GUINDEO AGUERRI

10. Diez propuestas para cuidarse y cuidar en las profesiones sociales.

Hacia la construcción de una cultura del cuidado en los profesionales

Ten proposals to care for oneself and others in the social professions.

Towards the construction of a culture of care for professionals....

CARMina PUIG CRUELlS

11. Voces Migrantes frente a la Violencia de Género: Una investigación para la Acción en San Francisco (EEUU)

Migrant Voices Confronting Gender-based Violence: A Research for

Action in San Francisco (USA).

María Pilar Tudela VÁzQUEZ

\section{RESEÑAS}

Título: El Trabajo Social ante el reto de la crisis y la educación superior.

Autor(es): Enrique Pastor Seller, María Teresa Martínez Fuentes, Manuela Avilés Hernández y Yolanda Domenech López (Coords.)

Edita: Editorial Universitas, S.A. Madrid, 2014

ISBN: 978-84-7991-424-0

Título: Las Prácticas curriculares en el Grado de Trabajo Social. Supervisión y construcción del conocimiento desde la práctica profesional.

Autor: Enrique Pastor Seller (editor).

Edita: Editorial Universitas, S.A. Madrid, 2014, 289 pp.

ISBN: 978-84-7991-433-2

Título: Trabajo Social con Comunidades.

Autor: Pastor Seller, E. (2015).

Edita: Editorial Universitas, S.A. Madrid, 2015. 257 pp.

ISBN: 978-84-7991-451-6

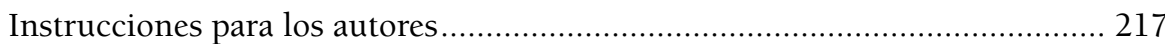

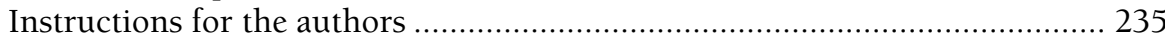

Protocolo revisores externos .................................................................. 251

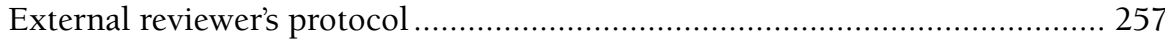




\title{
EL JUEGO COMO ADICCIÓN SOCIAL: CRÓNICA DE UNA PATOLOGÍA ANUNCIADA
}

\author{
Gambling as a social addiction: chronicle of a pathology foretold \\ Pilar Blanco Miguel ${ }^{1}$, Mercedes González Vélez ${ }^{2}$ y Cinta Martos Sánchez ${ }^{3}$
}

\section{Resumen}

Antecedentes. Desde que en 1977 se legalizaron los juegos de azar en España, éstos han terminado por convertirse en un grave problema psicosocial. Existen conductas de juego que, aunque en sus inicios si le son atribuibles todos los caracteres positivos de esta práctica, con el tiempo terminan perdiendo su identidad, transformándose en un acto totalmente alienante. Objetivos. Conocer la dimensión social del juego determinando cómo está presente en las primeras experiencias con el juego, así como el significado que ésta adquiere, una vez el jugador se ve inmerso en este proceso adictivo. Método. Metodológicamente se ha optado por la perspectiva cualitativa, ya que ésta se muestra mucho más útil a nuestros intereses de estudio. Como base principal, hemos recurrido a la historia de vida, ya que ésta nos permitía conocer la verdadera magnitud que encarna esta problemática desde el punto de vista de los afectados. Resultados. De manera general hemos descubierto como la dimensión social está muy presente en el juego, ya que hemos valorado cómo ésta termina delimitando tanto el proceso de la adicción, como la percepción que se tiene del propio problema. Conclusiones. Destacar que el inicio de esta práctica viene argumentado bajo la idea de que al formar parte de la cotidianidad, el juego se cuela (a edades muy tempranas) en la vida de un ludópata en forma de entretenimiento social. Pero al final, lo que empieza siendo una actividad divertida acaba convirtiéndose en una verdadera problemática social.

Palabras clave: Adicción al juego; dimensión social, conceptualización del problema; estigmatización social, enfermedad adictiva.

\begin{abstract}
Background. Since gambling was legalized in Spain in 1977, many voices that testify that they have become a serious problem that affects more and more people. There is gaming behavior which initially contains all the positive characteristics of this practice, but which eventually ends up losing its identity and it becomes a totally alienating act. Objectives. Knowing the social dimension of the game and determining how it is present in the first experiences of the game, and the meaning this behavior acquires, once the player is immersed in this addictive process. Method. Methodologically a qualitative perspective has been chosen because it is much more useful to our research interests. As the main base, life stories have been used, as it allowed us to know the true extent that this issue embodies from the point of view of those affected. Results. Generally we have found as the social dimension is very present in the game, as we evaluated how it ends up defining both the process of addiction and the perception we have of the problem itself. Conclusions. Note that the start of this practice (under the idea of being part of everyday life), slips (at young ages) into the life of a gambler in the form of entertainment or social entertainment. But in the end what begins as a fun activity just turns into a real social problem.
\end{abstract}

Keywords: Gambling addiction; Social dimension; Conceptualization of the problem; Social stigmatization; Addictive disease.

Recibido: 20/02/2015

Aceptado: 13/05/2015

Publicado: 03/12/2015

1. Universidad de Huelva. Dpto. de Sociología y Trabajo Social, Huelva, España. Campus de El Carmen. Avda. 3 de Marzo, s/n. 21071 Huelva. Teléfono: 959219539; E-mail: pblanco@uhu.es

2. Universidad de Huelva. Dpto. de Sociología y Trabajo Social, Facultad de Trabajo Social de Huelva, España.

3. Universidad de Huelva. Dpto. de Sociología y Trabajo Social, Facultad de Trabajo Social de Huelva, España. 


\section{Introducción: El juego como problemática social}

En las últimas décadas hemos asistido a una proliferación, sin precedentes, de todo lo que tiene que ver con el mundo que rodea al juego. Cada cierto tiempo aparecen en el «imaginario del juego» nuevos tipos que incrementan sin descanso la vasta lista de los ya existentes con los que hacer «soñar» a una población de jugadores cada vez más extensa. Todos alguna vez en nuestra vida, hemos apostado bajo la idea de querer pasar un buen rato, pero sobre todo lo hemos hecho inducidos por la imagen tentadora de que la suerte nos sonría y nos agasaje con la «diosa fortuna» que haga nuestra existencia mucho más fausta.

Abierta la puerta del «gambling» (juego por apuesta) serán sólo unos pocos los que se dejen arrastrar por su erótica y acaben por conmutar los pensamientos y sentimientos positivos anidados en el principio (diversión y mejorar la economía), por la lógica destructora de apostar por el simple hecho de apostar, por sentir la emoción del riesgo a apostar, de jugarse el dinero y arriesgarse a ganar o a perderlo todo, incluida su propia dignidad. Este tipo de jugadores son los que acaban formando el grupo de «enfermos del juego» más conocidos como ludópatas o adictos al juego ${ }^{4}$. De hecho, como muy bien apuntan Mazón y Chóliz (2012), la posibilidad de poder jugar utilizando las plataformas que ofrecen las nuevas tecnologías (Internet, televisión móvil, etc.) está ampliando el universo de nuevos jugadores (jóvenes), que si antes eran ajenos o jugaban de una forma marginal, ahora pueden ser considerados como los ludópatas del siglo XXI. Aunque es difícil conocer la prevalencia de la adicción al juego para este sector de la población, algunas investigaciones constatan que estas son altas, situándose entre el 3\% y el 18\% (Sarabia, Estévez y Herrero, 2014) 5 .

Se sabe que el juego de apuesta o de dinero es la actividad de ocio que ocasiona más abusos y conflictos, originados casi siempre por su gran potencial adictivo. Alonso-Fernández (2003: 195) describe muy bien esta situación cuando explicita sin descuido o con descuido -el juego de dinero- lo amenaza con dominarle como objeto adictivo, llevarle a la ruina económica y, según expresión de algún adicto al juego, mata su alma.

4. Aparte de estos dos conceptos, destacar que a esta patología psicosocial se le otorgan otros términos, entre ellos: ludomanía, sociosis lúdica, juego compulsivo, ludoadicción, ludodependencia y juego problemático.

5. Según estos autores, la oscilación está sujeta a tres factores: el país y año donde se ha tomado la muestra, el instrumento empleado para realizar la mediación y si se trata de juego online u offline. 
España es el país de la Unión Europea que más dinero gasta por habitante en juego y uno de los primeros del mundo. Actualmente nuestro país está viviendo una auténtica revolución en lo que a juegos de azar se refiere. Entre las posibles causas, Chóliz (2014), apuesta por el rol determinante que han tenido tanto, las TIC como la publicidad. Esta transformación empieza a hacerse visible, una vez es aprobada la ley 13/2011 de Ordenación del Juego mediante la cual se legaliza el juego online en España. Según datos recogidos de la memoria anual del juego, en el año 2011 el tamaño de mercado de juego en nuestro país, en términos de cantidad jugada, fue de 26.585 millones de euros, cifra que se ha reducido en un 2,8\% si la comparamos con el año 2010. Esta tendencia bajista, iniciada desde el año 2008, es atribuible principalmente a dos factores: al impacto de las crisis económica sobre la renta disponible y el nivel de consumo de los hogares españoles, y a la aparición de operadores online con un incremento anual acumulativo en su volumen de ingresos y cantidades jugadas de cerca del 30\% (Blanco, 2014). De hecho si valoramos los datos que del 2013 ofrece la Dirección General de Ordenación del JuegoDGOJ (2014), veremos cómo esta modalidad de juego online llega a superar al gasto en casinos, bingos o loterías de la ONCE (Chóliz, 2014).

La reflexión de estos datos nos ayuda a comprender las distintas informaciones que, desde distintos organismos especializados en el tema (asociaciones de jugadores, unidades de psiquiatría especializadas, etc.) expresan cuando plantean que en España la ludopatía se ha constituido como un grave problema social para un gran número de personas. Si tenemos en cuenta su prevalencia, los datos epidemiológicos indican que más de medio millón de españoles adultos son ludópatas. En la actualidad el juego online es la segunda causa principal de la adicción en jugadores patológicos que están en proceso de rehabilitación Si contáramos a los menores las cifras subirían, ya que éstos no se han mostrado impasibles al fenómeno del juego y cada vez son más las voces que alertan del incremento de este problema en los impúberes, no en vano, Chóliz (2014) los define como el sector más vulnerable. Aunque todavía son pocos los menores que acuden a consulta por problemas de juego, esta situación está empezando a cambiar, ya que está operando un cambio a nivel de conciencia social que está permitiendo que muchas familias sean conscientes del problema y soliciten tratamiento (Báez, Echeburúa y Fernández-Montalvo, 1994).

El juego está en todas partes y cómo bien nos recuerdan De la Gándara, Fuertes y Álvarez (2000: 9): El ocio, y el azar, el juego y la vida cuatro elementos que configuran buena parte de la naturaleza humana. La cuestión está en cómo saber integrar esa parte sin que eso se traslade en un gran problema. 
Antes de ser considerada la adicción al juego como una categoría diagnóstica recogida en el DSM-III ${ }^{6}$, la consideración social del juego quedaba en manos del instrumento moral, que le atribuía al jugador la identidad de persona viciosa, irresponsable y librador del sufrimiento familiar. Resultante de esta concepción aparece uno de las rasgos que más ha determinado esta conducta -el sigilo-. La clandestinidad ha perseguido a un jugador que, sabiéndose culpable de su conducta, era incapaz de desvelar tal comportamiento por miedo a la vergüenza y a la recriminación social. Hecho público el problema, la penitencia pasaba por mostrar arrepentimiento apelando a su sentido ético, al deber y a la fuerza de la responsabilidad.

Aún con algunos rescoldos que apagar, la situación actual se muestra, en algunos aspectos, muy distinta a la descrita en el anterior fragmento ¿Cómo se ha operado este cambio? Fundamentalmente el cambio de significado viene avalado por un mayor conocimiento del tema y por hacer público un problema que permanecía muy oculto. Hoy se sabe que esta adicción no es un problema moral, sino una enfermedad o un síntoma de una enfermedad subyacente. De ahí que el objetivo fundamental de este trabajo esté centrado en conocer cómo la dimensión social del juego viene a determinar gran parte de las historias de ludopatía analizas.

\section{Material y método}

Dado que nuestro interés estaba centrado en analizar y comprender un problema teniendo como referencia básica a las personas que lo padecen, consideramos necesario elegir una perspectiva metodológica que se sirva de estrategias que permitan comprender el fenómeno que se estudia teniendo en cuenta la dimensión intersubjetiva. Es decir, una epistemología interpretativa que, como muy bien apunta Cea D`Ancona (1996: 46): Esté centrada en el sujeto individual y en el descubrimiento del significado, los motivos y las intenciones de su acción.

Por ello elegimos la vertiente comprensiva-interpretativa ya que ésta está interesada en interpretar y comprender los fenómenos sociales desde el punto de vista de los sujetos que viven el hecho de primera mano, en este caso comprender el fenómeno social de la adicción al juego desde esos mismos parámetros a fin de llegar a vislumbrarlo.

6. Es en 1980 cuando el juego se recoge, por primera vez, como categoría diagnóstica en el Manual Diagnóstico y Estadístico de los Trastornos Mentales (DSM-III) de la American Psychiatre Association (APA). 
Cómo sabemos, bajo esta forma de mirar la realidad, se esconden técnicas muy relevantes. De todas ellas, elegimos la historia de vida. Ésta fue llevada a cabo, tanto a ludópatas como familiares, consiguiendo un total de 42 historias de vida distribuyéndose del siguiente modo: 22 para los jugadores y 20 para los familiares. Dentro de este último, la muestra conseguida fue de 16 para la categoría relativa a cónyuge/pareja, 3 para la de hijos y 1 para la de madre. En cuanto al ámbito de estudio reseñar que ha sido la población afectada por la problemática de la ludopatía (jugador y familia), que está en proceso de rehabilitación la seleccionada. Para ello se ha elegido a la Asociación Onubense Jugadores en Rehabilitación (AONUJER) situada en Huelva capital, aunque su radio de acción está abierto a toda la provincia. No obstante, también contamos con algunos documentos biográficos escritos (posteriormente validados de forma oral por el propio sujeto) de otros jugadores y familiares pertenecientes a otras provincias de Andalucía (FAJER). Tras conocer el perfil de los usuarios jugadores que en ese momento constaban como pacientes de la asociación, optamos por seguir unos criterios de selección que tuvieran en cuenta variables tan significativas como el sexo, la edad, la procedencia geográfica, y el nivel de tratamiento en el que se encontraban en ese momento. Con respecto al familiar, el criterio de elección de los familiares se creyó conveniente elegir al familiar del jugador que previamente hubiera sido seleccionado en la muestra del colectivo de jugadores. Tan sólo se ha podido obtener el relato de cuatro mujeres jugadoras. Situación que visualiza el principal punto débil de este estudio, confirmando una vez más la realidad observada, cuando alude al tema de que son muy pocas las jugadoras que deciden asistir a centros de tratamiento para salir de la adicción. Aunque en el desarrollo del trabajo de campo, relativo a la realización de las historias de vida, se contaba con una fecha de inicio (mayo del 2007) y de finalización (diciembre del 2007), está última no pudo cumplirse dado que, sobre el terreno decidimos no cerrarla y así dejar abierta la posibilidad de que pudiera irse incorporando algún que otro sujeto más a la muestra inicial (sobre todo en las categorías menos representadas como la de mujer jugadora e hijos de jugador). Al final ésta se dio por concluida una vez que consideramos que esto era imposible, ya que pasado el tiempo, no se incorporaban nuevos sujetos al proceso de rehabilitación (noviembre de 2009).

\section{Resultados}

En el intento de dar respuestas claras a las preguntas ¿por qué una persona juega? y ¿por qué sigue jugando a sabiendas de los problemas que le acarrea esa actividad?, nos damos cuenta que el argumento no se nos encamina en 
una sola dirección, sino todo lo contrario, ante nosotros se abre un mundo lleno de bifurcaciones que nos permiten hablar de una etiología multifactorial. La causalidad de la ludopatía adictiva viene definida o determinada por la interacción de un conjunto de factores pertenecientes a varias esferas: la individual, la familiar y la sociocultural. De esto se desprende que ningún factor es imprescindible o necesario, salvo el de ser jugador como bien anota Alonso-Fernández (2003). Aunque la presencia de cualquiera de ellos sirva para elevar en mayor o menor grado la vulnerabilidad del sujeto, también debemos tener presente la idea de que, por sí solo, ningún factor puede dar cuenta del inicio, desarrollo y mantenimiento de este problema tan complejo.

Situándonos en nuestro caso concreto de estudio, veremos que son varias las razones que se esgrimen a la hora de reflexionar sobre este asunto. Aunque en un principio, algunos de los jugadores manifiesten arrancar del mismo punto de partida: -estar en un bar y echar a la máquina lo que me sobra después de haber pagado la consumición-, sin embargo la acción de echar lleva implícita situaciones de fondo prácticamente social.

De forma habitual, el jugador piensa que su juego no tienen por qué tener un motivo, de ahí que no encuentre razón o razones ciertas al principio de su narración. Esta incapacidad para dar cuenta de cuál pudo ser el factor o factores que propulsaron su adicción es una pauta constante en su discurso. De manera general tienden a creer que uno empieza a jugar porque suele estar en el lugar adecuado (un bar) y a partir de ahí, las situaciones surgen con la inercia hasta que llega un momento en que sin pensarlo se encuentran atrapados en las redes del juego.

Yo hace tres o cuatro años, yo iba al bar me tomaba mi café y lo que ves es eso, ¿no? Ves a uno echando en la máquina, ves a un tío jugando a las cartas, o ves a otro jugando al dominó y, claro, prácticamente lo vives desde chico. Entonces yo empecé con lo que me sobraba del café y claro si te da 200 ó 300 pesetas te las guardabas en el bolsillo pero, al cabo del tiempo no eran las 200 pesetas que te daba, sino que esas 200 ó 300 pesetas que te daba las volvías a echar (Jugador, 24 años).

Lo mío empezó con lo típico, echas en una máquina, te toca un premio y empiezas a jugar, a jugar, (...) hasta que no puedes parar (Jugador, 30 años).

Pese a esto, son muchos los que haciendo un ejercicio de reflexión son capaces de situar las cosas de forma más clara. El jugador cuando piensa seriamente en el por qué va a un bar o cafetería y echa una moneda en la máquina o porque de repente se encuentra sentado en una sala de bingo, lo hace siendo muy consciente de cuál es su realidad. Realidad que según lo contado, ponen de manifiesto situaciones de índole muy social como pueden ser: la fácil disponibilidad del juego, el esparcimiento social, el ocio, el consumismo, etc. 
Si partimos del pensamiento más común de que un sujeto empieza a flirtear con el juego por razones tan obvias como las que aluden al mundo del entretenimiento, la lúdica o el esparcimiento social, enseguida nos damos cuenta de que, en muchas de las historias de juego narradas por nuestros sujetos de estudio esto sucede realmente. De hecho bien se podría decir que, dada su accesibilidad, éste tiende a formar parte de la vida de un ludópata desde la infancia como una forma más de esparcimiento social.

De siempre, desde pequeñito vas a los bares y ves a la gente jugar a las cartas, al dominó, a la máquina o en nuestras propias casas. En las casas el juego no se tiene por algo malo, sólo es una forma de entretenerse, de pasar el rato con la familia y en la calle con los amigos (Jugador, 44 años)

De forma general, todos coinciden en afirmar que se empieza a jugar por placer porque genera sensaciones muy gratificantes y ratos agradables con los amigos. Da igual el tipo de juego, la cuestión es aprovechar el tiempo de ocio de que dispone uno para salir un rato, divertirse y si acompaña la diosa fortuna, irte a casa con algún premio ganado.

Empiezas a jugar por diversión, porque los amigos o los compañeros de trabajo te lo dicen. Entonces una tarde uno de compañeros míos, con el que yo hablaba mucho, te dice que han abierto un bingo aquí en la merced y dice que está muy bien que nos ponen el cafelito y tal y bueno... dijimos pues vamos a ir a ver cómo va aquello, por tener otra diversión (Jugador, 60 años).

Yo nunca he jugado antes a nada y nos fuimos un día de despedida de soltera con unas amigas a Sevilla y decidieron meterse en el Bingo. Era la primera vez y no sabía cómo mirar la pantalla. Y me lo pasé muy bien. La verdad es que me gustó y se me quedó la cosa de ir y... (Jugadora, 39 años).

En algún caso nos hemos encontrado con que el afán incontrolado por divertirse va unido a una sensación absoluta por disfrutar su libertad, su forma de entender el mundo. Libertad que se introduce como un elemento que tiende a marcar todas sus relaciones personales.

A mí siempre me ha gustado ser muy libre. Mi marido también tenía su vida. Le gustaba salir y entrar si tenía que acompañarlo lo acompañaba pero a él también le gustaba ir sólo.. Y empecé, empecé y me fui a dar cuenta que no estaba haciendo otra cosa que ir al bingo. Yo soy una persona muy libre. No me gusta... yo les he dado mucha libertad a mis hijos para que sean libres, pero a mí las cosas a la fuerza me producen una angustia horrorosa. A la fuerza las cosas no (Jugadora, 54 años).

Además de servir como esparcimiento en muchos casos, el juego viene a funcionar como elemento de interacción social, sobre todo entre los más jóvenes, ya que empiezan jugando con videojuegos, consolas y ordenadores en casa y 
acaban compartiendo recreativo y máquina de juego cuando salen a disfrutar el ocio en pandilla.

He sido jugador durante muchos años de mi vida. Yo siempre jugaba con mis amigos, salíamos los fines de semana y siempre nos íbamos al mismo recreativo a jugar a las máquinas... la verdad es que nunca piensas esto (Jugador, 35 años).

De igual modo sucede con los jugadores más adultos que, como colofón a un día laboral y antes de llegar a casa, disfrutan de un rato de ocio con los compañeros de trabajo, metiéndose en un bar, tomando algo y jugando pequeñas cantidades a la máquina.

Para mí era una diversión, iba con los compañeros de trabajo a tomar unas cervezas después de finalizar la jornada y echábamos un par de euros a las máquinas cada uno, y si nos tocaba algo pagábamos las copas y si no nos tocaba nada, hasta el otro día (Jugador, 34 años)

Yo jugaba con mis amigos, nos lo pasábamos bien, había días que poníamos diez euros cada uno y nos lo gastábamos jugando. Yo tenía novia y antes iba a verla todos los días, pero después iba a verla y con las mismas, a la media hora ya me quería ir. A mí me gustaba más mi ambiente, con mis amigos. (Jugador, 24 años).

En algunas narraciones nos hemos encontrado con la idea de que los patrones de comportamiento lúdico pueden proceder de la imitación. Al igual que sucede con otras adicciones, en el juego funciona una actitud gregaria de mimesis y de querer emular a otras personas, y más si son conocidas como sucede con el grupo de amigos. Sabemos que la imitación visual tiende a funcionar como un mecanismo psicosocial básico en la adquisición de hábitos y rutinas que puede traer consigo el desarrollo de conductas des-adaptativas, sobre todo si este se produce a edades muy tempranas, como sucede muchas veces con el juego.

Mi caída empieza cuando, empezando a ver a mis amigos jugando, yo nunca lo había hecho, me entró esa curiosidad que nos entra a las personas cuando vemos que algo nos llama la atención, que nos divierte y a partir de ahí empezó mi ruina. Al principio cuando no jugaba mucho, me pasaba horas viendo a mis amigos y a otra gente jugar y poco a poco yo me fui enganchando (Jugador, 45 años).

Por último señalar que, entre otras de las razones expuestas, están las que tienen que ver con el mundo devorador del consumismo. Consumo que queda ideado y mostrado en el deseo de querer cosas que los demás tienen y que uno por su situación económica, nunca ha podido tener. Deseo se hace realizable a través de una máquina, de un bingo o de un ordenador. 
Yo tenía un gran ansia de dinero para poder tener una vida con más caprichos y en la ruleta pronto empecé a ganarlo, con $50 €$ que ingresé en mi cuenta de apuestas llegué a tener en pocos días $3.000 €$ (Jugador, 30 años).

Cuando empecé a jugar lo hice por lucro personal. Yo no conocía el tema del juego ni nada de eso. Lo que pasa que yo tengo una cuñada que sí iba al bingo y me decía: he ganao esto y aquello y yo me decía y ¿eso como será? Y me dio la cosa por ir y empecé a ir de vez en cuando para ver si me tocaba o ganaba algo de dinero (Jugadora, 66 años).

Yo de chico siempre soñaba con tener muchas cosas, sería por la juventud... pero yo quería una bicicleta, una moto y no la podía tener. Yo siempre he deseado tener muchas cosas y no sé... habrá sido esa ambición lo que me ha llevado a hacer lo que no debía (Jugador, 29 años).

\section{Discusión y Conclusiones}

Si atendemos a los razonamientos dados por nuestros sujetos de estudio, nos damos cuenta de que éstos se aproximan al discurso obtenido en otros estudios, sobre todo de naturaleza cualitativa (Urdániz, 1999; López Jiménez, 2002) dónde se ha tenido en cuenta este factor de análisis. Tanto es así que, la importancia de estos factores en la etiología de la adición al juego viene reflejada, según expresa Alonso-Fernández (2003), en la diversidad de los datos epidemiológicos. Datos que albergan cifras escalofriantes de prevalencia de la ludopatía adictiva en los países occidentales, oscilando sus tasas entre el 1 y el 2\% de la población adulta. A partir de aquí puede surgir la pregunta ipor qué la acumulación de las adicciones sociales se centraliza en la mayoría de los países occidentales? Se postula que esto estaría relacionado con el modo en cómo se han configurado esas sociedades; sociedades que desprenden auténtico distrés (estrés excesivo) creando una verdadera necesidad de gratificación relajante proporcionada por distintas adicciones, entre ellas el juego, la compra y otras actividades.

A la luz de los resultados, y teniendo en cuenta el análisis que algunos autores hacen (Chóliz, 2014; Mazón y Chóliz, 2012), podemos considerar que los factores sociales que mejor explican la adquisición de las conductas de juego, entre otros, serían: la gran disponibilidad, su fácil accesibilidad, su gran aceptación social, su alta difusión y la laxitud en las restricciones legales. Dentro de la exposición al juego también habría que diferenciar varios aspectos como el tipo y número de juegos legalizados, el acceso a los juegos, el poder adictivo del juego y las primeras experiencias que se tiene con él. De igual modo, también se contempla la gran influencia que ejercen los medios de comunicación en su difusión y la falta de una normativa legal en materia de publicidad que limite la presión al consumo que las empresas del sector 
hacen de algunos juegos, sobre todo, los que se realizan online o durante los eventos deportivos (Mazón y Chóliz, 2012: 298). Constantemente la publicidad, a través de sus mensajes subliminales, nos promete riqueza y felicidad a cambio de muy poco dinero.

En parte todos somos conscientes de que en las últimas décadas las cifras de personas que terminan por volverse adictas al juego no han parado de crecer. Hecho que es atribuible para la mayoría de los expertos, al gran desarrollo tomado por el juego legalizado cuya extensión, según expresan algunos autores (Alonso-Fernández,2003 y Chóliz, 2014), ha sido potenciada por la mala gestión, la laxitud de las restricciones legales y la excesiva generosidad o ambigüedad de la legislación reguladora del juego; y en este sentido nuestro país es un claro ejemplo de ello. Como ejemplo, Becoña, Labrador, Echeburúa, Ochoa y Vallejo (1995) recogen los argumentos esgrimidos por el gobierno español para mantener una legislación muy permisiva y que se resumen en: facilitar entretenimiento a los turistas, evitar que los españoles se vayan al extranjero a jugar, y recuperar para los fondos públicos parte de ese dinero $\mathrm{Si}$ hacemos una comparativa con otros países de la Unión Europea veremos que España despunta por el desproporcionado número de locales de juego (legales e ilegales) existentes. Se han llegado a contabilizar unas cuatrocientas mil máquinas tragaperras, cifra algo superior a la que presentan de manera conjunta Alemania ${ }^{7}$ y Reino Unido.

Actualmente se sabe que la accesibilidad al juego correlaciona positivamente con la probabilidad de practicarlo -cuanto mayor es el acceso al juego, mayor es la probabilidad de practicarlo (Secades y Villa, 1988). De ahí que sea sencillo determinar que -hoy por hoy-jugar se plantee como una tarea muy fácil por dos motivos: por la gran oferta de juegos de azar que hay disponibles, y por la excesiva aceptación social que todavía se tiene del juego. En contraposición a la droga, el juego cuenta con el beneplácito de todos, justificándolo a través de una serie de creencias positivas que básicamente pueden resumirse en su «nula peligrosidad y sus cuantiosos beneficios económicos». Esta permisividad allana mucho el camino a los dispendios que se originan en torno al juego. Cómo ejemplo de ello, Mazón y Chóliz (2012), aluden a los grandes proyectos económicos de creación de lugares de juego en los que se concentran varios casinos y actividades de ocio y negocio, y que bajo el beneplácito de las autoridades y la falacia del beneficio económico, intentan abrirse camino sin tener en cuenta los costes que a nivel de adicción pueden acarrear.

7. El caso específico de Alemania hay que atribuirlo, según recoge Alonso-Fernández (2003), al hecho de haber limitado la intervención legal del control sobre el juego a las máquinas automáticas, dejando fuera los casinos, la lotería y la bolsa. 
En la misma línea, diversos estudios (Allcock, 1986; Ladouceur y Mireault, 1988; Lejoyeux y Adès, 1999) han demostrado que existe una estrecha relación entre la accesibilidad de los juegos de apuestas de azar y la tasa de prevalencia del juego patológico. En parte, esto explicaría el incremento de las tasas de juego patológico entre la población más joven, que está consiguiendo cambiar la imagen clásica que siempre se ha tenido del ludópata adicto; de ahí que cualquier defensa que se intente hacer de él, no nos valga para justificar la negligencia que existe en torno a su existencia (sobre todo a nivel legal). Cuestión que se acentúa, si tenemos en cuenta los costes anexos a esta adicción y que terminan invalidando cualquier opción argumentativa.

Similar importancia adquiere el tema de la oferta de juego. Actualmente nos vemos sometidos al acoso constante de los juegos de azar, y el boom de las máquinas recreativas con premio es un ejemplo de ello. Están presentes en todos los sitios: bares, restaurantes, hoteles, etc. Persecución que se ha visto incrementada por la oferta que ofrece Internet y con la que puedes jugar a cualquier hora. De ahí que se sugiera que, la ilimitada disponibilidad de sistemas de juego de azar legalizados, es uno de los elementos que más incursión ha tenido, tanto en la génesis del problema, como en su mantenimiento. Otro de los factores atribuibles al incremento de las tasas de jugadores, sería el hecho de que la lista de los tipos de juegos de azar (incluidos los online) no ha parado de crecer; cada vez es más amplia: distintas modalidades de loterías, las cartas, los dados, las apuestas, las quinielas deportivas, el bingo, los juegos de los casinos, las máquinas tragaperras, etc. Y como juegos adictivos sin intervención del dinero tenemos los videojuegos y los juegos por ordenador. Si valoramos su potencial adictivo, veremos que son las máquinas tragaperras las que provocan una mayor dependencia adictiva (la mayoría los son a estas máquinas o en combinación con otros juegos).

De este riesgo no se escapan ni los más jóvenes ni los mayores. Cada vez se reconoce más que estos colectivos junto al del ama de casa son los más vulnerables. No olvidemos que entre los lugares de encuentro y reunión de los jóvenes se localizan las salas de juegos. Cómo podemos ver, estos espacios funcionan como lugares exclusivos (sólo jóvenes) que les facilitan los contactos sociales; son de aceptación por parte de los progenitores y las autoridades; refuerzan las normas del grupo de iguales; son lugares muy accesibles ya que están situados de forma estratégica en las ciudades (cerca de los puntos de diversión); y cuando se quiere jugar su coste económico es bajo, además de que también permiten ver jugar a los compañeros sin tener que gastar dinero (Secades y Villa, 1998). Pero a estos tradicionales espacios le han salido nuevos competidores -los espacios online-. Según la NetValue de 2002, el 17\% de las 
personas que visitan los sitios de juegos online son menores de edad (Sarabia, Estévez y Herrero, 2014: 59).

Aparte de tenerlo fácil, el joven cuenta con otro factor de apoyo muy importante que es la presión social para jugar proveniente del grupo de amigos. Su existencia ha sido demostrada por varios estudios (Snyder, 1986). Algunos adolescentes, sobre todo los que frecuentan las salas recreativas, ven en el juego una forma de integrarse en un grupo y hacerles sentirse importantes y respetados frente a sus amigos. Quizás, esto podría haber sido distinto si los jóvenes hubieran tenido en su mano otro tipo de alternativas dónde poder disfrutar de su tiempo libre y de ocio. Al no ser así, no extraña que para algunos grupos de jóvenes estos lugares se hayan convertido en una parte importante de su subcultura (Secades y Villa, 1998).

No podemos dejar de destacar la gran importancia que tienen los medios de comunicación y las nuevas tecnologías en la vida de los más jóvenes. El pasar horas y horas delante de un televisor, de una pantalla de ordenador o de una videoconsola les hace ser más vulnerables a la adicción. De hecho, Secades y Villa (1998), resaltan que ya se ha encontrado en los niños una relación entre ver la televisión en exceso en los primeros años, el tiempo dedicado a los videojuegos y el uso abusivo de las máquinas tragaperras. Se parte de la idea de que los videojuegos pueden ser el primer paso que condujera al niño a ser jugador en el futuro, ya que se acostumbra a un patrón de consumo de juego que, en la edad adulta podrá mantener mediante la implicación en juegos con apuestas económicas (Gaja, 1993). De ahí que algunos profesionales aboguen por un uso racional de los mismos, ya que cada vez se tiene más clara la certeza de que éstos pueden ser la antesala de la ludopatía adictiva, cómo hemos podido comprobar en algunos de las historias de vida narradas por algunos de nuestros jugadores.

Para concluir, es importante reseñar que el juego va ligado al sistema social que lo crea y lo ampara, quedando sujeto a un mayor o menor nivel de permisividad social dependiendo de la carga moral y ética que sobre él hayan querido establecer los diferentes legisladores sociales. Situación que será aprovechada por el ludópata para cobijar su imparable conducta de juego y así tener mecanismos sociales que signifiquen su existencia. No en vano los daños colaterales que deja la economía del juego son muchos, y la responsabilidad social para acometer sus costes muy exigua, de ahí que se apueste por el juego ético como un compromiso en la prevención desde el ámbito político y social (Chóliz, 2014). Cada vez resulta más difícil crear verdaderos antídotos que mitiguen los costes de vivir en una sociedad muy competitiva e impersonal, donde el valor de la persona queda relegado a un segundo plano en aras 
de la valía que ocupan las nuevas éticas ideadas. No obstante la realidad se impone a la ficción demostrando que las nuevas formas de confrontar la vida están cimentadas en pautas totalmente alienables y de esto dan fe los datos obtenidos en este trabajo, ya que el discurso dado por los jugadores y jugadoras aparece confirmando este hecho. Si en un principio el juego les sirve de correctivo ante situaciones poco gratas, al final éste acaba formando parte de su vorágine agravando el problema y esto sólo sucede cuando dejan de vislumbrar el sofismo de creerse estar viviendo en un mundo figurado como si fuese real, empujados por su propio pensamiento irracional.

\section{Bibliografía}

Ádes, J. y Lejoyeux, M. (2003). Las nuevas adicciones. Internet, sexo, juego, deporte, compras, trabajo y dinero. Barcelona: Kairós.

AlONSO-FERNÁNDEZ, F. (2003). Las nuevas adicciones. Madrid: TEA Ediciones.

American Psychiatric Association (1994). DSM-IV. Manual diagnóstico y estadístico de los trastornos mentales. Barcelona: Masson.

Báez, C., ECheburúa, E. y Fernández-Montalvo, J. (1994). Características demográficas, de personalidad y psicopatológicas de los jugadores patológicos de máquinas tragaperras en tratamiento: un estudio descriptivo. Clínica y Salud, 5, 289-305.

Blanco Miguel, P. (2014). El estudio de las adicciones sociales. El juego como adicción social: Problemática social, contexto familiar y movimiento asociativo. El caso de Huelva. Tesis doctoral inédita. Universidad de Huelva, Huelva. España.

Cea D’Ancona, M.A. (1996). Metodología Cuantitativa: Estrategias y Técnica de Investigación Social. Madrid: Síntesis.

ChÓliz Montañés, M. (2014). Historia de una adicción: del vico al trastorno del juego. Cuadernos de Medicina Psicosomática y Psiquiatría de Enlace Revista Iberoamericana de Psicosomática, 111, 84-88.

ChÓliz Montañés, M. (2014). ¿Juego ético?: Un compromiso en la prevención de la adicción al juego, desde el ámbito político y social. Revista Española de Drogodependencias, 4, 5-9.

Comisión Nacional del Juego (2011). Memoria de juego 2011. Dirección General de Ordenación del Juego. Secretaría de Estado de Hacienda. Ministerio de Hacienda y Administraciones Públicas.

De la GÁngara, J.J., Fuertes, J.C. y Álvarez, M.T. (2000). El juego patológico una adicción como otra cualquiera, Comunidad de Madrid. Consejería de Sanidad. Agencia Antidroga.

LÓPEZ JiMÉNEZ, A. (2002). Los juegos de azar. Juego social y ludopatía, Zaragoza: Gobierno de Aragón y Universidad de Zaragoza. 
ECheburúa, E., De Corral, P. y Amor, P.J. (2005). El reto de las nuevas adicciones: objetivos terapéuticos y vías de intervención. Psicología Conductual, 13 (3), 511-525.

Fernández-Montalvo, J. y CAStillo, A. (2004). Repercusiones familiares del juego patológico: una revisión clínica, Salud y Drogas, 4 (2), 149-166.

GajA, R. (1993). Videojuegos. ¿Alienación o desarrollo?. Barcelona: Grijalbo.

MAZÓN, M. y CHÓLIZ, M. (2012). Factores económicos implicados en el juego y la adicción al juego. Revista Española de Drogodependencias, 3, 287-300.

Moreno Mariscal, S. (Coord.) (2007). Guía Clínica: Actuar ante el juego patológico. Consejería para la Igualdad y Bienestar Social, Junta de Andalucía.

PRieto, M. (1999). Para comprender la adicción al juego. Bilbao: Desclée De Brouwer.

Sarabia, I., Estévez, A. y Herrero, D. (2014). Situación del juego con dinero en jóvenes y adolescentes. Revista Española de Drogodependencias, 39 (3), 57-68.

Secades Villa, R. y Villa Canal, A. (1998). El Juego Patológico. Prevención, Evaluación y Tratamiento en la Adolescencia. Madrid: Pirámide.

URdÁmiz, G., IzCO, A., MuÑoz, O. y Salinas, M. (1999). Estudio cualitativo sobre la ludopatía en Navarra. Anales Sis San Navarra, 22 (Supl.3),155-162.

\section{ANTECEDENTES}

Investigación procedente del trabajo de campo de tesis doctoral leída en enero 2014 


\title{
SISTEMATIZACIÓN Y GENERACIÓN DE CONOCIMIENTOS EN TRABAJO SOCIAL. APORTES METODOLÓGICOS A LA FORMACIÓN PROFESIONAL
}

\author{
Systematization and generation of knowledge in social work. \\ Methodological contributions to vocational training
}

PATRicia Castañeda MenESES ${ }^{1}$

\begin{abstract}
Resumen
La sistematización es considerada una estrategia de generación de conocimientos para el trabajo social latinoamericano, que aporta nuevas oportunidades de análisis y reflexión desde las dinámicas propias y particulares que caracterizan a la intervención social. Sin embargo, para avanzar en esta tarea se advierte la necesidad de fortalecer sus repertorios metodológicos y legitimar sus aportes en los contextos académicos y formativos. En este marco, el presente artículo expone algunas consideraciones respecto del insuficiente desarrollo de la sistematización en el mundo académico, sus características distintivas respecto de la investigación y una propuesta de pauta metodológica tipo para trabajo social, que permite orientar procesos de sistematización de la práctica social. La pauta metodológica propuesta ha sido validada en experiencias académicas desarrolladas durante los últimos veinte años por la Escuela de Trabajo Social de la Universidad de Valparaíso, Chile.
\end{abstract}

Palabras clave: Sistematización, Generación de Conocimiento Social, Trabajo Social

\begin{abstract}
Systematization is considered a strategy to generate knowledge for Latin American social work, bringing new opportunities for analysis and reflection from the particular dynamics that characterize the social intervention. However, to further this task, there is a need to strengthen its methodological repertoire and legitimize their contributions in academic and training contexts. In this context, this paper presents some considerations regarding the insufficient development of systematization in academia, the distinctive characteristics regarding research and proposes a kind methodological guideline for social work, which can be a form of systematization of social practice. The methodological guideline proposed has been validated in academic experiences developed over the last twenty years by the School of Social Work at the Universidad de Valparaíso, Chile.
\end{abstract}

Keywords: Systematization, Generation of Social Knowledge, Social Work

Recibido: 03/03/2015

Aceptado: 04/06/2015

Publicado: 03/12/2015

1. Académica e Investigadora. Escuela de Trabajo Social. Universidad de Valparaíso, Chile. Avda. Colón 2128 Valparaíso, Chile. Teléfono 56-32-250 86 53. correo electrónico patricia.castaneda@ uv.cl 


\section{Antecedentes Generales: Investigación Social y Sistematización}

La sistematización constituye una estrategia de generación de conocimientos expresamente valorada por el trabajo social latinoamericano, dado que se considera una estrategia de generación de conocimientos capaz de rescatar y valorar los aprendizajes profesionales generados directamente desde la práctica social para integrarlos al acervo social especializado (Díaz y González, 2011:12-18). Sin embargo, como contrapartida y a pesar de que la sistematización ofrece una oportunidad invaluable para el análisis de la intervención social desde sus propios códigos y dinámicas (Aguayo, 2006:119-122), también se le ha considerado una estrategia insuficientemente explorada y validada en el mundo académico especializado (Valdés, 1992: 9-12; Gagneten, 1987:39-68), otorgando mayor valía a los procesos de investigación social desarrollados desde paradigmas clásicos por las rutas de sistematización, las que se consideran alternativas reflexivas que aún transitan por etapas de consolidación metodológica En un análisis comparativo con la investigación social se pueden constatar los siguientes contrapuntos:

a. En el mundo universitario, la investigación social es considerada la vía matriz legitimada para la generación de nuevos conocimientos disciplinarios. Sus dimensiones ontológica, epistemológica y metodológica en torno al análisis de la realidad social se han desarrollado históricamente al alero de la academia, validando procedimientos unívocos destinados al levantamiento y análisis de la información y formatos tipo de comunicación de resultados. Las ciencias sociales y humanidades, las ciencias económicas y administrativas, las ciencias de la educación y las ciencias de la salud se adscriben a la estricta aplicación de las convenciones vigentes en la investigación social, subrayando el requisito de pleno dominio para acceder a los códigos formales definidos para el conocimiento.

b. La investigación social desarrolla rigurosos protocolos de levantamiento y análisis de información, que se generan a partir de la problematización del tema central de estudio. Desde allí, todos los datos que se recopilen serán alineados desde los referentes teóricos y conceptuales que operan como marco de respaldo técnico para el proceso. En esa perspectiva, la investigación diseña su propia ruta de trabajo y no se desvía del camino previamente trazado. No obstante que la realidad social se manifieste en forma dinámica, impredecible y en ocasiones contradictoria, los procesos de investigación son capaces de estabilizar dichas fuerzas y establecer puntos de apoyo que les permiten 
obtener la información precisa en un contexto social en plena ebullición. Si alguna contingencia trasciende a los resultados del estudio, será en condiciones de excepción y bajo la ambiciosa definición de hallazgo.

c. Particularmente, se observa que los procesos de desarrollo disciplinario de las ciencias sociales se han caracterizado históricamente por la convergencia entre sus avances teóricos y sus progresos metodológicos, generando por tanto un proceso de validación conjunta y simultánea de ambas vertientes, que ha sido capaz de respaldar plenamente la configuración de las matrices disciplinares interpretativas de la realidad social que constituyen cada corpus de conocimientos. Teniendo presente esta referencia para analizar el difícil proceso de validación que ha enfrentado la sistematización en la academia como estrategia de generación de conocimientos sociales, es posible observar la asimetría resultante entre, por una parte, los frondosos marcos teóricos conceptuales provenientes de las ciencias sociales y que necesariamente tributan al proceso; $y$, por otra parte un frágil contrapunto metodológico en etapas aún exploratorias, que no alcanza a contener los procesos interpretativos requeridos desde las particularidades de la intervención social, por lo que los incipientes repertorios metodológicos disponibles para sistematizar y que no representan convenciones totalmente reconocidas y asumidas por el mundo científico, son observadas con comprensible duda y cuestionamiento desde las posiciones académicas clásicas. Reconociendo que ningún avance en el campo del conocimiento se encuentra exento de oposición y resistencia, la situación actual de la sistematización en el marco académico devela un lento avance en su legitimación, que en ocasiones incluso se manifiesta en una abierta negación o descalificación a las oportunidades de reflexión que promete su aplicación, no alcanzando por lo tanto los necesarios estímulos y contrapuntos que permitieran estimular su incorporación plena en los claustros académicos para enfrentar los desafíos provenientes de la generación de conocimiento social desde la contingencia.

d. Para la academia, el mundo social es un contexto genérico en donde se implementan los procesos de investigación y generación de conocimiento clásicos definidos en forma avanzada por equipos profesionales expertos. La realidad social puede ser observada, medida, comprendida, descrita y analizada desde categorías teóricas situadas fuera de la contingencia cotidiana. En esta perspectiva, el mundo social es 
concebido como un repositorio que aportará la información requerida para contrastar o refutar la validez de una teoría o una hipótesis concebida en las aulas universitarias. Como consecuencia se genera una relación asimétrica entre teoría y práctica, en donde la primera posee una mayor valoración académica, en detrimento de la segunda. Por tanto, la ambición de la sistematización respecto a la generación de conocimiento desde la propia práctica se enfrenta desde el inicio con una adversa valoración de lo que define como su piedra angular (Züñiga, 1992: 22:24).

e. Por lo general, el mundo académico tradicional se sitúa en forma externa respecto de los procesos de intervención social cotidianos que realiza el colectivo profesional en ejercicio. En ese marco, la universidad observa el mundo social desde una relativa distancia que se encuentra organizada desde las categorías analíticas aportadas por la teoría y no interviene directamente en las dinámicas de cambio social generadas por un programa o proyecto social en ejecución. Por tanto, su preocupación no está centrada en la contingencia permanente propia de los avatares que caracterizan a la intervención directa ni en la demanda de sistematizar sus aprendizajes y reflexiones.

A diferencia de la investigación que problematiza en forma específica un tema social de interés y busca renovadas explicaciones o comprensiones del mismo (Hérnandez y cols., 2010:33-111), la sistematización centra su atención en la intervención social, siendo su aspiración la generación de nuevo conocimiento a partir de las reflexiones y aprendizajes que emergen en forma dinámica desde el quehacer profesional inserto en la intervención directa (Ardón, 2000:19-36; Santibañez, 1993:11). Ilustrativamente comparadas, por una parte la investigación social opera como una fotografía que aspira a registrar fielmente las manifestaciones de la situación social de interés en una imagen única que comunique la síntesis del proceso. Por su parte, la sistematización se despliega en un sistema de registro homólogo a una película cinematográfica, que debe comunicar una trama que convoca diversos personajes y locaciones a través de un guión o argumento que se desarrolla a lo largo de un período de tiempo determinado, sin por ello perder su coherencia, consistencia y rigor. Por lo tanto, sus afanes demandan la formulación de sistemas de registro plurales, que permitan recoger y analizar los diversos lenguajes audiovisuales que se expresan a lo largo de la trama. Y si bien la investigación social y la sistematización coinciden en su afanosa búsqueda de generación de conocimiento social, sus caminos reflexivos se bifurcan. Mientras la primera 
apoya su lógica de análisis principalmente en la deducción y la conjetura, la segunda lo hará a través de la inducción y la inferencia, configurando un campo de fuerzas opuestas que ofrecen diferentes matices en los relatos de la realidad social a la que aspiran analizar.

\section{Aprendizajes metodológicos en sistematización}

La Escuela de Trabajo Social de la Universidad de Valparaíso, Chile; ha realizado esfuerzos sostenidos a lo largo de los últimos 20 años en torno a la implementación de procesos metodológicos de sistematización bajo la responsabilidad técnica directa de la autora del presente artículo, buscado potenciar el desarrollo de procesos de generación de conocimientos sociales que emergen desde la práctica profesional. Lo anterior, ha permitido el modelamiento y posterior validación de una propuesta metodológica tipo que aporta en el desarrollo de experiencias de sistematización realizadas por estudiantes, profesionales y equipo académico en situaciones formativas asociadas a prácticas profesionales, seminarios de titulación y pasantías, fortaleciendo progresivamente las convenciones requeridas para la generación de conocimiento social desde esta perspectiva particular. El análisis metodológico de los procesos de sistematización realizados en forma sistemática en la unidad académica, ha consolidado la siguiente pauta tipo que organiza las diferentes etapas de trabajo requeridas a partir de la secuencia de trabajo propuesta (Castañeda, 2014:99-114).

a. Contextos de la Experiencia. Comprende contextos institucionales, programáticos, territoriales, sociales, económicos, de política social, de sujetos de intervención, entre las opciones de mayor referencia. Su inclusión en un informe de sistematización está asociada a los requerimientos que cada experiencia en particular demande para su caracterización específica. Por tanto, pueden seleccionarse contextos de entre los declarados con mayor recurrencia o sumarse nuevos ámbitos con plena libertad de definición.

b. Referentes Teóricos Conceptuales en que se inscribe la experiencia, con especial énfasis en las redes conceptuales que manejan en forma directa los equipos profesionales a cargo de la intervención social.

c. Decisiones Metodológicas.

- Fundamentación metodológica. Planteamientos metodológicos que respaldan la elección de la sistematización como estrategia de generación de conocimientos. La mayor dificultad en este apartado corresponde a la diferenciación entre sistematización, 
investigación social y evaluación social, dado que la experiencia de intervención real estudiantil es acotada y tiende a superponer las racionalidades de los tres repertorios metodológicos identificados.

- Delimitación de la sistematización. Responde a la pregunta ¿qué sistematizar?, considerando los diversos matices y focos de atención desde donde una experiencia puede ser analizada. Las experiencias realizadas por la unidad académica en contextos profesionales de Trabajo Social refieren las siguientes categorías de delimitación de sistematización: Modelos de intervención, innovaciones metodológicas y aprendizajes profesionales de la intervención social en las dimensiones asociadas a procesos socioeducativos, sociorecreativos, de coordinación, de trabajo en red y de gestión, entre los de mayor recurrencia.

- Objetivos de sistematización. La formulación de objetivos refiere a tipologías verbales vinculadas a la generación de conocimientos y a procesos reflexivos impulsados desde la práctica. Así entonces a los verbos clásicos de identificar, caracterizar, describir o analizar se suman a verbos más integradores como representar, transferir, revisar, organizar y proponer.

- Colectivos participantes de la experiencia. Corresponden a todas las personas, participantes y equipos de trabajo que se encuentren vinculadas en forma directa o indirecta con la experiencia de intervención social. Por tanto, se supera la mirada de universo excluyente propio de la investigación y se suman miradas diversas en torno a la percepción de los procesos de trabajo realizados con sus protagonistas directos e indirectos, convocados en igualdad de condiciones para participar en la reconstrucción y validación de la experiencia.

- Técnicas y estrategias de recolección de información con fines de sistematización. Siendo las de mayor frecuencia y pertinencia la revisión documental, la entrevista y la observación participante con fines de sistematización.

- Plan de análisis de la información. Contempla la declaración metodológica de las decisiones de análisis de información contempladas en el proceso de sistematización.

- Procedimientos de validación. Los resultados obtenidos requieren un proceso de validación que identifica como procedimientos el 
juicio experto, la base ampliada de acuerdos y triangulación en sus diferentes modalidades de fuentes, técnicas, tiempos o teóricas.

d. Desarrollo del Proceso de Análisis con fines de Sistematización. Por lo general, la secuencia del análisis se inicia desde el nivel predominantemente descriptivo organizado desde los objetivos de sistematización planteados, desde donde se comienza a reconstruir la práctica desde el relato y la evidencia. Lo anterior, debiera evolucionar a través a procesos de mayor trascendencia analítica, que permitiesen acceder a los patrones, estructuras, relaciones y tensiones presentes en la experiencia y que pueden ser develados desde el cuestionamiento conceptual y la reflexión profesional (García, Ibáñez et al, 1986:367). Su comunicación escrita puede utilizar como recursos las redes conceptuales, gráficas descriptivas, sistemas categoriales y estructuras de secuencia o causalidad, aportando con renovadas interpretaciones de la realidad social desde códigos formales comunicables para el mundo social, el mundo profesional y el mundo académico.

e. Reflexiones, Aprendizajes y Conclusiones del Proceso. Etapa final del proceso que permite arribar a las síntesis conceptuales y/o procedimentales que ilustran los procesos claves de la intervención social. Su nivel de abstracción será clave para que los aprendizajes de la experiencia tengan oportunidades de transferibilidad como renovados marcos interpretativos que enriquezcan el análisis de situaciones sociales homólogas.

La propuesta metodológica expuesta precedentemente ha fortalecido los aportes de Trabajo Social en sistematización. Los avances obtenidos demuestran que la información requerida para el análisis siempre emerge desde la propia experiencia y que el desarrollo de la sistematización puede realizarse en forma simultánea o posterior a la implementación del programa o proyecto de intervención social definido de interés para su reflexión avanzada. Asimismo, los aprendizajes obtenidos permiten precisar que la sistematización puede ser realizada directamente por el propio equipo responsable de la ejecución del programa o proyecto social; o es posible delegar la tarea a una tercera instancia técnica.

La capacidad de realizar un proceso de análisis que trascienda el mero relato descriptivo es el mayor reto del equipo a cargo. Dado que los análisis de información no responden a pautas predefinidas, se reconoce que esta etapa requiere de un proceso de interpretación que se ajuste plenamente a la dinámica social que se aspira a sistematizar y que conjugue los aportes de 
la teoría y de la práctica en un todo integrado que resulte fiel al proceso de intervención, permitiéndole su plena expresión en el marco de un documento formal. Los sistemas de registros y evidencias del proceso de intervención social representen un importante complemento en esta etapa, dado que son considerados las bases de datos claves respecto de las cuáles los procesos de análisis se despliegan.

La validación de los resultados del análisis es otorgada preferentemente por los propios protagonistas de la experiencia de intervención social. El juicio experto se amplifica, abarcando no solo a los equipos técnicos y profesionales en la conformidad y respaldo de los resultados obtenidos, sino que también se extiende a las propias personas participantes, las que en su calidad de usuaria directa o indirecta integran su perspectiva al proceso y su conformidad a los análisis y a las reflexiones realizadas (Díaz, 2009:19). Complementariamente, la base ampliada de acuerdos, entendida como el esfuerzo de subrayar las convergencias que poseen las diversas instancias participantes en la experiencia, aporta flexibilidad a la validación, constatando los acuerdos sin forzar posiciones únicas y sin anular las divergencias. Estas estrategias permiten mantener los matices requeridos en la comunicación de procesos de intervención social, los que en los múltiples avatares que conllevan en su implementación distan mucho de alcanzar síntesis únicas o afirmaciones unívocas respecto a los aprendizajes obtenidos.

\section{Reflexiones finales}

La posibilidad de integrar los aprendizajes metodológicos descritos en experiencias de sistematización, ha fortalecido los procesos de generación de conocimientos sociales, abriendo posibilidades inéditas a la propia práctica de expresarse en plenitud desde sus propios códigos y dinámicas. Así, entonces, la sistematización releva que la generación de conocimientos sociales no es de exclusivo predominio de las instancias académicas, sino un patrimonio factible de construir y resignificar colectivamente en torno a la intervención social. Invita a superar las miradas instrumentales y tecnocráticas respecto de la realidad social, redescubriendo los matices y las diversidades que están presentes en el trabajo cotidiano profesional. Constituye una potente promesa de generación de un espacio propio para los aprendizajes de la intervención, en el estrecho y jerárquico margen de los conocimientos científicos y disciplinarios.

La experiencia realizada a la fecha sugiere que los respaldos, los registros y los innumerables vestigios generados por los diversos actores vinculados a un proceso de intervención social poseen un particular valor en la 
sistematización, dado que constituyen las unidades básicas capaces de otorgar los cimientos para el desarrollo del proceso reflexivo que aspira a transitar desde lo evidente a lo trascendente. La contribución de las evidencias en el proceso de sistematización, se define desde los atributos de amplitud y profundidad. Por una parte, la amplitud refiere a la creciente disponibilidad de formatos y recursos de registro existentes, que permiten capturar las diferentes dimensiones del proceso de intervención. Las múltiples combinaciones posibles que ofrecen la escritura, el sonido, y la imagen se potencian en manos de un equipo profesional avezado y creativo capaz de reconocer las inagotables posibilidades que el registro representa en el rescate y en la recreación del evento real en vistas a su rescate y comunicación. Por otra parte, la profundidad consolida la diversidad de evidencias generadas por la amplitud, contribuyendo al desarrollo de un proceso de análisis con densidad suficiente para respaldar con solidez la inferencia con fines reflexivos a la que aspira la sistematización.

Para trabajo social, la sistematización es una conexión directa con su núcleo histórico fundacional organizado en torno a la intervención social. Es la posibilidad de atesorar sus estrategias, de fortalecer sus repertorios profesionales, de comunicar la valía de su trabajo cotidiano, en un código que reconoce y en donde se reconoce. Los recientes procesos de rediseño curricular de las escuelas universitarias de trabajo social en Chile han recogido este desafío, incorporando a la sistematización en sus cátedras, experiencias formativas prácticas y trabajos de titulación, considerándola una ruta alternativa válida frente a la investigación social y con similar valía como requisito académico. Asimismo, se suman programas de formación avanzada en post grado de Trabajo Social, Gestión Social y Ciencias Sociales de diversas instituciones universitarias, que reconocen a la sistematización como repertorio académico en sus trabajos de graduación finales. Esfuerzos que sin duda aportan en forma decisiva en la validación de los procedimientos metodológicos, en la rigurosidad de los resultados obtenidos y en los nuevos conocimientos que actualmente la profesión es capaz de generar desde su propia práctica.

Si bien es cierto se reconoce que falta aún camino por recorrer en la consolidación de la sistematización como recurso técnico permanente en la profesión, es una importante constatación el hecho de que su valoración real ya es una etapa ganada en el colectivo profesional y que actualmente el proceso de incorporación a los repertorios formativos de pregrado y post grado le suma una renovada impronta de validación académica para trabajo social. Finalmente, puede afirmarse que para una profesión que reconoce en la intervención social su alter ego, la sistematización es una opción legítima, que 
permite generar un acervo especializado y distintivo dentro de los corpus de conocimientos de las ciencias sociales. Negar tal condición, permite inferir que el juicio negativo solo podría provenir de quienes no la valoran o no la conocen en los ámbitos donde se despliega plenamente. Es decir, quienes desconocieran los aportes y el potencial de la sistematización, desconocerían los aportes y el potencial que la intervención social representa para el desarrollo profesional de Trabajo Social.

Valparaíso, Verano del 2015

\section{Bibliografía}

AguAYo, C. (2006) Las profesiones modernas. Dilemas del conocimiento y el poder. Santiago de Chile, Ediciones Universidad Tecnológica Metropolitana.

Ardón, M. (2000) Guía Metodológica para la Sistematización Participativa de Experiencias en Agricultura Sostenible. San Salvador, Programa para la Agricultura Sostenible en Laderas de América Central PASOLAC. Capturado en http://www.esm4p.info/biblioteca/files/original/6489962f9620268bbcl8c6 5396caf73f.pdf

Castañeda, P. (2014) Propuestas Metodológicas para Trabajo Social en intervención Social y Sistematización. Cuaderno Metodológico. (1. ${ }^{a}$ Ed.). Valparaíso, Universidad de Valparaíso.

Díaz, C; JARA, C y Robert A. (2009) Develando experiencias. Otra mirada a la sistematización. San José, Instituto Interamericano de Cooperación para la agricultura, IICA. Capturado en http://www.redalforja.org/images/stories/pdf/ libro\%20de\%20sistematizacion.pdf

DíAZ, C. y GONZÁLEZ R. (2011) Perspectivas éticas y políticas de la sistematización. Ocotal. Nueva Segovia. Alforja - Cantera Coedición.

García F, Ibañez, J. y Alvira F. (1982) El Análisis de la Realidad Social. Madrid, Alianza Editorial.

GaGNETEN, M. (1987) Hacia una metodología de sistematización de la práctica. Buenos Aires. Editorial Humanitas.

HeRnándeZ R., FernándeZ C. y BAPTista M. (2010), Metodología de la Investigación. (5 Ed.) México D.F. Editorial Mc Graw-Hill.

SANTibAÑEZ, E. (1993) Manual para la sistematización de proyectos educativos de acción social. Santiago de Chile, Centro de Investigación y Desarrollo de la Educación CIDE.

VALDÉS, X. (1992) Las cuentas pendientes de la sistematización. Revista de Trabajo Social Pontificia Universidad Católica de Chile.61, 9-17.

ZúNIIGA R. (1992) Sobre el sistematizar. Revista de Trabajo Social Pontificia Universidad Católica de Chile. 61, 19-29. 


\title{
DIVERSIDAD FAMILIAR: UNA EXPERIENCIA DOCENTE EN EL GRADO DE TRABAJO SOCIAL
}

\author{
Family diversity: a teaching experience in social work degree \\ BÁrbara Lorence Lara ${ }^{1}$, Javier PÉrez Padilla ${ }^{2}$, SuSAna MEnÉndez Álvarez- \\ DARDET $^{3}$ e IVÁN RODRÍGUEZ PASCUAL ${ }^{4}$
}

\section{Resumen}

El estudio del cambio familiar, la diversidad familiar y sus implicaciones desde el ámbito asistencial y de los Servicios Sociales es una parte fundamental de la formación del Trabajador Social. Este trabajo propone una experiencia vinculada a la innovación docente que apuesta por el enfoque interdisciplinar y transversal en la formación del trabajador social y tiene por objetivos: (1) describir una actividad formativa investigadora sobre diversidad familiar desarrollada en el Grado de Trabajo Social; y (2) presentar los resultados de investigación de la actividad formativa realizada. Un total de 216 estudiantes participaron recopilando información de 258 personas con edades comprendidas entre los 22 y los 85 años con ayuda de un cuestionario que evalúa aspectos relacionados con el concepto de familia y la aceptación hacia los nuevos modelos familiares. Los resultados de esta actividad mostraron que las personas entrevistadas por el alumnado tomaron en cuenta para definir el concepto de familia criterios funcionales y relacionales. Además, se observó que el grado de aceptación hacia las diversas formas familiares era elevado, aunque se encontraron diferencias en función del perfil del entrevistado. Esta actividad favorece la toma de conciencia por parte del alumnado de la importancia de la investigación social en la práctica profesional así como la existencia de prejuicios ante determinadas situaciones familiares no convencionales.

Palabras clave: actividad formativa investigadora, diversidad familiar, Trabajo Social, innovación docente.

\begin{abstract}
The study about family change, family diversity, and the implications for care and Social Services fields, are central topics in the academic training of Social Workers. The present paper shows an innovative educational experience characterized by an interdisciplinary and cross-curricular approach. The main purposes of this paper are: (1) to describe an educational and research activity carried out in the Social Work Degree; and (2) to present the research results obtained in the activity. A group of 216 university students collected data about a sample of 258 subjects (age range: 22 to 85 years) using a questionnaire focused on the concept of family and the acceptance of new models of families. Results obtained showed that the concept of family was mainly based on both functional and relational criteria, and also a high level of acceptance of the different types of families, but with differences associated to the subjects' profile. For students, this activity promotes the awareness of both the importance of social research for the practice and the existence of prejudice about nonconventional families.
\end{abstract}

Keywords: educational and research activity, family diversity, Social Work, educational innovation.

1. Bárbara Lorence Lara. Departamento de Psicología Evolutiva y de la Educación. Facultad Ciencias de la Educación. Universidad de Huelva. Campus del Carmen. Avda. Tres de Marzo s/n. Huelva. Tlf:.+34 (9) 59219209

2. Departamento de Psicología Evolutiva y de la Educación. Facultad Ciencias de la Educación. Universidad de Huelva.

3. Departamento de Psicología Evolutiva y de la Educación. Facultad Ciencias de la Educación. Universidad de Huelva.

4. Departamento de Sociología y Trabajo Social. Facultad de Trabajo Social. Universidad de Huelva. 


\section{Introducción}

La diversidad familiar, entendida como quiebra del modelo normativo de familia nuclear y de sus elementos constitutivos (prácticas, creencias y restricciones legales) ha implicado un principio de relativa desinstitucionalización y privatización de las relaciones familiares. Si bien todavía hay quien sostiene, desde una posición sociológica conservadora, una cierta legitimidad natural en la familia nuclear tradicional y el vínculo matrimonial heterosexual (Donati, 2003), existe más bien un consenso a la hora de considerar que cada vez más es necesario hablar de una diversidad de formas familiares, más que de una familia.

Así, la pluralidad familiar fue uno de los temas estrella con los que los estudiosos de la familia cerraron el siglo XX. Se trata de una constante vital de las sociedades individualizadas y secularizadas del mundo occidental, resultado tanto de importantes transformaciones identificadas en una segunda transición demográfica (Van de Kaa, 1987) como de una tendencia clara a la posmodernización (y por tanto relativización) de los valores de las sociedades tradicionales (Meil, 1999). Debido a estas transformaciones, reconocemos hoy por igual la importancia de las formas familiares que se asemejan a la todavía mayoritaria familia nuclear así como todas aquellas que han venido a poner el contrapunto a dicha realidad familiar y en especial a las familias monoparentales (y monomarentales) y reconstituidas, las parejas de personas que cohabitan (también del mismo sexo), los hogares unipersonales y otras formas todavía más apartadas de los modelos sancionados tradicionalmente (la descendencia homoparental, también los llamados Living Apart Together, la maternidad en solitario por decisión propia, etc.) que entreveran el tejido de las distintas situaciones y experiencias vitales asociadas a los proyectos de vida familiar. Se puede aceptar el juicio de María del Mar González y su equipo en que «estamos ante un panorama familiar ciertamente complejo que nos lleva a afirmar que hemos pasado de la familia modelo a los modelos de familia» (González, Díez, López, Martín y Morgado, 2013), con todas las incertidumbres y desventajas que esta especie de escenario de lazos y biografías flexibles o cambiantes - como lo denominan Beck y Beck-Gernsheim (2012)trae para los individuos. Y no es sólo una tendencia del mundo occidental, sino un hecho que ya ha sido constatado en el marco de la sociedad española, que en las últimas décadas parece haber profundizado una fuerte transición familiar hacia una gran aceptación de esta diversidad y una clara convergencia con el proceso de posmodernización y desinstitucionalización presente en el contexto europeo (Ayuso, 2010; Flaquer, 1999; Iglesias de Ussel y Ayuso, 2012; Jurado, 2008; Jurado y Naldini, 2007; Meil, 1999, 2004). 
Esta profunda transformación ha dejado su huella en la composición de los núcleos familiares españoles (ver Tabla 1), particularmente reflejada en los

Tabla 1. Tipología de relaciones matrimoniales o de pareja, con o sin hijos (Fuente: Iglesias de Ussel y Ayuso, 2012: 369-370)

\begin{tabular}{|c|c|c|}
\hline & Denominación & Características \\
\hline \multirow{2}{*}{$\begin{array}{l}\text { Soltería tras } \\
\text { emancipación, } \\
\text { divorcio o } \\
\text { cohabitación } \\
\end{array}$} & Singles & $\begin{array}{l}\text { Personas solteras que no quieren tener pareja } \\
\text { estable sólo relaciones esporádicas }\end{array}$ \\
\hline & $\begin{array}{l}\text { Solteros/as } \\
\text { post-pareja }\end{array}$ & $\begin{array}{l}\text { Personas solteras tras la separación o divorcio, } \\
\text { viudedad o cohabitación estable }\end{array}$ \\
\hline \multirow{4}{*}{$\begin{array}{l}\text { Parejas o } \\
\text { matrimonios } \\
\text { sin convivencia } \\
\text { habitual }\end{array}$} & \begin{tabular}{|l} 
Long Distance \\
Relationships
\end{tabular} & $\begin{array}{l}\text { Relaciones a distancia, por internet, virtuales, } \\
\text { etc. }\end{array}$ \\
\hline & Living ApartTogether & $\begin{array}{l}\text { Con pareja pero sin compartir una residencia } \\
\text { común (pueden residir en la misma ciudad) }\end{array}$ \\
\hline & $\begin{array}{l}\text { Parejas de fin de } \\
\text { semana }\end{array}$ & $\begin{array}{l}\text { Parejas estables que por diversas circunstancias } \\
\text { viven en diferentes municipios y sólo hacen } \\
\text { vida en común los fines de semana, vacaciones } \\
\text { etc. }\end{array}$ \\
\hline & $\begin{array}{l}\text { Parejas } \\
\text { transnacionales }\end{array}$ & $\begin{array}{l}\text { Parejas estables que pasan temporadas seguidas } \\
\text { separados residiendo en distintos países por la } \\
\text { movilidad de uno o ambos miembros }\end{array}$ \\
\hline \multirow{6}{*}{$\begin{array}{l}\text { Parejas o } \\
\text { matrimonios } \\
\text { con } \\
\text { convivencia } \\
\text { habitual }\end{array}$} & $\begin{array}{l}\text { Parejas de doble } \\
\text { carrera y/o doble } \\
\text { ingreso }\end{array}$ & $\begin{array}{l}\text { Ambos miembros de la pareja tienen estudios } \\
\text { universitarios y/o ambos tienen trabajos } \\
\text { remunerados fuera de casa }\end{array}$ \\
\hline & Parejas mixtas & $\begin{array}{l}\text { Parejas en las que alguno de sus miembros es de } \\
\text { distinta nacionalidad, raza o etnia. }\end{array}$ \\
\hline & Parejas de hecho & $\begin{array}{l}\text { Son uniones no reconocidas civilmente, pueden } \\
\text { ser hetero u homosexuales, así como pre o } \\
\text { post-matrimoniales }\end{array}$ \\
\hline & \begin{tabular}{|l|l} 
Parejas de \\
homosexuales
\end{tabular} & $\begin{array}{l}\text { Uniones de personas con el mismo sexo y con } \\
\text { reconocimiento civil }\end{array}$ \\
\hline & Parejas sin hijos & Parejas que no pueden o no quieren tener hijos \\
\hline & $\begin{array}{l}\text { Parejas en «nido } \\
\text { vacío» }\end{array}$ & $\begin{array}{l}\text { Parejas que tienen hijos ya emancipados y no } \\
\text { residen con ellos en el hogar }\end{array}$ \\
\hline \multirow{4}{*}{$\begin{array}{l}\text { Personas con } \\
\text { hijos }\end{array}$} & $\begin{array}{l}\text { Monoparentales } \\
\text { procedentes de } \\
\text { ruptura }\end{array}$ & $\begin{array}{l}\text { Persona adulta con un hijo a cargo como } \\
\text { consecuencia de separación, divorcio o } \\
\text { viudedad }\end{array}$ \\
\hline & $\begin{array}{l}\text { Madres solas por } \\
\text { elección }\end{array}$ & Madres con hijo a cargo por decisión propia \\
\hline & $\begin{array}{l}\text { Familias } \\
\text { reconstituidas }\end{array}$ & $\begin{array}{l}\text { Pareja en la que hay algún hijo no común fruto } \\
\text { de una relación anterior }\end{array}$ \\
\hline & Fecundidad tardía & $\begin{array}{l}\text { Mujeres que tienen su primer hijo por encima } \\
\text { de los } 30 \text { años }\end{array}$ \\
\hline
\end{tabular}


datos intercensales de composición de los hogares (Castro y Seiz, 2014); tanto es así que la clasificación y categorización de estos nuevos tipos familiares, así como sus rasgos característicos se ha convertido en un problema per se (Iglesias de Ussel y Ayuso, 2012). Es de destacar que esta transformación no se produce únicamente por el añadido de nuevas formas de convivencia familiar, sino por cambios internos que están diversificando incluso el panorama de los núcleos familiares tradicionales, afectando a su ciclo de vida, funcionamiento interpersonal, expectativas de estabilidad, etc. No obstante, el cambio en la composición y estructura familiar no agota la cuestión de la diversidad familiar. Igualmente se acepta que la sociedad española parece haber recorrido un largo camino de cambio familiar desde la consideración de la familia desde definiciones estructurales normativas (basadas en su forma y elementos, como el matrimonio o el número de miembros de la misma) hacia otras de carácter más funcional y relacional, que posibilitan un reconocimiento más abierto de las formas familiares (Rodríguez y Menéndez, 2003). Esta cuestión de las definiciones de familia no es baladí, en la medida en que constituye uno de los centros de interés del presente trabajo.

Si queremos tener una perspectiva global de este panorama social es importante examinar las actitudes y prejuicios que tiende a compartir la población general. Resulta interesante tener en cuenta que las connotaciones negativas y positivas que acompañan al concepto de familia y sus diferentes formas trascienden al trato que éstas reciben por parte de la sociedad (Aguado, 2010). Se han realizado pocas investigaciones al respecto, los resultados disponibles apuntan a una mayor tolerancia a la diversidad familiar en la sociedad aunque no todos los modelos de familias son igualmente aceptados, ni siquiera por los profesionales que trabajan con los menores y sus familias. Prueba de ello es el estudio desarrollado con profesionales del ámbito educativo, preferentemente maestros, en el que a pesar de la gran aceptación encontrada hacia la pluralidad familiar, las situaciones de homoparentalidad, y de monoparentalidad por separación y/o divorcio de los progenitores no resultaron tan aceptadas como otros tipos de familia (Morgado, Jiménez-Lagares y González, 2009). Teniendo en cuenta que las investigaciones realizadas hasta ahora concluyen que la estructura familiar por sí misma no es un elemento que se relacione con el bienestar infanto-juvenil (Arranz, Martín, Oliva y Parra, 2010), la investigación en esta línea resulta de máximo interés para la práctica profesional.

Aunque el interés por la diversidad como fenómeno global parece haberse enfriado en los últimos años, consecuencia lógica por otra parte de la aceptación y normalización que esta pluralidad de proyectos familiares vitales tiene en la sociedad española, somos de la opinión de que las transformaciones 
antes descritas son el inicio de un desafío, no su conclusión. Toda vez que la vivencia familiar se diversifica y hace plural esto genera, a su vez, una serie de cambios en cascada sobre otras instituciones, particularmente, sobre el tejido asistencial institucional que, si bien escaso en nuestro país, rodea a los núcleos familiares. No cabe duda de que el Trabajo Social tiene un papel primordial en este marco relacional y muy especialmente en el ámbito de la política de protección social y la atención a las demandas y necesidades de las familias, por lo demás agravadas por un contexto de crisis económica severa. La idea de que nuevos modelos familiares requieren de un replanteamiento que formule también nuevas formas de intervención social sobre esta realidad familiar cambiante, desde luego, no es nueva (Rodríguez, 2002; 2004). Sin embargo, es cierto que en la última década hemos visto crecer el interés por la cuestión de las nuevas demandas asistenciales directamente ligadas a la forma cambiante de la familia y su ciclo vital, así como a la relación entre las nuevas familias y su ajuste psicosocial (Martínez-Monteagudo, Estévez e Inglés, 2013). Otros autores prefieren poner el acento en la necesidad de reconocer a las familias como actores complejos en el ámbito de las políticas sociales desde un enfoque de ciudadanía y atención integral que dé respuesta efectiva a los cambios en las necesidades de las familias y sus redes, así como desligar el concepto de diversidad familiar del de desestructuración familiar para evitar producir respuestas asistenciales estigmatizadoras (Brullet, 2010; Herrera, Castón, Pagés y Ayuso, 2002).

Como se ha comentado anteriormente, la presencia de estereotipos y prejuicios negativos en torno a las nuevas realidades familiares pueden perjudicar el bienestar de las familias en la medida que éstos pueden ir acompañados de conductas discriminatorias de los profesionales que trabajan con ellas. A la luz de las evidencias, este trabajo en un intento de combatir la persistencia de las representaciones sociales normativas de la familia en los estudiantes de Trabajo Social plantea en la titulación del grado una actividad formativa transversal (González, Abolafio y Zapata, 2014). Esta acción educativa se sitúa en el modelo educativo propuesto por el Marco Europeo de Educación Superior, que pretende la búsqueda de la formación integral de las personas, centrada en la adquisición de conocimientos, capacidades y habilidades, a partir de la reflexión crítica personal.

Se trata de una actividad en la que los estudiantes desarrollan una investigación descriptiva sobre diversidad familiar, impulsando así la idea de universalidad en la población beneficiaria de las actuaciones de un trabajador social (Gallego, Gualda y Vázquez, 1995). Se plantea una acción de corte investigadora principalmente por dos motivos: (a) según el estudio desarrollado 
por Barrera, Malagón y Sarasola (2014) el conocimiento de la investigación desde el Trabajo Social es un área preferente de formación reclamada por los trabajadores sociales en activo, lo que supondría una mejora en la cualificación técnica de los nuevos egresados; (b) este tipo de metodología favorece la consecución de aprendizajes significativos y funcionales como consecuencia de la investigación, cooperación y reflexión crítica de los datos empíricos recogidos (Moreira, 2012). Por todo ello, esta propuesta plantea un marco interdisciplinar del estudio de la diversidad familiar en la que, haciendo partícipe a los estudiantes de una investigación, se recogen resultados empíricos que favorecen el debate y la discusión sobre este tema.

Lo que sigue, por tanto, es el relato de una experiencia vinculada a la innovación docente que muestra un fuerte esfuerzo de contextualización dentro del ámbito competencial de una profesión tan estrechamente ligada al trabajo y la intervención con familias. Los objetivos de este trabajo son:

1. Describir una actividad formativa investigadora desarrollada en el Grado de Trabajo Social sobre diversidad familiar.

2. Presentar los resultados de investigación extraídos de la actividad formativa realizada en Trabajo Social.

\section{Descripción de la actividad formativa investigadora}

El concepto de familia y la aceptación de la diversidad familiares una actividad académica dirigida que se viene realizando desde 2011-2012 en el tercer curso del Grado en Trabajo Social de la Universidad de Huelva (España) y que ha contado con la participación de un total de 213 estudiantes. En concreto, se plantea como una propuesta formativa transversal desde las asignaturas Riesgo y Protección del Desarrollo Psicológico en la Familia y Sociología de la Infancia y la Familia, dos materias optativas integradas en la mención Trabajo Social con Familias de la citada titulación. Esta actividad se desarrolla con el propósito de que los estudiantes: (a) analicen las diferentes nociones de familia y en qué medida se consideran como tal distintas situaciones calificadas como de estructura no convencional; (b) examinen la variabilidad de la representación social de la familia asociada a algunas características personales y variables sociodemográficas; (c) se familiaricen con técnicas de recogida, codificación e interpretación de datos; y (d) desarrollen habilidades analíticas, de síntesis y precisión en la expresión escrita. Como puede apreciarse, los dos primeros objetivos están relacionados con el trabajo sobre determinados contenidos (incluidos en el temario de ambas asignaturas), mientras que los dos últimos tienen un carácter más procedimental y permiten abordar algunas 
competencias fundamentales para la práctica profesional, relativas al manejo y análisis de información numérica y a la expresión por escrito. Hay que destacar que este planteamiento entronca directamente con el conjunto de competencias profesionales definidas en el título de Grado en Trabajo Social, especialmente con las que están relacionadas con la investigación y diagnóstico del entorno social y el trabajo con unidades familiares (Erstad, 2002).

Se trata de una investigación basada en un diseño transversal en la que los estudiantes recopilan información de personas de su entorno cercano (muestreo intencional) sobre el concepto de familia y sus múltiples formas, para posteriormente analizar y discutir los datos al hilo de los objetivos propuestos. Desde el inicio trabajan en grupos reducidos en las diferentes fases que comprende una investigación bajo la supervisión coordinada de los docentes de las dos asignaturas. Los resultados y la discusión de los mismos tendrán que presentarla en una única memoria grupal que se evalúa, también de manera coordinada, en las dos materias.

Los materiales necesarios para llevar a cabo la actividad son de dos tipos. En primer lugar, los estudiantes necesitan disponer a priori de algunas herramientas que les permitan recopilar datos y codificarlos (ver puntos del 1 al 4 más abajo). Por otro lado, la actividad también requiere de otros materiales que son elaborados a partir de los anteriores en distintos momentos (5-6) y que, por tanto, se facilitan a medida que van estando disponibles a lo largo del desarrollo de la actividad. Asimismo, se ofrece a los alumnos una guía de la memoria final que deben redactar (7) y que se evalúa en las dos asignaturas. Los materiales son los siguientes:

1. Breve cuestionario estructurado que, además de algunos datos sociodemográficos (edad, sexo, nivel de estudios...) y un indicador global sobre la orientación ideológica, propone dos dimensiones de estudio: el concepto de familia y la aceptación de la diversidad familiar. Para ello, se plantea a la persona entrevistada que: a) defina qué es para él o ella una familia; y b) se le proponen un total de 10 ejemplos de familias no convencionales de diverso tipo, para que indique hasta qué punto considera que cada una de estas situaciones son una familia, mediante una escala Likert de 1 (completamente en desacuerdo) a 4 (completamente de acuerdo) (ver Anexo 1).

2. Directrices y categorías de codificación de los datos recogidos en cada entrevista (ver Anexo 2).

3. Base de datos para que los estudiantes trasladen a ella los datos recogidos. 
4. Software informático para completar la base de datos. Los dos primeros cursos se utilizó Excell y, desde 2013-2014, se facilita el enlace para descargar y utilizar el programa de software libre PSPP.

5. Base de datos con toda la información recogida por todos los estudiantes, tanto del curso académico de que se trate como de los anteriores.

6. Resumen de los resultados obtenidos y analizados en clase.

7. Guía de la memoria final evaluable.

El procedimiento para llevar a cabo la actividad se organiza en una serie de sesiones presenciales y no presenciales de trabajo, de acuerdo al siguiente calendario:

- La actividad se lleva a cabo cuando en las dos asignaturas se han trabajado, desde las perspectivas psicológica y sociológica propias de cada asignatura, los contenidos teóricos necesarios: la familia y su papel como contexto de desarrollo psicológico, el cambio familiar y sus implicaciones, las familias no convencionales....

- Referente a la población objeto de estudio, se le indica a cada estudiante que administre el cuestionario descrito anteriormente a cualquier persona conocida mayor de 20 años. Una vez completada la fase de recogida de datos por todos los estudiantes se codifican en papel las respuestas obtenidas de acuerdo con las categorías del Anexo 2.

- En una sesión de trabajo presencial, cada equipo ${ }^{5}$ debe acudir con un ordenador en el que hayan instalado el paquete de análisis estadístico PSPP. En esta sesión de trabajo cada grupo traslada las entrevistas codificadas a la base de datos cuya estructura se les ha facilitado, y se resuelven las posibles dudas al respecto. A medida que cada equipo tiene completada su base de datos con la información que han recogido, el docente la va incorporando a una única base de datos general que, unida a la de los cursos anteriores, es el material básico para realizar los análisis y obtener así la información para llevar a cabo la actividad.

- Los datos acumulados se analizan en una segunda sesión presencial bajo la guía del equipo docente. Para esa sesión se recomienda a los estudiantes revisar lo aprendido en Métodos y Técnicas de Investigación Social, asignatura obligatoria que cursan el año anterior.

5. Los estudiantes están organizados desde el principio de la asignatura en equipos de trabajo reducidos (máximo cinco personas) para llevar a cabo las actividades académicas dirigidas. 
- A lo largo de un seminario de análisis en el que están presentes los docentes de las dos asignaturas, se comentan grupalmente, desde un enfoque transversal, los principales resultados obtenidos.

- A partir de la sesión anterior, los estudiantes disponen de una semana para elaborar y entregar la memoria de la actividad, de acuerdo con unas indicaciones y un formato específicos. En dichas memorias deben superar el nivel descriptivo de análisis para entrar en un diálogo con los datos que conduzca tanto a una profundización sobre el propio concepto de diversidad familiar y sus implicaciones en nuestro entorno social, como a una reflexión sobre el papel del Trabajo Social en la atención a la diversidad familiar.

- Durante esta semana al menos una de las clases previstas en el horario habitual de las dos materias es de trabajo autónomo, con objeto de que cada grupo pueda reunirse y trabajar en la elaboración de la memoria. La evaluación de ésta es realizada de manera coordinada por los docentes de las dos asignaturas, y la calificación obtenida por cada equipo repercute en la nota final que se obtiene en ambas materias.

\section{Resultados obtenidos en la actividad formativa investigadora}

Para la elaboración de la memoria de la actividad formativa los estudiantes contaron con una muestra total de 258 personas, con edades comprendidas entre los 22 y los 85 años $(M=39.66, D T=12.65)$, distribuidos en porcentajes desiguales en función del sexo ( $58.9 \%$ mujeres y $41.1 \%$ hombres). Estas personas participaron en la investigación de forma voluntaria, previo consentimiento informado y firmado. La mayor parte de los individuos de la muestra tienen un nivel de estudios alto (44.6\%) o medio (39.5\%) y se describen ideológicamente como personas progresistas y de izquierda (55.6\%). Un 58.5\% convive de manera estable con su pareja, y el $60 \%$ tienen hijos.

El eje principal del análisis de estos datos y, lógicamente, del trabajo que se realiza con el alumnado es la identificación de diferentes formas de entender y aceptar la diversidad familiar, particularmente manejando diferentes «definiciones» de lo que es la familia. Precisamente, a la hora de definir qué es una familia sólo un $16.3 \%$ de las personas entrevistadas han ofrecido respuestas que indican una noción basada principalmente en la estructura o composición de la familia («Una pareja con sus hijos», «Un hombre y una mujer que viven juntos -aunque no estén casados- y que casi siempre tienen o piensan tener hijos»...). En el 36.3\% de los casos, la familia es definida en función de las relaciones interpersonales que hay entre sus miembros ( $P$ Personas que viven juntas, se quieren y se apoyan», "Un grupo de gente que convive y se relaciona 
diariamente, y que saben que pueden contar unos con otros»...). Finalmente, las definiciones del $47.4 \%$ de la muestra incorporan y combinan los elementos anteriores, es decir, se trata de una noción de familia basada tanto en relaciones especialmente intensas entre sus miembros como en una determinada composición («Padres que viven con hijos, cuidándolos y educándolos», "Adultos que crían a sus hijos, y también hijos ya adultos que viven sus padres mayores, el caso es que todos se quieren y se apoyan»...).

En cuanto al grado de aceptación de los diversos ejemplos de familias no convencionales, la Tabla 2 ofrece los resultados del análisis descriptivo efectuado. Concretamente se presentan las situaciones ordenadas en función de las medias obtenidas (a mayor media mayor grado de aceptación en cuanto a considerar la situación descrita como una familia). Como puede apreciarse, en términos generales los modelos de familia más aceptados entre las personas entrevistadas por los estudiantes tienden a ser los integrados por una pareja heterosexual con algún menor de edad, seguidos por los diferentes ejemplos en los que o bien hay un único progenitor que es una mujer o bien no hay hijos. Los modelos familiares situados al final de tabla son la familia con un único progenitor varón y las dos situaciones propuestas en las que los dos progenitores del mismo sexo. Merece la pena destacar que las desviaciones tipo de las distintas situaciones tienden a ser más elevadas mientras más baja es la media obtenida, es decir, mientras menos acuerdo promedio hay con que la situación es una familia más heterogeneidad hay en las respuestas aportadas y, por tanto, más diversidad existe en las opiniones al respecto.

Tabla 2. Aceptación de familias no convencionales

\begin{tabular}{|l|c|c|}
\hline \multicolumn{1}{|c|}{ TIPO DE FAMILIA } & Media & Desviación típica \\
\hline L. Pareja de hecho con hijos & 3.69 & 0.66 \\
\hline I. Reconstituida (tras viudedad) & 3.63 & 0.67 \\
\hline H. Reconstituida (tras maternidad en solitario) & 3.61 & 0.65 \\
\hline J. Monomarental (madre soltera) & 3.57 & 0.72 \\
\hline K. Monomarental (tras divorcio) & 3.56 & 0.73 \\
\hline N. Pareja sin hijos & 3.41 & 0.91 \\
\hline M. Monoparental (padre soltero) & 3.41 & 0.83 \\
\hline Q. Homoparental (dos hombres) & 3.20 & 1.09 \\
\hline P. Homoparental (dos mujeres) & 3.13 & 1.05 \\
\hline O. Monoparental (tras divorcio) & 3.09 & 0.97 \\
\hline
\end{tabular}

Nota: Las letras se refieren a la pregunta específica del cuestionario. 
Por otra parte, la prueba $F$ de Snedecor (ANOVA) para la comparación de variables cuantitativas muestra algunas diferencias estadísticamente significativas asociadas a características de las personas entrevistadas, es decir, la noción de familia y las opiniones sobre la diversidad familiar tienden a ser diferentes en individuos con un perfil también diferente. Este perfil está definido fundamentalmente a partir de la edad y la orientación ideológica. Así, las personas entrevistadas con una mayor edad tienden en mayor medida a ofrecer una definición de familia basada en la estructura o la composición de la misma $(F(2,251)=5.06, p<.01)$ y sus puntuaciones son en general más bajas en todas las situaciones no convencionales propuestas en el cuestionario; los análisis de correlación utilizando el estadístico de Pearson indican que esta tendencia llega a ser estadísticamente significativa en el caso de las familias monoparentales encabezadas por una madre soltera $(r(258)=-.145$, $p<.05)$ y un padre soltero $(r(258)=-.176, p<.005)$, la pareja de hecho con hijos $(r(258)=-.205, p<.001)$ y las familias homoparentales de dos mujeres

Tabla 3. Aceptación de familias no convencionales y orientación ideológica

\begin{tabular}{|c|c|c|c|c|c|}
\hline TIPO DE FAMILIA & $\begin{array}{l}\text { Izquierda } \\
\text { (I) }\end{array}$ & $\begin{array}{l}\text { Centro } \\
\text { (C) }\end{array}$ & $\begin{array}{c}\text { Derecha } \\
\text { (D) }\end{array}$ & F de Snedecor & $\begin{array}{l}\text { Pos-hoc } \\
\text { DMS }\end{array}$ \\
\hline L. Pareja de hecho con hijos & 3,78 & 3,68 & 3,31 & $6.125^{* * *}$ & $\mathrm{I}-\mathrm{D} * * *$ \\
\hline $\begin{array}{l}\text { J. Monomarental } \\
\text { (madre soltera) }\end{array}$ & 3,76 & 3,49 & 3 & $16.653 * * * *$ & $\begin{array}{l}\mathrm{I}-\mathrm{C}^{* *} \\
\mathrm{I}-\mathrm{D}^{* * * *} \\
\mathrm{C}-\mathrm{D}^{* * *}\end{array}$ \\
\hline $\begin{array}{l}\begin{array}{l}\text { I. Reconstituida } \\
\text { (tras viudedad) }\end{array} \\
\end{array}$ & 3,72 & 3,67 & 3,21 & $8.417 * * * *$ & $\begin{array}{l}\mathrm{I}-\mathrm{D}^{* * * *} \\
\mathrm{C}-\mathrm{D}^{* * *}\end{array}$ \\
\hline $\begin{array}{l}\text { H. Reconstituida } \\
\text { (tras maternidad en solitario) }\end{array}$ & 3,71 & 3,56 & 3,34 & $4.493 * *$ & $\mathrm{I}-\mathrm{D}^{* *}$ \\
\hline $\begin{array}{l}\begin{array}{l}\text { K. Monoparental (tras } \\
\text { divorcio) }\end{array} \\
\end{array}$ & 3,69 & 3,49 & 3,24 & $5.596^{* * *}$ & $\begin{array}{l}-C^{*} \\
I_{-} D^{* *}\end{array}$ \\
\hline $\begin{array}{l}\text { M. Monoparental } \\
\text { (padre soltero) }\end{array}$ & 3,56 & 3,27 & 3,14 & $5.029 * *$ & \begin{tabular}{|l|}
$\mathrm{I}-\mathrm{C}^{*}$ \\
$\mathrm{I}-\mathrm{D}^{*}$
\end{tabular} \\
\hline $\begin{array}{l}\text { P. Homoparental } \\
\text { (dos hombres) }\end{array}$ & 3,56 & 2,91 & 2,41 & $20.642 * * * *$ & $\begin{array}{l}\mathrm{I}-\mathrm{C}^{* * * *} \\
\mathrm{I}-\mathrm{D}^{* * * *} \\
\mathrm{C}-\mathrm{D}^{* *}\end{array}$ \\
\hline N. Pareja sin hijos & 3,5 & 3,3 & 3,24 & $n s$ & \\
\hline $\begin{array}{l}\text { Q. Homoparental } \\
\text { (dos mujeres) }\end{array}$ & 3,5 & 2,84 & 2,28 & $26.183 * * * *$ & $\begin{array}{l}\mathrm{I}-\mathrm{C}^{* * * *} \\
\mathrm{I}-\mathrm{D}^{* * * *} \\
\mathrm{C}-\mathrm{D}^{* *}\end{array}$ \\
\hline O. Divorcio custodia paterna & 3,29 & 3,04 & 2,48 & $9.669 * * * *$ & $\begin{array}{l}\mathrm{I}-\mathrm{D}^{* * * *} \\
\mathrm{D}-\mathrm{C}^{* *}\end{array}$ \\
\hline
\end{tabular}

Nota: $n s=$ no significativo, ${ }^{*} p<.05,{ }^{* *} p<.01,{ }^{* * *} p<.005,{ }^{* * *} p<.001$ 
$(r(258)=-.141, p<.05) \mathrm{y}$ dos hombres $(r(254)=-.140, p<.05)$. En cuanto a la ideología, la prueba de $F$ de Snedecor revela que las personas con una orientación más progresista asignan puntuaciones más elevadas en casi todos los casos menos en la pareja sin hijos. Posteriormente, los análisis pos-hoc (utilizando el estadístico DMS) mostraron diferencias estadísticamente significativas en todas las situaciones analizadas entre las personas con una ideología de izquierda y de derecha.

Finalmente estos análisis estadísticos, que se repiten cada curso a medida que se acumulan los casos recogidos cada año, constituye el material con el que los estudiantes elaboran la memoria analítica que, como ya se ha señalado, se evalúan en ambas asignaturas del Grado.

\section{Discusión y conclusiones}

Los objetivos del presente trabajo se centran tanto en describir una actividad formativa desarrollada en el Grado de Trabajo Social sobre diversidad familiar como en exponer los resultados de investigación extraídos de la citada actividad realizada por los estudiantes de Trabajo Social.

Con respecto al primer objetivo, el alumnado que realiza la actividad descrita culmina un proceso que comienza con la presentación del concepto de diversidad familiar y las primeras entrevistas, continúa en las diferentes sesiones presenciales de presentación de resultados, y desemboca finalmente en la elaboración de las memorias donde reflexionan los conceptos analizados. Por tanto, se reproduce un ciclo completo de investigación: del planteamiento teórico al trabajo de campo y producción de resultados, y de ahí a la discusión de los mismos. Esto produce una familiarización amplia del estudiante de Trabajo Social con el ámbito de la investigación aplicada al conocimiento del entorno de intervención y trabajo con las familias (Barrera et al., 2014; Erstad, 2002). Pero además invita al mismo a la profundización analítica en el dato empírico, sin descuidar su relación con la aplicación al trabajo práctico en el contexto de la intervención con personas, grupos y comunidades. Además, se debe señalar que la metodología docente empleada ha seguido los principios de la Teoría del aprendizaje significativo: actividad colaborativa, proceso de discusión entre iguales y con el docente, y negociación de significados (Moreira, 2012), favoreciendo la toma de conciencia de la complejidad inherente al concepto de diversidad familiar.

De esta manera, al inicio del proceso de la investigación, el alumnado analiza teóricamente diferentes nociones de familia en función tanto de su estructura como del tipo de relación (Iglesias de Ussel y Ayuso, 2012), confrontándolas implícitamente con sus organizadores previos (Moreira, 2012). De esta 
manera, se promueve el reconocimiento de esta diversidad por parte del futuro trabajador social, menoscabando así la persistencia de las representaciones sociales normativas de la familia que pueden estar presentes en el alumnado (González et al., 2014). Y es que, tal como apuntan González y colaboradores (2013), la concepción tradicional de la familia se torna más compleja cuando se considera la pluralidad de realidades que la definen. El análisis de los datos y la reflexión grupal acerca de los resultados permite reflexionar en torno al concepto de familia y la aceptación social existente en relación a la diversidad familiar, así como las dimensiones ligadas a su mayor o menor tolerancia, lo que a su vez genera, en el contexto de la propia experiencia, una reflexión sobre las implicaciones desde el ámbito profesional para el Trabajador Social en su interacción con las unidades familiares.

Con respecto al segundo objetivo de este trabajo, cabe señalar que un porcentaje mayoritario de los individuos entrevistados por los estudiantes del Grado de Trabajo Social definieron a las familias tomando en consideración las relaciones interpersonales existentes entre los miembros que las componen (alrededor del 81\%), bien como la única característica definitoria de este constructo o bien en combinación con otros elementos de carácter estructural. La importancia otorgada en estas definiciones a las relaciones que se producen entre los miembros de un mismo sistema familiar basadas en el afecto, la intimidad y la reciprocidad, es consonante con las descripciones dadas por los expertos. Asimismo, Palacios y Rodrigo (1998) entienden a la familia como «la unión de personas que comparten un proyecto vital de existencia común que se quiere duradero, en el que se generan fuertes sentimientos de pertenencia a dicho grupo, existe un compromiso personal entre sus miembros y se establecen intensas relaciones de intimidad, reciprocidad y dependencia» (p. 33). Estos resultados van en la misma línea que el análisis expuesto en un trabajo de Rodríguez y Menéndez (2003), en el que se resaltaba la progresión del concepto de familia de una definición más estructural a una más funcional y relacional, alejada de criterios normativos estrictos basados en la estructura y/o composición de la familia.

En cuanto a las diversas situaciones propuestas, los individuos entrevistados mostraron una alta aceptación a la pluralidad familiar lo que refleja el proceso de posmodernización y desinstitucionalización presente en el contexto europeo en torno a la transformación de la familia (e.g., Iglesias de Ussel y Ayuso, 2012). No obstante, los resultados obtenidos reflejan que no todos los tipos de familias son igualmente aceptados, circunstancia esta que también se ha resaltado en otras investigaciones (Morgado et al., 2009). Así, este estudio mostró que las familias integradas por una pareja hetereosexual y las familias 
monomarentales recibían un mayor reconocimiento como familia que aquellas conformadas por un único progenitor varón y las homoparentales. La variabilidad en la aceptación de la pluralidad familiar está asociada a determinadas características personales y sociodemográficas de las personas. En consonancia con otro estudio desarrollado con profesores de Educación Primaria (Morgado et al., 2009), esta variabilidad se asoció a la edad y la orientación ideológica: los individuos de mayor edad y con una ideología más conservadora mostraron menor tolerancia hacia los nuevos modelos familiares.

En conclusión, la investigación realizada por el alumnado se caracteriza por un enfoque sensibilizador ante la diversidad familiar (González et al., 2014) puesto que promueve, a través de la adquisición de habilidades de investigación científica, tanto la toma de conciencia de un fenómeno complejo como la reflexión crítica personal en torno a las nuevas formas de intervención social considerando la diversidad familiar y sus formas siempre cambiantes. De esta manera, la innovación docente se revela como una herramienta particularmente útil para abordar una cuestión dinámica y cambiante, la del cambio familiar y su progresiva desinstitucionalización, así como para invitar al alumnado a incorporar una reflexión autónoma sobre las consecuencias de la diversidad en su quehacer profesional, y al mismo tiempo familiarizarse con los procedimientos comunes que posibilitan la investigación sobre dicho rango de fenómenos.

\section{Agradecimientos}

El presente trabajo ha sido realizado en parte gracias al programa de becas de Formación de Personal Docente e Investigador (FPDI) de la Consejería de Economía, Innovación y Ciencia de la Junta de Andalucía.

\section{Referencias}

AguAdo, L. (2010). Escuela inclusiva y diversidad de modelos familiares. Revista Iberoamericana de Educación, 53(6), 2-11.

Arranz, E., Martín, J., Oliva, A. y Parra, A. (2010). Análisis de los problemas y necesidades educativas de las nuevas estructuras familiares. Intervención Psicosocial, 19(3), 243-251.

Ayuso, L. (2010). Juventud y familia en los comienzos del siglo XXI. En J. González, P. González y L. Ayuso (coords.), Jóvenes españoles 2010 (pp. 115175). Madrid: Fundación SM.

Barrera, E., Malagón. J. L. y Sarasola, J. L. (2014). Estudio sobre formación e intervención profesional del trabajador social en Sevilla: aportaciones de la experiencia profesional. Cuadernos de Trabajo Social, 27(2), 291-305. 
BeCK, U. y BECK-GERnSHEIM, E. (2012). Amor a distancia. Nuevas formas de vida en la era global. Barcelona: Paidós.

BRUllet, C. (2010). Cambios familiares y nuevas políticas sociales en España y Cataluña. El cuidado de la vida cotidiana a lo largo del ciclo de vida. Educar, 4, 51-79.

CAstro, T. y Seiz, M. (2014). La transformación de las familias en España desde una perspectiva sociodemográfica.VII Informe sobre exclusión y desarrollo social en España. Madrid: Fundación Foessa. Recuperado el 20 de mayo de 2015 de http://www.foessa2014.es/informe/documentos_trabajo.php

Donati, P. (2003). Manual de sociología de la familia. Pamplona: Ediciones universidad de Navarra-EUNSA.

ERSTAD, I. H. (2002). La investigación en la práctica del Trabajo Social: la experiencia como fuente de conocimientos. Alternativas: Cuadernos de Trabajo Social, 10, 413-425.

FLAQUER, L. (1999). La estrella menguante del padre. Barcelona: Ariel.

GAllego, M. J., GuAldA, E. y VÁzQuez, O. (1995). Las ideas previas de los alumnos de $1 .^{\circ}$ de Trabajo Social de Huelva respecto a la profesión. Alternativas: Cuadernos de Trabajo Social, 3, 165-185.

GonzÁlez, M., DíEz, M., LóPez, F., Martínez, E. y Morgado, B. (2013). Diversidad Familiar y Estrategias de Conciliación en Andalucía. Sevilla: Instituto Andaluz de la Mujer-Consejería de la Presidencia e Igualdad.

GONZÁlEZ, V., ABOlAFIO, E. y ZAPATA, J. (2014). Representaciones sociales sobre el concepto de familia(s) de los estudiantes de Trabajo Social: un estudio multicéntrico internacional. En E. Pastor (ed.), El trabajo Social ante el reto de la crisis y la Educación Superior (pp. 1663-1670). Madrid: Editorial Universitas.

Herrera, M., Castón, P., PAgÉs, S. y AyUso, L. (2002). Familia y asistencia: Una relación a revisar. Gestión y Análisis de Políticas Públicas, 23, 3-22.

IgLesias DE UsSEL, J. y AYUSO, L. (2012). La familia. En A. Trinidad y J. Iglesias de Ussel (coords.), Leer la sociedad: una introducción a la sociología general (pp. 365-390). Madrid: Tecnos.

JURADO, T. (2008). Las nuevas familias españolas. En M. Requena y J. J. González (coords.), Tres décadas de cambio social en España. Madrid: Alianza.

JuRAdo, T. y NAldini, M. (2007). Democratización de la familia y cambios demográficos en España. En T. Jurado (coord.), Cambios Familiares y Trabajo Social. Madrid: Ediciones Académicas.

Martínez-Monteagudo, M., Estévez E. e InGLÉs, C.J. (2013). Diversidad familiar y ajuste psicosocial en la sociedad actual. Psicologia.com, 17(6). Recuperado el 15 de Diciembre del 2014 de http://hdl.handle.net/10401/6171.

MeIL, G. (1999). La postmodernización de la familia española. Madrid: Acento editorial. 
MeIL, G. (2004). La familia española en el contexto de la Unión Europea. Arbor: Ciencia, Pensamiento y Cultura, 178(702), 421-449.

Moreira, M. A. (2012). ¿Al final, qué es aprendizaje significativo? Qurriculum: Revista de Teoría, Investigación y Práctica Educativa, 25, 29-56.

Morgado, B., JimÉnEZ-LAGARES, I. y GonZÁLEZ, M. M. (2009). Ideas del profesorado de primaria acerca de la diversidad familiar. Cultura y Educación, 21(4), 441-451.

PAlacios, J. y Rodrigo, M. J. (1998). La familia como contexto de desarrollo humano. En M. J. Rodrigo y J. Palacios (coords.), Familia y desarrollo humano (pp. 24-44). Madrid: Alianza.

RODRíGUEZ, I. (2002). Infancia, ruptura matrimonial y diversidad familiar: una aproximación sociológica útil al Trabajo Social. Portularia: Revista de Trabajo Social, 2, 283-298.

RODRÍGUEZ, I. (2004). Qué nueva intervención para qué nuevas realidades familiares: el problema de la diversidad familiar en la sociedad española y sus implicaciones en el Trabajo Social. Alternativas: Cuadernos de Trabajo Social, 12, 65-78.

RodRíGUEZ, I. y MENÉNDEZ, S. (2003). El reto de las nuevas realidades familiares. Portularia: Revista de Trabajo Social, 3, 9-32.

VAN DE KAA, D. J. (1987). Europe's second demographic transition. Population Bullelin, 41(1), 1-57. 


\section{Anexo 1. Entrevista}

A. Sexo: O Mujer O Hombre B. Edad: ——años

C. Situación de convivencia: — D. Hijos/as: O Sí O No

E. Nivel de estudios:

F. Orientación ideológica:

G. ¿Qué es para ti una familia? Si tuvieras que definirle a alguien lo que es una familia, ¿qué le dirías?

\begin{tabular}{|c|c|c|c|c|}
\hline $\begin{array}{l}\text { A continuación voy a leerte ejemplos de distintas } \\
\text { situaciones de convivencia, y me gustaría que me } \\
\text { dijeras si estás más o menos de acuerdo con que sean } \\
\text { una familia. (Describir la escala de respuesta: } 1=\text { Nada } \\
\text { de acuerdo, } 2=\text { Algo de acuerdo, } 3=\text { Bastante de acuerdo, } \\
4=\text { Muy de acuerdo) }\end{array}$ & 1 & 2 & 3 & 4 \\
\hline $\begin{array}{l}\text { H. Una madre soltera se casa con un hombre que no es } \\
\text { el padre de su hijo, y llevan cuatro años viviendo los tres } \\
\text { juntos }\end{array}$ & $\mathrm{O}$ & $\mathrm{O}$ & $\mathrm{O}$ & $\mathrm{O}$ \\
\hline $\begin{array}{l}\text { I. Un padre a los tres años de quedarse viudo se ha vuelto } \\
\text { a casar, y ahora vive con su esposa y las dos hijas que } \\
\text { tuvo con su primera mujer }\end{array}$ & $\mathrm{O}$ & $\mathrm{O}$ & $\mathrm{O}$ & $\mathrm{O}$ \\
\hline J. Una madre soltera vive sola con su hijo & $\mathrm{O}$ & $\mathrm{O}$ & $\mathrm{O}$ & $\mathrm{O}$ \\
\hline $\begin{array}{l}\text { K. Una mujer lleva cinco años divorciada y vive sola con } \\
\text { su hijo }\end{array}$ & $\mathrm{O}$ & $\mathrm{O}$ & $\mathrm{O}$ & $\mathrm{O}$ \\
\hline $\begin{array}{l}\text { L. Un hombre y una mujer viven juntos sin estar casados } \\
\text { y tienes tres hijos }\end{array}$ & $\mathrm{O}$ & $\mathrm{O}$ & $\mathrm{O}$ & $\mathrm{O}$ \\
\hline M. Un padre vive solo con su hijo & $\mathrm{O}$ & $\mathrm{O}$ & $\mathrm{O}$ & $\mathrm{O}$ \\
\hline $\begin{array}{l}\text { N. Una pareja lleva seis años casada pero no tienen hijos } \\
\text { porque no les apetece }\end{array}$ & $\mathrm{O}$ & $\mathrm{O}$ & $\mathrm{O}$ & $\mathrm{O}$ \\
\hline $\begin{array}{l}\text { O. Una mujer divorciada convive desde hace cuatro años } \\
\text { con un hombre sin estar casados. Los dos hijos que tuvo } \\
\text { en su matrimonio viven entre semana con su padre, que } \\
\text { es quien tiene la custodia, y los fines de semana con ella } \\
\text { y su pareja actual }\end{array}$ & $\mathrm{O}$ & $\mathrm{O}$ & $\mathrm{O}$ & $\mathrm{O}$ \\
\hline $\begin{array}{l}\text { P. Una pareja de mujeres vive desde hace cinco años con } \\
\text { el hijo de una de ellas, que estuvo antes casada con un } \\
\text { hombre }\end{array}$ & $\mathrm{O}$ & $\mathrm{O}$ & $\mathrm{O}$ & $\mathrm{O}$ \\
\hline $\begin{array}{l}\text { Q. Una pareja de hombres ha adoptado una niña y viven } \\
\text { los tres juntos desde hace cinco años }\end{array}$ & $\mathrm{O}$ & $\mathrm{O}$ & $\mathrm{O}$ & $\mathrm{O}$ \\
\hline
\end{tabular}




\section{Anexo 2. Directrices de codificación}

Debéis trasladar las respuestas de cada persona entrevistada por los miembros del grupo a la base de datos de PSPP que se facilitará a través de la plataforma Moodle, mediante las siguientes categorías numéricas:

A. Sexo:

B. Edad: Número de años

$1=$ Mujer

$2=$ Hombre

C. Situación de convivencia:

$1=$ Soltero/a y vive con sus padres.

2 = Soltero/a y vive fuera de casa de sus padres (solo o con amigos).

3 = Casado/a o convive de manera estable con su pareja.

4 = Separado/a o divorciado/a.

$5=$ Viudo/a.

D. Hijos:

$1=$ Sí

$2=$ No

\section{F. Orientación ideológica:}

1 = Izquierda, progresista

$2=$ Centro

$3=$ Derecha, conservadora

G. Concepto de familia:

1 = Basado en la estructura o composición

2 = Basado en las relaciones interpersonales y/o el compromiso de futuro

3 = Combinación de 1 y 2

Aceptación de cada situación:

$1=$ Nada de acuerdo 2 = Algo de acuerdo 3 = Bastante de acuerdo $4=$ Muy de acuerdo
E. Nivel de estudios:

$1=$ Bajo (primarios iniciados o finalizados)

2 = Medio (secundarios iniciados o finalizados)

$3=$ Alto (superiores iniciados o finalizados) 


\begin{tabular}{|l|l|}
\hline Tipo de familia & Aceptación \\
\hline H. Reconstituida (tras maternidad en solitario) & \\
\hline I. Reconstituida (tras viudedad) & \\
\hline J. Monoparental (madre soltera) & \\
\hline K. Monoparental (tras divorcio) & \\
\hline L. Pareja de hecho con hijos & \\
\hline M. Monoparental (padre soltero) & \\
\hline N. Pareja sin hijos & \\
\hline O. Divorcio custodia paterna & \\
\hline P. Homoparental (dos mujeres) & \\
\hline Q. Homoparental (dos hombres) & \\
\hline
\end{tabular}





\title{
REGULACIÓN DEL ESPACIO PÚBLICO: IMPACTO DE LAS ORDENANZAS MUNICIPALES EN EL EJERCICIO DE LA PROSTITUCIÓN DESDE LA VOZ DE LAS TRABAJADORAS DEL $\mathrm{SEXO}^{1}$
}

\author{
Regulation of public space: the impact of municipal bylaws in the pursuit \\ of prostitution from the voices of sex workers
}

Celia PÉREZ MartíN²

\begin{abstract}
Resumen
El ejercicio de la prostitución sigue considerándose a día de hoy una actividad denigrante para las mujeres, que implica rechazo social y discriminación y, en consecuencia, las empuja a situaciones que acrecientan su vulnerabilidad social. Por tanto, es importante profundizar en el estigma que existe del trabajo sexual y el papel fundamental que este juega en la configuración del imaginario colectivo. Partiendo de un análisis feminista se realiza un acercamiento a los dos posicionamientos existentes hoy en día ante la prostitución: el discurso dominante abolicionista, desde el que se entiende que esta ahonda en las estructuras patriarcales y atenta contra la dignidad de las personas que la ejercen y la postura pro-derechos, la cual defiende la actividad como un trabajo, por lo que debe implicar la adquisición de derechos laborales y sociales. Este artículo analiza cómo afectan las ordenanzas municipales al ejercicio de la prostitución, a partir de su estudio comparativo y el acercamiento al imaginario colectivo y opinión de las mujeres en relación al conjunto de medidas sancionadoras que plantean la prohibición de la prostitución en el espacio público. Así mismo, esta aproximación apunta cambios en las condiciones de trabajo de las mujeres y, en consecuencia, un sentimiento interiorizado de mayor vulnerabilidad, por lo que se concluye la necesidad de visibilizar, a través de sus voces y el reconocimiento de su papel como interlocutoras válidas, el conjunto de sus preocupaciones y demandas.
\end{abstract}

\begin{abstract}
Prostitution is still considered today a degrading activity for women, involving social rejection and discrimination and, consequently, leads to social situations that increase their vulnerability. It is therefore important to look into the stigma of sex work and the key role it plays in shaping the collective imagination. From a feminist analysis, an approach to the two existing positions today regarding prostitution is presented: the abolitionist dominant discourse, from which it is understood that it delves into the patriarchal structures against the dignity of those who practice and the pro rights posture that defends prostitution as work activity, so it must involve the acquisition of labor and social rights. This article analyzes how bylaws affect prostitution, from a comparative study and approach to the collective imagination and opinion of women in relation to the set of countermeasures posed banning prostitution in public spaces. Moreover, this approach suggests changes in the working conditions of women and consequently shows internalized feelings of greater vulnerability. Therefore, this article concludes with the need to visualize all their concerns and demands, through their voices and the recognition of their role as valid interlocutors.
\end{abstract}

Keywords: Sex work, collective imagination, stigma, municipal bylaws, public space.

Palabras clave: Trabajo sexual, imaginario colectivo, estigma, ordenanzas municipales, espacio público.

Recibido: 24/03/2015

Aceptado: 10/07/2015

Publicado: 03/12/2015

1. El presente artículo es una síntesis del Trabajo Fin de Máster presentado en 2013 por la misma autora en los estudios de Máster de Trabajo Social Comunitario: Gestión y Evaluación de Servicios Sociales de la Universidad Complutense de Madrid, actualmente no publicado.

2. Celia Pérez Martín. Trabajadora social por la Universidad Complutense, Máster Oficial en Trabajo Social Comunitario y Magíster en Género y Desarrollo por el ICEI-UCM. Colaboradora Honorífica del Departamento de Trabajo Social de la Universidad Complutense de Madrid. Campus de Somosaguas. 28223 Pozuelo de Alarcón. Madrid. Teléfono: 616540905. E-mail: cperez.trs@gmail.com 


\section{Introducción}

El siguiente artículo refleja una síntesis de los resultados obtenidos de la investigación realizada en colaboración con el Colectivo Hetaira en Madrid, -asociación que trabaja por la defensa de los derechos de las trabajadoras del sexo, la reivindicación de la mejora de condiciones de trabajo y la autoorganización de todas ellas en defensa de sus intereses como trabajadoras-, como parte de los estudios de Máster en Trabajo Social Comunitario de la Universidad Complutense de Madrid (Pérez, 2013). El estudio pretende indagar en las consecuencias que tienen sobre el conjunto de mujeres que ejerce la prostitución la implantación de las ordenanzas municipales que regulan la actividad en la vía pública. En palabras de la autora Juliano, «ahora lo que produce «alarma ciudadana» y que se manifiesta como una de las preocupaciones prioritarias de la población, es la existencia de personas que ocupan un lugar en el espacio diferente del que se les ha asignado»(Juliano, 2006: 35), lo cual implica por un lado, catalogar a un grupo social como diferente y colocarle en los márgenes del sistema y por otro, excluirle de él, lo que conlleva inevitablemente a que las políticas que persiguen el orden social guíen su intervención en dos sentidos, bien bajo el asistencialismo o las medidas represivas.

En suma, el simple hecho de otorgar a la mujer una determinada denominación, hace que la visión que se tiene del ejercicio de la prostitución se acoja a diferentes formas de conceptualizarse donde designar a la mujer como prostituta o puta hace que se le enmarque únicamente por aquello que hace mientras que, como trabajadora sexual, implícitamente denota el deseo de reconocer a la prostitución como una actividad laboral. Por último, el referirse como mujer prostituida conlleva considerar a la mujer una víctima y ente pasivo de la actividad que realiza, donde la acción siempre recae sobre un tercero (Meneses, 2007). A lo largo de la investigación, que pretende ser un instrumento con el que acercarse a la realidad del fenómeno, se utilizan indistintamente los términos trabajo sexual y prostitución, aun habiéndose recogido un número mayor de mujeres que prefieren autodenominarse como trabajadoras del sexo. Aunque el estudio se centra únicamente en mujeres y transexuales, se tienen también en cuenta a otros agentes, como los clientes, proxenetas, chulos y comerciantes entre otros que, no solamente se encuentran inmersos en el ejercicio sino que, además, puedan ser objeto de discurso de las mujeres.

Se trata de un mercado sexual en el que junto a la oferta laboral (personas que realizan servicios sexuales) existe una demanda (una numerosa y variada clientela, estructurada por diversos niveles de renta, gustos/deseos, posiciones en el mercado matrimonial, etc.) y un sin número de agentes mediadores 
que movilizan, canalizan y facilitan el encuentro entre demandantes y oferentes (Agustín, 2001: 539).

En definitiva, para entender el fenómeno de la prostitución es necesario revisar el contexto público donde actualmente tienen vigencia el conjunto de ordenanzas municipales, desde la propia construcción y significado que atribuyen las mujeres a la actividad, entendiendo que este aguarda un conjunto de percepciones en torno al ejercicio que son de interés conocer.

\section{Una aproximación a la realidad del trabajo sexual y los principales debates}

\subsection{Estigma, estereotipos e imaginarios sociales}

El concepto de estigma recogido por Goffman (2003) alude a un atributo profundamente desacreditador en las interacciones sociales que implica discriminación, lo que reduce el acceso de las personas a los recursos sociales y merma el conjunto de sus posibilidades y de participación en la comunidad. En el caso de la prostitución, el estigma funciona como una estrategia patriarcal ligada a la construcción de los roles de género donde, además de no tolerar la transgresión de las normas sexuales por las mujeres es utilizado para no considerar su independencia económica como una opción rentable, si esta deriva de los servicios de la prostitución (Juliano, 2006; Osborne, 2003 citado por Arella, Fernández, Nicolás y Vartabedian, 2007), realzando la dicotomía entre buenas y malas mujeres. Además, se otorga una identidad construida desde el exterior, por lo que «las trabajadoras sexuales son «putas», son malas madres, son mujeres manipuladas, son mujeres explotadas» (Arella et al., 2007: 62).

Este victimismo y la consideración de la mujer como objeto de manipulación por parte de un tercero, conduce inevitablemente a no contemplar la situación real de la mayoría de las mujeres que ejercen la prostitución, ocultar su capacidad de decisión y no aceptar su independencia personal y económica. En contraposición a esta visión, el testimonio de la prostituta y activista italiana Carlo Corso difiere del imaginario social establecido, valorando la capacidad de decisión que tienen las mujeres: «yo no soy víctima de nadie. Evidentemente he sufrido por las dificultades de la vida, pero como todos. No quiero ser una víctima de estos sufrimientos: los combato y quiero salir victoriosa» (Corso y Landi, 2000: 182).

\subsection{El debate sobre los modelos: marco legal en el caso de España}

Tomando de referencia algunas autoras, a continuación se recogen resumidamente los modelos de regulación jurídica que cada país impulsa en cuanto 
al tema de la prostitución (Osborne 1988; Rubio, 2008, Gay, Sanz y Otazo, 2003 y Poyatos i Matas, 2009). Aunque por lo general los estados presenten modelos mixtos, el debate actual se encuentra entre el modelo abolicionista y legalización. El prohibicionismo considera la prostitución un atentado contra la dignidad de la mujer, por lo que esta no puede ni debe ser tolerada desde el punto de vista social, moral y jurídico. Su fin único sería su eliminación tomando a la mujer en consideración de delincuente. El reglamentarismo, sin embargo, partiría de tolerar la prostitución bien como una actividad funcional o un mal menor que no puede evitarse, debiendo remitirse a lugares cerrados y quedando sujeta a represión, control y vigilancia, donde la mujer es señalada como persona peligrosa. En cuanto al abolicionismo, postura más defendida desde el feminismo, la prostitución debe ser erradicada ya que implica condiciones de explotación para las mujeres y violencia de género. Sus medidas irán encaminadas a la protección de la mujer, en calidad de víctima, y la persecución de clientes y proxenetas, entendiendo que son estos quienes promueven la actividad. Por último, el modelo laboral o legalización, parte del reconocimiento de derechos laborales siempre y cuando el ejercicio sea elegido libremente, por lo que enfatiza en diferenciar la prostitución libre de la trata con fines de explotación forzada. Bajo este paradigma, la mujer no es vista en calidad de delincuente, persona peligrosa o víctima, sino que es considerada una trabajadora.

En el caso del Estado Español la actual reforma del Código Penal ${ }^{3}$ especifica que «en la misma pena incurrirá el que se lucre explotando la prostitución de otra persona, aun con el consentimiento de la misma» (art. 188). La prostitución, al no ser considerada delito ni tampoco ilegal, no cuenta con regulación específica en cómo debe desempeñarse cuando se ejerce voluntariamente. Sin embargo, esta situación de alegalidad es el escenario idóneo para que surjan normativas a nivel municipal ${ }^{4}$, en las que «bien el ejercicio -aunque voluntario- de la prostitución bien la compra de servicios sexuales pueden constituir infracción administrativa si así lo dispone la normativa administrativa municipal aplicable» (Villacampa, 2012: 129); normativas

3. Contemplado bajo la Ley Orgánica 11/2003, de 29 de septiembre, de medidas concretas en materia de seguridad ciudadana, violencia doméstica e integración social de los extranjeros

4. Referido a las Ordenanzas Municipales, normativas reguladoras de los espacios públicos con el fin de fomentar y garantizar la convivencia ciudadana y el civismo, y que en lo relativo al ejercicio de la prostitución prohíben, tanto el ofrecimiento, como la solicitud, la negociación o la aceptación, directa o indirectamente de servicios sexuales retribuidos en el espacio público, así como el hecho de mantener relaciones sexuales en dicho espacio. 
surgidas principalmente de una necesidad de eliminar la visibilidad del ejercicio de la prostitución en la vía pública.

\section{Metodología}

Este artículo es síntesis de las observaciones y trabajo de campo realizado en las principales zonas de prostitución de calle de Madrid durante los meses de enero a julio de 2012. La investigación parte de la hipótesis de que la percepción de las mujeres que ejercen la prostitución, acerca de sus necesidades y demandas, se sitúa en contra de la entrada en vigor de las normativas, pues entienden que merma su calidad de vida y trabajo. Además, las Ordenanzas Municipales implican una transformación en las condiciones de negociación de las mujeres al propiciar la clandestinidad del servicio y un incremento del tiempo de trabajo en la calle a partir del régimen sancionador, lo que intensifica los efectos negativos en un contexto de falta de oportunidades en el actual mercado laboral. El estudio tiene, por tanto, la finalidad analizar el contenido de las Ordenanzas Municipales vigentes en el territorio Español y recoger la valoración por parte del conjunto de mujeres. Los objetivos específicos que orientan la investigación, son los siguientes:

- Estudiar los antecedentes y el contexto de las Ordenanzas Municipales, con el consiguiente análisis comparativo de su preámbulo justificativo, competencias y tipología de sanción más representativa.

- Conocer la significación que atribuyen las mujeres al ejercicio de la prostitución, realizando un acercamiento al estigma social que rodea a la actividad.

- Analizar la posición que adoptan las mujeres ante las normativas vigentes en el territorio español que persiguen la prostitución de calle, indagando en el conjunto de consecuencias para el ejercicio.

Ahora bien, como es propio del enfoque cualitativo, el estudio no pretende alcanzar la representatividad estadística para inferir o generalizar los resultados obtenidos, sino que el objetivo consiste en mostrar y analizar el sentido atribuido por parte de los sujetos que intervienen en el fenómeno que nos ocupa -en nuestro caso las organizaciones y las mujeres que ejercen la prostitución- hacia el fenómeno y el contexto de las normativas. Se recurre al carácter cualitativo por entender que mejor se adecua al objetivo perseguido y además permite conocer de cerca los diferentes espacios de prostitución aproximándose al ejercicio «(...) como una realidad dinámica y en continua transformación» (Berroa, Gijón y Zapata, 2010: 3). Las técnicas utilizadas 
para ello han sido: entrevistas individuales en profundidad (semi-estucturadas), observación participante de los diferentes escenarios de prostitución en medio abierto ${ }^{5}$, acompañamiento en las tareas de investigación del Colectivo Hetaira y revisión de fuentes bibliográficas y documentales. Para llevar a cabo el trabajo de campo se eligieron tres espacios de observación directa por considerar que en ellos sigue existiendo un ejercicio continuado y, por tanto, eran representativos para la recogida del discurso de las mujeres en torno a la realidad de la prostitución en la vía pública, donde algunas zonas ya se encuentran reguladas mediante normativa municipal: Madrid centro (que comprende la calle Montera, Desengaño-Ballesta, Plaza de Jacinto Benavente, Calle Atocha y Cruz), el distrito de Villaverde y el Municipio de Alcalá de Henares.

Mapa 1. Zonas de ejercicio de prostitución de calle

(Distritos de la Ciudad de Madrid y alrededores)

\section{LEYENDA}
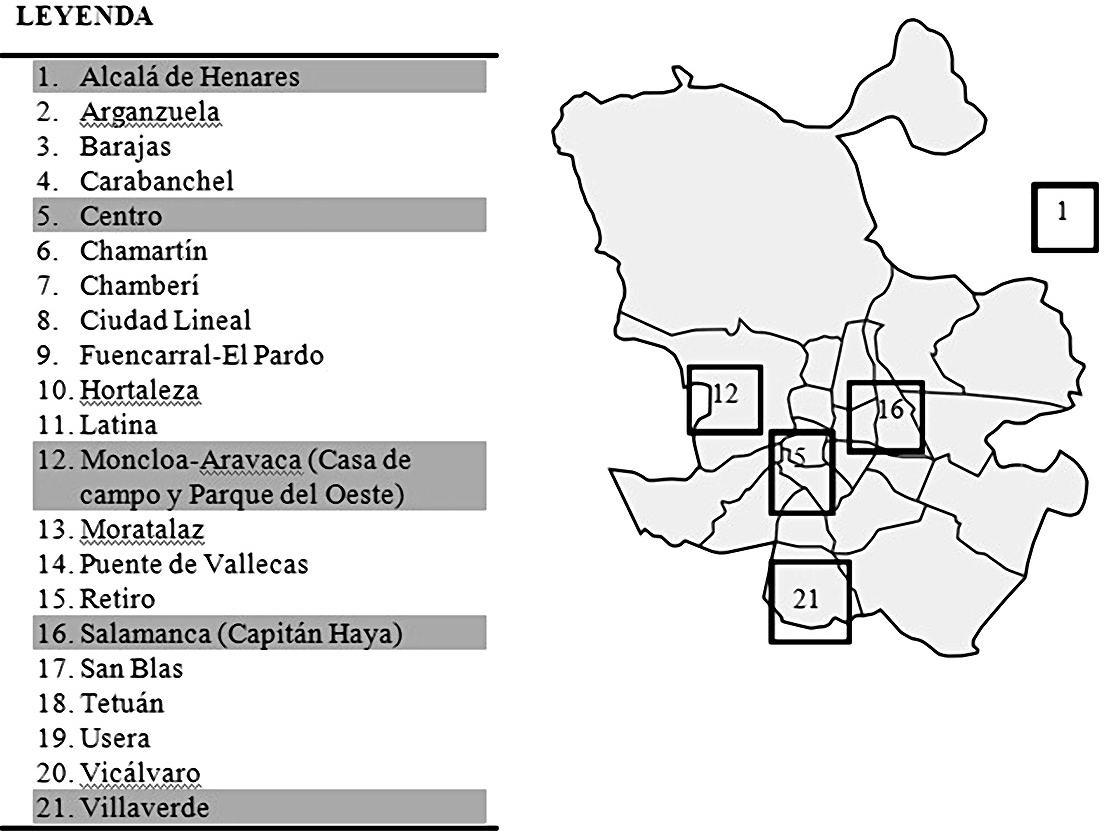

Fuente: Elaboración propia

5. Por «medio abierto» se entiende aquel tipo de prostitución ejercida en el espacio público (calle, polígonos industriales), mientras que «medio cerrado» refiere a una clasificación más extensa, puesto que comprende la que se realiza en clubes de alterne, saunas, plazas y/o pisos entre otras modalidades. 
Para el diseño muestral de las mujeres y Ordenanzas Municipales se ha decidido que este se corresponda con el tipo intencional o dirigido, por lo que se hará uso de la intención del investigador/a, donde prime la interpretación de los datos y comprensión de los sujetos (Ruiz Olabuénaga et al., 1998). A partir de la observación participante en los escenarios donde se ejerce la prostitución y la recogida de discursos fueron seleccionadas un total de ocho mujeres, 4 biológicas y 4 transexuales, intentando atender a la heterogeneidad del colectivo y considerando que, en ambos casos, la estigmatización del trabajo sexual recae con mayor ímpetu sobre las segundas. Además, fueron tenidas en cuenta variables de carácter demográfico y social -procedencia geográfica, edad, lugar de trabajo, etc.-, así como de historia de vida personal -motivos de ingreso y permanencia en el ejercicio de la prostitución-, donde los procedimientos utilizados han sido realizados tras un consentimiento informado, primando la privacidad de las entrevistadas.

Tabla 1. Perfil de mujeres entrevistadas

\begin{tabular}{|l|l|l|l|l|}
\hline INFORMANTES & \multicolumn{1}{|c|}{ EDAD } & \multicolumn{1}{|c|}{ SEXO } & $\begin{array}{c}\text { PROCEDENCIA } \\
\text { GEOGRÁFICA }\end{array}$ & ZONA DE EJERCICIO \\
\hline Mujer 1 (M1) & 37 años & Mujer & Colombia & Desengaño-Ballesta \\
\hline Mujer 2 (M2) & 50 años & Transexual & Ecuador & Desengaño-Ballesta \\
\hline Mujer 3 (M3) & 36 años & Transexual & Ecuador & Polígono de Alcalá \\
\hline Mujer 4 (M4) & 37 años & Transexual & Ecuador & Poligono de Alcalá \\
\hline Mujer 5 (M5) & 29 años & Mujer & España & Polígono de Villaverde \\
\hline Mujer 6 (M6) & 36 años & Mujer & Rumanía & Calle Montera \\
\hline Mujer 7 (M7) & 29 años & Mujer & Marruecos & Plaza. Jacinto Benavente \\
\hline Mujer 8 (M8) & 35 años & Transexual & Ecuador & Polígono de Villaverde \\
\hline
\end{tabular}

Fuente: Elaboración propia

En el caso de las Ordenanzas la muestra se compone de un total de siete. La muestra escogida para el análisis se formó a partir de unos criterios preestablecidos, con el fin de que el grupo escogido respondiera a una representatividad dentro del conjunto de normativas existentes. Los criterios a tener en cuenta fueron: tamaño del hábitat o municipio, referido al número de habitantes, ciudades que hubieran experimentado alguna modificación en su Ordenanza 
Municipal, contexto de la normativa, según su aplicación sea general o específica, y tipología de penalización, en cuanto a si la sanción iba dirigida al cliente, demandante del servicio, o incluía a la mujer, encargada de ofrecerle.

Tabla 2. Criterios para el diseño muestral de las Ordenanzas Municipales objeto de estudio

\begin{tabular}{|c|c|c|c|c|c|c|c|c|c|}
\hline \multicolumn{2}{|c|}{ Tamaño ciudad/municipio } & \multicolumn{2}{|c|}{ Modificación } & \multicolumn{2}{|c|}{ Penalización } & \multicolumn{3}{|c|}{ Contexto de aplicación } \\
\hline $\begin{array}{c}\text { Grande } \\
\left(^{*}\right)\end{array}$ & $\begin{array}{c}\text { Mediano } \\
\left(^{* *}\right)\end{array}$ & $\begin{array}{c}\text { Pequeño } \\
(* *)\end{array}$ & Si & No & $\begin{array}{c}\text { Mujer / } \\
\text { Cliente }\end{array}$ & Cliente & General & Específica ${ }^{* *}$ & $\begin{array}{c}\text { Prostitucióny } \\
\text { mendicidad }^{3}\end{array}$ \\
\hline & & & & & & & & & \\
\hline & & & & & & & & & \\
\hline & & & & & & & & & \\
\hline & & & & & & & & & \\
\hline & & & & & & & & & \\
\hline & & & & & & & & & \\
\hline
\end{tabular}

Fuente: Elaboración propia a partir de la información reflejada en las Ordenanzas Municipales.

Tamaño del Municipio: (*) Municipios con más de 1.000 .000 habitantes; $(* *) \geq 200.000 \leq 1.000 .000$ habitantes; $(* * *)$ $\geq 100.000 \leq 200.000$ habitantes. Modificación: Si ha sufrido o no modificación en relación a la normativa original Penalización: según si la sanción va dirigida a los dos agentes mujer/cliente o solamente al cliente. Contexto: (1) Enfocada a un conjunto de actuaciones o actividades (2) Enfocada al ofrecimiento de servicios sexuales. (3). Enfocada a prostitución y mendicidad.

Albacete $\square$ Alcalá de Henares $\square$ Alicante $\square$ Badajoz $\square$ Barcelona

Bilbao

Sevilla

\section{Acercamiento al entramado social que rodea al ejercicio de la prostitución}

\subsection{Prostitución y espacio público: la calle}

De acuerdo con datos de la memoria 2012 de la Asociación Hetaira, un 51.5\% de las mujeres que ejercen la prostitución en Madrid proceden de América Latina, un 23.2\% de Europa del Este, 10.8\% son originarias de Europa Occidental y, en una menor proporción, se encuentran aquellas mujeres provenientes de África subsahariana (7.6\%), El Magreb (6.6\%) y Asia (0.1\%) los 1.264 contactos anuales con mujeres que se dedican al trabajo sexual en zonas públicas, en locales de interior a través de internet, un $49.1 \%$ derivan de mujeres que ejercen en la calle con más de 50 nacionalidades diferentes.

6. Los datos registrados establecen un total de 1.264 contactos anuales con mujeres que se dedican al trabajo sexual en zonas públicas, en locales de interior, en el centro de atención o a través de internet, de los cuales un $49,1 \%$ se corresponde con mujeres que ejercen en la calle. Recuperado de la memoria anual del año 2012, disponible en www. colectivohetaira.org. 
Las mujeres que ejercen la prostitución en el centro de Madrid exponen que tienen preferencia de captar su clientela de esta forma, otorgando al espacio público un valor que les da mayor seguridad y autoafirmación. Sin embargo, el espacio se encuentra diferenciado para hombres y mujeres, donde estas últimas quedan mayormente relegadas a los ambientes privados, aquellos que rozan más el significado afectivo y son más invisibles (Arella, 2009). Además, los espacios se encuentran contrastados según si son mujeres biológicas o transexuales las que ejercen la actividad, siendo mayormente objeto de fuerte control policial las zonas céntricas de Madrid y los polígonos industriales; estos últimos en relación a la posible existencia de situaciones de trata con fines de explotación sexual, por ser lugares más alejados de los núcleos urbanos. Aun así se han vislumbrado que la presencia de mujeres en las calles son objeto de conflictos vecinales y de comerciantes, por lo que del discurso de las mujeres se ha recogido que, en ocasiones, han sido obligadas por la fuerte presión social a dejar su lugar de referencia y tener que desplazarse a otros que gozan de desconocimiento e inseguridad y en los que han de lograr posicionarse en relación al resto de mujeres. En este sentido, varias conversaciones apuntan a las situaciones de violencia que, en ocasiones, se dan entre las propias mujeres.

Aquí una tiene que ganarse su sitio...no es no más llegar y listo. A mí me han tirado de los pelos, tirado al suelo y hasta amenazado con matarme unas mujeres con que ese era su sitio...Yo no me paré y continué...y hasta ahora... (Diario de Campo, 18 de marzo)

La prostitución se configura como una construcción social que va en contra de los cánones establecidos sexualmente (Leite, 1992; Parker, 1991, citado por De Paula, 2000), siendo las mujeres bajo estos mandatos transgresoras de la norma. En este sentido, en el espacio público las mujeres diferencian entre el ambiente de trabajo y el de su vida personal y privada, donde las identidades de género y la estigmatización juegan un papel crucial para que estas delimiten bien ambos.

Porque yo no soy prostituta las $24 \mathrm{~h}$. Yo trabajo en la industria del sexo unas horas y luego soy una mujer normal (M8).

Algunas mujeres consideran el ejercicio como algo que les genera vergüenza refiriéndose a la actividad como un mal menor al que no queda más opción que adaptarse para la supervivencia mientras que otras, de forma voluntaria, desarrollan estrategias de autoafirmación eligiendo la actividad por considerarla, dentro de las oportunidades que existen en el mercado de trabajo, una opción que proporciona mayor independencia económica. Defienden la calle por sentirse principales dueñas de la actividad, por su flexibilidad y opciones 
de libertad, pudiendo elegir, según su lugar de residencia, la zona que mejor consideren para ejercer su trabajo (Agustín, 2001).

Por dos razones: yo vivo por aquí, cerca, no gasto en transporte (....) Y acá en la calle, elijo cuando salir a trabajar... ientiendes? (M2).

Aún así, la calle también conlleva condiciones muy duras como las altas y bajas temperaturas, las horas de pie, la competencia diaria y el estar visible ante las miradas de los transeúntes. Aun así, esta sigue representando un entorno que otorga seguridad y aporta cierta estabilidad por lo conocido donde «el deseo de las mujeres de permanecer en un sitio específico puede responder a una necesidad de autoposicionamiento, a la necesidad de un marco de referencia estable» (Oso y Ulloa, 2001: 92).

Una mujer española de 71 años, nos dice que ella tiene suerte porque con algunos ya se conoce. iQue son muchos años! (Diario de Campo, 13 de marzo).

Las mujeres valoran su capacidad en la toma de decisiones ante la actividad, realzando el dominio de su propio negocio cuando refieren a la libertad de la calle, como un espacio en el que hacer balance de sus costes y beneficios. En cuanto a los Clubes, sienten reticencias pues entienden que terceras personas adquieren parte de lo que son sus ganancias y con las imposiciones de los dueños no son jefas de la negociación del servicio.

Yo en la calle soy dueña de mis servicios, y puedo decir, aceptar o denegar un servicio que no me interesa (M4).

(...) ¿En un Club? Si yo no hago lo que el cliente me dice, yo no atiendo a un cliente que no me gusta, si viene una persona indeseable que no me encanta atenderla, al día siguiente ya no tengo trabajo (M8).

Aun así, y aunque los discursos apuntan hacia una percepción de emancipación en las condiciones del ejercicio, puede sentirse que existe cierta obligatoriedad del oficio.

(...) no hay otra opción más que buscar la calle (M2).

En relación a las ordenanzas municipales se destaca que todas ellas tienden a evitar la potestad sancionadora como primera medida y en ese sentido irían encaminadas a ser una respuesta democrática y equilibrada a estas nuevas situaciones y circunstancias, basándose en el reconocimiento del derecho de todas las personas a comportarse libremente en los espacios públicos y a ser respetadas en su libertad ${ }^{7}$. En esta línea, la realidad es bien distinta si observamos que la mayoría de normativas defienden la regulación como medida para prevenir la explotación y trata de determinados colectivos, lo que conlleva a

7. Extraído de la Exposición de Motivos de la Ordenanza cívica de Barcelona de 2006. 
considerar el ejercicio únicamente como la máxima expresión de la violencia de género ${ }^{8}$, donde todas las mujeres son calificadas como víctimas ${ }^{9}$. Estas normativas, además de multar tanto a clientes como a mujeres, regulan todo tipo de actividades que son desarrolladas en el espacio público y que se consideran que pueden violar el orden social (aquí se encontraría recogida la mendicidad, las actividades musicales en la calle, los gorrillas, etc). Además, en el apartado referido al ejercicio de la prostitución normalmente incluyen un apartado de intervención donde quedan recogidas acciones dirigidas al abandono del ejercicio por parte de las mujeres, lo que no deja salida para todo ese conjunto de mujeres que encuentran en la actividad una salida laboral a su situación. El definitiva, el conjunto de ordenanzas que prohíben la prostitución de calle con el fin de regular el espacio público, implican una serie de medidas represivas y de control hacia las mujeres en consideración de víctimas, donde todas las intervenciones van enfocadas a la rehabilitación, abandono del ejercicio y reinserción de las mujeres.

\subsection{La voz de las trabajadoras del sexo}

\subsubsection{El significado de la prostitución para las mujeres}

El discurso recogido de las mujeres, en cuanto a la significación que tienen de la prostitución sugiere que, en su mayoría, perciben el ejercicio como una actividad que les proporciona mayores ingresos que otros empleos, considerándola fuente de independencia económica. El ejercicio de la prostitución constituye en las mujeres, sobre todo en aquellas de origen inmigrante, una de las principales salidas laborales y a su vez una de las menos valoradas socialmente (Osborne, 2004; Bonelli y Ulloa, 2001). En el caso del presente estudio, las mujeres consideran el ejercicio como una opción rentable, como medio con el que poder emanciparse y el cual tiende a otorgarles mayor dignidad que otras actividades a las que se podrían dedicar:

(...) yo no quiero limpiar vómitos, yo no tengo por qué hacer algo que no me gusta, tengo que hacer algo que me gusta (...) yo no vendo mi cuerpo, yo le doy

8. La prostitución debe ser contemplada en el marco del Convenio de Naciones Unidas para la Represión de la Trata de Personas y de la Explotación de la Prostitución Ajena, de 2 de Diciembre de 1949, que considera la existencia de explotación sexual aunque exista consentimiento de la víctima Extraído de la Exposición de Motivos de la Ordenanza cívica de Sevilla de 2008.

9. En este sentido el victimismo que se da a las mujeres no coincide con el uso de los términos utilizados en las normativas. Véase como ejemplo la Ordenanza de Badajoz que utiliza los términos «infractor/infractora» para referirse al cliente/mujer como si la prostitución constituyera una actividad delictiva. 
placer a alguien y por ese placer él me remunera económicamente (Carolina, entrevista 8).

Otra cuestión a destacar, dentro del imaginario colectivo, es el lugar que toman las mujeres. En líneas generales, se posicionan en contra de la estigmatización que existe cuando se atribuye la connotación de «mala madre» a la mujer prostituta, por lo que defienden el ejercicio como una vía que les permite brindar las mejores condiciones de vida a sus descendientes y familiares, enfatizando a través de ellos su necesidad de mantenerse en la calle. En este sentido el imaginario social existente, donde se cataloga a las mujeres bajo su condición de prostituta -por aquello que se cree que son y no por la actividad que realizan- (Juliano, 2006), quedaría a un lado si se tiene en cuenta el discurso de las mujeres. Es así como muchas de ellas rompen con esta idea de la mala madre, entendiendo la prostitución como un recurso puntual, siendo vivido como tal más que como un problema en sí mismo.

Es el recurso que tiene la mujer para salir adelante. Mediante este ejercicio ha sacado y saca adelante sus hijos (Lucía, entrevista 4).

La prostitución, aún generando autonomía en la mujer, es considerada aquella actividad con menor prestigio social y con mayor estigmatización (Juliano, 2006). Se consideraría relevante destacar, que en este estudio todas hablan de la prostitución como un trabajo, como una opción laboral legítima, a pesar de variar la forma que tienen de interiorizar el ejercicio. El estigma, sin duda, puede ser considerablemente la causa de que muchas de ellas oculten su actividad, no haciendo explícita la procedencia de sus ingresos.

No, ellos no saben nada, ¿qué iba a pensar mi hijo si se entera que su madre es una puta de la Montera? (Diario de Campo, 20 de febrero).

$\mathrm{O}$ por el contrario, de que reivindiquen su actividad rompiendo con la asignación que recae sobre ellas, considerando la prostitución como un camino alternativo que ellas mismas han elegido.

(...) me encanta ver que una persona se va contenta y feliz del momento que yo le he brindado. Y eso me gusta, y eso para mí es mi trabajo (Carolina, entrevista, $8)$.

Aún así, el trabajo sexual adquiere en las mujeres varias significaciones que se vincularían al estigma. Dejemos que sean las propias trabajadoras del sexo quienes lo expresen:

¿Cómo defino yo el trabajo sexual? pues que te digo, es un trabajo triste, te apena. (...) se le puede llamar trabajo pero no es trabajo isabes? Porque ahí no te ven como mujer, ahí no te ven como nada, sino simplemente van...te ven como un wáter, (...) voy y lo utilizo, le doy a la cisterna y chao. Eso es, así defino yo este trabajo (Adelaida, entrevista 1) 
(...) ¿Por qué trabajar en la prostitución? El mundo y la sociedad no te brindan muchas oportunidades. Es mentira que hay muchas expectativas o un amplio núcleo de trabajo o algo, es mentira. Y si lo hay, habemos personas que no lo queremos o no lo aceptamos (Carolina, entrevista 8).

A este hecho ya hacía referencia Garaizábal cuando señalaba, que «dedicarse a la prostitución implica un estigma que, en muchos casos, es interiorizado por ellas, generando vergüenzas y sentimientos negativos que provocan vivencias contradictorias: ganas de seguir y de abandonar este trabajo» (Garaizábal 2007, p. 51). Y así ha sido, que a través de ciertas actitudes y comentarios que se recogieron en las observaciones de campo se revela que habría mujeres que ejercen de forma consciente y voluntaria, sin que una tercera persona intervenga en su toma de decisiones. Cabe considerar que este hecho nos lleva también a explicar las condiciones materiales de la «libre» elección que en muchas ocasiones aboca la prostitución, donde en varios discursos se manifiesta y percibe la libertad que tienen muchas mujeres rumanas a la hora de ejercer, lo que lleva a romper con en el imaginario social establecido.

No hay que confundir chulo con marido. Claro tú pensarás, ¿qué marido te deja que trabajes en la calle, que seas mujer de otros hombres? Otra cosa es no querer depender de él económicamente, por eso estoy en la calle, pero por decisión mía no porque él me obligue (Cristina, Diario de Campo, 20 de mayo).

Por último, otro de los aspectos del imaginario colectivo que tienen las mujeres de la prostitución es el papel que ocupa la figura del «chulo» en el ejercicio, persona «que las cuida y las controla en la calle, llegando a manejar completamente su tiempo, su dinero y sus afectos» (Oso y Ulloa, 2001, p. 91). Con las mujeres rumanas, el contacto suele ser más costoso, debido principalmente al idioma y a esta figura que algunas parecen tener. Otras, sin embargo, comentan haber comenzado en la prostitución bajo esta figura, pero tras saldar la deuda, ahora ejercen por sí mismas de forma libre.

(...) vino engañada con un conocido (...) ahora trabaja en la calle lo que a ella le da la gana (...) Que tiene total libertad. (Diario de Campo, 27 de febrero).

Además del chulo se señala que ha surgido la figura conocida como «controladora del espacio», a la que las mujeres deben pagar una cantidad semanal por ejercer en un lugar determinado de la calle. De uno de los discursos se extrae que, ante este nuevo agente el chulo, con todo ello, otorgaría cierta seguridad y protección.

(...) un chulo en sí te tiene ahí trabajando pero está por ahí dando vueltas y si tienes algún problema te ayuda aunque le des todo. Y ellos pues no, vienen una vez a la semana, recogen su dinero y se van, ni protección ni nada. (Ana María, entrevista 5). 


\subsubsection{Las Ordenanzas Municipales}

\subsubsection{Grado de conocimiento}

La aproximación al discurso y las opiniones recogidas en las zonas visitadas de ejercicio sugiere que las mujeres presentan cierto grado de conocimiento acerca de las normativas municipales, el cual deriva normalmente de algunas compañeras que trabajan en otras ciudades de España o bien, de los medios de comunicación. En su mayoría pareciera que únicamente conocen el hecho de que quieren erradicar la prostitución de calle y que estas conllevan una sanción económica. No suelen hacer referencia al conjunto de intervenciones y ayudas que se ofrecen desde las normativas, ni si es únicamente la prostitución o hay más prácticas que se encuentran reguladas. Cuando se refiere al hecho de qué conocen acerca de las normativas todas ellas responden con palabras que denotan cierto carácter prohibitivo y represivo. Se percibiría el hecho de que, a pesar de no conocer las normativas en profundidad, las mujeres tienen generalizado un sentimiento de preocupación en relación a cómo van a afectarles.

Porque imagínate que me pillan y me multan, ¿de dónde saco yo tanto dinero si a veces no me llega para comer tres veces al día? (Cristina, entrevista 6).

Sin embargo, aquellas mujeres que ejercen la prostitución en lugares donde ya hay implantada una normativa, como es el caso de Alcalá de Henares, o que tienen mayores experiencias participativas y/o vínculo con las organizaciones, se aprecia que tienen un conocimiento más consolidado, y quizá más próximo a la realidad, de lo que son y/o conllevan las normativas cívicas. Relatan que primeramente fueron avisadas por la policía, en palabras de Mari Tere, «se les va a acabar (...) van a poner una normativa» $y$, tras este aviso, se pasó a concederlas un tiempo para que abandonaran la calle.

Es una normativa que en nada protege a nadie, a nadie. O sea, nos pone en un estado muy bien dicho de in-de-fen-sión. Para eso está elaborada, y si no está elaborada, la aplicación es esa (Lucía, entrevista 4).

\subsubsection{Criminalización}

El conjunto de medidas represivas que han surtido efecto sobre el ejercicio de la prostitución, en mayor medida sobre aquella que se ejerce en la calle, cabría suponer que queda íntimamente relacionado con la doble moral existente en cuanto a la prostitución, en el que el control policial, sobre la venta de servicios sexuales en la calle, -práctica demandada y utilizada a gran escala-, persigue la finalidad de que esta no sea visible. Pareciera que las trabajadoras del sexo cuestionan esta doble moral en cuanto a la sexualidad normativa de 
las mujeres, lo cual se recoge de un testimonio donde Lucía lo explica desde un ejemplo visible en la calle.

Fijate tú que los gays tienen sus cotos privados donde pueden estar, pero las prostitutas no. (...) y es así, no visible porque los hombres no se ponen tacones... Por ejemplo, en Montera, están las chicas ahi paradas en una esquina y es muy escandaloso, pero están los chicos, también están parados así y no es escandaloso (...) (Lucía, entrevista 4).

Además, la criminalización conlleva un sentimiento generalizado en las mujeres de victimización de su actividad que considera que, estas en su conjunto, ejercen coaccionadas y no condicionadas, fomentando la percepción social existente como víctimas de trata e invisibilizando como consecuencia a aquellas que ejercen de forma voluntaria. De los discursos de las mujeres se pueden extraer testimonios donde se posicionarían contrarias a equiparar prostitución voluntaria con prostitución forzada, reafirmando, por lo tanto, esa voluntariedad que tienden a defender del ejercicio.

Una cosa es prostitución y otra cosa es explotación sexual, una cosa es una mujer que ejerce su oficio de meretriz, de ramera, y otra cosa es una pobre mujer que está siendo explotada, engañada (Lucía, entrevista 4).

Además de víctimas cabe recalcar que, las mujeres, por lo general, sienten que la protección que debería prestarles la policía directamente desaparece en tanto dejan de ser protegidas con las normativas municipales, puesto que, con las sanciones que incurren en lo que consideran que es su trabajo a lo único que conllevan es a criminalizar su ejercicio, y por lo tanto, a ser vistas como delincuentes, donde la prostitución se liga a actividades delictivas y drogadicción. La mayor parte de ellas siente que al atributo de «puta» se les suma uno más, el de «delincuente».

Siempre se ha unido la prostitución con la delincuencia, con la droga, y todo aquello, y no tiene porqué. Simplemente, todas estas cosas tienen un mismo componente que es el compartir la calle (Lucía, entrevista 4).

Con ello, la criminalización del ejercicio estaría muchas veces impulsada por el trato que otorga en ocasiones la policía a las trabajadoras del sexo, por ejemplo, y tal y como apuntó el discurso, fotografiarlas sin su consentimiento. Los testimonios recogidos apuntarían hacia una cierta insatisfacción, en torno a la seguridad que debieran proporcionarles, lo que hace que merme y se agrave con la implantación de una posible normativa su sentimiento de protección. Refieren al hecho de que tenderán a verles más como enemigos que como figuras protectoras.

(...) la policía no colabora conmigo, no me ayuda a que yo esté segura trabajando en la calle (Carolina, entrevista 8). 
De ahí, que además refieran que sufren continuos controles policiales en los que, en mayor medida a las extranjeras, se les impone la obligación de presentar su documentación a pesar de no estar siendo partícipe de ninguna actividad delictiva.

\subsubsection{Protección v/s libertad}

El conjunto de normativas que sanciona el ejercicio de la prostitución en la calle, de alguna manera, coaccionaría esa libertad a la que referían las mujeres en el significado que atribuyen al espacio público. Estas demandan no solamente la libertad del ejercicio sino su consiguiente protección, sin embargo, sus palabras refieren a que con las normativas se sienten menos protegidas, disminuyendo su libertad en la calle, lo que les lleva a tener que acogerse a otras formas de ejercer lo que consideran que es su trabajo. Hablan de la «clandestinidad del ejercicio», puesto que sienten que se verán en la obligación de buscar otros lugares que no sean visibles para ejercer su actividad, explicando la opción de ejercer en Clubes o pisos, y la repercusión que puede traer en sus condiciones de trabajo el hecho de cambiar de ambiente.

Con todo ello, de lo que expresan las mujeres se deducen estrategias para no perder esa libertad de la calle a la que refieren, autoposicionándose como dueñas de sus servicios. Sin embargo, este conjunto de tácticas normalmente les llevan a situarse en una posición inferior al cliente, mermando su poder y agudizando su condición de vulnerabilidad social.

\subsubsection{Posición ante el cliente}

Los discursos coinciden en apuntar que aunque la prostitución va a seguir existiendo a pesar de imponer normativas que la prohíban, va a disminuir la afluencia de los clientes y empeorar las condiciones de trabajo. Las mujeres sienten que el contexto en el que se da la negociación, del cual ellas deben ser dueñas, va a sufrir modificaciones, lo que lleva a la posibilidad de que haya un cambio de roles. En su conjunto perciben que ahora el cliente goza de más poder sobre la mujer y se «aprovecha» de las condiciones que experimenta el trabajo sexual para imponer sus precios.

(...) el cliente, si antes pagaba 25-30 euros ahora está ofreciendo 15 y 10 (Adelaida, entrevista 1).

Un ejemplo de este cambio en la negociación lo encontramos en el testimonio de Lucía, transexual ecuatoriana, quien nos habla de la pérdida del «arte de negociar», lo que conlleva que los tratos sean más rápidos y no se expongan claramente las condiciones del tipo de servicio que se va a realizar. 
(...) porque evidentemente cuando pactas, cuando estas contratando, es un tiempo, es un tiempo, si te parece bien, esto es tanto...el arte de negociar y de seducir. (...) (Lucía, entrevista 4).

Además, esta inferioridad ante el cliente a la que refieren las mujeres tiene como consecuencias: uno, la devaluación del servicio sexual, intensificando el hecho de que tengan que trabajar más horas en la calle y dos, un mayor riesgo a que surjan agresiones y/o situaciones de violencia. Además, para evitar las sanciones, tanto la mujer como el cliente se ven en la obligación de realizar el servicio sexual en lugares más alejados de la zona de trabajo y/o del control policial. Dos mujeres que ejercen en el Polígono de Alcalá de Henares así lo expresan:

(...) no voy a poder negociar libremente con el cliente. Cuando el venga me voy a tener que embarcar muy a la ligera, me voy a tener que ir lejos con él, sin saber con quién me voy (Carolina, entrevista 8).

...invirtiendo claro, muchas más horas que antes. Antes 100 euros te los hacías en hora y media a lo mejor, ahora...en 5 o 6 horas... (Mari Tere, entrevista 3).

Con todo ello cabría suponer que esta inferioridad está íntimamente ligada al hecho de que se intensifiquen las prácticas de riesgo.

(...) estar todo el día trabajando un día detrás de otro no me pasa, porque se ha puesto de moda el «sin preservativo» (Ana María, entrevista 5).

\subsubsection{Estigmatización}

El estigma como atributo que llevaría a la descalificación y, por lo tanto, a un impedimento de la persona en su proceso de adaptación social (Goffman, 2003) deriva en visibilizar a las trabajadoras del sexo en el lado opuesto de lo correcto socialmente, -referido a la buena madre o esposa-, dotando al ejercicio como algo anómalo donde las mujeres son catalogadas dentro del ámbito de las conductas desviadas. A este hecho ya refiere Juliano (2006), cuando apunta a que esta diferenciación conlleva al rechazo de las trabajadoras sexuales, donde el problema radica «en la actitud social hacia las prostitutas» (p. 110), situándolas en contextos con mayor probabilidad de marginación y vulneración social. En relación con lo explicado, se extrae en palabras de Carolina:

Me siento estigmatizada no por el trabajo que hago de prostitución, sino porque veo que mis derechos cada día son burlados (Carolina, entrevista 8).

Esta estigmatización a la que referíamos anteriormente recae de una manera más abrumadora sobre las mujeres transexuales, quienes sufren el constante rechazo social vinculado, por un lado, a la discriminación que existe 
por ejercer una actividad enmarcada dentro de las desviaciones femeninas $y$, por otro, por la pertenencia a un colectivo que no es integrado dentro de los cánones sexuales socialmente correctos. Así se recoge la interiorización del estigma de algunas mujeres transexuales:

Lorena, es transexual y tiene 28 años. La policía le ha dicho «Pedro, ¿no quieres otra hoja?» (Diario de Campo, 25 de abril).

(...) yo paso vergüenza, a mi no me gusta que la gente quede viendo así como un animal raro, si yo soy un ser humano, joder, no soy un extraterrestre. (Cristina, entrevista 2).

\subsubsection{Conflicto}

Los conflictos percibidos por las mujeres en el ejercicio de la prostitución discurren en dos sentidos. Por una parte los que hacen referencia a las compañeras, derivados por lo general del empeoramiento de las condiciones de trabajo que conlleva que surjan mayores niveles de competencia y, por consiguiente, enfrentamientos por el espacio; y por otra, aquellos en los que entrarían a formar parte la comunidad vecinal de la zona donde se ejerce la prostitución. En el primer caso, las mujeres opinan que el conflicto con las compañeras surge cuando existe diferenciación en los precios que establecen de sus servicios.

Si tu no lo haces o tu lo desprecias otra se lo va a llevar (...) hay una chica que se va por 10 o 7 euros... a veces la necesidad es tanta que prefieres irte por eso $y$ no quedarte sin nada más bien (Adelaida, entrevista 1).

En el segundo caso, el discurso apuntaría a que el conflicto con la comunidad se encuentra intrínsecamente ligado al estigma. Se considera que este es resultado directo de la estigmatización del trabajo sexual, lo que deriva en un sentimiento generalizado en las mujeres como agentes de desorden y malestar social. Por lo general, la mayor preocupación en torno a la convivencia se encuentra en aquellas zonas de ejercicio del centro de Madrid, puesto que son lugares más transitados, visibles y expuestos al turismo de la ciudad. En el caso de los polígonos industriales y zonas más alejadas las mujeres sienten que con su actividad no generan molestias, aunque son conscientes de la controversia que puede generar la visibilidad de cuerpos desnudos en la vía pública,

Donde yo me pongo no hay naves, no hay casas, el que va por esas calles o está perdido o va a lo que va (Ana María, entrevista 5).

\subsubsection{Qué proponen}

Del discurso general de las mujeres se recoge que se posicionarían contrarias a las normativas, tanto las que sancionan a la mujer y al cliente, como aquellas 
que van enfocadas únicamente hacia este último, por entender que merman su calidad de vida y trabajo. Todas ellas refieren al ejercicio de la prostitución como un trabajo, por lo que recalcan la importancia de la mejora de sus condiciones, así como el hecho de ser tenidas en cuenta en la toma de decisiones en cuanto a su situación, puesto que consideran que les afecta directamente por ser el agente principal, junto al cliente, del servicio sexual. Las mujeres reivindican espacios donde poder ejercer libremente sin molestar ni ser molestadas, así como derechos para lo que ellas consideran que es su trabajo y forma de sustentarse económicamente. A través de sus palabras se recogería la unánime demanda de intervenir como interlocutoras válidas en la negociación de los espacios.

Los cursos con opciones laborales son también salidas (Adelaida, entrevista 1).

Que cada una pague o sus impuestos o tenga por lo menos su seguridad social (...) si pasa un coche de policía es por seguridad (Mari Tere, entrevista 3).

(...) negociar, pactar los espacios, porque siempre hemos tenido un lema: queremos trabajar sin molestar, ni ser molestada (Lucía, entrevista 4).

Tienen pensada una nueva normativa para Madrid, pero ¿y tienen pensado sentarse a dialogar con nosotras? (...) ¿tienen pensado hablar con las personas indicadas? (...) (Lucía, entrevista 4).

La percepción generalizada de las mujeres, en cuanto a sus necesidades y demandas, se manifiesta en contra de la entrada en vigor de las normativas, por entender que merma su calidad de vida y trabajo. Así, tras el acercamiento a sus discursos se constata la posición unánime acerca de que estas no ayudan a erradicar la prostitución de calle, sino a dejar en un estado de mayor indefensión y vulnerabilidad social a las trabajadoras del sexo.

\section{Conclusiones}

A través de estas páginas se ha tratado de mostrar el impacto que tienen el conjunto de Ordenanzas Municipales en el ejercicio de la prostitución y, en consecuencia, en la vida de las mujeres. Es cierto que refieren a la actividad como una opción legítima, situándose contrarias al discurso dominante y al estigma vigente socialmente atribuido a la prostitución, por lo que anteponen y reivindican el ejercicio como trabajo y no como desviación. Este hecho podría responder a un discurso que pretende mantener el posicionamiento de las propias mujeres, alejándose de esa vulnerabilidad que en ocasiones desde fuera se les atribuye, por lo que sería interesante reflexionar sobre las dificultades que experimentan en cuanto a la toma de decisiones o las opciones de elección reales de las que disponen. En relación a las consecuencias derivadas 
de las normativas cívicas se recoge que no solamente se clandestinizará el ejercicio, derivado de cambios en la negociación con el cliente y un progresivo movimiento de las mujeres a lugares cerrados, sino que además, el intento de buscar recursos económicos en caso de percibir una sanción intensificará las que son sus horas de trabajo en la calle como resultado de una falta de oportunidades en otros sectores. La prostitución, como actividad estigmatizada desde la moralidad sexual femenina, es además ahora sancionada por el conjunto de normativas, lo cual propicia que no solamente se acreciente la situación de vulnerabilidad en las mujeres, disminuyendo su participación en la comunidad, sino que se vean incrementadas las diferencias entre los diferentes colectivos. Las Ordenanzas Municipales no dejan de contemplar la prostitución como una actividad que atenta contra la convivencia y el bienestar social de la ciudadanía, vinculándola a violencia de género y/o exclusión social. Este conjunto de hechos podría implicar no tener en cuenta la opinión de las mujeres ni la heterogeneidad de situaciones que se dan en el trabajo sexual, donde hay mujeres que encuentran en el ejercicio una opción rentable para la obtención de ingresos económicos, sin estar determinada en todos los casos por situaciones que impliquen coacción o engaño. En este sentido, la normativa que prevé implantar la ciudad de Madrid cabe pensar que generará cambios en la oferta-demanda de servicios sexuales de aquellas mujeres que ejercen en la calle. Además, la consiguiente transformación en las estrategias que emplean para la captación de clientes -referidas a la negociación, seguridad, protección, etc.- podría conllevar a agravar su situación, posicionándolas en contextos a los que inicialmente se hizo referencia: mayor vulnerabilidad y estigmatización. El estudio señala que las mujeres se posicionan contrarias a las normativas cívicas, por entender que merman su calidad de vida y trabajo. Esta posición, junto con el resto de elementos considerados, nos sugieren las siguientes reflexiones finales:

- Los posibles cambios estructurales derivados de modificaciones en el escenario -a raíz de las normativas como medidas disuasorias o represivas ante el ejercicio-, podrían generar en las mujeres nuevas situaciones de adaptación. Dichas situaciones, que se originan en su mayoría como consecuencia de movimientos y cambios de contexto en la actividad, podrían incidir en las mujeres provocando un nuevo enfrentamiento ante el estigma de la prostitución.

- La discriminación y estigmatización del trabajo sexual condiciona a las mujeres a permanecer en situación de mayor vulnerabilidad social -entendida desde estas líneas como la privación de los derechos 
fundamentales en cuanto a la actividad que realizan-, lo que repercute en su bienestar y las inhabilita como agentes de participación sujetos de derecho. El aumento de esta vulnerabilidad podría derivar en una posible situación de marginación, por lo que el conjunto de mujeres que ejercen la prostitución en la calle tienden a demandar, en su mayoría, la mejora de las condiciones en el ejercicio.

- El hecho de que las mujeres no sean tenidas en cuenta en el debate social sobre su situación ni sean partícipes en el transcurso de las normativas que salen en su contra, se deriva de no solo del estigma social sino de los discursos de carácter moral; desde estas aportaciones no se vislumbra a la prostitución como una forma de contestación a las estructuras patriarcales ni como opción económica para la emancipación de las mujeres. Aspecto que ellas, por el contrario, si contemplan $y$, en tanto, defienden.

La propuesta, por tanto, es continuar recogiendo las significaciones atribuidas a la actividad que realizan las mujeres, a fin de conocer y ahondar en el conjunto de estrategias utilizadas para posicionarse donde hoy lo hacen, considerando esta perspectiva esencial para comprender la multiplicidad de realidades existentes en el trabajo sexual. «Soy una mujer que pertenezco a la sociedad (...) y como tal, se me debería de respetar mi trabajo» en segundo lugar son palabras de una trabajadora del sexo, pero ante todo y en primer lugar, de una ciudadana que como tal debería tener garantizados sus derechos. Mirar a las mujeres desde otro prisma, alejado del estigma en cuanto a los modelos sexualmente correctos para ellas puede ser un objetivo a largo plazo sin embargo, desde estas páginas, se ha intentado aproximarse a lo que conforma su imaginario colectivo, aquel que contempla las diferentes formas de contestación de las mujeres, su transgresión a la norma, el conjunto de sus sentimientos, las valoraciones de lo que consideran su libertad de elección. Aquel que, aun habiéndome apoyado en referencias teóricas, ha emanado en palabras de las propias protagonistas, valorando el conjunto de sus opiniones y poniendo de manifiesto el deseo conjunto de las trabajadoras del sexo... SENTIRSE ESCUCHADAS. 


\section{Bibliografía}

Agustín, L. (2001). Mujeres migrantes ocupadas en servicios sexuales. En Colectivo IOÉ, Mujer, Inmigración y Trabajo (pp. 533-582). Madrid: IMSERSO. Arella (2009). Gestión del espacio público y derecho a la ciudad. El caso del trabajo sexual. En V. Valiño (Coord.), Defender y repensar los derechos sociales en tiempos de crisis (pp. 81-89). Barcelona: El Tinter.

Arella, C., Fernández, C., Nicolás, G. y VArtabedian, J. (2007). Los pasos invisibles de la prostitución. Estigma, persecución y vulneración de las trabajadoras sexuales en Barcelona. Barcelona: Virus Editorial.

BerroA, M., Gijón, M. y ZAPATA, D. (2010). Prostitución y espacio público: una aproximación desde la intervención. Comunicación presentada en el I Seminario de Juventud y Sociedad., Facultad de Educación y Psicología, Universidad de Girona. Recuperado en http://www.udg.edu/LinkClick.aspx? fileticket=jhwoT 4kbUxo\%3D\&tabid=14409\&language=ca-ES. [2013, 7 de abril] .

Bonelli, E. y UlloA, M. (2001). Tráfico e inmigración de mujeres en España. Colombianas y ecuatorianas en los servicios domésticos y sexuales. Madrid: Acsur-Las Segovias.

CORSO, C. y LANDI, S. (2000). Retrato de Intensos Colores. Madrid: Talasa Ediciones.

De PaUla, R. (2000). Hablan las putas. Sobre prácticas sexuales, preservativos y SIDA en el mundo de la prostitución. Barcelona: Editorial Virus.

GARAiZÁbAL, C. (2007). El estigma de la prostitución. En M. Briz y C. Garaizábal (Coords.), La Prostitución a Debate. Por los derechos de las Prostitutas (pp. 4356). Madrid: Talasa Ediciones.

GaY, S., SAnZ, M. y Otazo, E. (2003). ¿Prostitución = profesión? Una relación a debate. Aequalitas, 13, 12-27.

Goffman, E. (2003). Estigma: La identidad deteriorada. Buenos Aires: Amorrortu. Juliano, D. (2006). Excluidas y Marginales. Madrid: Cátedra Ediciones.

MENESES, C. (2007). Riesgo, vulnerabilidad y prostitución. Documentación Social, $144,11-36$.

PÉREZ, C. (2013) ¿Cómo me creo mi burbuja de protección? Una aproximación al imaginario colectivo de las mujeres que ejercen la prostitución de calle: su posición ante las Ordenanzas Municipales. Trabajo fin de máster no publicado. Universidad Complutense de Madrid.

OSBORNE, R. (1988). Debates actuales en torno a la pornografía y a la prostitución. Papers, núm. 30, 97-10.

Osborne, R. (2004). Introducción. En R. Osborne (ed.), Trabajador@s del sexo. Derechos, Migraciones y Tráfico en el siglo XXI (pp.11-43). Barcelona: Bellaterra.

Oso, L. y UlloA, M. (2001). Tráfico e inmigración femenina desde la voz de las mujeres inmigrantes. En E. Bonelli y M. Ulloa (Coord.), Tráfico e inmigración 
de mujeres en España. Colombianas y ecuatorianas en los servicios domésticos y sexuales (pp. 65-118). Madrid: Acsur-Las Segovias.

Poyatos i MATAS, G. (2009). La Prostitución como trabajo autónomo. Barcelona: Bosch.

RUBiO, A (2008). La teoría abolicionista de la prostitución desde una perspectiva feminista. En I. Holgado (ed.), Prostituciones. Diálogos sobre sexo de pago (pp. 73-95). Barcelona: Icaria Editorial.

Villacampa, C. (2012). Políticas de criminalización de la prostitución: análisis crítico de su fundamentación y resultados. Revista de derecho penal y criminología, 3. ${ }^{a}$ Época, 7, 81-142.

\section{Legislación}

Ayuntamiento de Albacete (2012, 23 de febrero). Ordenanza reguladora de los espacios públicos de Albacete para fomentar y garantizar la convivencia ciudadana y el civismo. Publicada en el BOP N. ${ }^{\circ} 152$ [en línea]. Recuperado de http://www.dipualba.es/bop/ficheros/2012/27/BOP\%2027-12-P-137.PDF [2013, 13 de marzo].

Ayuntamiento de Alcalá de Henares (2010, 19 de octubre). Ordenanza Municipal para fomentar y garantizar la convivencia ciudadana en el espacio público de Alcalá de Henares. En BOCM N. ${ }^{\circ} 250$ [en línea]. Recuperado de http:// www.bocm.es/boletin/CM_Boletin_BOCM/2010/10/19/25000.PDF [2013, 12 de marzo].

Ayuntamiento de Alicante (2011, 23 de marzo). Ordenanza de mendicidad y prostitución en espacios públicos del Término Municipal de Alicante. En BOP N. ${ }^{\circ} 57$ [en línea]. Recuperado de http://www.dip-alicante.es/bop2/pdftotal/2011/03/23-03-11.pdf [2013, 13 de marzo].

Ayuntamiento de Badajoz (2011, 05 de agosto). Ordenanza para preservar la utilización del espacio público de Badajoz y poblados, del ofrecimiento y demanda de servicios sexuales. En BOP N. ${ }^{\circ} 149$ [en línea]. Recuperado de http:// www.dip- badajoz.es/bop/ventana_anuncio.php?id_anuncio=61384\&FechaS olicitada=2011-08-05 [2013, 12 de marzo].

Ayuntamiento de Barcelona (2006, 24 de enero). Ordenanza de medidas para fomentar y garantizar la convivencia ciudadana en el espacio público de Barcelona. En Ajuntament de Barcelona [en línea]. Recuperado de http://www. bcn.cat/hisenda/es/principals_multes_convivencia_explicacio.html [2013, 13 de marzo].

Ayuntamiento de Barcelona (2012, 17 de agosto). Modificación de la Ordenanza de medidas para fomentar y garantizar la convivencia ciudadana en el espacio público de Barcelona. En Ajuntament de Barcelona [en línea]. Recuperado de http://w110.bcn.cat/portal/site/Homes/menuitem. 
b38d4301d421bffa4eb14ebla2ef8a 0c/?vgnextoid=af3d318360ce8310Vgn VCM10000072fea8c0RCRD\&vgnextfmt=fo rmatDetall\&lang=es_ES [2013, 13 de marzo].

Ayuntamiento de Bilbao (2010, 27 de septiembre). Ordenanza del Espacio Público de Bilbao. En BOB N. ${ }^{\circ} 186$ [en línea]. Recuperado de http://www.bizkaia.net/ lehendakaritza/Bao_bob/2010/09/20100927al86.pdf\#page= 5 [2013, 13 de marzo].

Ayuntamiento de Calviá (2003, 01 de noviembre). Ordenanza Municipal de Policía y Buen Gobierno del Ayuntamiento de Calviá. En BOIB N. ${ }^{\circ} 81$ [en línea]. Recuperado de http://boib.caib.es/pdf/2003152/mpl01.pdf [2013, 12 de marzo].

Ayuntamiento de Sevilla (2010, 18 de julio). Ordenanza para luchar contra la prostitución y la trata con fines de explotación sexual en la Ciudad de Sevilla. En BOP N. ${ }^{\circ} 166$ [en línea]. Recuperado de http://www.dipusevilla.es/export/ bop/200807/18fasc02.pdf [2013, 13 de marzo].

Poder Legislativo de España (2003, 30 de septiembre). Ley Orgánica 11/2003. En BOE N. ${ }^{\circ} 234$ [en línea]. Recuperado de http://www.boe.es/boe/dias/2003/09/30/ pdfs/A35398-35404.pdf [2013, 12 de marzo]. 


\title{
ACOGIMIENTO RESIDENCIAL Y PRODUCCIÓN DE SUBJETIVIDADES: IDENTIDADES Y TRAYECTORIAS CIUDADANAS DE LOS NIÑOS Y NIÑAS EN PROTECCIÓN
}

\author{
Child residential care and the production of subjectivity: \\ children's indentities and citizenship trajectories
}

JULIA RAMIRO

\section{Resumen}

El artículo analiza los procesos identitarios de los niños/as y adolescentes en acogimiento residencial, relacionados con la construcción de sus trayectorias ciudadanas. Siguiendo el método biográfico y realizando entrevistas abiertas en profundidad, se exploran tanto el impacto de los valores institucionales como la incidencia de las normas y rutinas residenciales en la producción de sus subjetividades. Desde el enfoque de la ciudadanía vivida, se muestra cómo los niños y niñas acogidos representan, reelaboran e interactúan con el sistema de normas y valores de la protección a la infancia. El análisis del material empírico pone de manifiesto las tensiones existentes en los relatos de los niños/as entrevistados en torno a sus identidades y pertenencias y su visión particular sobre el ser ciudadano. Ambas cuestiones deben ser vistas como consecuencia del impacto del marco simbólico de la protección y el producto (aunque reelaborado) del conjunto de prácticas cotidianas en los recursos de acogimiento residencial.

Palabras clave. Niños/as en protección, acogimiento residencial, Identidades y pertenencias, trayectorias ciudadanas.

\begin{abstract}
The article analyzes the identity processes of children in residential care related to their construction of citizenship trajectories. Using a biographical method and in-depth interviews, this study explores the impact of institutional values and the influence of rules and routines on the children's production of subjectivity. Taking into account the citizenship from below approach, it shows how children living in care picture and interact with the regulations and values of the Child Protection System. The analysis of the empirical material illustrates relevant tensions involved in the children's narratives about their identities and belongings and their visions about being a citizen. Both might be seen as a result of the impact of the symbolic protection framework and the consequence of the set of daily practices in residential care institutions.
\end{abstract}

Keywords. Children living in care, Residential care, Identities and belongings, Citizenship trajectories.

Recibido: 03/06/2015

Aceptado: 10/07/2015

Publicado: 03/12/2015

1. Universidad Nacional de Educación a Distancia. Facultad de Derecho. Dpto. Servicios Sociales y Fundamentos Histórico-jurídicos. C/ Obispo Trejo, 2 CP: 28040, Madrid. jramiro@der.uned.es 


\section{Introducción}

En la actualidad, el acogimiento residencial se encuentra en el epicentro de los debates sociales sobre la protección a la infancia. Frente a otros países europeos y pese al reciente esfuerzo desinstitucionalizador, iniciado a tenor de la Comisión Especial del Senado para estudiar la problemática de la adopción nacional y los temas afines relacionados con ella, como acogimiento, desamparo e institucionalización (2008) y del Anteproyecto de Ley Orgánica del Sistema de protección a la Infancia y a la Adolescencia (2011), España sigue registrando altas tasas de institucionalización. Aunque no existen datos claros y actualizados, sólo en el año 2013 se adoptaron un total de 35.045 medidas de acogimiento y, de éstas, el 38,2\% correspondieron al acogimiento residencial, con una estimación de 13.041 niños/as y adolescentes derivados a los diferentes recursos de protección a lo largo del territorio español. Estos datos reflejan, por un lado, la necesidad de profundizar en la comprensión del papel actual del acogimiento residencial y, por otro, de conocer cómo incide en la vida de los niños/as y adolescentes acogidos.

En este contexto, la integración cívica y social de los niños/as institucionalizados se ha planteado como uno de los principales objetos de preocupación social desde la reforma jurídica de protección a la infancia de 1987, con la Ley 21/1987 de 11 de noviembre, por la que se modifican determinados artículos del Código Civil y de la Ley de Enjuiciamiento Civil en materia de adopción. Desde entonces, la idea de normalización opera como principio rector en el diseño y organización de los recursos residenciales para la infancia en protección. Así, recientemente, el estudio Estándares de calidad en acogimiento residencialEQUAR (2012) $)^{2}$ señalaba los estudios y formación, la normalización e integración, el desarrollo y autonomía y el uso de las consecuencias educativas como predictores de integración social y bienestar de los niños/as acogidos. La enunciación de dichas condiciones, como parte constitutiva de la calidad en el acogimiento residencial, remite a las funciones históricas de la protección a la infancia: regulación, control y ordenamiento de las ciudadanías (Ramiro, 2015). Por ello, se entiende que: «El trabajo de atención residencial debe partir de considerar al niño como un sujeto en desarrollo y, por tanto, con una especial necesidad de ser estimulado, guiado y protegido hacia unos objetivos de madurez y socialización que en muchos casos tendrán que contemplar la transición a la vida adulta e independiente» (EQUAL, 2012: 68).

2. Investigación realizada por la Asociación NIERU, con el apoyo del Grupo de Investigación en Familia e Infancia de la Universidad de Oviedo, coordinada por FAPMI y financiada por el Ministerio de Sanidad, Servicios Sociales e Igualdad. 
La asociación del concepto de ciudadanía con la adultez es característica de un modelo clásico que tradicionalmente, desde el plano legal y formal, ha excluido a los niños por motivos de dependencia emocional e inmadurez psicológica. Sin embargo, esta idea ha sido ampliamente contestada desde las ciencias sociales (Cockburn, 1998; Cohen, 2005; Lister, 2007; Moosa-Mitha, 2005; Roche, 1999), alegando que una sociedad comprometida e inclusiva con los niños/as ha de partir de una concepción de la ciudadanía más amplia. De hecho, la ciudadanía es, para todos, más que un conjunto de derechos reconocidos política y legalmente. Se trata también de un proceso relacional que incluye dimensiones sustantivas tales como las responsabilidades, la participación, las identidades y pertenencias (Lister, 2007).

El presente trabajo centra su interés en la última dimensión señalada y en cómo ésta incide en la construcción de la ciudadanía entre los niños/as y jóvenes institucionalizados. Por tanto, el artículo explora los procesos identitarios de los niños/as y adolescentes protegidos en el marco de los recursos residenciales, teniendo en cuenta que éstos se erigen como estructuras de normalización y control social.

Cabe destacar que, en el marco de la intervención social y del trabajo social, con este trabajo, se pretende devolver el protagonismo a los niños/as y adolescentes en protección pues, si bien la imagen dominante sobre ellos se fundamenta en su «inherente» vulnerabilidad y/o potencial conflictividad, poco se conoce acerca de las experiencias de estos niños y niñas, narradas por ellos mismos, y sobre cómo responden a los valores institucionales de la protección a la infancia.

\section{Metodología}

A nivel metodológico, se han seleccionado el método biográfico y las entrevistas abiertas en profundidad como los instrumentos más adecuados para recoger las experiencias vitales de los niños/as y adolescentes protegidos durante su trayectoria por el sistema de protección. Se trata de conocer cómo los niños y niñas experimentan y responden a las conceptualizaciones institucionales que inciden en la construcción de sus identidades y de ciudadanía.

Siguiendo el enfoque del construccionismo social (Berger y Luckmann, 1967; Mead, 1934), las identidades son entendidas como interacciones complejas en continua renegociación, a través de los intercambios lingüísticos y las acciones sociales; por lo que la consideración del marco simbólico y normativo en el que se desenvuelven resulta crucial para su análisis. Así mismo, el control se propone como un proceso social imbricado en las distintas actividades propuestas en los recursos de acogimiento residencial: tareas, 
actividades de ocio y tiempo libre, posesiones, relaciones sociales, estructuración del tiempo, movilidad y privacidad (Millham, Bullock y Cherret, 1975) a modo de instituciones totales (Goffman, 1961).

En la medida en que identidades y ciudadanía son propuestas como procesos dinámicos y reinterpretativos, se hace necesario enfocar el estudio desde la perspectiva de la ciudadanía vivida (James, 2011; Liebel, 2008; Lister, 2007; Spyrou, 2008) pues, se parte de la consideración de los niños/as y adolescentes como sujetos y agentes de su propio proceso de integración social y cívica ${ }^{3}$. Postura epistemológica que, por otra parte, facilita el acceso a las representaciones, actitudes y relaciones que intervienen en la construcción de las identidades y ciudadanía de estos niños, niñas y adolescentes.

El material analizado se compone de nueve entrevistas biográficas en profundidad realizadas a jóvenes que ya han salido del sistema de protección (chicos y chicas entre 17 y 23 años), documentos personales (cuarenta y una cartas de niños/as y adolescentes acogidos en recursos de protección, recopiladas entre 2008 y 2010) y un caso/expediente de doble tutela (2012).

Para la selección de la población entrevistada se han tenido en cuenta las variables institucionales y existenciales (Ibáñez, 2003). Del cruce de ambas se obtienen los interlocutores, cubriendo así la variabilidad existente entre los recursos de protección (tipo de recurso e ideología ${ }^{4}$ ) y entre los perfiles sociodemográficos (sexo y edad) e institucionales (motivos de la protección y régimen de la misma) de los jóvenes entrevistados.

Así mismo, el campo se desarrolla en la Comunidad de Madrid, por cuanto puede ser considerada, junto con Cataluña, como una de las autonomías pioneras en incorporar las recomendaciones establecidas por la UNCRC de 1989 sobre los derechos de los niños y niñas y su ciudadanía (activa), a través de Ley 6/1995, de 28 de marzo, de Garantías de los Derechos de la Infancia y la Adolescencia y el Decreto 88/98 de 21 de Mayo de 1998: Estatuto de las Residencias de Atención a la Infancia y Adolescencia, entre otros.

3. A fin al concepto de reproducción interpretativa acunado por Corsaro (1997: 18-19) desde el que se pone de manifiesto la idea de que los niños y niñas no se limitan simplemente a interiorizar la sociedad y la cultura, si no que contribuyen activamente a dicha cultura y al cambio de la misma. En el ámbito nacional, se puede consultar la obra de Gaitán (2014) sobre los derechos de los niños en el trabajo social.

4. Se tiene en cuenta el tipo de recurso (Moss, 1975) en relación al tamaño del mismo (residencia, hogar, piso, etc.) y la ideología referida a sistemas culturales más o menos cerrados (Tizard et al., 1975): laica y/o religiosa. 
Tabla 1. Interlocutores entrevistados

\begin{tabular}{|c|c|c|l|l|}
\hline $\begin{array}{c}\text { Inter- } \\
\text { locutor }\end{array}$ & Sexo & $\begin{array}{c}\text { Edad } \\
\text { (años) }\end{array}$ & \multicolumn{1}{|c|}{$\begin{array}{c}\text { Medida y motivos de la } \\
\text { protección }\end{array}$} & \multicolumn{1}{|c|}{ Recurso } \\
\hline I1 & Mujer & 24 & $\begin{array}{l}\text { Guarda } \\
\text { Trastorno de la conducta }\end{array}$ & Centro terapéutico \\
\hline I2 & Hombre & 21 & $\begin{array}{l}\text { Guarda } \\
\text { Problemas de } \\
\text { comportamiento }\end{array}$ & $\begin{array}{l}\text { Residencia infantil pública y } \\
\text { laica y centro terapéutico }\end{array}$ \\
\hline I3 & Mujer & 21 & $\begin{array}{l}\text { Tutela } \\
\text { Abusos sexuales }\end{array}$ & $\begin{array}{l}\text { Residencia infantil privada } \\
\text { laica. }\end{array}$ \\
\hline I4 & Hombre & 19 & $\begin{array}{l}\text { Tutela } \\
\text { Abandono }\end{array}$ & $\begin{array}{l}\text { Residencia infantil privada y } \\
\text { laica y centro terapéutico }\end{array}$ \\
\hline I5 & Mujer & 20 & $\begin{array}{l}\text { Tutela } \\
\text { Negligencia y abandono }\end{array}$ & $\begin{array}{l}\text { Residencia infantil privada y } \\
\text { religiosa. }\end{array}$ \\
\hline I7 & Mujer & 18 & $\begin{array}{l}\text { Guarda y posterior tutela. } \\
\text { Pobreza }\end{array}$ & $\begin{array}{l}\text { Residencia de primera } \\
\text { acogida, residencia infantil } \\
\text { pública y laica y centro } \\
\text { terapéutico. }\end{array}$ \\
\hline I8 & Hombre & 20 & $\begin{array}{l}\text { Tutela } \\
\text { Drogodependencia parental }\end{array}$ & $\begin{array}{l}\text { Residencia infantil privada } \\
\text { laica. }\end{array}$ \\
\hline Mujer & 21 & $\begin{array}{l}\text { Puarda } \\
\text { Trastornos emocionales }\end{array}$ & $\begin{array}{l}\text { Residencia de primera } \\
\text { acogida y residencia infantil } \\
\text { privada y laica. }\end{array}$ \\
\hline
\end{tabular}

\section{Protección y acogimiento residencial en la producción de subjetividades}

Los recursos de protección, como contextos existenciales (Ibáñez, 2003), no sólo inciden el discurso identitario producido por los niños, niñas y adolescentes (Marc y Picard, 1992), sino que también contribuyen a la producción de subjetividades por cuanto significan normas, valores, lenguajes, herramientas, procedimientos y modos de hacer (Castoriadis, 1988). En relación al objetivo de la integración cívica y social, estos niños son protegidos a través de un proceso dirigido a la reproducción del magma de significaciones imaginarias (Castoriadis, 1988) de la protección. Dicho magma descansa en una imagen negativa de los niños/as institucionalizados, guiando el modo de hacer cotidiano hacia el control social y estableciendo normas, límites y rutinas.

La representación negativa de la infancia en acogimiento residencial se debe en gran parte a la idea de normalización, activada con la reforma de 
1987, que identifica a la familia (adaptada socialmente) como la institución privilegiada para la integración y el desarrollo del niño y la preservación de los valores sociales. De este modo, en el imaginario institucional, mientras que el acogimiento familiar y/o la adopción son vistas como formas «normalizadas» de protección, existe una tendencia a identificar el acogimiento residencial con recursos dirigidos a niños/as y adolescentes que por diversas razones no pueden crecer en una familia, lo que conlleva un daño irreversible y/o genera conductas antisociales.

Horarios, normas y rutinas

Consecuencia del marco institucional y simbólico de la protección, las identidades individuales y sociales de estos niños/as y adolescentes se estructuran en torno a la idea de normalización, donde la normalidad significa la interiorización de las normas y rutinas y la idea de familia es fundamental en la producción de sus subjetividades.

De este modo, algunos niños pusieron de manifiesto la importancia de sus comportamientos dentro y fuera de los recursos de acogimiento, las normas que tenían que cumplir y cómo estas prácticas dan forma a su identidad actual y futura:

En esta casa cuando entre tenia mis manias, defectos... pero poco a poco, he ido mejorando, como persona (creo yo). Me han enseñado cosas, educado [...] para que cuando salgamos de esta casa seamos gente bien: educados generosos y buenas personas (Carta).

De hecho, los horarios se constituyen como una parte central en los relatos producidos por los niños y niñas sobre la vida cotidiana en los centros, residencias u hogares y la incidencia de éstos en la imagen de sí mismos:

Gracias a los horarios aprendes a ser un poco más organizada (19).

Incluso, narran su historia de vida como una secuencia de fechas, situando los momentos vividos como estructuradores de sus biografías en torno a la edad y el ingreso en las instituciones de protección:

Ahí estuve casi un mes o dos meses antes de cumplir [...] 8 meses antes de cumplir los 13, que eran los 12, y hasta los 16, hasta un mes antes de cumplir $\operatorname{los} 15$ (I2).

Hola me llamo Pedro, tengo 13 años casi 14 años porque el 24 de diciembre los cumplo. En la casa estoy muy bien siempre se han preocupado por mi llevo aquí 7 años (Carta). 


\section{Familia como institución generadora de normalidad}

Para la mayoría de los niños, niñas y jóvenes entrevistados, la idea de normalidad corresponde con el hecho de vivir y crecer en una familia; lo cual genera cierta ambivalencia identitaria. Algunos jóvenes sienten que han tenido una vida e infancia normales porque, aunque no hayan vivido con sus familias, han crecido en un ambiente normalizado (residencia infantil). Sin embargo, ellos/as sienten que el hecho de no haber tenido una familia los diferencia de otros niños.

No me veo diferente, bueno, he tenido una vida diferente a la gente normal que han vivido con sus padres pero me veo normal, como cualquier chica (I5).

La idea de familia también funciona como referente para designar la normalidad, de la misma manera que es la legitimación de las normas por parte de los/as jóvenes.

Con mi educador-tutor muy bien, muy bien. Es como mi padre [...] Para mí la residencia de menores es como tu familia [...] con horarios, todo estructurado pero una vida normal que no te influye luego, al salir... que vamos, que eres como otra persona normal (I3)

Para mí eran mi familia ¿sabes? (17).

En estas narrativas, la idea de familia funciona como factor de legitimidad de las normas impuestas o como fundamento de las «buenas relaciones», coincidiendo con una experiencia de ruptura respecto a la familia de origen (tutelas). Por el contrario, aquellos que estuvieron en guarda y sostuvieron la relación con sus familias invierten el discurso. Es decir, la no aceptación de la norma deviene de la no identificación de la misma con la figura familiar.

Yo no voy a estar un mes en una habitación y, además, vosotros podéis ser mis tutores pero no sois ni mi madre, ni mi padre para decir con quién me tengo que juntar, si tengo que ir a fútbol o no tengo que ir (I2).

Es decir, los niños/as y jóvenes no sólo construyen sus identidades reelaborando el marco normativo e institucional, sino que éste también es reinterpretado para la aceptación, oposición y/o negociación de las prácticas cotidianas ejercidas en los recursos de protección. De esta manera, los niños y niñas en acogimiento residencial muestran su capacidad de contestación ante el sistema instituido que, lejos de ser interpretado como parte de una conflictividad atribuía, manifiesta las distintas formas de ejercer su agencia como sujetos sociales e individuales. 
Pertenencias y categorías sociales en el magma simbólico de la protección

Las identidades se construyen sobre categorías de referencia y comparación, componiendo pertenencias que integran al grupo, pero también implican la identificación personal, el establecimiento de vínculos afectivos, la asunción de normas y hábitos compartidos y el sentimiento de solidaridad hacia los otros miembros del grupo (Weil, 1996). Consecuencia del magma simbólico $y$ de significaciones de la protección, en las narrativas de los niños, niñas y jóvenes se encuentran constantes referencias a las categorías ser niño/a y ser un niño/a de centro.

\section{Ser niño/a, ser adulto}

Para estos niños/as y jóvenes, la edad se corresponde -en relación proporcional- con la consideración percibida por parte de los adultos y las instituciones. De hecho, es a partir de las diferencias conceptuales en la identidad entre niños/as y adultos (Jenks, 1996) que surge el problema mismo de la situación de los niños y niñas como ciudadanos (James, 2011: 161), pues la ciudadanía plena se asocia a la adultez en las sociedades democráticas occidentales.

Así, en las narrativas producidas por los jóvenes es fácil encontrar referencias a la dicotomía niño/a-adulto pues ser adulto significa culturalmente ser responsable, independientemente de la edad biológica. Llegar a ser adulto es identificado con tener un «buen» comportamiento en oposición al de ser niño/a (o adolescente). El niño/a es percibido como un ser de personalidad inherentemente problemática o conflictiva. Ser adulto no se relaciona necesariamente con la edad, si no con la adquisición de ciertos tipos de comportamiento caracterizados por el control de las emociones y la tranquilidad personal:

Yo era problemático en casa, como un niño de 12 o 13 años [...] fui por si también quería yo no estar tan alborotado como estaba y hacerme adulto con 12 (I2).

Por otra parte, el incremento de la edad es asociado por los niños/as y jóvenes con ser tratados como personas independientes y con tener mayor libertad para actuar. Esto es visto como consecuencia de la autoconsciencia sobre las cosas y lo que ocurre alrededor, en la medida en que se acercan a la adultez. Los jóvenes asocian el estatus de poder con la edad, fruto de todo un discurso normativo aprendido y de carácter paternalista:

Un día, por ejemplo, nos acostábamos más tarde, pero porque la monja nos dejaba, veía que podíamos hacerlo porque éramos un poco mayores y responsables (I5). 
La adquisición progresiva de autonomía es asociada a la madurez y ésta con la edad, pero también con las experiencias vividas. El mundo de la infancia es el mundo del juego y éste el de la no consciencia de lo que ocurre alrededor.

A mí me ha hecho una persona muy madura [...] Me lo ha dicho mucha gente que ninguna chica de 20 años es tan madura (I5).

Los educadores para dejarme salir me exigían madurar, que madurara, que fuese más responsable y que no fuese una cabra loca (I7).

La madurez es asociada a la independencia (no interdependencia) o ausencia de ayuda en la toma de decisiones, fruto del modelo liberal de ciudadanía instituido que descansa en un sentido privado y negativo de la libertad y de la autonomía, característico del modelo liberal de ciudadanía imperante.

\section{Ser un niñola de centro}

Esta pertenencia social del niño/a implica su inclusión en la colectividad de la categoría o grupo niño/a de centro:

Soy una niña tutelada en un piso de protección (Carta).

Sin embargo, la pertenencia al grupo niño/a de centro no es experimentada necesariamente en base al sentimiento de lealtad hacia ella. La inclusión, más bien, se realiza mediante la asunción del rol niño tutelado dentro de la colectividad y de la apropiación e interiorización de, al menos, parte del marco simbólico-cultural instituido por el sistema de protección, es decir, de la idea de familia, la importancia de las normas en la producción de subjetividad y la representación del niño/a protegido/a como un ser conflictivo y culpable.

El centro terapéutico es el peor centro que te puedas echar a la cara porque va la peor gente. En el mío no iba gente mala, iba gente... vamos, no hay gente mala nunca pero sí hay niños traviesos, no malos (I7).

En el centro, el grupo de chicos que estábamos era como nuestra familia, más o menos teníamos algo en común (I1).

El ser un niño/a de centro funciona como etiqueta y significado en la constitución de su propia subjetividad. Vivir en un recurso de acogimiento residencial contribuye al sentido de sí mismos y de su identidad.

Soy una niña que está en un piso de protección. Desde que llegué aquí me alegre mucho. Al principio creí que era un internado pero me he dado cuenta que no tiene que ver nada con un internado. Estoy en una casa normal (Carta).

Frente a la idea colectiva de la infancia protegida como un grupo relativamente homogéneo donde los niños comparten características y experiencias similares, los niños/as y adolescentes protegidos establecen distinciones internas 
o subcategorías en la protección y, en función de ello, atribuyen determinadas características a los diferentes recursos de acogida.

En todos los discursos, las residencias de primera acogida ${ }^{5}$ son vistas como unos centros muy negativos e invasores y son identificados como recursos dirigidos a los niños/as inmigrantes no acompañados y estos, a su vez, con el conflicto social.

Ir la residencia esta de primera acogida... porque había allí gente muy conflictiva (I3).

Me mandaron a residencia de primera acogida y se notaba que [...] había muchísima gente que sobre todo eran extranjeros, chicos marroquís que vienen sin papeles y tal... y yo eso... ya no me meto ahí (19).

Los niños/as y adolescentes protegidos responden al marco político- normativo cultural y moral compartido socialmente. En este escenario el conflicto social es identificado con los «otros» (niños/as inmigrantes no acompañados). Pese a que estos jóvenes han vivido parte de su infancia o adolescencia sin sus familias, al igual que los jóvenes migrantes, su experiencia de separación familiar es vivida como algo involuntario; mientras que la experiencia de los «otros» es vista como algo decidido por ellos y, por tanto no normal.

\section{Los procesos de construcción ciudadana}

Como ya pusieran de manifiesto estudios como los de R. Thomson et al. (2004), los jóvenes entrevistados tienden a identificar la ciudadanía con la edad adulta. Esta asociación responde al modelo clásico de ciudadanía en el que el ciudadano por antonomasia es el adulto independiente económicamente y al que no sólo se le atribuye la ciudadanía plena, sino también las características de madurez, responsabilidad y autonomía; por lo que se le permite adquirir plenos derechos y participar política y socialmente.

Para los niños/a y jóvenes, cumplir 18 años supone la adquisición de la adultez pero, sobre todo, la oportunidad real de hacer libremente, tomando y poniendo en práctica sus propias decisiones. Hecho que ha ser visto como una consecuencia directa del impacto de las políticas de la infancia sobre la vida de los niños y niñas. Es más, para los niños/as y jóvenes protegidos, la ciudadanía es identificada sobre todo con la posibilidad de la (auto)determinación, en contraste con una experiencia vital marcada por la exclusión tanto del proceso y organización de su propia protección como de las prácticas establecidas

5. Macrocentros de tránsito donde los niños /as y adolescentes permanecen hasta que la administración autonómica les asigna otro recurso de acogimiento residencial. 
para sus vidas cotidianas; debido a su condición de «menores de edad»y, sobre todo, como «niños o niñas de centro», vulnerables o conflictivos.

Yo tenía ganas de cumplir 18, de hacerme mayor [...] sólo quería tener 18 años y ser adulta (I5).

Incluso en los casos en los que los jóvenes entrevistados tienen un diagnóstico de enfermedad mental, sus elecciones se dirigen hacia la ansiada independencia y autonomía.

Aquí me dan una ayuda al mes que es de 720 euros y por el piso pago 270 euros y me incluye la luz, el agua y todo [...] De los 270 que yo pago me dan 41,60 a la semana para ir a hacer la compra. Yo me voy con la moto al supermercado y cojo y digo 'Hoy quiero patatas, como es viernes, me voy a comprar una bolsa de patatas' y cocino y eso. Y se está aquí mejor que en España (I1).

El establecimiento de las propias reglas (cotidianas), como ir a hacer la compra o decidir qué comer y cuándo, es visto como un signo inequívoco de autonomía, pero sobre todo como el margen de libertad (social) a partir del cual se les permite ser tratados como personas, independientemente de su edad o (in) capacidad.

Al igual que algunos investigadores han puesto de manifiesto (Lister et al. 2003) en la experiencia del Reino Unido, los jóvenes entrevistados representan la idea de ciudadanía a partir de dos modelos fundamentalmente: 1) independencia económica; y 2) participación social, ambos relacionados con el proceso de inclusión/exclusión socio-política y social. No obstante, en las narrativas producidas $-\mathrm{y}$ en el caso español- se puede encontrar un tercer modelo de la construcción de la ciudadanía asociada a la familia.

\section{Ciudadanía como independencia económica}

Acorde con el modelo de independencia económica, los jóvenes consideran el empleo como la expresión de la adultez y el estatus ciudadano, en la medida en que obtienen un salario y, con ello, la independencia económica de las instituciones. Para ellos, disponer de ese salario (aunque sea bajo y precario) les legitima para tomar sus propias decisiones y ordenar sus vidas.

Y nada, yo ahora que me ha metido mi vieja en un piso de mayores, debuty, la verdad y me estoy sacando la ESO [... ] Mi hermana me va a meter a currar en Springfield (I4).

Yo llevo ya cuatro años trabajando y, bueno, yo antes era una niña y tú me podías decir 'déjame dinero' y te lo dejaba. Claro, yo no sabía pero lo he aprendido... y el tema de no gastar tanto o si gasto apuntarlo (I5). 
No podías tomar muchas decisiones, tampoco era mucha autonomía [...] Yo porque empecé a trabajar [...] Ellos decían que yo a las 21 h tenía que estar en la residencia y yo decía que no. Ellos decían que las normas eran para todos y yo 'ya, pero es que todos no están trabajando' (17).

Cabe señalar que estos niños y niñas, en muchas ocasiones, se ven forzados a incluirse en el mercado laboral al cumplir los 18 años porque no disponen de la protección y soporte económico de sus familias y/o las instituciones que hasta la fecha les habían «protegido». Por tanto, ellos entienden que la independencia económica es una forma de emancipación de la autoridad del sistema de protección pero también, para muchos de ellos, la única manera de sobrevivir.

Cuando hice los 18, dijo el director 'Ya tienes 18, ya te puedes ir' y no había ni un piso, no tenía arreglados los papeles para ir a ningún curso, ni dónde te vas a ir... Eso era: puertas abiertas, sal y búscate la vida (I1).

La infancia es a menudo considerada como un periodo de especial vulnerabilidad y pasividad durante la cual los niños/as se preparan para su vida futura como adultos. La noción del «devenir» constituye una visión romántica de la infancia caracterizada por la ausencia de preocupaciones, proponiendo el énfasis en la preparación de los niños y niñas para la vida adulta a través de un conjunto de prácticas supervisadas y controladas que incluyen la educación formal.

Reflejo de esta imagen colectiva, en las narrativas producidas por los jóvenes, la idea de responsabilidad y la adquisición de capacidades adultas, marcadas por la noción de la independencia (económica), se relaciona con la participación en la educación formal.

La imagen de la educación formal es identificada, por un lado, como una experiencia que provee de madurez y culmina en la adquisición de la condición de persona y por otro, como un vehículo para cambiar activamente identidades futuras y para alcanzar un estatus social -y económico- más alto.

Eso de limpiar las piscinas... en vez de los cursos de matemáticas que teníamos sólo en invierno, ahí aprendíamos más. Y yo porque tenía 17 pero el Ramón, el que tenía 14, no se podía formar bien y la consecuencia habrá sido que ahora no habrá sido nada (I1).

Cuando entré en el piso, en el instituto me iba mal porque tenía una situación familiar difícil y a mí el instituto no me parecía... [...] Lo que pasa es que pues era un ignorante, era un chaval (I8).

Porque por ahora el estudio es mi vida, quiero conseguirlo (Carta). 


\section{Ciudadanía como participación social}

El modelo de participación social se relaciona con la idea de ciudadanía social. Muchos de los jóvenes entrevistados mostraron actitudes proactivas hacia la ayuda, expresando su interés por actividades de voluntariado o por realizar estudios relacionados con la «ayuda».

Yo siempre he tenido una vocación para ayudar a las personas. Siempre he sido muy de ayudar a la gente, me ha gustado ayudar a la gente y había pensado ser auxiliar de clínica veterinaria [...] o auxiliar de enfermería (I9).

No obstante, los jóvenes no consideraron este tipo de actividades desde una perspectiva filantrópica, sino más bien como una forma de desarrollar prácticas y proveer de oportunidades a otros niños/as para que puedan ejercer sus derechos.
Yo le he hablado con mis amigos y les digo 'me gustaría trabajar con niños' y me dicen 'a ver, piensa tío, te ha pasado a ti esto...' y digo 'pero es que me gus- taría, es que me encantan los niños' 'ipero te verías como para ponerles leyes o para ponerle la mano a un niño?' 'no, no, que va de educador no, de jardín de infancia en una guardería...' Es que siempre me han gustado los niños. Yo siempre les digo a mis amigos que si me hago educador, tengan por seguro que yo sería educador tirando a amigo [...] hay educadores y educadores. Hay educadores que si tienes un problema puedes hablar con ellos (I2).

Como muestran los extractos anteriores la ayuda se relaciona con la condición de persona y ésta con el reconocimiento del «otro-niño/a»o «ponerse en la piel de» como arguye la siguiente interlocutora:

A mí me encantaría ser educadora porque no es lo mismo ser educador que ser un niño ¿sabes? Estar en la piel de un niño, no es lo mismo. Y si yo en algún caso, pudiera estudiar algo, estudiaría eso porque yo me he puesto en la piel de los niños (17).

Por otra parte, los jóvenes manifestaron no haberse sentido reconocidos como personas de pleno derecho durante su experiencia de protección, lo que es visto por ellos como una forma manifiesta de exclusión social. Por tanto, para ellos, la participación social significa también presencia socio-política en los espacios públicos, la cual es fundamental para ser considerado ciudadano (en un sentido sustantivo).

\section{Ciudadanía como familia}

Fruto de una tradición socio-cultural e histórica fundamentada en la institución familiar como espacio privilegiado para la formación e inclusión cívica, la construcción familiar de la ciudadanía se constituye como el tercer modelo de ciudadanía representado en los discursos delos niños/as y adolescentes. 
Incluso para algunos de ellos formar una familia implica necesariamente tener hijos. La familia es considerada como el entorno donde los niños y niñas tienen la oportunidad real de ser tratados y considerados como «personas» desde el presente y en el futuro.

Mis planes: sacarme los estudios y luego formar una familia, aparte de que me gustan mucho los niños, formar con mi novia una familia. Me gustaría hacer bachillerato y luego trabajar de mozo de almacén o ya que estoy tan metido en el tema de niños, trabajar en el tema de niños (I2).

Como señala Gil Calvo (1988), en nuestra sociedad para que se dé la integración social (y cívica) completa no sólo hay que disponer de un empleo remunerado estable y propiedades (independencia económica) o ejercer alguna clase de participación pública (voto, opinión, etc.), en el imaginario colectivo, hay que contraer responsabilidades familiares (conyugales, paternales y domiciliares).

\section{Conclusiones}

El discurso colectivo de los niños/as y jóvenes institucionalizados es bastante homogéneo. No obstante, se advierte una mayor incidencia de la variabilidad «régimen de protección» (guarda o tutela) como determinante de la producción de subjetividades.

Las narrativas de los niños/as y jóvenes entrevistados ponen de manifiesto su capacidad de acción y contestación ante la imagen socialmente instituida del niño institucionalizado, aunque al mismo tiempo, el análisis del material empírico muestra las tensiones existentes en los relatos de los niños entrevistados sobre sus identidades y pertenencias. Esta dualidad debe ser vista como fruto del impacto del marco simbólico de la protección; así como el producto, aunque reelaborado, del conjunto de prácticas cotidianas en los recursos de acogimiento residencial. Por un lado, los niños, niñas y jóvenes tienden a legitimar su exclusión ordinaria de la toma de decisiones según la edad y a la (in)capacidad atribuida, particularmente aquellos que estuvieron acogidos en régimen de tutela. Por otro, cada uno de sus relatos contiene el deseo o la frustración de no haber sido tenidos en cuenta en los asuntos que afectan a sus vidas, lo que queda referido en la forma en la que construyen y proyectan su ciudadanía.

De la misma manera, se muestra cómo el contexto simbólico de la protección incide en la visión de estos niños/as y adolescentes sobre los significados del ser adulto y ser ciudadano, identificándose tres modelos de ciudadanía dominantes: independencia económica, participación social y formación de la familia. Mientras que los dos primeros modelos responden a una concepción 
de la ciudadanía característica del modelo clásico liberal, la tercera incorpora los valores culturales específicos del caso español, atribuyendo especial relevancia a la formación de una familia en la adquisición de la ciudadanía plena.

\section{Bibliografía}

BERGER, P. y LuCKMAnN, T. (1967). The Social Construction of Reality. New York: Doubleday.

BOLETÍN DE DATOS ESTADÍSTICO DE MEDIDAS DE PROTECCIÓN A LA INFANCIA. (datos 2013), n. ${ }^{\circ} 16$. Recuperado de http://www.observatoriodelainfancia.msssi.gob.es/productos/home.htm

CASTORIADis, C. (1988). Los dominios del hombre: la encrucijada del laberinto. Barcelona: Gedisa.

COCKBURN, T. (1998). Children and Citizenship in Britain: A Case for a Socially Interdependent Model of Citizenship. Childhood, 5(1), 99-117.

CoHEN, E. (2005). Neither Seen Nor Heard: Children's Citizenship in Contemporary Democracies. Citizenship Studies, 9(2), 221-240.

GAITÁN, Lourdes. (2014). De «menores» a protagonistas. Los derechos de los niños en el trabajo social. Madrid: Consejo General de Trabajo Social.

GIL CALVO, E. (1988). «La discontinuidad social y la integración de los marginados». Revista Alfoz, 57, 45-54.

Goffman, E. (1961). Asylums: Essays on the Social Situation of Mental Patients and Other Inmates. New York: Dubledzay.

IBÁÑNEZ, J. [1979] (2003). Más allá de la Sociología. El grupo de discusión: Técnica y crítica. Madrid: Siglo XXI.

INFORMES, ESTUDIOS E INVESTIGACIÓN. (2012). Estándares de calidad en acogimiento residencial- EQUAR. Ministerio de Sanidad, Servicios Sociales e Igualdad. Recuperado de: http://www.observatoriodelainfancia.msssi.gob.es/ productos/home.htm

JAMES, A. (2011). To be (come) or not to be (come). Understanding children's citizenship. The ANNALS of the American Academy of Political and Social Science, 633(1), 167-179.

JENKS, C. (1996). Childhood. London: Routledge.

LIEBEL, M. (2008). Citizenship from below: children's rights and social movements. En J. Williams y A. Invernizzi (eds.), Children and Citizenship (pp. 32-43). London: Sage.

Lister, R., SMith, N., Middlenton, S. y Cox, L. (2003). Young People Talk about Citizenship: Empirical Perspectives on Theoretical and Political Debates. Citizenship Studies, 7(2), 235-253.

LISTER, R. (2007). Why citizenship: Where, when and how children?. Theoretical Inquiries in Law, 8(2), 693-718. 
MARC, E., y PICARD, D. (1992). La interacción social: cultura, instituciones y comunicación. Barcelona: Paidós.

Mead, G.H. (1934). Mind, Self and Society. Chicago University Press.

Millham, S., Bullock, R., y CherRet, P. (1975). A conceptual scheme for the comparative analysis of residential institutions. En J. Tizard, I. Sinclair y R.V.G. Clarke (eds.), Varieties in Residential Experiences (pp. 203-224). London and Boston: Routledge \& Kegan Paul.

Moosa-Mitha, M. (2005). A Difference-Centred Alternative to Theorizing of Children's Rights. Citizenship Studies, 9(4), 369-388.

Moss, P. (1975). Residential Care of Children: A General View. En J. Tizard, I. Sinclair y R.V.G. Clarke (eds.), Varieties of Residential Experiences (pp. 17-51). New York: Routledge \& K. Paul.

RAMiro, J. (2015). De los derechos para la infancia a la ciudadanía de los niños. Estrategias de orden y control social (Siglos XVIII al XXI). e-SLegal History Review, 19, 1-42.

Roche, J. (1999). Children: Rights, Participation and Citizenship. Childhood. $6(4), 475-493$.

Thomson, R., holland, J., McGrellis, Bell, R., Henderson, S. y Sharpe, S. (2004). Inventing Adulthoods; A Biographical Approach to Understanding Youth Citizenship. Sociological Review. 52(2), 139-294.

TizARD, J., SinClair, I., y ClARKE, R.V.G. (1975). Varieties of Residential Experiences. New York: Routledge \& K. Paul.

WeIL, S. [1943] (1996). Echar Raíces. Madrid: Trotta. 


\title{
SERVICIOS SOCIALES EN LA COMUNITAT VALENCIANA: EL ACTUAL 'MODELO VALENCIANO' Y UNA NUEVA AGENDA DE CONSTRUCCIÓN DE UN MODELO DERECHOS SOCIALES
}

\author{
Social Services in the region of Valencia: the current 'valencian model' and \\ a new set of ideas for the construction of a model of social rights
}

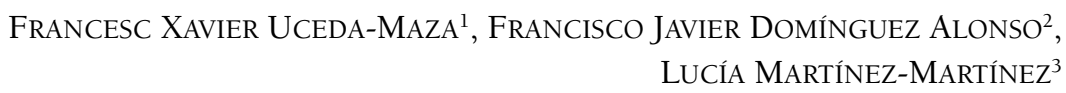

Resumen

Introducción: La aprobación de la LRSAL* presenta un panorama de cambio para los Sistemas de Servicios Sociales de España, sobre todo en lo atingente a lo local. Un grupo de expertos/as de la Comunitat Valenciana ha trabajado esta circunstancia como una oportunidad positiva.

Material y Métodos: Mediante el análisis documental y el debate de la realidad del sector realizado por este grupo de expertos/as, se ha desgranado el modelo actual de los servicios sociales municipales valencianos, se ha reflexionado en sus diferencias con los modelos basados en leyes de tercera generación, y a partir de ello, se atreve a proponer las bases para la construcción de un nuevo modelo del Sistema Valenciano de Servicios Sociales.

Resultados: Los resultados nos han llevado a indicar que el modelo actual de los servicios sociales valencianos se caracteriza por haberse desarrollado de forma centralizada, desordenada, con escasa calidad y al margen del territorio. La comparativa en legislación nos indica que no se asienta sobre derechos subjetivos, tiene desestructurados e invisibilizados sus recursos, y sobre todo carece por completo de planificación en todos los ámbitos del sistema, siendo especialmente grave en el ámbito de la organización funcional y territorial.

Discusión y conclusiones: El nuevo modelo se debe asentar en la planificación estratégica, la proximidad, la prevención, la calidad, la colaboración de y entre todos sus actores, y sobre todo en la primacía de las personas sobre el sistema.

Palabras clave: Servicios Sociales, proximidad, planificación estratégica, leyes de tercera generación, derecho subjetivo, Trabajo Social.

* Ley 27/2013, de Racionalización y Sostenibilidad de la Administración Local
Abstract

Introduction: The endorsement of the LRSAL ${ }^{* *}$ presents an environment of change for the social services systems in Spain, especially at the local level. A group of experts in the region of Valencia (Comunitat Valenciana) have found in this situation a positive opportunity to bring about change.

Material and Methods: Through documentary analysis and discussion of the reality of the sector carried out by this group of experts, the current model of the Valencian municipal social services has been divided into sections, and a reflection has been carried out taking into account models based on third-generation rights. From that perspective, the group of experts are in a position to propose the basis for the construction of a new model of the Valencian social services system.

Results: The results have led us to suggest that the current model of the Valencian social services is characterized by having a centralized, disorganized and poor quality structure which is outside the territory. The comparison with the legislation indicates that it is not based on subjective rights, as resources are badly structured and above all, there is a lack of planning in all the stages of the system, which is especially serious in the scope of the functional and territorial organization.

Discussions and conclusions: The new model should be based on strategic planning, proximity, prevention, quality, and collaboration between all participants, and especially in the primacy of the people over the system.

Keywords: Social Services, proximity, strategic planning, third-generation rights, individual right, Social Work.

\footnotetext{
** Law 27/2013, Rationalization and Sustainability of Local Administration in Spain
}

1. Universitat de València. Departament de Treball Social i Serveis Socials. Avgda. Tarongers n. ${ }^{\circ}$ 4-B. 46071 València. Tel: 963828835. Francesc.Uceda@uv.es

Institución de apoyo a la investigación: Universitat de València. Instituto Interuniversitario de Desarrollo Local (IIDL). Programa de ayudas de investigación para acciones especiales de la UV. Precompetitivo. (UV-INV-PRECOMP12-82190).

2. Universitat d'Alacant. Departament de Treball Social i Serveis Socials

3. Universitat de València. Departament de Treball Social i Serveis Socials 


\section{Introducción}

«El sistema de los Servicios Sociales se ha desarrollado intensamente en los últimos 30 años adquiriendo la identidad suficiente para ser reconocido como un instrumento fundamental de nuestro Estado del Bienestar, constituyendo uno de sus pilares»(Uceda, 2011: 237). Este sistema moderno de Servicios Sociales nace con la aprobación de La Constitución (1978), y la asunción de competencias en materia de «asistencia social» por las Comunidades Autónomas $^{4}$ (art. 148.1.20. ${ }^{a}$ de la Constitución Española) ${ }^{5}$. A partir de 1982 las comunidades autónomas legislan como materia propia, habiéndose desarrollado 17 sistemas diferentes de Servicios Sociales (Vilà, 2012).

Cuando las CC.AA asumen las transferencias realizadas desde la Administración General del Estado, se encuentran con la necesidad de ordenar y regular los bienes y obligaciones recibidos, pero también con expandir, modernizar y democratizar la acción social, ya que es un ámbito donde marcar la impronta política y trascender a la ciudadanía.

Desde 1982 y hasta 1992 nacen las leyes de primera generación en servicios sociales que «tienen la virtud de conseguir institucionalizar un nuevo sistema de protección social» (Santos, 2012: 106). Con ellas «se busca diseñar un sistema claramente diferenciado de la herencia benéfico-asistencial propia del periodo franquista» (Carbonero y Caro, 2013: 123).

Este nuevo sistema asienta sus bases en el ámbito local, por la tradición existente en el Estado Español desde las leyes de beneficencia de dotar a las administraciones locales (grandes ayuntamientos y diputaciones) de estructuras de asistencia social (Hospitales, Orfanatos, Asilos, etc.) ${ }^{6}$. La Ley 7/85 de Bases de Régimen Local, normaliza está tradición y reconoce la obligación de las Administraciones Locales, de prestar Servicios Sociales, al asignar en su artículo 26.1.c, la competencia en materia de Servicios Sociales a los municipios de más de 20.000 habitantes, y a las Diputaciones provinciales les otorga el papel de ayudar a los municipios de menos habitantes para la implantación y mantenimiento de los Servicios Sociales en todo el territorio nacional.

4. A partir de ahora, CC.AA.

5. El Estado no considera este tema competencia suya y aunque hace intentos por legislar en la materia, de hecho se elabora un borrador de ley, algunas CC.AA rechazan esta posibilidad, de acuerdo con este artículo 148, y a su vez son las que van introduciendo en sus Estatutos la competencia exclusiva en materia de Asistencia Social. (Ley Orgánica 5/1982 de 1 de julio del Estatuto de Autonomía de la Comunitat Valenciana, artículo 31, apartado 24).

6. Es el único sistema donde la administración local ejerce amplías competencias desde la primera Ley de Beneficencia de 1822. (Uceda, 2011). 
Ante el déficit de una norma estatal que unifique unos servicios mínimos en todo el Estado, en 1987 se aprueba el Plan Concertado de Prestaciones Básicas en Servicios Sociales en Corporaciones Locales ${ }^{7}$, con la finalidad de establecer unos mínimos comunes en todos los municipios y subvencionar parte de la inversión inicial necesaria para la implantación de los servicios sociales, aunque «no era un instrumento de financiación incondicional de la Administración Local» (Carbonero y Caro, 2013: 125).

A partir de 1993 se inicia un proceso de revisión de las leyes de servicios sociales vigentes en las CC.AA, denominado por Vilà «segundas leyes» (2012: 144), o leyes de segunda generación. Para el autor no aportan nada nuevo o substantivo a las anteriores, solo buscan la extensión y consolidación del sistema, y en algunos casos, solo dejar la impronta política del nuevo partido que asciende al poder.

Es en el año 2006, con la aprobación de la Ley de Promoción de la Autonomía Personal y Atención a la Dependencia ${ }^{8}$, que introduce un sistema garantista (derecho subjetivo y Catálogo de recursos), cuando se inicia una revolución legislativa en Servicios Sociales y aparecen las Leyes de Tercera Generación. Según Casado y Fantova la LPAPAD constituye «un primer paso hacia la protección jurisdiccional del derecho a los servicios sociales, en los que incide directamente, y a partir de la que cabe esperar la consolidación futura del cuarto pilar del Estado de bienestar» (2007: 145).

Ante el hito de la aprobación de la LPAPAD, se realizaron esfuerzos metodológicos desde el ámbito técnico para apoyar en el proceso de creación de las nuevas leyes, y que éstas recogieran las últimas innovaciones conceptuales y organizativas reivindicadas por los y las profesionales de servicios sociales. A destacar el documento realizado desde la Asociación Directoras y Gerentes de Servicios Sociales titulado Las nuevas Leyes de Servicios Sociales. Criterios para valorar su elaboración o sus contenidos (García, 2007), que aspiraba a que en el conjunto de las nuevas leyes hubiera una unidad conceptual y metodológica.

Para Aguilar (2013) el sistema se halla en crisis, siendo anterior a la actual crisis económica, al postular las leyes un sistema que no coincide con lo que realmente se realiza, y que habitualmente no se cumple, truncando los anhelos de la ciudadanía y de las y los profesionales.

A esta debilidad estructural del sistema hay que añadir en estos momentos lo que ha supuesto la actual crisis financiero/económica, y los Programas Nacionales de Reforma y de control del déficit aplicados por las administraciones

7. A partir de ahora $\mathrm{PCPB}$

8. A partir de ahora LPAPAD

Alternativas. Cuadernos de Trabajo Social, 22, 2015, pp. 93-121 - ISSN 1133-0473 DOI: 10.14198/ALTERN2015.22.06 
que ha llevado a recortar en unos casos y suprimir en otros, servicios públicos, entre ellos los que se prestaban desde la LPAPAD y el PCPB. El Plan Nacional de Reformas enviado a Bruselas recoge que con la aplicación de la LRSAL y la supresión de Servicios Sociales en los Ayuntamientos, se ahorraran 3.282 millones, casi la totalidad de lo que invierten con fondos propios las Corporaciones Locales en ellos en el conjunto de España ${ }^{9}$.

Por otra parte, la Ley 27/2013, de 27 de diciembre, de racionalización y sostenibilidad de la Administración Local (LRSAL) supone una modificación muy importante en las atribuciones de los Ayuntamientos en todas sus áreas de intervención competencial. Está aprobada y vigente, pero existen diferentes interpretaciones para poder aplicarla en distintos sentidos, sobre todo en el ámbito de los Ss.Ss. También habrá que esperar el resultado de los recursos acerca de su legalidad ya que se considera que vulnera, desde distintas perspectivas, la autonomía local ${ }^{10}$.

La LRSAL dice en el art. 25 2.e) que los municipios ejercerán como competencia propia sólo la «Evaluación e información de situaciones de necesidad social y la atención inmediata a las personas en situación o riesgo de exclusión social», y en el art. 26 se determinan que sólo en los municipios con población superior a 20.000 habitantes.

Las Diputaciones asumirán esta competencia en Ayuntamientos con menos de 20.000 habitantes. También podrán solicitarlo así los Ayuntamientos de más de 20.000 habitantes. Las Diputaciones podrán elegir la forma de gestión que mejor garantice el cumplimiento de los principios de eficiencia y sostenibilidad, por lo que se abre la puerta a la privatización.

Por otra parte, la competencia en materia de «Prestación de los servicios sociales» se atribuye a la Administración Autonómica, pudiendo ésta delegar en los municipios pero siguiendo criterios homogéneos y asumiendo la C.A el $100 \%$ de la financiación necesaria.

Según la Disposición Transitoria Segunda (asunción por las CC.AA de las competencias relativas a Ss.Ss) se indica: a) Las Comunidades Autónomas a

9. La financiación de los servicios sociales se distribuyen de la siguiente forma: $2.119 \mathrm{mi}-$ llones la Administración General del Estado, de los que transfiere a las Comunidades Autónomas 1.404; las Comunidades Autónomas 9.793 millones de los que transfieren a las Entidades Locales 1.452 y finalmente éstas de sus recursos propios 3.821 millones. En aplicación de la LRSAL las Entidades Locales deberán dejar de invertir en sus Servicios Sociales una buena parte de los fondos que venían invirtiendo hasta el momento. Datos de la Asociación Estatal de Directoras y Gerentes de Servicios Sociales.Índice DEC 2013.

10. Se han presentado 9 recursos de inconstitucionalidad, admitidos a trámite por el Tribunal Constitucional. 
31 de diciembre de 2015 asumen la titularidad de los Ss. Ss.; b) Previa elaboración de un plan para la evaluación, reestructuración e implantación de los servicios, las CC.AA. en el ámbito de sus competencias, habrán de asumir la cobertura inmediata de dicha prestación; c) La gestión de las CC.AA. no podrá suponer un mayor gasto para el conjunto de las Administraciones Públicas; d) Sin perjuicio de la posibilidad de las CC.AA. de delegar dichas competencias en los municipios o diputaciones provinciales y e) Si no los asumen y no los delegan, los servicios seguirán prestándose por los municipios con cargo a la comunidad autónoma.

La Ley 5/1989, de 6 de julio, de Servicios Sociales de la Comunitat Valenciana ${ }^{11}$ es la primera Ley de la C.V., similar a todas las de primera generación. En el año 1997 se aprueba la segunda ley de servicios sociales (Ley 5/97), que pertenecería al grupo de las «segundas leyes», que prácticamente no ha sido desarrollada ${ }^{12}$. En los años siguientes el Consell inicia una etapa de aprobación de normativas que, lejos de armonizar el sistema, lo fragmentan y diluyen, incluso contradicen a la Ley 5/97 (Uceda, Pitarch, Pérez-Cosín y Rosaleny, 2012).

Ante este escenario confuso y el contexto de cambio en el que estamos inmersos en estos años, el presente artículo realiza un diagnóstico de los elementos substantivos de los Servicios Sociales en la C.V., una comparación con la legislación de otras CC.AA y la formulación de unas propuestas para una nueva Ley de Servicios Sociales.

\section{Material y métodos}

Los resultados que aquí se muestran forman parte de un proyecto de investigación mayor realizado en el Instituto Interuniversitario de Desarrollo Local de la Universitat de València. Su finalidad ha sido aplicada, y su objetivo ofrecer un análisis de la situación y generar propuestas para una nueva articulación a los actores políticos, sociales y profesionales.

Específicamente en este artículo se muestran parte de los resultados del análisis del 'Modelo Valenciano'13 de Servicios Sociales, a partir de la situación

11. En adelante C.V.

12. Preveía el desarrollo de planes que aclaraban el sistema y especialmente el papel de los ayuntamientos como: Plan Concertado de Servicios Sociales, Plan General de Ordenación, Plan de Financiación de las Entidades Locales, Convenios plurianuales con las entidades locales que no se han desarrollado. (Belis y Moreno, 2002).

13. Entrecomillamos la expresión 'modelo valenciano' ya que en realidad no se puede considerar un modelo digno a seguir. 
actual y de las necesidades reales detectadas por los/as técnicos/as del sistema y se proponen las bases para la construcción de un nuevo sistema de Servicios Sociales en la C.V.

Se han utilizado dos técnicas de investigación dentro de una estrategia cualitativa: a) Panel de expertos y b) Análisis documental. El panel de expertos, se constituyó en la investigación, a partir de informantes clave, que por su trabajo, vinculación al sistema y conocimiento profundo desde distintos ámbitos del sistema podían realizar un análisis cualitativo del modelo valenciano y formular los presupuestos sobre los que se debía articular una nueva etapa en el sistema. Junto a los expertos que figuran en la Tabla 1, asistieron en calidad de observadores tres miembros del equipo de investigación ${ }^{14}$, que introdujeron preguntas, solicitaron aclaraciones y registraron los debates.

Tabla 1. Panel de Expertos de Servicios Sociales

\begin{tabular}{|l|l|l|c|l|}
\hline Experta/o & Profesión & Ámbito de Trabajo & $\begin{array}{c}\text { Años de } \\
\text { trabajo en } \\
\text { el sistema }\end{array}$ & $\begin{array}{c}\text { Vinculado } \\
\text { actualmente }\end{array}$ \\
\hline PAA & $\begin{array}{l}\text { Trabajador } \\
\text { Social }\end{array}$ & Diputación de València & 25 & $\mathrm{Si}$ \\
\hline MGA & Psicólogo & Conselleria Bienestar Social & 30 & $\mathrm{Si}$ \\
\hline MML & $\begin{array}{l}\text { Trabajadora } \\
\text { Social }\end{array}$ & $\begin{array}{l}\text { Servicios Sociales Municipales- } \\
\text { Ayuntamiento menor 10.000 hab }\end{array}$ & 23 & Si \\
\hline AMV & $\begin{array}{l}\text { Trabajadora } \\
\text { Social }\end{array}$ & Conselleria Bienestar Social & 37 & $\begin{array}{l}\text { No (jubilada } \\
\text { hace 2 años) }\end{array}$ \\
\hline JRP & Psicólogo & $\begin{array}{l}\text { Servicios Sociales Municipales- } \\
\text { Ayuntamiento más 40.000 hab }\end{array}$ & 29 & Si \\
\hline JESM & Psicólogo & Conselleria Bienestar Social & 23 & Si \\
\hline XSM & $\begin{array}{l}\text { Trabajadora } \\
\text { Social }\end{array}$ & Conselleria Bienestar Social & 22 & Si \\
\hline
\end{tabular}

Fuente: Elaboración Propia

Este panel de expertos/as debatió de forma conjunta durante cuatro encuentros, dos se dedicaron al diagnóstico; el primero a establecer los ejes de análisis y el segundo a formular la situación, el tercer encuentro se dedicó a analizar la comparativa de las leyes de las diferentes CC.AA (realizada previamente

14. Los autores del artículo.

Alternativas. Cuadernos de Trabajo Social, 22, 2015, pp. 93-121 - ISSN 1133-0473 
por los/as observadores/as), y el cuarto encuentro a formular y consensuar las proposiciones para una nueva ley. En cada uno de los encuentros, se realizó un registro por parte de los/as observadores/as que servía para el análisis individual de cada informante y punto de partida del siguiente encuentro.

El análisis documental se ha realizado a partir de las legislaciones más modernas en servicios sociales ${ }^{15}$ de España, es decir de las Leyes de tercera generación. Se ha intentado que sea lo más detallado posible tanto del conjunto de legislación como de las directrices de planificación de las diversas CC.AA. Estas legislaciones las hemos comparamos con la legislación y la planificación de la C.V. en esta materia.

En éste análisis se ha recogido solamente los ítems substantivos de las diferentes leyes seleccionadas que permiten trazar un panorama global y sirvan de análisis al panel de expertos para formular las propuestas para un futuro marco de Servicios Sociales valenciano.

La comparativa entre legislaciones se plantea en base a; a)las formas de acceso al sistema, b)la estructura funcional y territorial del mismo, c)las metodologías de trabajo y participación que detallan, d)distribución competencial y coordinación, e)calidad y f)financiación, y todo ello bajo la existencia o no de una planificación que ayude a mejorar el sistema.

\section{Resultados}

\subsection{El 'modelo valenciano' de Servicios Sociales}

A continuación se señalan algunas de las características principales del 'Modelo Valenciano' de Servicios Sociales a partir de la sistematización de la información aportada por los/as expertos/as. La tabla se organiza en cuatro columnas, en la primera denominada «características» hace referencia los elementos substantivos de los SS.SS a analizar, la segunda situación valenciana, la tercera implicaciones en el ámbito local y la cuarta observaciones, donde se incorporan datos de otras CC.AA o referencias que contextualicen.

15. Navarra, Cantabria, Catalunya, Galicia, Euskadi, Illes Balears, Aragón, La Rioja, Castilla-La Mancha y Castilla-León, según Vilà (2012: 145) 


\section{Tabla 2. Características del 'Modelo Valenciano' de Servicios Sociales}

\begin{tabular}{|c|c|c|c|}
\hline Características & Situación Valenciana & $\begin{array}{l}\text { Implicaciones en el } \\
\text { ámbito local }\end{array}$ & Observaciones \\
\hline Planificación & $\begin{array}{l}\text { Los únicos documentos } \\
\text { existentes son el Plan de } \\
\text { actuación de Ss.Ss (1989) } \\
\text { y la Mapificación de Ss.ss } \\
\text { (1991) }\end{array}$ & $\begin{array}{l}\text { Se desconocen las } \\
\text { necesidades en su } \\
\text { conjunto, la adecuación } \\
\text { de los recursos y la } \\
\text { justificación de su } \\
\text { ubicación. } \\
\text { Graves desequilibrios } \\
\text { territoriales en la } \\
\text { distribución de los } \\
\text { recursos. } \\
\text { Inexistencia de previsión } \\
\text { y prevención en las } \\
\text { actuaciones. } \\
\end{array}$ & $\begin{array}{l}\text { Las CC.AA, publican } \\
\text { cada cinco años su } \\
\text { planificación estratégica. }\end{array}$ \\
\hline $\begin{array}{l}\text { Coordinación y } \\
\text { cooperación }\end{array}$ & $\begin{array}{l}\text { No existen niveles, } \\
\text { instrumentos, ni } \\
\text { protocolos que } \\
\text { favorezcan la } \\
\text { coordinación y } \\
\text { cooperación entre } \\
\text { la Generalitat, las } \\
\text { Diputaciones y los } \\
\text { Ayuntamientos. } \\
\text { Tampoco entre lo público } \\
\text { y lo privado. }\end{array}$ & $\begin{array}{l}\text { No es posible racionalizar } \\
\text { ni optimizar los escasos } \\
\text { servicios y programas } \\
\text { existentes. } \\
\text { La ciudadanía sufre } \\
\text { la descoordinación } \\
\text { pues la resolución de } \\
\text { múltiples situaciones } \\
\text { y expedientes requiere } \\
\text { de la cooperación } \\
\text { institucional. }\end{array}$ & $\begin{array}{l}\text { Otras CC.AA, han } \\
\text { aprobado normativas } \\
\text { para garantizar } \\
\text { la coordinación } \\
\text { y cooperación } \\
\text { institucional. }\end{array}$ \\
\hline Participación & $\begin{array}{l}\text { El Consejo Valenciano de } \\
\text { B.S., existe formalmente } \\
\text { pero sin contenido. } \\
\text { Se han creado consejos } \\
\text { sectoriales (mayor, etc.), } \\
\text { pero sin contenido. }\end{array}$ & $\begin{array}{l}\text { Existen Ayuntamientos } \\
\text { donde se han creado } \\
\text { estructuras de } \\
\text { participación (p.e. } \\
\text { Ayto Valencia Taules } \\
\text { de Solidaritat) pero } \\
\text { en la mayoría no se } \\
\text { han creado, o sólo } \\
\text { formalmente. }\end{array}$ & $\begin{array}{l}\text { Cada grupo de interés } \\
\text { (asociaciones, etc.) } \\
\text { impulsa sus acciones y } \\
\text { acuerda su financiación, } \\
\text { perdiendo la visión } \\
\text { holística. }\end{array}$ \\
\hline $\begin{array}{l}\text { Prestaciones y } \\
\text { Servicios }\end{array}$ & $\begin{array}{l}\text { Inexistencia de Catálogo } \\
\text { y Cartera de Servicios y } \\
\text { prestaciones del sistema, } \\
\text { donde se regula la } \\
\text { extensión e intensidad. }\end{array}$ & $\begin{array}{l}\text { En cada Ayuntamiento } \\
\text { y en función de } \\
\text { sus posibilidades, } \\
\text { sensibilidad política, } \\
\text { impulso profesional, } \\
\text { etc., se implantan unos } \\
\text { programas o servicios, } \\
\text { se desarrollan de una } \\
\text { manera u otra, o no se } \\
\text { desarrollan. }\end{array}$ & $\begin{array}{l}\text { En las CC.AA se han } \\
\text { publicado catálogos y } \\
\text { carteras de Servicios } \\
\text { y Prestaciones donde } \\
\text { se identifican titular, } \\
\text { extensión e intensidad. } \\
\text { Los niveles básicos y } \\
\text { complementarios de las } \\
\text { prestaciones. }\end{array}$ \\
\hline
\end{tabular}




\begin{tabular}{|c|c|c|c|}
\hline Características & Situación Valenciana & $\begin{array}{l}\text { Implicaciones en el } \\
\text { ámbito local }\end{array}$ & Observaciones \\
\hline Evaluación & $\begin{array}{l}\text { No existe ningún } \\
\text { documento que evalué el } \\
\text { sistema. } \\
\text { No se han implantado } \\
\text { sistemas de calidad, } \\
\text { donde se recaben las } \\
\text { aportaciones de los } \\
\text { grupos de interés: } \\
\text { profesionales, usuarios/ } \\
\text { as y entidades de acción } \\
\text { social. } \\
\text { La C.V es la única que no } \\
\text { dispone de un análisis de } \\
\text { datos del SIUSS. }\end{array}$ & $\begin{array}{l}\text { Los ayuntamientos no } \\
\text { disponen de estándares } \\
\text { de calidad sobre los que } \\
\text { analizar y evaluar sus } \\
\text { servicios y prestaciones. } \\
\text { Cada Ayto elabora su } \\
\text { propia forma de recoger } \\
\text { los datos, y analizarlos. } \\
\text { Existe Ayuntamientos } \\
\text { en los que no se ha } \\
\text { implantado o se ha hecho } \\
\text { muy deficientemente el } \\
\text { SIUSS. }\end{array}$ & $\begin{array}{l}\text { Las CC.AA, han } \\
\text { implantado el SIUSS en } \\
\text { todos los ayuntamientos } \\
\text { y las memorias se } \\
\text { elaboran a partir del } \\
\text { mismo. } \\
\text { Existen planes de } \\
\text { Calidad, para reconocer y } \\
\text { aplicar estándares. }\end{array}$ \\
\hline $\begin{array}{l}\text { Apoyo Técnico, } \\
\text { soporte y } \\
\text { supervisión }\end{array}$ & $\begin{array}{l}\text { No existen mapas } \\
\text { de procesos ni } \\
\text { procedimientos } \\
\text { unificados. } \\
\text { No existen equipos de } \\
\text { supervisión profesional y } \\
\text { de análisis del sistema. } \\
\text { Sólo existen para } \\
\text { actuaciones sectoriales: } \\
\text { violencia de género, } \\
\text { maltrato infantil, ... }\end{array}$ & $\begin{array}{l}\text { Cada ayuntamiento ha } \\
\text { desarrollado sus procesos } \\
\text { y procedimientos. } \\
\text { Se ahonda cada vez más } \\
\text { en la desigualdad entre } \\
\text { los municipios y por } \\
\text { ende entre la ciudadanía. } \\
\text { Prevalencia de la } \\
\text { inercia institucional y } \\
\text { burocrática. }\end{array}$ & $\begin{array}{l}\text { Otras CC.AA, han } \\
\text { desarrollado mapas } \\
\text { de procesos y } \\
\text { procedimientos para cada } \\
\text { uno de los Servicios y } \\
\text { prestaciones. } \\
\text { Existen equipos de } \\
\text { supervisión profesional. }\end{array}$ \\
\hline $\begin{array}{l}\text { Financiación de } \\
\text { los SS.SS de las } \\
\text { Corporaciones } \\
\text { Locales }\end{array}$ & $\begin{array}{l}\text { No existen convenios } \\
\text { plurianuales para } \\
\text { el sostenimiento de } \\
\text { estructuras y equipos } \\
\text { permanentes. } \\
\text { Incumplimiento del } \\
\text { sistema pactado en el } \\
\text { Plan Concertado del } 33 \% \\
\text { de cada administración. } \\
\text { Se invierte } 212,15 € \text { (entre } \\
\text { Generalitat y Aytos). }\end{array}$ & $\begin{array}{l}\text { Los ayuntamientos cada } \\
\text { año se encuentran con la } \\
\text { incertidumbre, de cuanta } \\
\text { financiación dispondrán } \\
\text { para los servicios y } \\
\text { prestaciones. } \\
\text { Los ayuntamientos } \\
\text { sostienen el 70\% el } \\
\text { sistema, frente al 20\% la } \\
\text { Generalitat y el 10\% el } \\
\text { Ministerio. } \\
\text { Cada ayuntamiento } \\
\text { destina en función de su } \\
\text { capacidad, compromiso y } \\
\text { sensibilidad. } \\
\text { Infrafinanciación e } \\
\text { inestabilidad en el } \\
\text { sistema. }\end{array}$ & $\begin{array}{l}\text { En otras CC.AA (p.e. } \\
\text { Extremadura, Castilla y } \\
\text { León, etc.), es la CA la } \\
\text { principal financiadora del } \\
\text { sistema (aprox. 60-70\%). } \\
\text { La media anual de } \\
\text { inversión en España es } \\
331,41 € x \text { xab (País Vasco } \\
554,64 € x \text { hab). }\end{array}$ \\
\hline
\end{tabular}




\begin{tabular}{|c|c|c|c|}
\hline Características & Situación Valenciana & $\begin{array}{l}\text { Implicaciones en el } \\
\text { ámbito local }\end{array}$ & Observaciones \\
\hline $\begin{array}{l}\text { Reconocimiento } \\
\text { de derechos y } \\
\text { modelo }\end{array}$ & $\begin{array}{l}\text { Prácticamente todas las } \\
\text { prestaciones se hallan } \\
\text { dentro de un modelo } \\
\text { de asistencia social, es } \\
\text { decir, vinculadas a que } \\
\text { haya presupuesto y más } \\
\text { basadas en lo económico } \\
\text { que en las intervenciones } \\
\text { profesionales }\end{array}$ & $\begin{array}{l}\text { Los ayuntamientos } \\
\text { necesariamente han } \\
\text { de desarrollar un } \\
\text { modelo prestacionista y } \\
\text { asistencial. } \\
\text { Cada vez existen } \\
\text { menos intervenciones } \\
\text { profesionales y más } \\
\text { prestaciones dinerarias. }\end{array}$ & $\begin{array}{l}\text { Las CC.AA, más } \\
\text { avanzadas se han } \\
\text { decantado por un modelo } \\
\text { basado en el derecho } \\
\text { subjetivo y por la } \\
\text { intervención profesional } \\
\text { y en red. }\end{array}$ \\
\hline $\begin{array}{l}\text { Profesionales y } \\
\text { equipos }\end{array}$ & $\begin{array}{l}\text { No existe por parte de } \\
\text { la Generalitat ningún } \\
\text { análisis sobre la ratios } \\
\text { necesarias, en función de } \\
\text { población etc. } \\
\text { La Ratio de población } \\
\text { por UTS es en la C.V. de } \\
\text { unos } 22.000 \text { hab. }\end{array}$ & $\begin{array}{l}\text { Cada ayuntamiento } \\
\text { destina en función de su } \\
\text { capacidad, compromiso y } \\
\text { sensibilidad. } \\
\text { Sobrecarga y saturación } \\
\text { profesional. }\end{array}$ & $\begin{array}{l}\text { La ratio de UTS (media } \\
\text { española) es de } 9.000 \\
\text { hab. } \\
\text { La Rioja es la mejor } \\
\text { posicionada con } 1.185 \\
\text { hab x UTS y Catalunya la } \\
\text { más cercana con } 12.500 \\
\text { Hab x UTS. }\end{array}$ \\
\hline $\begin{array}{l}\text { Organización } \\
\text { funcional }\end{array}$ & $\begin{array}{l}\text { Solo existen dos } \\
\text { niveles; generales y } \\
\text { especializados. } \\
\text { El salto de la atención } \\
\text { de lo primario a lo } \\
\text { especializado/ residencial } \\
\text { es excesivo, sin un nivel } \\
\text { que ayude a que las } \\
\text { actuaciones no deban } \\
\text { salir del ámbito de } \\
\text { residencia habitual del } \\
\text { ciudadano/a }\end{array}$ & $\begin{array}{l}\text { El necesario nivel } \\
\text { intermedio ha tenido } \\
\text { que ser impulsado } \\
\text { y financiado por } \\
\text { los Ayuntamientos. } \\
\text { Tiene escaso apoyo o } \\
\text { reconocimiento por parte } \\
\text { de la Generalitat. } \\
\text { La gran mayoría de } \\
\text { municipios de la C.V } \\
\text { carecen de este nivel } \\
\text { intermedio. }\end{array}$ & $\begin{array}{l}\text { Todas las CC.AA } \\
\text { disponen de tres niveles; } \\
\text { comunitarios, específicos } \\
\text { y especializados. } \\
\text { El pase de una atención } \\
\text { primaria a una muy } \\
\text { especializada es un } \\
\text { sobre coste del sistema } \\
\text { actual y potencia su } \\
\text { mercantilización }\end{array}$ \\
\hline $\begin{array}{l}\text { Organización } \\
\text { territorial }\end{array}$ & No existe & $\begin{array}{l}\text { Cada ayuntamiento } \\
\text { o agrupación de } \\
\text { los mismos se ha } \\
\text { desarrollado a su libre } \\
\text { albedrío. } \\
\text { Abandono de los } \\
\text { municipios rurales. }\end{array}$ & $\begin{array}{l}\text { Todas las CC.AA lo han } \\
\text { legislado estableciendo } \\
\text { Zonas de Ss. Ss (con } \\
\text { unos } 20.000 \text { hab) y } \\
\text { Áreas de Ss.Ss (con unos } \\
\text { 100.000hab) }\end{array}$ \\
\hline $\begin{array}{l}\text { Autonomía y } \\
\text { Dependencia }\end{array}$ & $\begin{array}{l}\text { Creación de un sistema } \\
\text { paralelo al de Ss.Ss. } \\
\text { Irrelevante implantación } \\
\text { del sistema: prevalencia } \\
\text { de la prestación } \\
\text { económica sobre los } \\
\text { servicios, el limbo }{ }^{1} \text { de la } \\
\text { dependencia. } \\
\text { Normativa propia más } \\
\text { restrictiva que la estatal. } \\
\text { La C.V invierte } 62.21 € x \\
\text { hab/año en el sistema }\end{array}$ & $\begin{array}{l}\text { Los Smad's no se adaptan } \\
\text { a la demarcación de } \\
\text { los servicios sociales } \\
\text { municipales. } \\
\text { La atención se escora } \\
\text { hacia prestaciones } \\
\text { vinculadas al servicio } \\
\text { en lugar de servicios } \\
\text { públicos propios que } \\
\text { generarían empleo. }\end{array}$ & $\begin{array}{l}\text { Otras CC.AA han } \\
\text { implantado la } \\
\text { dependencia dentro del } \\
\text { sistema de Ss.Ss. } \\
\text { Tenemos una puntuación } \\
\text { de } 0,4 \text { sobre } 10 \text {, mientras } \\
\text { que la media de las } \\
\text { CC.AA es de } 4,7 \text {, y la } \\
\text { mejor valorada, Castilla y } \\
\text { León, cuenta con un } 9,6 .{ }^{2} \\
\text { La media de inversión de } \\
\text { las CC.AA hab/año es de } \\
\text { 109.25€, y la de mayor } \\
\text { inversión es Cantabria } \\
\text { con } 174.35 € \text {. }\end{array}$ \\
\hline
\end{tabular}


Servicios Sociales en la Comunitat Valenciana: el actual 'modelo valenciano' y una... 103

\begin{tabular}{|l|l|l|l|}
\hline Características & \multicolumn{1}{|c|}{ Situación Valenciana } & \multicolumn{1}{|c|}{$\begin{array}{c}\text { Implicaciones en el } \\
\text { ámbito local }\end{array}$} & \multicolumn{1}{c|}{ Observaciones } \\
\hline $\begin{array}{l}\text { Rentas } \\
\text { Mánimas: renta } \\
\text { ciudadanizada de }\end{array}$ & $\begin{array}{l}\text { Derecho subjetivo no } \\
\text { garantizado. } \\
\text { Criterios de inclusión } \\
\text { restrictivos. } \\
\text { Sin profesionales } \\
\text { ni programas de } \\
\text { acompañamiento. }\end{array}$ & $\begin{array}{l}\text { Diferentes decisiones } \\
\text { políticas: municipios } \\
\text { con convenio y } \\
\text { otros sin convenio, } \\
\text { con repercusiones } \\
\text { importantes en el abono } \\
\text { de la prestación a las } \\
\text { personas. } \\
\text { Sobrecarga de los y las } \\
\text { profesionales. }\end{array}$ & $\begin{array}{l}\text { Según datos de } 2011^{3} \\
\text { la C.V tenía } 16.982 \\
\text { beneficiarios frente a } \\
\text { los 52.425 de Madrid } \\
\text { que tiene una población } \\
\text { similar a la valenciana y } \\
\text { menor tasa de pobreza }\end{array}$ \\
\hline
\end{tabular}

1. Denominación otorgada por la Asociación Estatal de Directoras y Gerentes de Servicios Sociales que hace referencia a los expedientes de la dependencia en el trascurso del tiempo desde su solicitud a su resolución.

2. Datos de XII Dictamen de la Dependencia (Enero 2014), realizado por la Asociación Estatal de Directoras y Gerentes de Servicios Sociales

3. Datos del Informe de rentas mínimas de inserción (2011). Mํo Sanidad, Servicios Sociales e Igualdad

Fuente: elaboración propia

Una primera panorámica de los SS.SS valencianos es su alejamiento del encuadre de los derechos sociales, fundamentalmente debido a las políticas públicas de la Generalitat Valenciana, ya que todavía no ha concretado un marco de derecho subjetivo como otras CC.AA. Asimismo, el sistema se halla débilmente articulado, pues la Ley 5/97 no ha sido prácticamente desarrollada.

Un hecho reciente que avala esta conclusión es la publicación de la Ley 4/2012 sobre los Derechos Sociales en la Comunitat Valenciana, que es una muestra más de la ausencia de derechos subjetivos porque se limita a describir todo una cartera de servicios sin acompañamiento presupuestaria, ni vinculación institucional y sin garantía de los derechos sociales.

\subsection{Comparativa de modelos de Servicios Sociales de las CC.AA frente a la Comunitat Valenciana}

Las tablas comparativas realizadas son extensas, dado que analizamos 11 CC.AA y 6 grandes ítems, pero es clave aportarlas en este artículo, ya que comparadas unas CC.AA con otras se puede deducir el esfuerzo en planificación, legislación, ordenación y financiación que hacen cada una de ellas. 


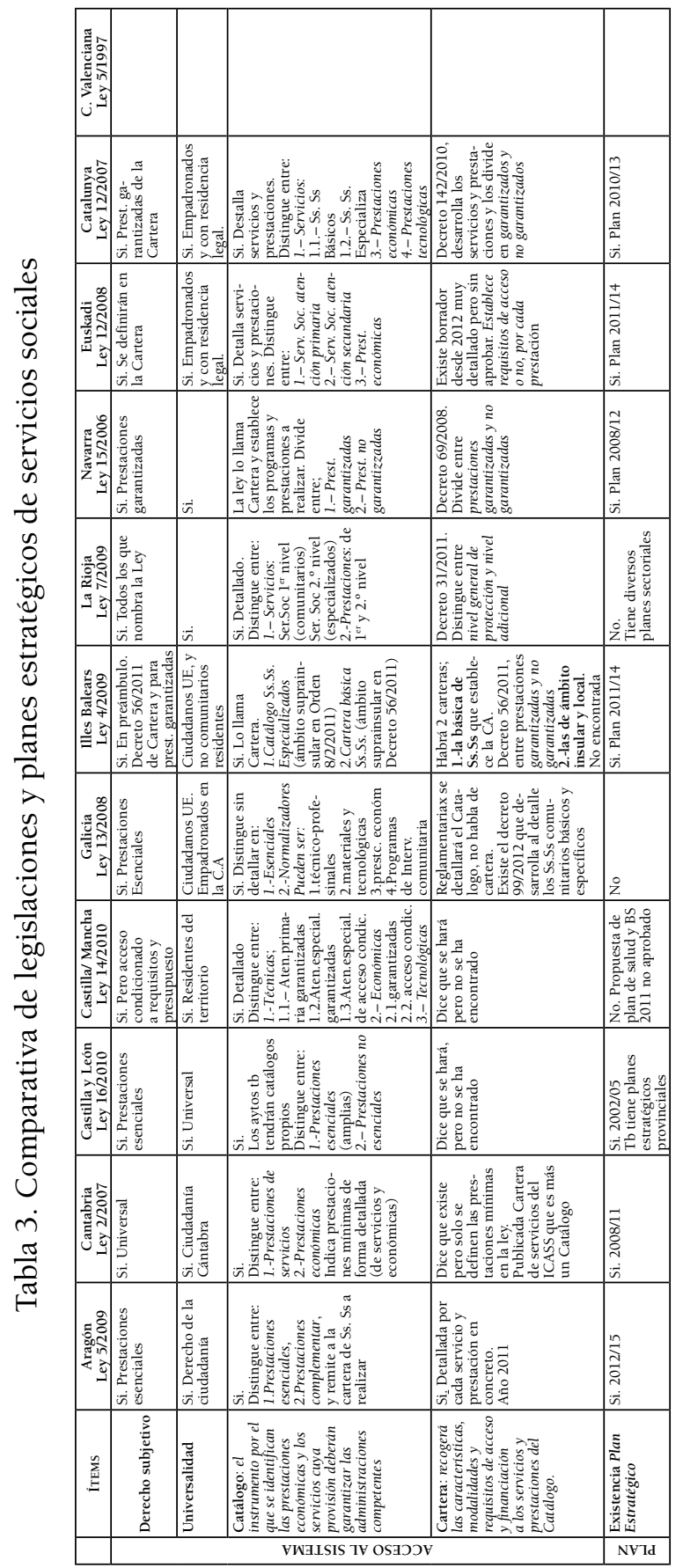

Alternativas. Cuadernos de Trabajo Social, 22, 2015, pp. 93-121 - ISSN 1133-0473 DOI: 10.14198/ALTERN2015.22.06 
Servicios Sociales en la Comunitat Valenciana: el actual 'modelo valenciano' y una... 105

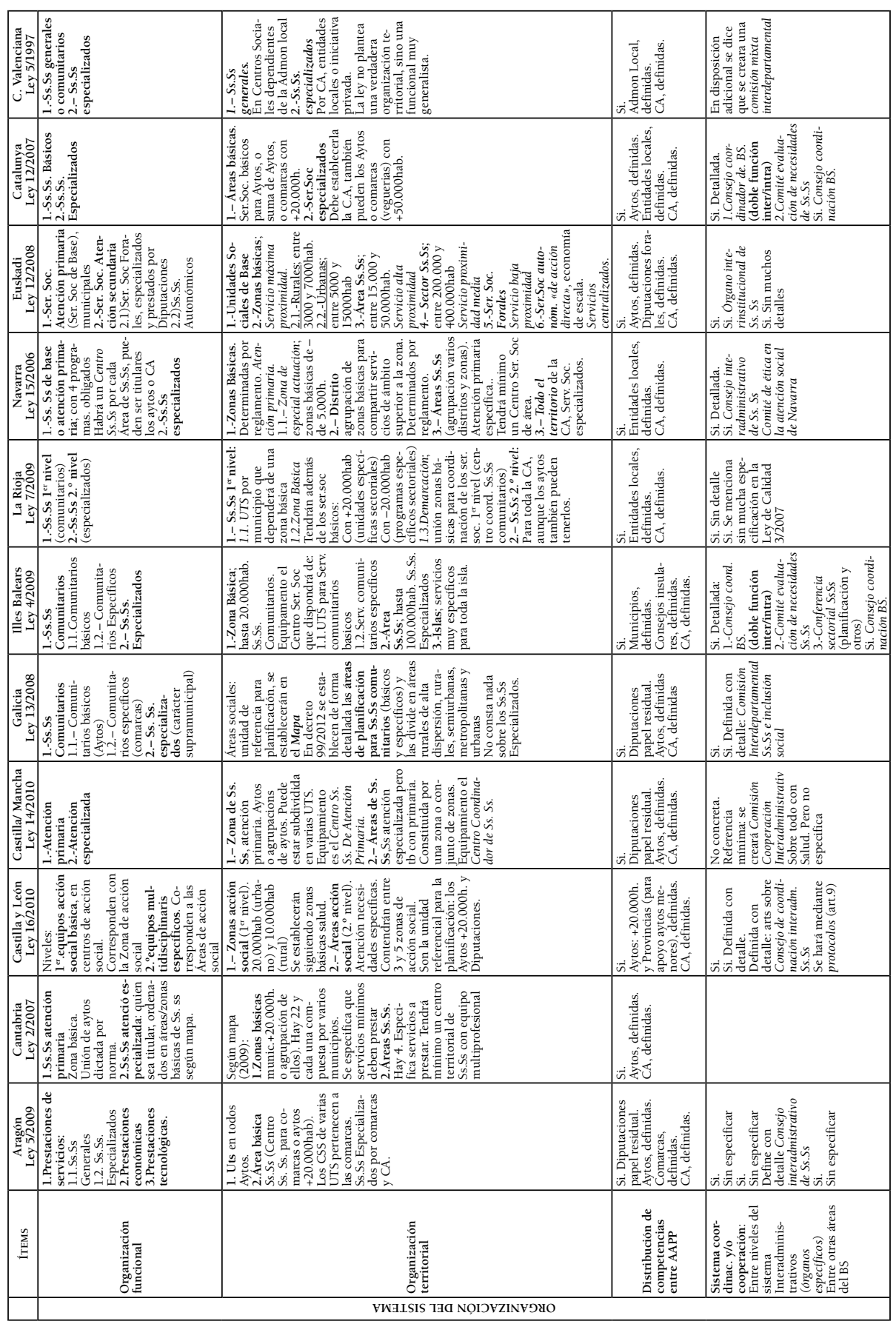

Alternativas. Cuadernos de Trabajo Social, 22, 2015, pp. 93-121 - ISSN 1133-0473 DOI: 10.14198/ALTERN2015.22.06 


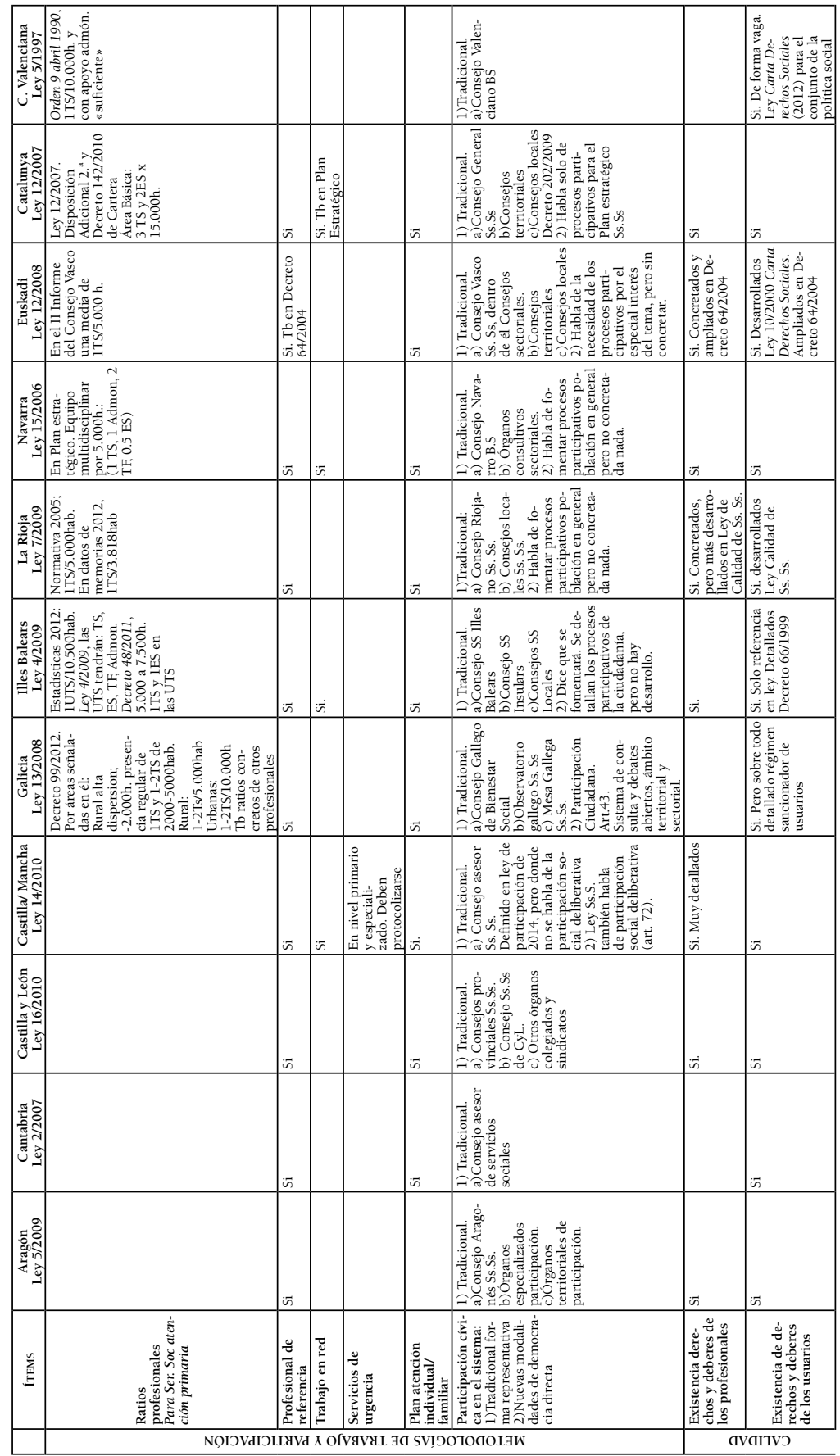

Alternativas. Cuadernos de Trabajo Social, 22, 2015, pp. 93-121 - ISSN 1133-0473 DOI: 10.14198/ALTERN2015.22.06 


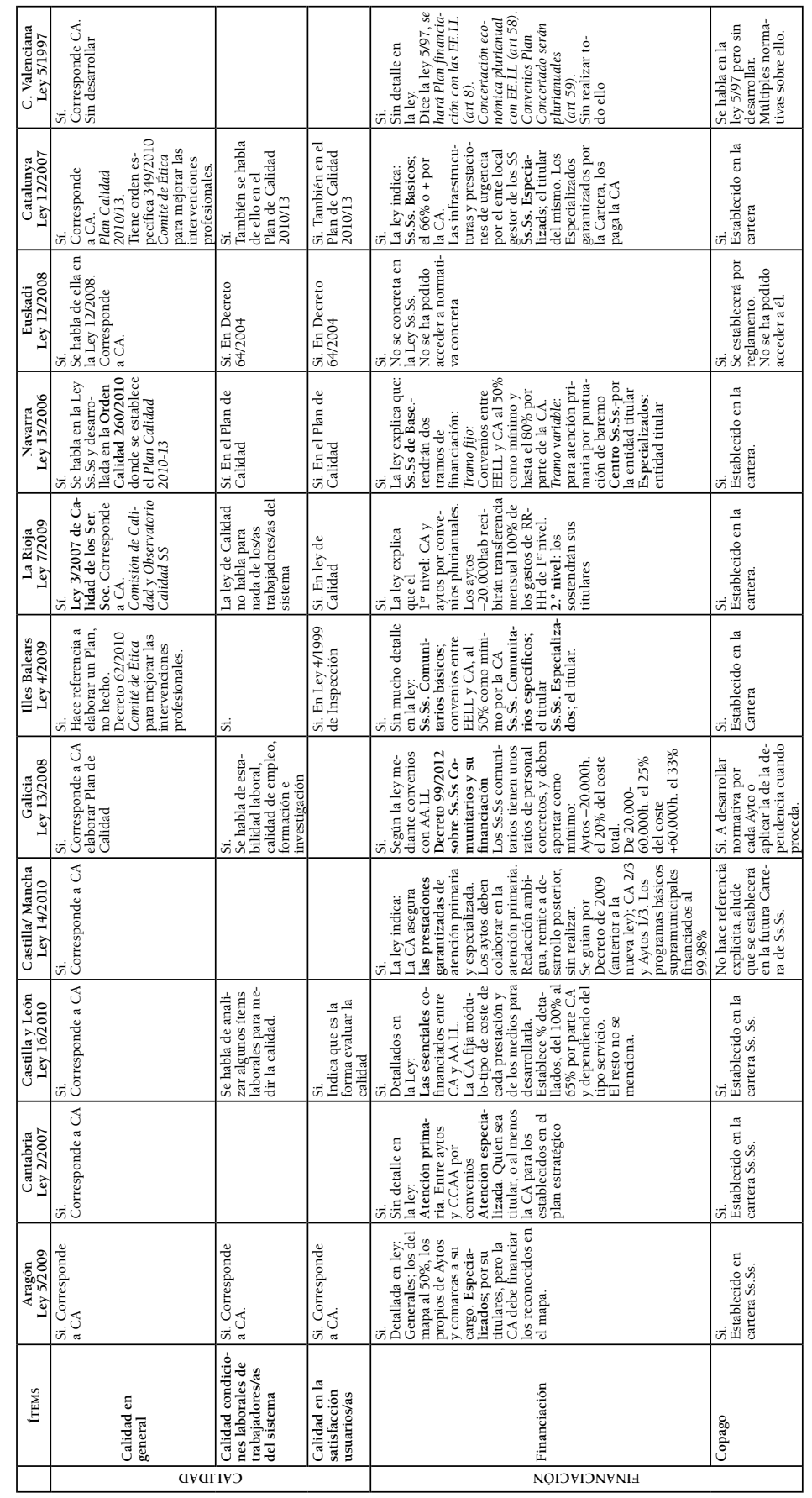

Alternativas. Cuadernos de Trabajo Social, 22, 2015, pp. 93-121 - ISSN 1133-0473 DOI: 10.14198/ALTERN2015.22.06 
Este análisis nos desvela que el ACCESO AL SISTEMA está definido de forma genérica como acceso universal para el conjunto de la población, aunque todas matizan que residentes legales o ciudadanos de la UE, dejando explícitamente fuera a los inmigrantes/residentes/extranjeros ilegales. La C.V. utiliza las denominaciones poco precisas de «valencianos/as, transeúntes y extranjeros con tratado de reciprocidad» y respecto a la situación de los inmigrantes irregulares numerosas órdenes los excluyen de las prestaciones principales.

El conjunto de legislaciones analizadas mencionan que se basan en el derecho subjetivo de uso de prestaciones del sistema, pero enseguida aclaran que este derecho subjetivo solo es referente a las prestaciones que la propia ley o que sus catálogos de desarrollo determinen como esenciales o garantizadas. En la C. V. el derecho subjetivo es inexistente en todos los ámbitos de los servicios sociales. De hecho el índice DEC $2013^{16}$ otorga a esta comunidad un cero absoluto en el apartado de derechos y decisión política.

Con respecto a la existencia de un Catálogo de Servicios Sociales y de una Cartera de Servicios Sociales, cabe destacar que todos mencionan ambos instrumentos y casi todas los tienen bien desarrollados. El instrumento menos desarrollado es la Cartera, falta en algunos de ellos. Se ha generado la legislación para concretar la cartera de servicios que han de otorgar las entidades locales, pero en algunas ocasiones falta definir los propios de su responsabilidad (véase Galicia e Illes Balears).

Sobre la existencia de Catálogo o Cartera de Servicios Sociales en la C.V, ni se menciona la posibilidad de su existencia en la Ley 5/97 ni en ningún otro documento/Decreto/orden que se haya realizado en los últimos 30 años.

Sobre la existencia de una Planificación en SERvicios Sociales se detecta la inclusión de la misma en las diversas CC.AA. Casi todas disponen de planes estratégicos ${ }^{17}$, bien de servicios sociales o sectoriales, que unificados pueden dar una planificación integral del sistema, pero la Comunitat Valenciana aunque lo menciona en su art 5 de la Ley 5/97 de Servicios Sociales como competencia de la Generalitat, nunca ha realizado ningún intento planificador. La última planificación conocida es del años 1990-1991, en Domenech y García (1990).

Sobre LA ORGANIZACIÓN DEL SISTEMA todos tienen una similar organización funcional de servicios sociales de atención primaria o comunitaria, basados

16. Índice de Desarrollo de los Servicios Sociales 2013. Índice basado en el análisis de los derechos y decisión política (D), la relevancia económica (E) y la cobertura de servicios a la ciudadanía (C).

17. No se han encontrado para Galicia y Castilla La Mancha, ni por supuesto para la Comunitat Valenciana. 
en atender a la ciudadanía en su entorno habitual y que en varios casos se subdividen en básicos -haciendo referencia a los que definía el PCPB- y específicos para mencionar aquellos que han ido apareciendo con los años y que se prestan con una mayor intensidad o especialización que los anteriores pero siempre dentro de un trabajo comunitario, y los servicios sociales especializados, que ya se prestan fuera del ámbito de residencia del ciudadano/a, basados en la asistencia un recurso de tipo más residencial y con una intensidad de prestación elevada.

La organización territorial en el conjunto de las leyes se basa en la creación de zonas básicas de servicios sociales (con unos 20.000hab. y encargada de los servicios comunitarios básicos) y áreas de servicios sociales que contendrán varias zonas básicas de servicios sociales (la media poblacional para ellas que se menciona en la diversas leyes y planificaciones es de 100.000hab. y es donde se prestaran los servicios comunitarios más específicos). La prestación de los servicios sociales especializados que corresponden a las CC.AA está reflejada en las diversas planificaciones y se realiza en base al tipo de servicio y las necesidades de las zonas en concreto, observándose en el análisis documental realizado que casi siempre son fruto de una planificación estratégica donde han trabajado tanto ciudadanos/as como técnicos/as y administración pública.

Esta organización territorial no está realizada en la Comunitat Valenciana.

El apartado de coordinación y cooperación intra sistema o entre sistemas del bienestar es bastante conciso en las legislaciones y normas de desarrollo consultadas, ya que aunque se hace referencia a él y se habla de los distintos consejos o comités que se encargarán de su desarrollo, solo Navarra detalla como debe funcionar esa coordinación. En algunas legislaciones se establece que el principio de prevalencia de criterio de atención social lo poseen los servicios sociales comunitarios básicos, pero es la única norma de funcionamiento, que no coordinación, que se menciona concretamente.

Con respecto a las METODOLOGÍAS DE TRABAJO Y PARTICIPACIÓN analizadas remitimos a las tablas realizadas donde lo destacable es que los/as ciudadanos/ as tienen derecho a un profesional de referencia y un plan de atención social individual/familiar, que el ratio es de un trabajador social por cada 5.000 habitantes (media para los servicios comunitarios básicos), que pocos mencionan el trabajo en red y que solo Castilla-La Mancha menciona la existencia de un servicio social de urgencia. Respecto a la C.V., no existe referencias, ni preocupaciones metodológicas que se hayan plasmado en documentos posteriores a la Ley $5 / 97$. 
Con respecto a la participación de los/as ciudadanos/as en el sistema todas las leyes la plantean de forma tradicional mediante representatividad en Consejos, pocos mencionan la participación ciudadana directa, y cuando lo hacen es para hablar de ello de forma difusa y posponerla a un desarrollo posterior.

El apartado de CALIDAD está bastante desarrollado en las legislaciones consultadas, en sus planes estratégicos, e incluso algunas CC.AA tienen legislación o planificación estratégica específica para ello. Se puede ver que la preocupación por la calidad es una constante.

Sobre la FINANCIACIÓN del sistema pocas CC.AA especifican en su legislación como la realizarán, remitiéndose casi todos a la frase de «se establecerá mediante convenios». Solo honrosas excepciones como Castilla-León y Galicia la detallan por ley. Estas legislaciones solo hacen referencia concreta a la financiación de los servicios comunitarios (básicos y específicos) dejando los servicios sociales especializados «a cargo de la entidad que sea su titular», que en principio será la C.A.

\section{Discusión}

\section{1. el 'Modelo Valenciano' de Servicios Sociales}

En lo que respecta al 'Modelo Valenciano' de Servicios Sociales que tanto mencionamos, solo cabe decir que en realidad no existe un modelo que pueda ser reconocido como tal y tomado de referencia, más bien por su carencia de ordenación, fragmentación, ausencia de planificación y falta de concreción, es un antimodelo.

El sistema se sigue ordenando por la Ley 5/97, aunque no se ha desarrollado esta Ley en los puntos que ella misma indica ${ }^{18}$, y el día a día del 'modelo' se rige por decretos y órdenes totalmente desfasadas ${ }^{19}$.

En la Ley 5/97 de Servicios Sociales de la Comunitat Valenciana hay un reparto de las competencias entre la Generalitat y las entidades locales, dando a las Diputaciones la competencia de apoyar a los municipios de menos de 10.000hab. Ni en ella, ni en desarrollos legislativos posteriores, se plantea

18. Baste con mencionar; el art.5.a) «elaborar un plan general de servicios sociales de carácter plurianual», el 5.c) «establecer las prioridades tanto en la programación de las actuaciones como de las inversiones que deban realizarse en los equipamientos de servicios sociales, 5.d) «establecer unos mínimos de calidad que ha cumplir todos los centros y servicios de servicios sociales, 5.m) «desarrollar reglamentariamente la presente ley y dictar cuantas disposiciones se requieren para su aplicación»,...

19. Como ejemplo aún sigue en vigor parte de la Orden del 9 de abril de 1990, sobre registro, autorización y acreditación de los Ss.Ss en la C.V. 
un nivel intermedio de servicios sociales entre lo local y lo autonómico, los llamados -servicios sociales específicos-, como si sucede en otras CC.AA, y ha sido el nivel local el que ha desarrollado numerosos programas específicos, que superan su capacidad, en sectores como la infancia, mujer, exclusión social, tercera edad,..., generando obligaciones y costes que corresponden a la Generalitat Valenciana. Para los servicios sociales especializados tampoco existe documento de planificación. La organización territorial de los servicios sociales valencianos es una asignatura pendiente después de 20 años.

El irrelevante desarrollo de los servicios sociales valencianos ha hecho que el peso de los mismos recaiga sobre las administraciones locales, y esto conlleva que los ayuntamientos y mancomunidades en función de su capacidad, compromiso y sensibilidad, hayan tenido que desarrollar y apoyar numerosos servicios y prestaciones de forma dispar, instaurándose una gran desigualdad entre vecinos/as de diferentes municipios, asentándose un modelo asistencial, sin prevención ni intervención profesional, sin referencias territoriales ni directrices políticas ni técnicas claras, y con numerosas deficiencias. La obligación de planificación estratégica y el cumplimiento de las COMPETENCIAS DE la Generalitat Valenciana en Servicios Sociales según el art.5 de la Ley 5/1997, es inexistente.

'El modelo valenciano' constituye un ejemplo evidente de inestabilidad, improvisación, falta de planificación y desinterés de los/as políticos/as por los servicios sociales, esto se puede vislumbrar en el hecho de que al frente de la Conselleria de Bienestar Social, y pese estar gobernada la Generalitat por el mismo partido desde el año 1995, ha habido nueve Consellers/es (un promedio de uno cada dos años y de ellos/as cuatro condenados/as o imputados/ as ${ }^{20}$. Cada uno con diferentes gabinetes técnicos y políticos, y que nunca han tenido en su agenda una planificación estratégica del sistema.

\subsection{Comparativa de modelos de Servicios Sociales de las diversas CC.AA}

En lo referente a un análisis comparativo entre las legislaciones de servicios sociales de tercera generación de servicios sociales y la legislación de la Comunitat Valenciana, la discusión a proponer aquí es más bien escasa, ya que los resultados sistematizados son elocuentes.

20. José Sanmartín (1995-1997); Marcela Miró (1997-1999); Carmen Mas (1999-2000); Rafael Blasco (2000-2003) «condenado por Caso Cooperación»; Alicia de Miguel (2003-2007) «imputada Caso Gürtel»; Juan Cotino (2007-2009) «relacionado Caso Gürtel, Emarsa y Brugal»; Angélica Such (2009-2011) «imputada Caso Gürtel»; Jorge Cabré (2011-2012) y Asunción Sánchez (2012- actualidad). 
Solo mencionar que en apartados como el ACCESO AL SISTEMA, no existen Catálogo y Cartera de servicios, no son visibles los recursos existentes, no se concreta el acceso a ellos, de quien dependen, etc. El sistema valenciano sigue anclado desde el punto de vista del derecho en lo asistencial y en ocasiones en lo benéfico. Los derechos subjetivos no existen en la Comunitat Valenciana.

Respecto a la ORGANIZACIÓN DEL SISTEMA destacar que es necesaria una organización funcional urgente ya que el nivel intermedio de los servicios sociales específicos no existe de forma organizada y se está desarrollando por cada Ayuntamiento, creando por su cuenta servicios específicos que les es difícil de mantener y que van a desaparecer con la aplicación de la LRSAL, o que en muchos casos ni siquiera se han creado, ya que no existe planificación que lo decida ni lo obligue, configurándose así una división entre pueblos de primera y segunda categoría en cuanto a servicios sociales. La subdivisión funcional de los servicios comunitarios en básicos, a prestar por los ayuntamientos o mancomunidades, y en comunitarios específicos, a prestar por comarcas, sería la acertada a la realidad poblacional de nuestra Comunidad. La necesidad de planificación autonómica en el sistema de servicios sociales es abrumadora.

En lo referente a CALIDAD es preciso el establecimiento de estándares de calidad y máxime cuando casi todos los servicios sociales específicos y especializados son prestados por entidades de titularidad privada pero pagados con fondos públicos, ya que la única legislación de la que disponemos al respecto, el decreto 90/2002 sobre control de la calidad de los centros y servicios de acción social y entidades evaluadoras de la misma, solo habla de quién es considerado apto para controlar la calidad de los centros y programas de los servicios sociales, pero no de cuál debe ser esta calidad. El articulado de este decreto 90/2002 solo versa sobre la obligación de que todas las personas físicas o jurídicas, públicas o privadas, que trabajen en el campo de la acción social en la C.V, deben pasar controles de calidad (arts. 1 al 5) y a partir del art. 6 hasta el final de la norma se limita a describir quién puede ser entidad evaluadora de calidad y los procedimientos para obtener dicha acreditación de entidad evaluadora (se establece quién evaluará, sin saber qué se va a evaluar).

Sobre la inexistencia de LEGISLACIÓN SOBRE FINANCIACIÓN en la Comunitat Valenciana no cabe decir mucho, solo que no existe, y ello es consecuencia directa de cómo se valora este sistema en la agenda política de la Generalitat Valenciana.

Como finalización de esta discusión solo cabe citar de forma textual a Mira-Perceval, De Alfonseti, y Giménez Bertomeu, que resumen de forma magistral cuál es nuestro 'modelo valenciano' de servicios sociales,

En los más de veinte años de existencia del sistema de Servicios Sociales en la Comunidad Valenciana, ha existido una permanente disociación entre 
las formulaciones políticas respecto a los Servicios Sociales desde el punto de vista de sus fines y principios, por una parte, y la aplicación práctica de las mismas en cuanto a los medios arbitrados y efectos en los grupos socialmente diferenciados, por otra. Los Servicios Sociales, lejos de alcanzar las amplias aspiraciones apuntadas en la normativa que los regula, se han manifestado incapaces de dar respuesta a la importante demanda propiciada por los cambios sociales recientes y el sistema construido no consigue desvincularse de su imagen social de sistema de protección residual, orientado a dar respuesta a las necesidades más extremas de determinados colectivos o sectores de población. (2007: 69)

\section{Conclusiones}

La finalidad última de esta parte de la investigación era realizar una propuesta genérica sobre unas nuevas bases para la construcción de un nuevo Sistema de Servicios Sociales en la Comunitat Valenciana aprovechando las posibles «circunstancias positivas ${ }^{21}$ que se podrían derivar de la aprobación de la LRSAL y que van en la línea de crear una legislación para los servicios sociales, a continuación exponemos las grandes líneas maestras que han resultado de este panel de expertos/as en servicios sociales.

\section{1. propuesta para articular los Servicios Sociales valencianos}

El nuevo marco legal para las Administraciones Locales modifica substancialmente su ámbito competencial en materia de Servicios Sociales. Es un buen momento para reivindicar dos cuestiones: 1) la derogación de la LRSAL y 2) la aprobación de una Ley Estatal de Servicios Sociales que establezca el nivel básico común para todos/as los/as ciudadanos/as. En tanto se avanza en lo anterior, la C. V. ya tiene competencias exclusivas en Servicios Sociales según su Estatuto de Autonomía y dispone de un amplio abanico de posibilidades para ordenar el sistema, por lo que se deben iniciar estos trabajos pendientes desde hace muchos años.

A continuación señalaremos los dos ejes para el desarrollo de una Agenda de Servicios Sociales desde la Generalitat Valenciana, las Diputaciones y los

21. Nos referimos aquí al mandato que realiza esta ley que en su Disposición Transitoria Segunda (asunción por las CC.AA de las competencias relativas a Servicios Sociales) donde se indica en el punto «b) Previa elaboración de un plan para la evaluación, reestructuración e implantación de los servicios, las CC.AA. en el ámbito de sus competencias, habrán de asumir la cobertura inmediata de dicha prestación», que puede ser algo positivo para el actual antimodelo valenciano de servicios sociales actual, si se gestiona de forma diferente a lo que se ha estado haciendo en los últimos 20 años. 
Ayuntamientos: 1) Elementos sustantivos del sistema y, 2) Propuestas para una nueva articulación de los Servicios Sociales.

\subsubsection{Elementos sustantivos para unos nuevos servicios sociales}

La Unión Europea considera que las políticas sociales son principalmente responsabilidad de los Estados miembros, entiende que los Servicios Sociales tienen, entre otros, los siguientes objetivos: a) proteger contra los riesgos y apoyar a las familias; b) salvaguardar los derechos humanos fundamentales; c) contribuir a la no discriminación reforzando la igualdad y d) proteger a las personas contribuyendo a la mejora de sus condiciones y calidad de vida, garantizando su autonomía personal y facilitando la plena participación social.

Los servicios sociales deben ser concebidos y prestados de manera integrada desde la proximidad, y de acuerdo con la Comisión Europea: a) se basan en el principio de solidaridad o universalidad; b) dependen de la financiación pública para garantizar la igualdad de acceso; c) son considerados como servicios de interés general; d) garantizan los derechos humanos fundamentales y protegen a las personas más vulnerables; e) expresan la solidaridad ciudadana por la participación del voluntariado y f) están integrados en la tradición cultural o local (proximidad).

Los Servicios Sociales Valencianos deben analizar lo que ha sido su práctica institucional en los últimos treinta años, gestionar el conocimiento producido en el sistema desde el consenso científico y profesional, realizar una mirada hacia las CC.AA más avanzadas y construir su propio modelo desde la participación del conjunto de los actores. En cualquier caso deben reformularse amplia e intensamente desde los siguientes principios: Globalidad, Prevención, Normalización, Integralidad, Transversalidad, Solidaridad, Dimensión Comunitaria, Atención Personalizada, Interdisciplinariedad, Respeto a la Diferencia y a la Diversidad, Subsidiariedad, Integración, Inclusión Social, Autonomía Personal y Participación Ciudadana.

Es imprescindible realizar un Plan Estratégico de Servicios Sociales de la Comunitat Valenciana con la participación del conjunto de los actores del sistema. Es un plan del sistema, no de la Generalitat, ha de incorporar una evaluación previa del estado (Diagnóstico). Son demasiados años sin evaluar, sin conocer las necesidades y sin incorporar a todos/as en el proceso.

El liderazgo del sistema ha de realizarse desde la responsabilidad pública, como elemento vertebrador del sistema, es condición importante para el éxito. Es necesario un liderazgo político (la legitimidad y la decisión de iniciar y mantener el proceso, la gestión del entorno interinstitucional), un liderazgo 
técnico que oriente y coordine el proceso, y un liderazgo ciudadano en la definición de los derechos y su articulación.

Después de un período de virulenta crisis económica, desempleo y recortes en la protección social, la Inclusión Social ha de ser una prioridad, nadie ha de quedarse «tirado en la cuneta». Se ha de garantizar los mínimos vitales, desde el respeto y la normalización, excluyendo políticas sin prevención ni intervención social como las «ayudas nutricionales», y generando una red por la inclusión con los otros sistemas de protección social y las organizaciones y entidades de acción social. La atención integral del ciudadano/a es su fin, y no sólo la atención de causas colaterales y mediáticas.

Alianza entre los actores del sistema, dado que la interdependencia es cada vez más visible y necesaria, desde la honestidad y lealtad institucional, que ayuden a estructurar el sistema y le confieran la imagen de un verdadero sistema de protección social.

Centralidad de la persona en todo el sistema, garantizando sus derechos, acompañándola desde el/la profesional de referencia, y siendo su atención la base del mismo, ya que actualmente lo son las prestaciones, y no las personas y sus necesidades.

5.1.2. Propuestas de articulación de una nueva ley de Servicios Sociales de la comunitat valenciana.

Es necesario aprobar una nueva Ley de Servicios Sociales de la Comunitat Valenciana, que articule un modelo de servicios sociales sobre los elementos sustantivos señalados en el punto primero, que sea fruto de un proceso participativo desde un Plan Estratégico, y que incluya a todos los actores del sistema.

La nueva Ley de Servicios Sociales ha de incorporar dentro del sistema: los servicios sociales (nivel local y autonómico), el sistema de atención para la autonomía personal y las personas en situación de dependencia y, las rentas garantizadas de ciudanía.

Esta nueva Ley ha de basarse en:

a. Derecho Subjetivo, donde se reconozca y garantice la prestación a todas las personas que acrediten necesidad, y no condicionado a presupuestos.

b. Desde un Catálogo del sistema (prestaciones y servicios) y una Cartera, donde se defina la extensión e intensidad.

c. Se defina su organización funcional basada en tres niveles: Atención Primaria, la Específica y la Especializada, definidos desde la 
proximidad al ciudadano/a. El territorio como eje planificador del sistema, articulado en dos niveles: servicios sociales generales (comunitarios y específicos) y servicios sociales especializados.

d. Se estructure la organización territorial de prestación del sistema basada en zonas básicas y áreas de servicios sociales. La Zona Básica presta los servicios sociales de atención primaria y las Áreas para los servicios específicos, siendo la Comunidad Autónoma la responsable de los especializados. Atención especial a los municipios rurales.

e. Se elabore una mapificación de base territorial, donde se anclen los servicios y recursos específicos y especializados, desde criterios de proximidad y necesidad.

f. Se genere una estructura de coordinación interadministrativa e intra administrativa donde se recojan las conexiones locales, comarcales y autonómicas, así como con el resto de sistemas del bienestar, y entre lo público y lo privado.

g. Se identifique y promueva un marco de participación de la ciudadanía en el sistema, y que la utilización del mismo sea real y efectiva.

h. Se acompañe de una financiación local para los servicios sociales básicos y específicos, (afectada, condicionada) y al 100\% para los equipos profesionales. El resto de actuaciones a financiar por convenios que realmente se sujeten a las planificaciones estratégicas y sean seguidos y evaluados en su calidad y oportunidad.

i. Calidad, inspección, mejora continua, formación de profesionales, supervisión y control, (planes de calidad en dos ejes territoriales: local y autonómico), donde haya estándares definidos entre la administración local y la comunidad autónoma, y de cumplimiento para todos aquellos que participen en la gestión del sistema.

j. Potenciar las sinergias y alianzas que se dan dentro del sistema y con el resto de sistemas.

k. Realizar una planificación estratégica basada en el territorio y que sea «de abajo hacia arriba» en el mismo, puesto que la base debe ser la participación de todos los actores implicados desde el conocimiento real y concreto.

1. Realizar un Plan de Inclusión Social a nivel local y autonómico. Debe ser el eje vertebrador de las sinergias y colaboraciones de la atención centrada en las personas, el potenciador de alianzas para evitar las causas sociales de la exclusión, y el generador de empoderamiento de la ciudadanía en sus territorios. 
m. Un sistema basado en los Servicios, como impulsores de la atención social, el desarrollo local y el empoderamiento, frente a un sistema basado en ayudas económicas individualizadas.

n. La prevención de las causas de la exclusión social, por encima de la mera asistencia -lo único que se intenta atender en la Comunitat Valenciana- o la inserción o reinserción social.

\section{Bibliografía}

Aguilar Hendrickson, M. (2013). Los servicios sociales en la tormenta. Documentación Social. N. ${ }^{\circ} 166.145-167$.

Asociación Estatal de Directoras y Gerentes de Servicios Sociales. (2014). Los Servicios Sociales en España 2014. Madrid. Asociación de Directores y Gerentes.

Asociación Estatal de Directoras y Gerentes de Servicios Sociales. (2013). Índice DEC 2013. http://www.directoressociales.com/images/documentos/idec\%20 07.06.2013.pdf. (Consultado el 21/2/2015)

Belis, V. y Moreno, A. (2002). Evolución del sistema de servicios sociales en la comunidad valenciana. Arxius de Ciències Socials, 11, 8-29.

Carbonero Gamundí, M.A. y Caro Blanco, F. (2013). Huellas, principios y propuestas para el Sistema Público de Servicios Sociales en un contexto de crisis. Documentación Social $n .^{\circ} 170.121-142$.

Casado, D. y Fantova, F. (2007). Perfeccionamiento de los Servicios Sociales en España. Fundación FOESSA. Madrid

DOMÉNECH PASTOR, M. y GARCía RocA, J. (1990). Presentación y desarrollo de la ley. Revista de Servicios Sociales. Generalitat Valenciana, València.

FEMP. Informe sobre Las competencias de los Ayuntamientos en materia de Servicios Sociales tras la entrada en vigor de la Ley 27/2013 de la LRSAL. En http:// www.femp.es/files/3580-836-fichero/LAS\%20COMPETENCIAS\%20EN\%20 MATERIA\%20DE\%20SERVICIOS\%20SOCIALES\%20TRAS\%20LA\%20 ENTRADA\%20EN\%20VIGOR\%20DE\%20LA\%20LRSAL.pdf (consultado el 16/6/2014).

García Herrero, G. (coord.). (2007). Las nuevas Leyes de Servicios Sociales. Criterios para valorar su elaboración o sus contenidos. Asociación de Gerentes y Directoras de Servicios Sociales. Madrid. En http://www.directoressociales.com/images/LAS\%20NUEVAS\%20LEYES\%20DE\%20SERVICIOS\%20 SOCIALES.pdf (consultado el 4/9/2014).

Índice DEC 2013. Asociación de Gerentes y Directoras de Servicios Sociales En: http://www.directoressociales.com/images/documentos/idec\%2007.06.2013. pdf (consultado 1/9/2014). 
Informe de Rentas Mínimas de Inserción (2011). M. ${ }^{\circ}$ Sanidad, Servicios Sociales e Igualdad. En http://www.eapn.es/ARCHIVO/documentos/recursos/5/ InformeRMI2011.pdf (Consultado el 16/1/2014).

Informe del Ayuntamiento de Zaragoza sobre la aplicación de la LRSAL. En http:// www.zaragoza.es/cont/paginas/noticias/rsal.pdf (Consultado el 16/6/2014).

Informe del Ayuntamiento de Valencia sobre la aplicación de la LRSAL (reservado).

Mira-Perceval, M.T., De Alfonseti, N. y Giménez Bertomeu. V.M. (2007). Servicios Sociales. Estructura, dinámica, políticas y estrategias en España y la Comunidad Valenciana. Universidad de Alicante.

SAntos Martí. J. (2012). El cuarto Pilar. Un nuevo relato para los Servicios Sociales. Paraninfo. Madrid.

UCEDA I MAZA, F.X. (2011). Los Servicios Sociales en España: desarrollo y articulación en los nuevos escenarios. Documentación Social n. ${ }^{\circ}$ 162. 235-258.

Uceda i Maza, F.X., Pitarch Garrido, M.D., Pérez-Cosín, J.V. y Rosaleny CASTEll, R. (2012). La evolución de la estructura básica de los Servicios Sociales en la Comunitat Valenciana. Treinta años en el área metropolitana de Valencia. Revista Arxius, n. $^{\circ}$ 27. 83-100.

Vilà MANCEBO, A. (2012). La nueva generación de leyes autonómicas de servicios sociales (2006-2011): análisis comparativo. Revista Azarbe. n. ${ }^{\circ} 1.143-155$.

\section{Legislación}

Ley 5/2009, de 30 de junio, de Servicios Sociales de Aragón

DECRETO 143/2011, de 14 de junio, del Gobierno de Aragón, por el que se aprueba el Catálogo de Servicios Sociales de la Comunidad Autónoma de Aragón

I Plan estratégico de Ss.Ss de Aragón 2012-15

Árbol de prestaciones del Catálogo de Ss.Ss

DECRETO LEGISLATIVO 1/2006, de 27 de diciembre, del Gobierno de Aragón, Ley de Comarcalización de Aragón.

Ley de Cantabria 2/2007, de 27 de Marzo, de Derechos y Servicios Sociales. Orden EMP/51/2009, de 15 de mayo, por la que se establece el Mapa de Servicios Sociales de Cantabria.

BOC n. ${ }^{\circ} 136$ de 16/7/2009, Resolución aprobando el Plan Estratégico de Servicios Sociales 2008-2011 de la Comunidad Autónoma de Cantabria

Decreto $17 / 1989$, de 7 de abril, por el que se regula la organización y régimen de funcionamiento de los Servicios Sociales Comunitarios en Cantabria 
Ley de Cantabria 3/2009, de 27 de noviembre, de creación del Instituto Cántabro de Servicios Sociales

Ley 16/2010, de 20 de diciembre, de servicios sociales de Castilla y León Decreto 56/2005, aprobación del Plan estratégico de sistema de acción social de Castilla y León

Algunos planes estratégicos provinciales: León, Soria, Salamanca

Ley 14/2010, de 16 de diciembre, de servicios sociales de Castilla-La Mancha Decreto 181/2009, de 01/12/2009, sobre los convenios de colaboración con las Entidades Locales para el desarrollo de las Prestaciones Sociales Básicas de la Red Pública de Servicios Sociales

Decreto 287/2004, de 28 de diciembre, por el que se regula la estructura territorial de las Zonas y Áreas de Servicios Sociales y la estructura funcional del Sistema Público de Servicios Sociales de Castilla-La Mancha

Orden de 30-04-2008, de la Consejería de Bienestar Social, por la que se establecen las bases reguladoras y la convocatoria de subvenciones en el ámbito del Programa Regional de Acción Social, para la financiación de las Prestaciones Sociales Básicas de la Red Pública de Servicios Sociales en Castilla-La Mancha

Ley 13/2008, de 3 de diciembre, de servicios sociales de Galicia

Decreto 99/2012, de 16 de marzo, por el que se regulan los servicios sociales comunitarios y su financiación

Decreto 40/2014, de 20 de marzo, por el que se crea la Agencia Gallega de Servicios Sociales y se aprueban sus estatutos

Ley 4/2009, Servicios Sociales de las Illes Balears

Ley 4/1999de Inspección en materia de Ser.Soc

Ley 14/2001, de 29 de octubre, de atribución de competencias a los Consejos Insulares en materia de Servicios Sociales y Seguridad Social.

Decreto 48/2011, de 13 de mayo por el que se regulan los principios generales y las directrices de coordinación de los servicios sociales comunitarios básicos Decret 56/2011, Cartera Bàsica de Serveis Socials de les Illes Balears 2011-2014 Ordre de la consellera d'Afers Socials, de 8 de febrer de 2011 per la qual s'estableix el catàleg de serveis socials d'àmbit suprainsular de les Illes Balears Análisis del Plan de Prestaciones Básicas 2011. 
Decreto 66/1999, Reglamento Regulador del Sistema Balear de Servicios Sociales

Decreto 62/2010, la composición, el funcionamiento y las atribuciones del Comité de Ética de Servicios Sociales

Decreto 61/2010, la composición, la organización y el funcionamiento del Consejo de Servicios Sociales de las Illes Balears

Decret 97/2009, Consell de Coordinació de Benestar Social de les Illes Balears Plan estratégico de Mallorca 2010/13

Ley 7/2009, de 22 de diciembre, de Servicios Sociales de La Rioja Ley 3/2007, de 1 de marzo, de Calidad de los Servicios Sociales

Decreto 51/2010, de 12 de noviembre, por el que se regula el Consejo Riojano de Servicios Sociales

Decreto 31/2011, de 29 de abril, por el que se aprueba la Cartera de servicios y prestaciones del Sistema Público Riojano de Servicios Sociales

Memoria 2012. Dirección General de Servicios Sociales

Ley Foral 15/2006, de 14 de diciembre, de Servicios Sociales de Navarra

Decreto foral 33/2010 de la zonificación de Ser. Soc de Navarra

Decreto foral 32/2013 reglamento desarrollo de Programas y Financiación de los Servicios Sociales de Base. Tramo fijo

Orden foral 618/2013 se aprueba forma de medir el tramo variable de financiación de los Ser. Soc

Decreto foral 69/2008, cartera de Servicios Sociales y Cartera actualizada a 2012 (hoja interactiva de la web

Orden foral 260/2010, plan de Calidad Ss.Ss 2010-13

Documento base para Plan atención Comunitaria de los Servicios Sociales de Base

Plan estratégico Ser. Soc 2008-12

Ley 12/2008, de 5 de diciembre, de Servicios Sociales de Euskadi

Decreto 64/2004, de 6 de abril, Carta de derechos y obligaciones de usuarios y profesionales de los Ss. Ss en Euskadi.

Ley 10/2000, de 27 de diciembre, de Carta de Derechos Sociales.

Plan estratégico de Ser. Soc. de Euskadi 2011/14

Decreto 124/2006, de 13 de junio, del Consejo Vasco de Bienestar Social 
Mapa y Memoria económica de Ser. Soc. de Euskadi 2012

II Informe Consejo Vasco Ser. Soc. 2012.

Informe del Ararteko sobre los Ser. Soc. 2010

Ley 12/2007, de 11 de octubre, de Servicios Sociales, de Catalunya.

Ley 13/2006, de prestacions socials de caràcter econòmic

Decreto 202/2009, dels òrgans de participació i de coordinació del Sistema Català de Serveis Socials

Recomendaciones para la creación de los Consejos Territoriales y Locales

Decreto 142/2010, s'aprova la Cartera de Serveis Socials 2010-2011.(aún en vigor)

Orden ASC/349/2010, de 16 de juny, del Comitè d'Ètica dels Serveis Socials de Catalunya.

Plan Estratégico 2010/13

Plan Calidad 2010/13

El estado de los Ser. Soc. en Catalunya 2010/13

Ley 5/1997, Sistema de Servicios Sociales Comunidad Valenciana

Orden de 9 de abril de 1990, de la Consellería de Treball i Seguretat Social (explicación de programas Ss.Ss. generales y recursos especializados)

Decreto 90/2002, control de la calidad de los centros y servicios de acción social y entidades evaluadoras de la misma, en la Comunidad Valenciana

Ley 4/2012, Carta de Derechos Sociales de la Comunitat Valenciana. 



\title{
VALIDACIÓN DEL CUESTIONARIO DE ACTITUDES ANTE LAS INTERVENCIONES ASISTIDAS POR PERROS (CAINTAP) EN ESTUDIANTES UNIVERSITARIOS DEL SUR DE ESPAÑA: BENEFICIOS Y TEMORES PERCIBIDOS
}

\author{
Validation of the Questionnaire on Attitudes Towards Dog Assisted \\ Interventions (CAINTAP) among Southern Spanish college students: \\ perceived benefits and fears
}

\author{
Dr. Javier López-Cepero Borrego ${ }^{1,2}$, D. $^{a}$ María A. Perea-Mediavilla ${ }^{2,3}$, \\ D. ArCadio Tejada Roldán ${ }^{2}$, Dr. José Luis SARASOla-SÁnCHEZ-SERRANO ${ }^{3}$
}

\begin{abstract}
Resumen
Introducción: Las intervenciones asistidas por animales (IAA) cuentan con amplia tradición en varios países occidentales, donde diversas revisiones y meta-análisis han demostrado sus ventajas. No obstante, poco se sabe de las expectativas que los y las hispanohablantes mantienen al respecto. El presente estudio aporta una herramienta de evaluación sobre las actitudes hacia IAA. Material y métodos: un total de 474 estudiantes universitarios con edades de $X=22,7$ años $(d t=5,61)$, en su mayoría mujeres ( $80 \%)$, tomaron parte del estudio. El equipo de investigación desarrolló un instrumento de evaluación denominado Cuestionario sobre Actitudes hacia las Intervenciones Asistidas por Perros (CAINTAP). Resultados: el análisis factorial exploratorio retuvo 20 ítems en dos factores, etiquetados como Actitudes Positivas ( $\mathrm{N}=11)$ y Actitudes Negativas $(\mathrm{N}=9)$, ambos con alphas $>0,87$. El alumnado refirió mantener buenas expectativas hacia las IAA, mientras que los temores con mayor presencia correspondieron a comportamientos fácilmente modificables mediante adiestramiento. Discusión: este estudio aporta datos psicométricos del primer instrumento de evaluación sobre IAA en español, herramienta de utilidad para anticipar dificultades en centros en los que se desee llevar a cabo programas de intervención con perros.
\end{abstract}

Palabras clave: Intervenciones asistidas por animales, terapia asistida por animales, actividades asistidas por animales, estudiantes universitarios.

\begin{abstract}
Introduction: animal-assisted interventions (AAI) have a long tradition in some western countries, with many reviews and meta-analyses demonstrating their benefits, but little is known about expectations held by Spanish-speakers. This study develops an assessment tool, and provides empirical data on perceived opportunities and dangers. Methods: A total of $474 \mathrm{col}-$ lege students (aged $X=22.7$; $S D=5.61$ years), mostly women $(80 \%)$, took part in the study. Researchers developed the Questionnaire on Attitudes Towards Dogs Assisted Interventions (CAINTAP), which was then validated. Results: Exploratory factor analysis revealed a two-factor structure which retained 20 items, scales being coined Positive Attitudes $(\mathrm{N}=11)$ and Negative Attitudes $(\mathrm{N}=9)$, both with alphas greater than 0.87 . The students demonstrated good expectations for IAA, while the most frequent fears were related to easily modifiable behaviors. Discussion: This study provides psychometric data of the first questionnaire on IAA developed in Spanish, a useful tool that might help to anticipate difficulties regarding intervention with dogs.
\end{abstract}

Keywords: Animal-assisted interventions, animalassisted therapy, animal-assisted activities, college students.

1. Departamento de Personalidad, Evaluación y Tratamientos Psicológicos. Facultad de Psicología, Universidad de Sevilla. C/ Camilo José Cela, s/n. CP 41018, Sevilla. Teléfono: +34 954557801. E-mail: jalocebo@us.es. E-mails coautores: D. ${ }^{a}$ María A. Perea Mediavilla: manpermed@gmail. com, D. Arcadio Tejada Roldán: infointap@gmail.com, Dr. José Luis Sarasola-Sánchez-Serrano: jlsarsan@us.es.

2. INTAP.-Asociación Nacional de Intervenciones Asistidas por Perros y otros animales.

3. Universidad Pablo de Olavide. 


\section{Introducción}

Las intervenciones asistidas (IAA) se caracterizan por la introducción de animales como complemento a diversas disciplinas sociosanitarias y educativas (Hart, 2010). Estas intervenciones están recibiendo una atención creciente a nivel internacional, como demuestra el auge en el número de publicaciones científicas (López-Cepero et al., 2014) y la inclusión de descriptores específicos dentro de los Tesauros de bases de datos internacionales (como PsycINFO, que incluyó Animal-Assisted Therapy a mediados de 2013).

Aunque los animales han sido introducidos como facilitadores del cambio en diversos ámbitos desde el siglo XVIII (Serpell, 2010), la literatura recoge una amplia amalgama de términos y conceptos referentes a las IAA (Kruger y Serpell, 2010) que son utilizados de manera inconsistente (López-Cepero et al., 2012). No obstante, la propuesta que mayor arraigo ha conseguido hasta el momento entre las personas dedicadas a las IAA es la aportada por Pet Partners, entidad estadounidense anteriormente conocida como Delta Society, que distingue las actividades asistidas (encuentros puntuales que incluyen un animal, sin objetivos específicos más allá del propio ocio, y entre los cuales se contempla la educación asistida) y las terapias asistidas (que cuentan con diseño, programación y evaluación del cambio asimilables a cualquier otra terapia) (Pet Partners, sin fecha.) De todos los animales domésticos y de granja utilizados en las IAA, el perro es el que mayor presencia tiene en la literatura científica (Marino, 2012; Nimer y Lundhal, 2007; Perkins et al., 2008).

La interacción humano-animal ha sido empíricamente asociada a diversos efectos salutógenos, derivados tanto de la convivencia con el animal como mascota como de programas de intervención asistida (terapia, actividades, educación...). Entre los beneficios de la convivencia, por ejemplo, Virués-Ortega y Buela-Casal (2006) destacan la menor tasa cardiaca y mayor resistencia al estrés agudo de las personas que cuentan con mascotas, que podrían ser explicadas bien por la percepción de ser compañeros que no juzgan ni evalúan a sus dueños, bien por asociación condicionada con situaciones placenteras; en la misma línea, Barker y Wolen (2008) destacan la mayor tasa de supervivencia y adherencia a la rehabilitación en pacientes cardiópatas y la reducción de sintomatología depresiva, entre otros; por su parte Beetz, Uvnäs-Moberg, Julius y Kotrschal (2012) identifican la segregación de oxitocina como mediadora de los beneficios fisiológicos, sociales y de calidad de vida derivados de la IHA.

En cuanto a los beneficios obtenidos a través de programas de intervención asistida, la literatura ofrece diversos meta-análisis que recopilan resultados derivados de programas implementados en distintos colectivos. Nimer 
y col. (2007) analizaron 49 intervenciones de terapia asistida, encontrando evidencias de efectividad moderada en cuatro áreas de trabajo (trastornos del espectro autista, trastornos de conducta, bienestar emocional y problemas médicos); por su parte, Halm (2008) llevó a cabo un análisis centrado en intervenciones en ámbito hospitalario, encontrando hasta diez estudios que fueron clasificados de adecuados hasta totalmente recomendables por sus efectos positivos; en un tercer meta-análisis, Souter y Miller (2007), encontraron una relación significativa entre la participación en intervenciones asistidas y la mejora en pacientes diagnosticados de depresión mayor, diferencias que alcanzaron un tamaño de efecto medio en cinco estudios desarrollados con muestras estadounidenses. Revisiones bibliográficas como las realizadas por Filan y Llewellyn-Jones (2006), Perkins et al. (2008) o Steed y Smith (2002) también han destacado diversas ventajas aportadas por las intervenciones asistidas en personas mayores o con demencia. Por otra parte, Marino (2012) señala que un alto porcentaje de los estudios que ofrecen datos sobre la efectividad de las IAA incluyen debilidades metodológicas que pueden restar confiabilidad a sus conclusiones, si bien destaca que aquellos que sí incluyeron un control de los posibles sesgos (tales que el efecto placebo, efecto recencia, confusión conceptual, etc.) han encontrado efectos positivos de tamaño moderado derivados de las IAA, conclusión que coincide con lo apuntado por Nimer y col. (2007) y Souter y col. (2007).

A pesar de las evidencias a favor del uso de las IAA en distintos contextos, la literatura describe la ausencia de formación reglada durante los estudios de grado de disciplinas como Psicología, Medicina o Trabajo Social (Berget, Grepperud, Aasland y Braastad, 2013; Black, Chur-Hansen y Winefield, 2011; Risley-Curtiss, 2010), elemento que dificulta su inclusión durante el ejercicio profesional.

Varios estudios previos han analizado las actitudes de los profesionales hacia las intervenciones asistidas por animales. Ferrese, Forster, Kowalski y Wasilewski (1998; citado en Velde, Cipriani y Fisher, 2005) realizaron un análisis de las narraciones ofrecidas por terapeutas ocupacionales norteamericanos, destacando sus expectativas positivas en hasta siete áreas (aumento de motivación, beneficios físicos de la interacción, mejoras en el nivel de atención, mejoras del estado de ánimo, mejoras en la interacción social, ofrecer oportunidad de cuidar y crear un ambiente más similar al hogar). En una segunda experiencia, Black et al. (2011) llevaron a cabo entrevistas en profundidad a nueve psicólogos, concluyendo que las expectativas mezclaron tanto aspectos positivos (se esperaron mejoras en la relación terapéutica y en los resultados de la intervención) como negativos (temores ante la imprevisibilidad 
de los animales o la falta de apoyo de centros e instituciones) hacia las intervenciones asistidas.

Por otra parte, la literatura también incluye algunos estudios cuantitativos. Berget, Ekeberg y Braastad (2008) encontraron que dos tercios de una muestra de profesionales dedicados al cuidado psiquiátrico (médicos, psicólogos, enfermeros, etc.) consideraron que la inclusión de animales de granja podía mejorar la interacción entre terapeutas y pacientes, presentando mejores expectativas que hacia otras aproximaciones tradicionales de mayor arraigo. Berget y Grepperud (2011) concluyeron que entre un 55\% y un $87 \%$ de profesionales del ámbito psiquiátrico (sobre un total de 500 participantes) percibieron de alguna o mucha utilidad el uso de animales en el tratamiento de distintos trastornos mentales. En un trabajo posterior, Berget et al. (2013) cifraron en un $88 \%$ el porcentaje de que consideró necesario utilizar animales en las intervenciones con población psiquiátrica. Estos tres trabajos fueron realizados con muestras provenientes de Noruega. Por otra parte, en Australia, Moody, King y O'Rourke (2002) presentaron resultados derivados de la aplicación del Brisbane Animal Assisted Therapy Acceptability Test (BAATAT), único instrumento de evaluación de las actitudes ante las IAA localizado por nuestro equipo de investigación en la literatura, a los trabajadores de un ala pediátrica. Estos autores encontraron un alto nivel de acuerdo con las expectativas positivas antes de la implementación del programa de visitas, así como un descenso de las expectativas negativas después de la realización de dicha intervención.

En cuanto a las variables personales que pueden influir sobre la actitudes hacia las IAA, sólo el sexo del respondiente contó con apoyo empírico en la literatura previa, en la que son descritas expectativas más positivas en mujeres que en varones (Berget et al., 2008; Berget y col., 2011). Otras variables de interés estudiadas, como la experiencia con animales domésticos y/o de granja, la experiencia en intervenciones asistidas, el interés por participar en IAA o la profesión desempeñada no han mostrado una relación consistente en la literatura previa (Berget y col., 2011; López-Cepero, Perea-Mediavilla, Sarasola y Tejada, 2015; Moody et al., 2002; Perea-Mediavilla, López-Cepero, Tejada y Sarasola, 2014).

El presente trabajo se marca como objetivo ofrecer una evaluación cuantitativa de las actitudes hacia las IAA mantenidas por estudiantes universitarios de distintas Universidades Públicas de Andalucía Occidental. Para ello, se propone llevar a cabo la validación del Cuestionario de Actitudes ante las Intervenciones Asistidas por Perros (CAINTAP), ofreciendo datos acerca de su validez estructural, fiabilidad y validez concurrente. En un segundo 
momento, identificará las expectativas mantenidas por los estudiantes, ofreciendo información que pueda servir como guía para dar respuesta a los temores con mayor presencia entre los futuros profesionales.

\section{Método}

Participantes. El presente estudio contó con 474 estudiantes que se hallaron cursando estudios universitarios $(85,7 \%$ en grado o licenciatura; $14,3 \%$ en cursos de postgrado) de carácter presencial en las provincias de Huelva (19,0\% provenientes de la Universidad de Huelva) y Sevilla (34,7\% de la U. Pablo de Olavide y $46,3 \%$ de la U. de Sevilla). Un 50,8\% (N=251) de los participantes cursaron planes de estudios clasificados como Ciencias Sociales (Ciencias de la Educación, Trabajo Social, Educación Social, Sociología y Ciencias Políticas) y un 49,2\% ( $N=233$ ) lo hicieron en Ciencias de la Salud (Psicología y Enfermería). Por sexos, un 20,5\% refirió ser varón frente a un 79,5\% de mujeres (como punto de referencia, señalar que el Instituto Nacional de Estadística recogió en su último informe disponible, para el alumnado de nuevo ingreso del curso 2010-2011, que las mujeres representaron el 73,5\% en la rama de Ciencias de la Salud y el 60,6\% en Ciencias Sociales y Jurídicas en las tres universidades indicadas). La media de edad para el total de la muestra fue de 22,7 años $(\mathrm{dt}=5,61)$. Un 89,9\% de los participantes indicó no haber realizado ningún trabajo remunerado. Todos fueron mayores de edad y recibieron información sobre la voluntariedad de su participación. Una vez informados de los objetivos del estudio, se solicitó su asentimiento para participar, indicando datos de contacto del equipo investigador para atender dudas o preguntas que pudieran presentarse con posterioridad a la evaluación.

Instrumentos. La recogida de datos se realizó mediante la aplicación de tres formularios, presentados en un mismo documento. En primer lugar, fue incluida una hoja de variables sociodemográficas y educativas, en la que se solicitó información sobre el sexo, edad, estudios realizados y experiencia laboral del respondiente, a consignar en casilleros creados a tal efecto. En segundo lugar, se habilitó un apartado en el que describir la experiencia con animales de compañía (si existió y, en caso afirmativo, si fue positiva) y el interés por las aplicaciones de las IAA (si existió, si se poseyó formación o si se consideró de interés para la labor profesional, entre otras). Estos reactivos fueron respondidos marcando Sí/No en la hoja de respuestas.

El tercer formulario fue el Cuestionario de Actitudes ante las Intervenciones Asistidas por Perros (CAINTAP). Esta herramienta fue creada a través de una revisión de la literatura previa (ver Anderson, 2007; Wilson y Netting, 2012) 
y del Brisbane Animal Assisted Therapy Acceptance Test (BAATAT; Moody, King y O'Rourke, 2002). Dada la similitud entre varios ítems creados por el equipo de investigación para el presente trabajo y el BAATAT, se optó por incluir adaptaciones de 18 de los 21 elementos originales del instrumento de Moody et al. (2002), que fueron modificados para ser aplicables a diversos colectivos profesionales, y fueron incluidos 4 indicadores de nueva creación. Los 22 ítems resultantes evaluaron las expectativas de los participantes hacia cuestiones positivas (la intervención asistida beneficiará a la imagen del centro, los perros distraerán a las personas de sus preocupaciones) y negativas (los perros van a ladrar en el centro, los perros pueden ser una molestia para las personas que no participen de la intervención). Estos fueron respondidos usando una escala de cinco niveles de acuerdo, con valores comprendidos entre 1 (muy en desacuerdo) y 5 (muy de acuerdo) (ver Anexo).

Procedimiento. Se solicitó la colaboración de 19 docentes e investigadores, siguiendo un criterio de oportunidad, para que facilitaran el acceso a sus clases durante las últimas dos semanas del curso 2012-2013. 15 accedieron a participar, proporcionando acceso a 21 clases impartidas en 13 títulos diferentes. Un miembro del equipo se desplazó a cada una de estas clases para explicar los objetivos del estudio, asegurar la comprensión de las instrucciones y administrar las copias impresas. Se hizo constar la voluntariedad de la participación y fueron proporcionados datos de contacto del equipo de investigación.

Dadas las similitudes entre varios de los ítems extraídos de la literatura previa y el BAATAT, se optó por partir del instrumento de Moody et al. (2002), a fin de obtener información comparable con el trabajo original. Se llevó a cabo la traducción al español y una adaptación de contenidos que permitió ser de aplicación tanto a profesionales como a estudiantes, con independencia tanto del tipo de IAA (el original era de aplicación sólo a programas de visitas) como del colectivo con que se trabaje (no sólo en el área pediátrica). Tres ítems fueron eliminados ante la imposibilidad de aplicarlos fuera del contexto pediátrico, siendo sustituidos por nuevos elementos aplicables a diversos contextos de intervención. Los 22 ítems resultantes fueron administrados a varios colaboradores del equipo investigador a fin de comprobar y corregir posibles dificultades de redacción.

En el apartado estadístico fueron realizados procedimientos descriptivos (frecuencia, medidas de tendencia central, medidas de dispersión y análisis de distribución), análisis factorial exploratorio (extracción de componentes principales con autovalores mayores de 1, rotación Varimax), análisis de fiabilidad (alpha de Cronbach $>0,700$ ) correlaciones bivariadas ( $r$ de Pearson) y 
comparación de medias (prueba T de Student para muestras independientes). Estos procedimientos se realizaron a través del software SPSS, versión 20, utilizando un valor de significación de $p<0,05$. También se calculó el tamaño de efecto (TE) de las diferencias de medias, obtenido a través del valor resultante de dividir el valor absoluto de la diferencia de las medias de cada grupo entre la desviación típica del total de la muestra $[|X \mathrm{i}-X \mathrm{j}| / \sigma]$, considerándose para su valoración las orientaciones propuestas por Cohen (1988): tamaño de efecto pequeño para valores comprendidos $\geq 0,20 \mathrm{y}<0,50$; efecto moderado para valores $\geq 0,50$ y $<0,80$; y efecto grande para valores $\geq 0,80$.

\section{Resultados (I). Validación del CAINTAP.}

Validez Estructural. El análisis factorial exploratorio contó con una adecuación muestral suficiente (KMO=0,910; Esfericidad de Bartlett $p<0,000)$, ofreciendo una solución rotada con cuatro grupos de ítems (ver tabla 1). En total, la varianza explicada fue ligeramente inferior al $59 \%$. Una vez estudiada la matriz de la solución factorial, el equipo de investigación decidió retener sólo los dos primeros componentes, dada la diferencia en la varianza explicada (los dos primeros explicaron en torno al triple de varianza que los dos últimos) y el bajo número de reactivos contenidos en los factores $3 .^{\circ}$ y $4 .^{\circ}$

Dos ítems (numerados como 5 y 22) obtuvieron una saturación superior a 0,300 en ambos factores, por lo que el equipo investigador los asignó a la escala en la que presentaron mayor valor (dado que el reactivo 5 saturó negativamente, su puntuación aparece invertida en todos los cálculos realizados desde este punto en adelante). En total, 20 de los 22 ítems fueron retenidos en esta solución de dos factores, que fueron etiquetados como actitudes positivas hacia las IAA (factor 1) y actitudes negativas hacia las IAA (factor 2), respectivamente. La correlación entre ambos fue de $r=-0,468\left({ }^{* * *} p<0,001\right)$.

Fiabilidad. El índice alpha de Cronbach obtenido fue de 0,879 para la escala de Actitudes Positivas hacia las IAA (una vez invertido el valor del ítem 5) y de 0,884 para el factor de Actitudes Negativas hacia las IAA. Ninguno de estos valores mejoró por la exclusión de ítems. El valor de alpha para el total de 20 ítems fue de 0,658.

Validez concurrente. El análisis de la distribución de los dos factores identificados mostró un ajuste pobre a la curva normal en ambos casos, con valores $p<0,01$ o inferiores en las pruebas de Kolmogorov-Smirnov y Shapiro-Wilks, lo que justificó el uso de pruebas resistentes a esta situación en la comparación de medias obtenidas en el CAINTAP. 
Tabla 1. Solución factorial rotada (saturaciones $>0,300$ ) y varianza explicada. Entre paréntesis, valores de saturación de los ítems eliminados de cada escala por el equipo investigador

\begin{tabular}{|l|c|c|c|c|c|c|}
\hline \multirow{2}{*}{ Ítem (extracto) } & \multicolumn{3}{|c|}{ Factor } & \multirow{2}{*}{ X } & \multicolumn{1}{c|}{$\mathrm{dt}$} \\
\cline { 2 - 6 } & 1 & 2 & 3 & 4 & & \\
\hline 19. Actividad valiosa &, 827 & & & & 4,10 &, 937 \\
\hline 14. Residencia feliz &, 811 & & & & 4,13 &, 859 \\
\hline 16. Sitio más interesante &, 760 & & & & 4,07 &, 905 \\
\hline 21. Interés participantes &, 732 & & & & 4,23 &, 788 \\
\hline 18. Relax profesionales &, 680 & & & & 3,68 & 1,099 \\
\hline 10. Relax participantes &, 677 & & & & 4,11 &, 864 \\
\hline 13. Acuerdo profesionales &, 644 & & $(-, 335)$ & & 3,51 &, 994 \\
\hline 20. Familiares de acuerdo &, 620 & & $(-, 315)$ & & 3,34 &, 976 \\
\hline 4. Imagen del centro &, 616 & & & $(, 387)$ & 3,90 &, 940 \\
\hline 5. No es lugar adecuado* &,- 516 & $(, 389)$ & & & 2,32 & 1,194 \\
\hline 2. Menos carga de trabajo &, 406 & & & $(-, 342)$ & 2,46 & 1,087 \\
\hline 11. Pulgas/garrapatas & &, 863 & & & 2,26 & 1,221 \\
\hline 12. Infecciones & &, 856 & & & 2,19 & 1,156 \\
\hline 9. Morder & &, 821 & & & 2,24 & 1,159 \\
\hline 17. Arañar & &, 766 & & & 2,62 & 1,170 \\
\hline 15. Dañar instrumental & &, 718 & & & 2,72 & 1,184 \\
\hline 22. Molestia no participantes & $(-, 333)$ &, 469 & $(, 352)$ & & 3,02 & 1,141 \\
\hline 7. Alergias & & &, 766 & & 3,76 & 1,008 \\
\hline 6. Problemas respiratorios & &, 334 &, 721 & & 3,10 & 1,145 \\
\hline 1. Ladrar & &, 390 & &, 714 & 3,42 & 1,146 \\
\hline 3. Orinar/defecar &, 463 & &, 674 & 3,21 & 1,303 \\
\hline 8. Distraer de preocupaciones & & & &, 367 & 3,66 & 1,287 \\
\hline Varianza explicada & $23,96 \%$ & $20,03 \%$ & $7,61 \%$ & $7,30 \%$ & & \\
\hline
\end{tabular}

*El ítem 5 saturó de manera inversa en el factor 1.

El primer contraste realizado comparó las medias obtenidas en los dos factores propuestos para el CAINTAP según la variable sexo del respondiente. Las puntuaciones obtenidas por las mujeres participantes fueron descriptivamente superiores en la escala de actitudes positivas, mientras que las medias para el factor de actitudes negativas se distanciaron en menos de una 
Tabla 2. Actitudes ante las IAA en varones y mujeres. Se incluyen datos descriptivos, prueba de Levene para igualdad de varianzas y prueba T para igualdad de medias

\begin{tabular}{|l|l|r|c|c|c|c|c|c|c|c|}
\hline \multicolumn{2}{|c|}{ Sexo } & \multicolumn{4}{|c|}{ Descriptivos } & \multicolumn{2}{c|}{$\begin{array}{c}\text { Igualdad } \\
\text { var. }\end{array}$} & \multicolumn{3}{c|}{ Prueba T } \\
\cline { 3 - 12 } \multicolumn{2}{|c|}{} & \multicolumn{1}{|c|}{$\mathrm{N}$} & $X$ & $\mathrm{dt}$ & $\mathrm{e}_{\mathrm{t}}$ & $\mathrm{F}$ & $p$ & $t$ & $\mathrm{gl}$ & $p$ \\
\hline \multirow{2}{*}{ Act. Positiva } & Hombre & 93 & 40,56 & 6,83 & 0,71 &, 171 &, 679 & $-1,104$ & 457 &, 270 \\
\cline { 2 - 12 } & Mujer & 366 & 41,48 & 7,28 & 0,38 & & & & & \\
\hline Act. Negativa & Hombre & 95 & 24,72 & 6,95 & 0,71 & 2,678 &, 102 &,- 110 & 461 &, 913 \\
\cline { 2 - 11 } & Mujer & 368 & 24,81 & 7,82 & 0,41 & & & & & \\
\hline
\end{tabular}

centésima de punto. Ninguna de estas diferencias alcanzó significatividad estadística en el contraste T de Student (tabla 2).

La segunda variable cualitativa seleccionada fue el interés por incluir programas de IAA en el contexto laboral del respondiente. De media, las personas que indicaron tener interés por esta modalidad de intervención mostraron actitudes más favorables ante las IAA. Estas diferencias alcanzaron un nivel de significación estadística de $p<0,001$ para ambas escalas del CAINTAP (tabla 3). Tomando como referencia la media y desviación típica halladas para ambos factores (Actitudes Positivas: $X=41,29 ; \mathrm{dt}=7,19$ / Actitudes Negativas: $X=24,79$; $\mathrm{dt}=7,64$ ), el tamaño de efecto para ambos contrastes fue grande (Cohen, 1988).

Tabla 3. Actitudes ante las IAA según interés mostrado por incluir programas de IAA en contexto laboral. Se incluyen datos descriptivos, prueba de Levene para igualdad de varianzas, prueba $\mathrm{T}$ para igualdad de medias y tamaño de efecto

\begin{tabular}{|c|c|c|c|c|c|c|c|c|c|c|c|}
\hline \multirow{2}{*}{\multicolumn{2}{|c|}{$\begin{array}{c}\text { ¿Interés en la } \\
\text { IAA? }\end{array}$}} & \multicolumn{4}{|c|}{ Descriptivos } & \multicolumn{2}{|c|}{$\begin{array}{l}\text { Igualdad } \\
\text { var. }\end{array}$} & \multicolumn{3}{|c|}{ Prueba T } & \multirow[t]{2}{*}{ TE } \\
\hline & & \multirow{2}{*}{$\frac{\mathrm{N}}{401}$} & \multirow{2}{*}{$\frac{X}{42,50}$} & \multirow{2}{*}{$\frac{\mathrm{dt}}{6,14}$} & \multirow{2}{*}{$\frac{e_{t}}{0,31}$} & \multirow{2}{*}{$\frac{F}{2,106}$} & \multirow{2}{*}{$\frac{p}{, 147}$} & \multirow{2}{*}{$\frac{t}{11,390}$} & \multirow{2}{*}{$\frac{\mathrm{gl}}{448}$} & \multirow{2}{*}{$\frac{p}{, 000 * * *}$} & \\
\hline Act. Positiva & Sí & & & & & & & & & & 1,52 \\
\hline & No & 49 & 31,57 & 7,81 & 1,12 & & & & & & \\
\hline \multirow{2}{*}{$\begin{array}{l}\text { A c t t } \\
\text { Negativa }\end{array}$} & Sí & 403 & 24,10 & 7,35 & 0,37 & ,036 & 849 & $-5,522$ & 452 &, $000 * * *$ & 0,80 \\
\hline & No & 51 & 30,18 & 7,79 & 1,09 & & & & & & \\
\hline
\end{tabular}

$* * * p<0,001$

Alternativas. Cuadernos de Trabajo Social, 22, 2015, pp. 123-138 - ISSN 1133-0473 DOI: 10.14198/ALTERN2015.22.07 
Tabla 4. Actitudes ante las IAA según si el respondiente ha convivido con mascotas. Se incluyen datos descriptivos, prueba de Levene para igualdad de varianzas, prueba $\mathrm{T}$ para igualdad de medias y tamaño de efecto

\begin{tabular}{|c|c|c|c|c|c|c|c|c|c|c|c|}
\hline \multirow{2}{*}{\multicolumn{2}{|c|}{ ¿Mascota? }} & \multicolumn{4}{|c|}{ Descriptivos } & \multicolumn{2}{|c|}{$\begin{array}{l}\text { Igualdad } \\
\text { var. }\end{array}$} & \multicolumn{3}{|c|}{ Prueba T } & \multirow{3}{*}{$\begin{array}{c}\text { TE } \\
0,51\end{array}$} \\
\hline & & \multirow{2}{*}{$\frac{\mathrm{N}}{401}$} & \multirow{2}{*}{\begin{tabular}{|c|}
$X$ \\
41,76
\end{tabular}} & \multirow{2}{*}{$\frac{\mathrm{dt}}{7,00}$} & \multirow{2}{*}{$\frac{e_{t}}{0,35}$} & \multirow{2}{*}{\begin{tabular}{c|}
$F$ \\
927
\end{tabular}} & \multirow{2}{*}{$\frac{p}{336}$} & \multirow{2}{*}{$\frac{t}{-3,704}$} & \multirow{2}{*}{$\frac{\mathrm{gl}}{457}$} & \multirow{2}{*}{$\frac{p}{, 000^{* * *}}$} & \\
\hline Act. Positiva & Sí & & & & & & & & & & \\
\hline & No & 58 & 38,07 & 7,70 & 1,01 & & & & & & \\
\hline \multirow[t]{2}{*}{ Act. Negativa } & Sí & 405 & 24,24 & 7,54 & 0,37 & ,151 & ,697 & 4,187 & 461 &, $000 * * *$ & 0,60 \\
\hline & No & 58 & 28,66 & 7,31 & 0,96 & & & & & & \\
\hline
\end{tabular}

${ }^{* * *} p<0,001$

En tercer lugar, fueron comparadas las actitudes de los respondientes que informaron haber convivido con mascotas en algún momento de la vida y quienes refirieron no haber tenido animales domésticos a cargo. Las personas con experiencia en la convivencia con animales no humanos mostraron actitudes más favorables ante las IAA, diferencias que alcanzaron significación estadística $(p<0,001)$ en las dos escalas del CAINTAP (tabla 4). El tamaño de efecto para ambos contrastes fue moderado (Cohen, 1988).

\section{Resultados (II). Expectativas más frecuentes en torno a las IAA.}

La media obtenida en el total de la muestra para la escala de actitudes positivas ante las IAA fue de 41,3 puntos, siendo estadísticamente superior al punto medio esperado por azar ( $p<0,001$; ver tabla 5$)$. Cinco ítems de esta escala obtuvieron puntuaciones medias superiores a 4 puntos, situándose entre los valores «de acuerdo»y «muy de acuerdo»: «la IAA resultará interesante para los posibles participantes», «la IAA hará del centro un lugar más feliz», «la IAA ayudará a los participantes a relajarse», «este programa será una actividad valiosa para el centro» $\mathrm{y}$ «el centro será un sitio más interesante para trabajar». Entre los diez ítems con medias más altas se encontraron ocho de este factor junto con los dos reactivos eliminados en el análisis factorial exploratorio.

En cuanto a la escala de actitudes negativas ante las IAA, destaca que la media encontrada para el total de la muestra fuera estadísticamente inferior al punto medio teórico ( $p<0,001$; ver tabla 5$)$. Fueron obtenidos datos descriptivos de los ítems de esta escala para el total de la muestra, de las personas que indicaron no tener interés en desarrollar IAA en el futuro, y de las personas que no han tenido nunca una mascota al cargo (ver tabla 6). Los tres grupos 
Tabla 5. Prueba T para las medias de los factores del CAINTAP con respecto al punto medio teórico, producto del número de ítems multiplicado por 3, el valor medio de la escala

\begin{tabular}{|l|c|c|c|c|c|c|c|c|}
\hline & $\mathbf{N}$ & $\begin{array}{c}\text { Valor } \\
\text { prueba }\end{array}$ & $\boldsymbol{X}$ & $\mathrm{dt}$ & $\mathrm{e}_{\mathrm{t}}$ & $\boldsymbol{t}$ & $\mathrm{gl}$ & $\boldsymbol{p}$ \\
\hline Act. Positivas & 459 & 33 & 41,29 & 7,193 &, 336 & 24,706 & 458 &, $000^{* * *}$ \\
\hline $\begin{array}{l}\text { Act. } \\
\text { Negativas }\end{array}$ & 463 & 27 & 24,79 & 7,644 &, 355 & $-6,213$ & 462 &, $000^{* * *}$ \\
\hline
\end{tabular}

Tabla 6. Medias y desviación tipo para los ítems del factor de actitudes negativas del CAINTAP en el total de la muestra y para grupos seleccionados.

\begin{tabular}{|l|c|c|c|c|c|c|}
\hline & \multicolumn{2}{|c|}{$\begin{array}{c}\text { Total muestra } \\
(\mathrm{N}=474)\end{array}$} & \multicolumn{2}{c|}{$\begin{array}{c}\text { No desean IAA } \\
(\mathrm{N}=52)\end{array}$} & \multicolumn{2}{c|}{$\begin{array}{c}\text { Sin mascota } \\
(\mathrm{N}=60)\end{array}$} \\
\hline \multicolumn{1}{|c|}{ Ítem (extracto) } & $X$ & $\mathrm{dt}$ & $X$ & $\mathrm{dt}$ & $X$ & $\mathrm{dt}$ \\
\hline 1. Ladrar & 3,42 & 1,15 & 3,88 & 1,17 & 3,63 & 1,19 \\
\hline 3. Orinar/defecar & 3,21 & 1,30 & 3,55 & 1,33 & 3,55 & 1,30 \\
\hline 6. Problemas respiratorios & 3,10 & 1,15 & 3,61 & 1,20 & 3,60 &, 98 \\
\hline 22. Molestia no participantes & 3,02 & 1,14 & 3,62 & 1,12 & 3,50 & 1,03 \\
\hline 15. Dañar instrumental & 2,72 & 1,18 & 3,40 & 1,14 & 3,13 & 1,13 \\
\hline 17. Arañar & 2,62 & 1,17 & 3,15 & 1,07 & 3,03 & 1,13 \\
\hline 11. Pulgas/garrapatas & 2,26 & 1,22 & 3,06 & 1,26 & 2,75 & 1,32 \\
\hline 9. Morder & 2,24 & 1,16 & 2,84 & 1,24 & 2,80 & 1,26 \\
\hline 12. Infecciones & 2,19 & 1,16 & 3,02 & 1,21 & 2,72 & 1,26 \\
\hline Total escala & 24,79 & 7,64 & 30,18 & 7,79 & 28,66 & 7,31 \\
\hline
\end{tabular}

coincidieron en apuntar como dificultades más probables: «los perros van a ladrar en el centro», "es probable que los perros orinen o defequen en el centro», "puede que los perros empeoren determinados problemas respiratorios» $\mathrm{y}$ «los perros pueden ser una molestia para las personas que no participen en la intervención».

\section{Discusión y conclusiones}

El presente trabajo muestra información de interés sobre actitudes hacia las intervenciones asistidas por animales, aportando datos psicométricos del primer instrumento disponible en español (CAINTAP) e identificando las 
principales virtudes y riesgos percibidos por futuros profesionales de diversos ámbitos sociosanitarios y educativos.

En cuanto a la validación del cuestionario, la solución rotada de cuatro factores guarda ciertos parecidos con la propuesta de Moody et al. (2002). Sin embargo, el cambio en los contenidos y número de ítems incluidos en el CAINTAP, el bajo número de elementos contenidos por las dos últimas escalas y las grandes diferencias en cuanto a varianza explicada justificó la elección de una nueva solución que contuvo sólo dos factores. Esta decisión permitió retener 20 de los 22 ítems propuestos con una varianza explicada del $44 \%$. Por otra parte, los valores de alpha superaron el valor de 0,850 en ambos casos, con un valor de 0,650 para el total del instrumento, siendo estos datos superiores a los descritos por Moody et al. (2002). Estos indicios psicométricos, en combinación con la mayor facilidad para interpretar los resultados obtenidos a través del instrumento, hacen preferible la estructura de dos factores a los cuatro que aparecen en la propuesta original.

El presente trabajo también ofrece los primeros resultados acerca de la relación entre actitudes hacia las IAA y otras variables de interés en muestra española. Con respecto al sexo del respondiente, se encontró que las actitudes hacia las IAA fueron estadísticamente similares entre varones y mujeres, no corroborándose el efecto que dicha variable ha mostrado en trabajos previos (Berget et al., 2008; Berget y col., 2011). Este resultado puede estar mediatizado por la baja proporción de varones en la muestra (en torno a un $20 \%$ del total), si bien también debe plantearse el efecto de las diferencias culturales entre muestras (noruega y española). Sí se han encontrado diferencias actitudinales al comparar medias entre grupos diferenciados por otras dos variables de interés: la utilidad percibida de las IAA para la labor profesional y la experiencia previa con mascotas. A pesar de la ausencia de antecedentes en la literatura, los resultados han apuntado en la dirección esperada (mejores actitudes entre personas que consideran las IAA como un recurso valioso frente a quienes no la consideran, y actitudes más positivas entre quienes han estado al cuidado de mascotas frente a quienes nunca han tenido ninguna), con tamaños de efecto de intermedios a grandes. Estos hallazgos suponen otro apoyo a la validez del CAINTAP.

Por otra parte, el presente trabajo ha permitido extraer conclusiones relevantes acerca de las expectativas que los estudiantes universitarios de diversas ramas y especialidades mantienen acerca de las IAA, si bien el método de muestreo seguido (no probabilístico e inferior al $1 \%$ de la población estudiantil de las universidades implicadas) hace necesario extremar la precaución de cara a generalizar las conclusiones alcanzadas. 
En primer lugar, los resultados destacan que las actitudes hacia este tipo de intervención son positivas. Este hallazgo resulta especialmente relevante si se contrapone al hecho de que no exista formación reglada sobre las IAA en los Estudios de Grado en España, lo que conlleva que los futuros profesionales carezcan en su mayoría de conocimientos basados en la evidencia sobre las posibilidades y limitaciones de las IAA. En segundo lugar, el presente trabajo ha cuantificado y destacado que las actitudes negativas más extendidas, tanto para el total de la muestra como para los grupos seleccionados, corresponden a elementos fácilmente controlables por el equipo de intervención (por ejemplo, temor a que los animales ladren u orinen/defequen en el centro). En este sentido, los resultados presentados pueden servir de guía a los profesionales del área a la hora de orientar la presentación de sus programas, haciendo especial hincapié en los aspectos que suscitan mayores recelos entre los profesionales de distintos ámbitos.

Por todo lo apuntado, el CAINTAP aparece como un recurso valioso para todos los profesionales que deseen evaluar las expectativas que los profesionales del centro mantienen acerca de los programas de IAA. Esta herramienta es capaz de discriminar entre personas que difieren en opiniones y experiencias teóricamente relevantes, al mismo tiempo que ha mostrado adecuados niveles de fiabilidad. Por todo lo expuesto, el CAINTAP se erige como una opción adecuada para evaluar actitudes ante las IAA en contextos de intervención e investigación, llenando el vacío existente de instrumentos validados en nuestro idioma, y aportando diversas ventajas: es aplicable a cualquier persona, ya sea estudiante o profesional; puede administrarse con independencia del colectivo con el que trabaje, superando así a herramientas validadas en otros idiomas; y ofrece información relevante sobre las expectativas hacia las IAA en un determinado contexto de intervención, posibilitando dar una respuesta adecuada a las expectativas (positivas y negativas) mantenidas mediante la presentación de una visión más real y ajustada a la evidencia de las posibilidades de las IAA.

\section{Bibliografía}

Anderson, D.C. (2007). Assessing the Human-Animal Bond. EE. UU: Purdue University Press.

BARKER, S.B. y WOLEN, A.R. (2008). The benefits of human-companion animal interaction: a review. Journal of Veterinaty Medical Education, 35, 487-495. DOI: $10.3138 /$ jvme.35.4.487

BeETZ, A., UvNÄS-MoberG, K, Julius, H. y KotrsChal, K. (2012). Psychosocial and psychophysiological effects of human-animal interactions: the possible role of oxitocin. Frontiers in Psychology, 3, 1-15. DOI: 10.3389/fpsyg.2012.00234 
Berget, B., Ekeberg, O. and BraAstad, B.O. (2008). Attitudes to animal-assisted therapy with farm animals among health staff and farmers. Journal of Psychiatric and Mental Health Nursing, 15, 576-581. DOI: 10.1371/journal. pone.0083993

Berget, B. and GrepPerud, S. (2011). Animal-assisted interventions for psychiatric patients: beliefs in treatment effects among practitioners. European Journal of Integrative Medicine, 3, e91-e96. DOI: 10.1016/j.eujim.2011.03.001

Berget, B., Grepperud, S., Aasland, O.G. and BraAstad, B.O. (2013). Animalassisted interventions and psychiatric disorders: knowledge and attitudes among general practitioners, psychiatrist, and psychologists. Society and Animals, 21, 284-293. DOI: 10.1163/15685306-12341244

Black. A.F. Chur-Hansen. A., y Winefield. H.R. (2011). Australian psychologists' knowledge of and attitudes towards animal-assisted therapy. Clinical Psychologist, 15, 69-77. DOI: 10.1111/j.1742-9552.2011.00026.x

Cohen, J. (1988). Statistical Power Analysis for the Behavioral Sciences. (2a ed). NJ, EEUU: Erlbaum

FILAN, S.L. y LLEWELlYN-JONES, R.H. (2006). Animal-assisted therapy for dementia: a review of the literature. International Psychogeriatric, 18, 597-611. DOI: $10.1017 /$ S1041610206003322

HALM. M.A. (2008). The healing power of the human-animal connection. American Journal of Critical Care. 17. 373-376.

HART, L.A. (2010). Possitive effects of animals for psychosocially vulnerable people: a turning point for delivery. En H.A. Fine (Ed.). Handbook of animalassisted therapy: Theoretical foundations and guidelines for practice $\left(3 .^{a} \mathrm{ed}\right.$.) (pp.59-84). U.S.A.: Academic Press.

KRUGER. K.A., \& SERPELl. J.A. (2010). Animal-assisted interventions in mental Elath: definitions and theoretical foundations. In H.A. Fine (Ed.). Handbook of animal-assisted therapy: Theoretical foundations and guidelines for practice (3. ${ }^{a}$ ed.) (pp.33-48). U.S.A.: Academic Press.

lópez-Cepero, J., Blanco, N., Perea-Mediavilla, M.A., Tejada, A., RodríGuezFranco, L. y Blanco, A. (2012). Una aproximación al estado actual de las intervenciones asistidas por animales en la literatura científica. Logros y retos de futuro. En R. Quevedo-Blasco y V.J. Quevedo-Blasco (eds.), Avances en Psicología Clínica (pp. 898-992). Granada: AEPC.

López-Cepero, J., Perea-Mediavilla, M.A., Sarasola, J.L. y Tejada, A. (2015). Influence of biographical variables and academic background on attitudes towards animal assisted interventions. Human-Animal Interaction Bulletin, 3, 10-18.

López-Cepero, J., Rodríguez-Franco, L., Perea-Mediavilla, M.A., Blanco, N., TejadA, A. y Blanco, A. (2014). Animal-assisted interventions: review of 
current status and future challenges. International Journal of Psychology and Psychological Therapy, 14, 85-101.

MARINO, L. (2012). Construct validity of animal-assisted therapy and activities. How important is the animal on AAT? Anthrozoos, 25, s129-s151. DOI: 10.27 52/175303712X13353430377219

Moody, W.J., King, R. y O'Rourke, S. (2002). Attitudes of paediatric medical Ward staff to a dog visitation programme. Journal of Clinical Nursing, 11, 537544. DOI: 10.1046/j.1365-2702.2002.00618.x

Nimer. J. y LUNDAHL. B. (2007). Animal-assisted therapy: A meta-analysis. Anthrozoos, 20, 225-238. DOI: 10.2752/089279307X224773

Perea-Mediavilla, M.A., López-Cepero, J., Tejada, A. y Sarasola, J.L. (2014). Intervenciones asistidas por animales y calidad de vida: expectativas en estudiantes universitarios españoles. Escritos de Psicología, 7, 10-18. DOI: 10.5231/psy.writ.2014.1909

Perkins, J., Bartlett, H., Travers, C. y Rand, J. (2008). Dog-assisted therapy for older people with dementia. Australasian Journal of Ageing. 27. 177-182. DOI: 10.1111/j.1741-6612.2008.00317.x

Pet Partners (s.f.) Understanding the differences between AAA and AAT. Recuperado de www.petpartners.org en agosto de 2013.

RISLEY-CURTISS, C. (2010). Social Work Practitioners and the Human-Companion Animal Bond: A National Study. Social Work, 55, 38-46.

SERPELL. J.A. (2010). Animal-assisted interventions in historical perspective. En H.A. Fine (Ed.). Handbook of animal-assisted therapy: Theoretical foundations and guidelines for practice (3. ${ }^{\mathrm{a}}$ ed.) (pp.17-32). U.S.A.: Academic Press.

Souter, M.A. y Miller, M.D. (2007). Do animal-assisted activities effectively treat depression? A meta-analysis. Anthrozoos, 20, 167-180. DOI: 10.2752/175303707X207954

StEED. H.N. y SMITH. B.S. (2002). Animal assisted activities for geriatric patients. Activities. Adaptation and Aging, 27, 49-61. DOI:10.1300/J016v27n01_04

VeldE. B.P. Cipriani. J. y FiSHER. G. (2005). Resident and therapist views of animal-assisted therapy: implications for occupational therapy practice. Australian Occupational Therapy Journal, 52, 43-50. DOI: 10.1111/j.1440-1330.2004.00442.x

Virués-Ortega, J. y Buela-CASAL, G. (2006). Psychophysiological effects of human-animal interaction: theoretical issues and long-term interaction effects. The Journal of Nervous and Mental Disease, 194, 52-57. DOI: 10.1097/01. nmd.0000195354.03653.63

Wilson, C.C. y NetTing, F.E. (2012). The status of instrument development in the human-animal interaction field. Anthrozoos, 25, S11-S55. DOI: 10.2752/1 $75303712 \times 13353430376977$ 
ANEXO

Cuestionario de Actitudes hacia las Intervenciones Asistidas por Perros (CAINTAP)

A continuación, se presenta una serie de situaciones que pueden darse a la hora de introducir uno de los perros de nuestra asociación en un centro (recurso, asociación ) como en el que está usted trabajando (o le gustaría trabajar). Por favor, indique hasta qué punto está de acuerdo con las siguientes afirmaciones. Recuerde, las respuestas están comprendidas entre muy en desacuerdo (a la izquierda) y muy de acuerdo (a la derecha).

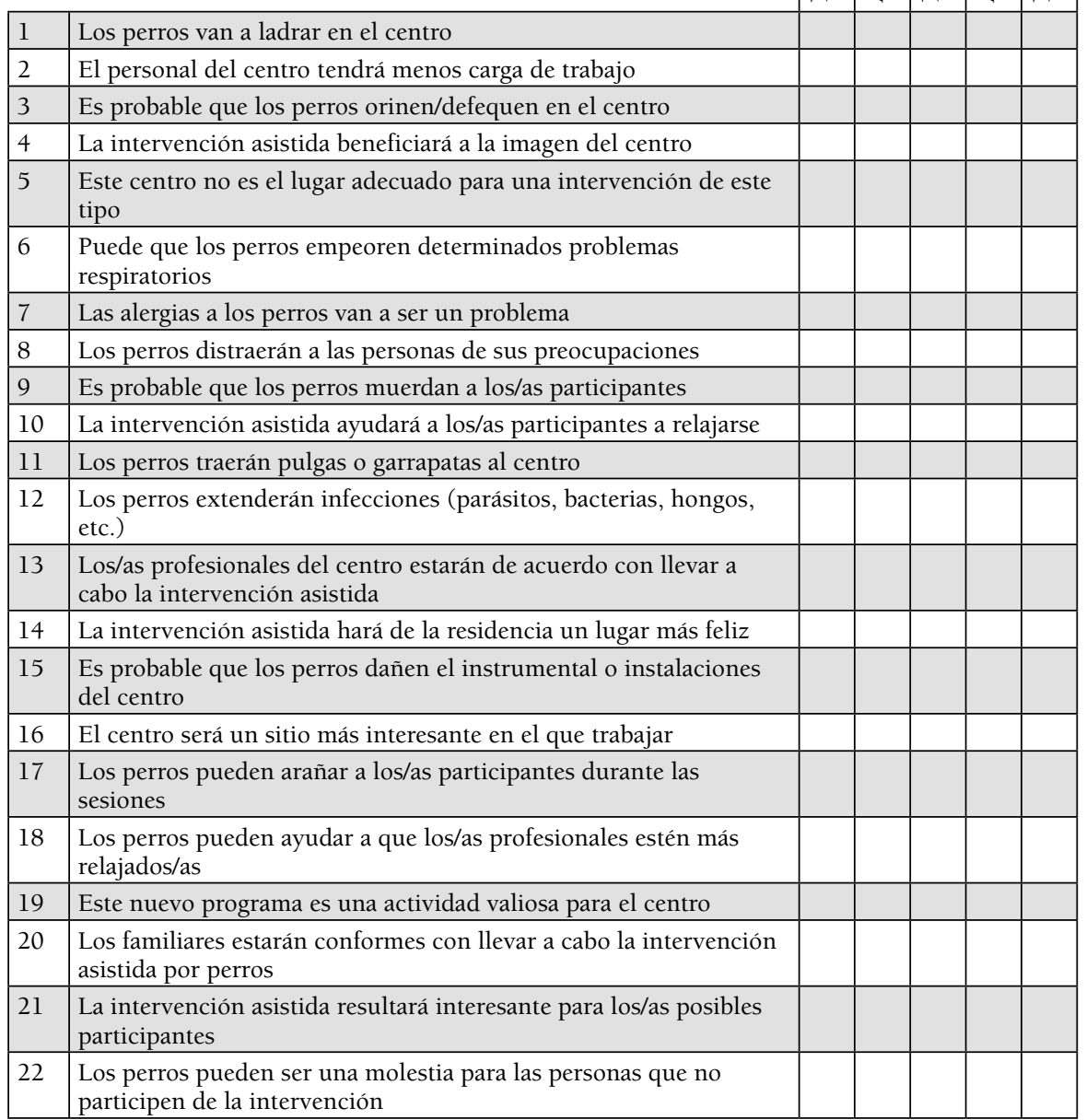




\title{
CALIDAD EN LOS SERVICIOS SOCIALES DE ACOGIMIENTO FAMILIAR
}

\author{
The quality of specialized family placement social services \\ M. ${ }^{\text {a }}$ Victoria OCHANDO RAMÍREZ ${ }^{1}$, AnNa Rucabado SAla ${ }^{2}$, \\ ANA RAQUEl ORTEGA MARTÍNEZ ${ }^{3}$
}

\section{Resumen}

Introducción: El objetivo de esta investigación ha sido determinar atributos de calidad propios para Servicios Sociales Especializados a través de la perspectiva de los profesionales.

Material y métodos: Se ha realizado una evaluación de calidad en un servicio de acogimiento familiar. Primeramente, se ha hecho un estudio de las expectativas y percepciones mediante las dimensiones de calidad de la herramienta SERVQUAL. Además en el marco del Modelo EFQM en su adaptación al sector público y las entidades de voluntariado de la Junta de Andalucía, se ha desarrollado un estudio exploratorio de la entidad y una autoevaluación de calidad.

Resultados: Los datos muestran la importancia de la evaluación de la calidad en estos servicios y las ventajas de combinar distintas técnicas para obtener información. De las respuestas de los participantes se han extraído una serie de atributos de calidad que generan calidad al servicio y a los profesionales.

Discusión: La evaluación ha permitido identificar tres puntos clave en la calidad del servicio de acogimiento familiar que son comunes para el resto de Servicios Sociales Especializados. Al mismo tiempo, se han identificado las dificultades que presentan los modelos de calidad para aplicarse directamente a estos servicios. Los resultados obtenidos avalan la necesidad de adaptar los modelos de calidad de referencia a cada realidad introduciendo indicadores de calidad específicos.

Palabras clave: calidad, evaluación, atributos de calidad, acogimiento familiar, Servicios Sociales Especializados.

\begin{abstract}
Introduction: The main goal of this study is to obtain specific quality dimensions for specialized social services from a professional perspective.

Material and Methods: In this study, quality assessment was conducted in the area of family placement services. The first step was a study of the expectations and perspectives using the service dimensions of the SERVQUAL tool. In addition, using the EFQM Excellence Model in an adaptation created for the public sector and volunteer organizations of the Junta of Andalusia, an exploratory study was carried out about the functioning of the organization and a quality self-evaluation.

Results: The data shows that quality assessment is very important for these services. The different means of approximating quality provides advantages. Participants have contributed to obtain quality dimensions for quality service and for professional satisfaction.

Discussion: this research study reveals three key aspects for quality in family placement services, which reveals the great similarity between specialized social services. There is also a difficulty in understanding and applying the existing quality models in these services. It suggests that quality models need to be adapted by introducing some specific indicators in order to be more effective.
\end{abstract}

Keywords: Quality, Quality dimensions, Family Placement, Specialized Social Services.

Recibido: 20/07/2015

Aceptado: 18/09/2015

Publicado: 03/12/2015

1. Universidad de Jaén. Departamento de Psicología. Jaén, España, Campus Las Lagunillas S/N, 23071 Jaén, España, 9532121 21, E-mail: mvochando@gmail.com

2. Universidad de Jaén. Departamento de Psicología. Jaén, España.

3. Universidad de Jaén. Departamento de Psicología. Jaén, España. 


\section{Introducción}

Hoy en día es muy frecuente recurrir a la calidad para apreciar el buen hacer de una organización o valorar un determinado servicio. Del mismo modo, cada vez más esta filosofía va impregnado los discursos de todos los ámbitos. Sin embargo, cuando nos plantemos la cuestión de la calidad en Servicios Sociales, por lo general, surge un vacío. Esta incertidumbre se debe en gran medida a las escasas iniciativas de gestión de la calidad que se han desarrollado en este contexto (Medina-Tornero, 2006; Parlamento Europeo, 2011), a diferencia de lo que sucede con otros Sistemas de Protección Social como puede ser Salud o Educación. Del mismo modo, tampoco se han estudiado cuáles han de ser los atributos de calidad que han de darse en este sistema.

En el caso de Servicios Sociales Especializados la cuestión responde al mismo patrón, es decir, la gestión de la calidad no se encuentra generalizada. Esto nos ha llevado a plantearnos el objetivo de determinar en los atributos de calidad de Servicios Sociales Especializados propios desde el punto de vista de los profesionales.

Además en este segundo nivel de atención, nos encontramos con otras limitaciones que tienen una gran repercusión en la calidad de los servicios prestados, y en consecuencia, en la calidad de vida de los ciudadanos que necesitan de ese servicio y en la calidad laboral de quienes lo prestan (Barranco, 2011).

En primer lugar, el hecho de que estos servicios sean tan heterogéneos entre sí ha impedido que se desarrollen unos criterios mínimos de calidad comunes para todos ellos. La heterogeneidad responde a dos circunstancias: una, referente a las múltiples formas de gestión y otra, a la titularidad de las entidades prestadoras que van desde los público hasta las empresas de la iniciativa privada y las entidades de voluntariado. Además, hay que mencionar la gran variedad de necesidades a las que hacer frente y que por lo general, se les da respuesta a través de la intervención especializada que se presta a sectores de población como las personas sin hogar, drogodependientes, tercera edad, discapacidad, menores, minorías, etc. Esta amalgama de factores ha ocasionado que la implantación de la calidad haya seguido patrones diferentes (Fundación Edad y Vida, 2008), basados fundamentalmente en la aplicación de modelos como las Normas ISO de la Organización Internacional de Estandarización, el modelo EFQM de la Fundación Europea de la Gestión de la Calidad, y la Norma ONG con calidad, diseñada por INTRESS y actualmente gestionada por ICONG. La gestión de la calidad ha predominado fundamentalmente en las entidades de gran tamaño y en especial, dentro de los sectores de personas mayores y con discapacidad. Además estas entidades 
ante la situación actual, han visto un incremento de la demandas (European Commission, 2013) que no se ha visto correspondida en todas las ocasiones por las prioridades políticas.

Pese a ello, las iniciativas de calidad han tenido en muchas ocasiones como objetivo en sí mismo la certificación de calidad. Esto tiene que ver con la situación generalizada que atraviesan los Servicios Sociales Especializados, ya que no tienen establecidas las vías de financiación como sucede con los Servicios Sociales Comunitarios. De ahí que para mantener determinados servicios sea necesario recurrir a la búsqueda de recursos, entre los cuales se encuentran las subvenciones públicas. Esto ocasiona que las entidades opten por certificar la calidad de sus servicios para hacer frente a la competencia del resto de entidades (Miranda, Chamorro y Rubio, 2007).

Relacionado con lo anterior, las entidades se encuentran además con las dificultades que entraña por sí mismo la implementación de sistemas de calidad: el lenguaje resulta ajeno a los Servicios Sociales Especializados, la aplicación de los modelos de calidad es compleja y también existen prejuicios relacionados con la normalización y sus ventajas entre las organizaciones y entre los propios profesionales del sector. Es decir, los modelos de referencia de calidad, genéricos para todo tipo de servicios no han logrado integrar las singularidades de estos servicios, donde el componente interrelacional adquiere una gran significación.

Precisamente por este motivo, se ha visto oportuno conocer hasta qué punto los modelos de calidad eran aplicables al contexto de Servicios Sociales Especializados; o si por el contrario, era necesario incorporar a dichos modelos otros indicadores de calidad propios. Igualmente se quería comprobar si los indicadores debían ser exclusivos para el acogimiento familiar o si podrían ser compartidos por los Servicios Sociales Especializados. Para ello, se ha realizado una evaluación de calidad que se ha centrado en una entidad de Servicios Sociales Especializados de pequeño tamaño y donde las experiencias de calidad han tenido poca repercusión debido a la privacidad y confidencialidad que exigen las situaciones que abordan. En concreto, se ha optado por una Institución Colaboradora de Integración Familiar (I.C.I.F.) responsable de gestionar los acogimientos familiares en una provincia andaluza.

El acogimiento familiar es una medida de protección que da respuesta a aquellas situaciones en que niños y niñas no pueden o no deben estar con sus padres biológicos y pasan a vivir temporal o permanentemente por otro núcleo familiar diferente al suyo de origen, que se encarga de su cuidado y educación. Se trata de evitar que el menor que se encuentre en una situación de desprotección, ingrese o permanezca en un Centro de Menores y con ello 
evitar así su institucionalización. El acogimiento familiar se produce durante el tiempo que se estudia la recuperabilidad de la familia de origen a través de la familia extensa del menor o de una familia ajena.

En estos servicios, la calidad supone no sólo la oportunidad de oír la voz y las necesidades de los usuarios, tal y como apunta Arenas (2015) en su estudio de calidad percibida, sino que supone ir mucho más allá. La gestión de la calidad en Servicios Especializados como el que nos ocupa, implica favorecer el bienestar de los menores por encima de todo y establecer procesos de calidad donde los plazos son más importantes si cabe, ya que se trata de minimizar los efectos no deseados de la protección (Cruz Roja Española, 2010) a estos menores que atraviesan circunstancias muy complejas (Del Valle, Bravo y López, 2009) derivadas de la separación familiar, el intervencionismo profesional y los múltiples cambios en las esferas de su vida. Además la protección de los menores ha de estar por encima de cuestiones como la disponibilidad presupuestaria, por lo que también es importante evitar incurrir en gastos innecesarios derivados de duplicidades y errores producidos por la no calidad.

Partiendo de estas premisas, se ha realizado una evaluación de calidad en la Asociación de Acogimiento Familiar. Esta entidad, se compone de un presidente y una coordinadora, y un equipo compuesto por cinco trabajadores, todos ellos con profesiones técnicas de carácter psicológico, social y legal. Además, el hecho de que la entidad evaluada dependa de la Administración Pública, a través de la Consejería de Igualdad, Salud y Políticas Sociales de la Junta de Andalucía, implica la asunción de los principios de calidad que se promueven para los servicios públicos. Esto es, situar al ciudadano en el centro de las actuaciones, promover la mejora continua, aprender de la experiencia propia o ajena, simplificar procesos y realizar evaluaciones de calidad. En este sentido, la evaluación realizada se ha centrado en la aplicación de los conceptos de la calidad y se hecho desde perspectiva de uno de los modelos de calidad, tal y como se explicará más adelante.

Esta evaluación no ha estado exenta de dificultades, ya que el acceso a la información en los casos de menores en situación de desamparo implica un elevado grado de confidencialidad, dada la sensibilidad del tema. Asimismo el lograr la apertura de la organización y de los profesionales para evidenciar lo que se está haciendo bien y aquello susceptible de ser mejorado, representa una dificultad añadida; al igual que el cerciorarse de que los indicadores de calidad que se propongan como específicos para el servicio de acogimiento, sean los que tienen que ser. 


\section{Material y métodos}

El proceso de evaluación de calidad se ha realizado desde la perspectiva de los profesionales de la entidad, con el fin de indagar en sus expectativas y percepciones del servicio. Para ello, se ha empleado la metodología cualitativa, por ser la más recomendada para este tipo de evaluaciones (Ministerio de Administraciones Públicas, 2006).

En esta ocasión, se ha querido realizar una evaluación de calidad que abordase distintos aspectos para obtener una visión holística del acogimiento familiar. Se ha visto que las evaluaciones de calidad centradas exclusivamente en el estudio de la satisfacción de alguno de los grupos de interés realizadas en algunos Servicios Sociales Especializados, no aportan datos sobre los aspectos de mejora de manera concreta.

En especial, estas limitaciones se presentan con el uso de la metodología cuantitativa. Por ejemplo, es habitual emplear la herramienta SERVQUAL desarrollada por Zeithman, Parasunaman y Berry (1992). Esta herramienta, es un cuestionario de 22 ítems que mide a través de una escala tipo Likert del 0 al 10 que permite evaluar la satisfacción con el servicio a través de cinco dimensiones: elementos tangibles, fiabilidad, capacidad de respuesta, seguridad y empatía. Sin embargo, aunque esta herramienta posibilita la obtención de una puntuación numérica y proporciona información sobre la satisfacción del servicio a partir de la diferencia existente entre las expectativas y percepciones, desde nuestro punto de vista, los datos que proporciona la herramienta sobre dichas dimensiones son más bien escasos y estructurados, no dejando cabida para otros atributos de calidad.

Puesto que con la evaluación realizada se quería conocer si existían otros indicadores de calidad que pudieran ser útiles para el servicio evaluado, se optó por utilizar las dimensiones que propone el modelo SERVQUAL para indagar sobre las expectativas y percepciones que tienen los profesionales sobre cada una de ellas. Para ello, se utilizado como técnica el grupo de discusión. Esta técnica ha favorecido que los participantes aportasen información sobre la satisfacción con las distintas dimensiones y los elementos que la engloban. Al mismo tiempo se han proporcionado detalles concretos sobre el servicio a partir de las dimensiones y sobre otros atributos de calidad relevantes. Se han realizado dos grupos, que responden a la totalidad de la población investigada: uno mixto compuesto por los dos directivos y los profesionales de la entidad, y otro exclusivo para el equipo de los profesionales de la entidad con objeto de contrastar la información. Las sesiones de discusión han durado hora y media cada una, y ha predominado el criterio de saturación de la información. 
De manera complementaria, se han utilizado otras técnicas para la evaluación de la calidad que han posibilitado conocer la calidad del servicio a nivel interno y en relación al contexto en el que se desenvuelve: el Servicio de Protección de Menores y otros sistemas asociados como son Salud, Educación y Servicios Sociales Comunitarios o de atención primaria.

De forma exploratoria, se ha indagado en el funcionamiento de la entidad a través de sus procesos. Se han utilizado técnicas como la observación, la revisión documental y las entrevistas semiestructuradas a todos los profesionales de la entidad en distintos momentos. Además, teniendo en cuenta que la normativa de calidad exige la utilización de un modelo de referencia para la evaluación de calidad, se ha empleado como guía el Modelo Europeo de Excelencia (EFQM) en su adaptación para el sector público y las organizaciones de voluntariado de la Junta de Andalucía (Dirección General de Administración Electrónica y Calidad de los Servicios, 2004b).

Posteriormente, se ha realizado una Autoevaluación de Calidad mediante el cuestionario-formulario establecido para los servicios públicos de la Junta de Andalucía (Dirección General de Administración Electrónica y Calidad de los Servicios, 2004a) que responde a los criterios agentes y resultados del modelo de calidad citado, que se ha rellenado de forma individual por parte de todos los participantes, con la ayuda inicial de la investigadora responsable. Después se ha realizado una reunión de consenso con los líderes.

\section{Resultados}

Los participantes consideran que la calidad aporta ventajas para el acogimiento que podría facilitarles su trabajo diario: «Puede permitirnos mejorar el servicio a la gente de fuera y de dentro»; «Puede hacer que todo sea más dinámico, más fácil y más seguro»; «Con la calidad sabes cómo puedes responder a cada situación»; «Mejora el funcionamiento a todos los niveles». El deseo de mejorar es un elemento que se reitera a lo largo de las distintas fases de la investigación, al igual que los aspectos que consideran que aportan calidad al servicio de acogimiento familiar.

El estudio de las expectativas y percepciones de los profesionales evaluados a partir de las dimensiones de SERVQUAL ha mostrado una gran satisfacción en la mayoría de las dimensiones, otorgando mucho interés a los aspectos relacionados con la atención profesional y el compañerismo: «Interés por el caso y que te preocupas»; «Buen ambiente, cooperación, poder contar con el otro, profesionalidad»; «Hay que destacar el compañerismo que tenemos y el apoyo». También ponen mucho interés en la mejora de los aspectos tangibles de la entidad: "Convendría separar las visitas de los despachos, se 
escucha el ruido de las visitas»; «Tema informático y audiovisual»; «Material adecuado a los niños».

En concreto, de las dimensiones de calidad de SERVQUAL extraídas en el grupo mixto de profesionales se han generado los siguientes atributos (Ver Fig. 1):

Fig. 1. Atributos de calidad según directivos y profesionales a partir de las dimensiones de SERVQUAL (Elaboración propia, 2015).

\begin{tabular}{|l|l|}
\hline Dimensiones SERVQUAL & \multicolumn{1}{|c|}{ Atributos de calidad } \\
\hline Aspectos tangibles & Fácil localización de la sede \\
\cline { 2 - 3 } & Adecuación de los espacios y seguridad de éstos \\
\cline { 2 - 3 } & Buen funcionamiento del equipamiento \\
\cline { 2 - 2 } & $\begin{array}{l}\text { Imagen corporativa homogénea que muestre la } \\
\text { vinculación pública }\end{array}$ \\
\cline { 2 - 3 } & Pulcritud \\
\hline Fiabilidad & Existencia del profesional de referencia \\
\cline { 2 - 3 } & Eficacia \\
\cline { 2 - 3 } & Cumplimiento de los plazos \\
\hline Capacidad de respuesta & Rapidez en las tareas administrativas \\
\cline { 2 - 3 } & Disponibilidad de los profesionales \\
\cline { 2 - 3 } & Atención profesional continuada y cercana \\
\cline { 2 - 3 } & Información suficiente a los grupos de interés. \\
\hline Seguridad & Profesionalidad \\
\cline { 2 - 3 } & Amabilidad de los profesionales \\
\cline { 2 - 3 } & Cohesión \\
\cline { 2 - 3 } & Sentido crítico \\
\hline Empatía & Confianza \\
\cline { 2 - 2 } & Atención individualizada \\
\cline { 2 - 2 } & Flexibilidad \\
\hline
\end{tabular}

Además de estos atributos, los profesionales en la sesión sin líderes sacan a relucir otros aspectos que le producen satisfacción e insatisfacción, los cuales no habían aparecido en el anterior grupo común: «Estamos bastante implicados en el trabajo porque creemos en él y en el acogimiento»; «No comparto la situación laboral»; «Genera una situación que no eliges». También se muestran preocupados por temas que no se plantean por parte de los líderes: 
«No sabemos lo que piensan». Todos muestran una actitud de conformidad en la mayoría de los puntos, concediendo una gran importancia a la motivación laboral con el trabajo desarrollado y el ámbito de actuación, excepto uno de ellos que no se siente tan desarrollado profesionalmente: «La motivación profesional y personal es grande, a pesar de la inestabilidad. Estamos insatisfechos por un lado, pero nos gusta el trabajo». En consecuencia, de esta sesión de discusión se han podido identificar dos dimensiones nuevas con sus correspondientes atributos de calidad:

- Calidad técnica: los profesionales hacen mención a la retroalimentación de su labor profesional, la formación continua y al aprendizaje de buenas prácticas.

- Calidad laboral: se incluye la motivación con el trabajo y ámbito de actuación, la estabilidad y derechos laborales, la resolución de conflictos y el liderazgo proactivo.

Durante el estudio exploratorio de la entidad, igualmente se han identificado atributos de calidad que son significativos y que convergen en gran medida con los anteriores. Dentro de los principios de calidad, todos los participantes ponen mucho énfasis en la orientación al cliente y la orientación a resultados. Los profesionales además inciden mucho en el liderazgo y en la gestión por procesos y hechos. En este último principio, aparecen algunos atributos adicionales que deben tenerse presentes: claridad en procesos y subprocesos, homogeneidad, facilidad de uso, trazabilidad y seguridad por el cumplimiento de la normativa.

En la autoevaluación, los profesionales manifiestan la dificultad del Modelo EFQM en su adaptación para el sector público y las organizaciones de voluntariado de la Junta de Andalucía (Dirección General de Administración Electrónica y Calidad de los Servicios, 2004b), así como de la herramienta de autoevaluación. En cualquier caso, la autoevaluación ha permitido confirmar y contrastar la información obtenida con anterioridad. Lo cual ha mostrado una gran coherencia en los datos obtenidos durante todo el proceso evaluativo. Los ejes prioritarios para los directivos y profesionales de de la entidad de acogimiento son: liderazgo, delimitación de objetivos y procesos, recogida sistemática de información, preocupación por la satisfacción de los grupos de interés externos y profesionales, y evaluación periódica de aspectos económicos y sobre todo, no económicos. 


\section{Discusión}

Las formas de aproximación a la calidad en la entidad evaluada han permitido conocer mejor cuál es la situación actual del servicio y comprender el contexto del acogimiento familiar. La evaluación de calidad ha permitido identificar los atributos que aportan calidad al servicio y calidad laboral a los profesionales. Además, en esta investigación ha resultado llamativo la gran similaritud en las opiniones de los directivos y los profesionales en la mayoría de los aspectos evaluados. Esto puede deberse a la gran involucración que todos presentan con los menores y a las dimensiones reducidas de la entidad, que fomenta la cercanía y el apoyo entre ambos tipos de profesionales. No obstante, los directivos muestran una percepción más positiva en cuanto al funcionamiento de la entidad. Esto evidencia que en las evaluaciones de calidad hay que complementar ambos puntos de vista para definir los atributos de calidad que deben de estar en estos servicios, siendo éstos los principales hallazgos encontrados en la evaluación.

Asimismo, se ha corroborado la idea inicial de que los modelos de calidad necesitan complementarse con indicadores propios, comunes para los Servicios Sociales Especializados. El servicio de acogimiento familiar presenta una serie de características comunes a los Servicios Sociales Especializados que deben considerarse. A saber, la orientación al cliente, la atención profesional y la coordinación externa (Ver Fig. 2).

La orientación al cliente supone en este caso poner todos los esfuerzos en procurar el bienestar de los menores, ya que no siempre las medidas de protección logran garantizar los derechos de este grupo de población (Bonal, 2010). El principio superior del bienestar del menor ha de manifestarse en los procesos que componen el servicio. La delimitación de los procesos administrativos y de sus tiempos de gestión contribuye a que el trabajo realizado sea más eficiente y satisfactorio para todos, especialmente para los menores que

Fig. 2. Características comunes de los Servicios Sociales Especializados (Elaboración propia, 2015).

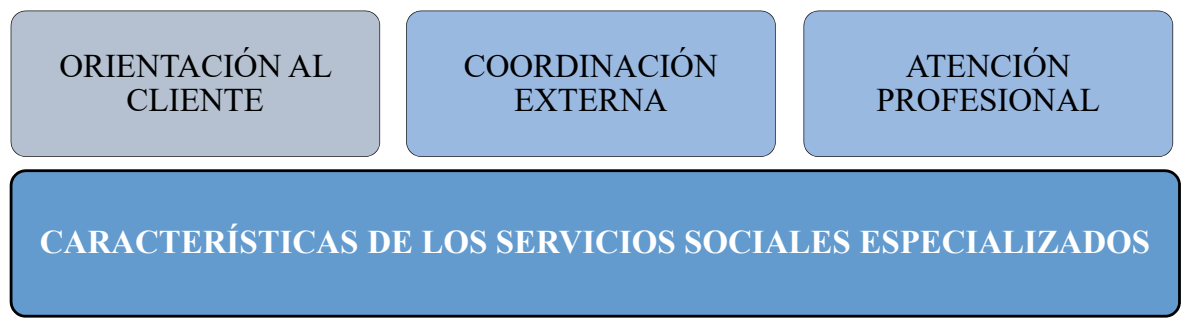

Alternativas. Cuadernos de Trabajo Social, 22, 2015, pp. 139-153 - ISSN 1133-0473 DOI: 10.14198/ALTERN2015.22.08 
han de soportar la lentitud de la burocracia, que también es la principal causa de insatisfacción para el resto de los ciudadanos según afirma la Agencia Estatal de Evaluación de las Políticas Públicas y la Calidad de los Servicios, AEVAL (2014).

En otros Servicios Sociales Especializados igualmente han de atender a un grupo de personas en una situación de vulnerabilidad social que tampoco tienen totalmente garantizados sus derechos mediante principios éticos.

En el caso de la entidad evaluada, la orientación al cliente exige además poner atención en el resto de grupos de interés: las familias acogedoras, y los propios profesionales. Sin embargo, no es muy habitual conocer la satisfacción de los profesionales del Sistema de Servicios Sociales. Pese a ello, es necesario que los profesionales se sientan contentos. En este sentido, el Parlamento Europeo (2011), señala la importancia de valorar más el trabajo de las personas que prestan servicios sociales por su gran dosis de compromiso y sensibilidad. Los profesionales participantes coinciden en que ha de reforzarse más la calidad laboral y señalan que afecta directamente en la calidad del servicio (The Social Protection Committee, 2010; Kvist, et al. 2014; Tyssen, et al., 2013). Igualmente, exponen que la motivación con el ámbito de actuación supone una de las dimensiones más valoradas en cuanto a la calidad laboral, por encima de otras como el salario, aspecto que se refleja también en otros estudios (Consejo General del Trabajo Social, 2014). También hay evidencias de que la satisfacción profesional es superior cuando la organización cuenta con un sistema de gestión de calidad como puede ser por ejemplo el Modelo Europeo (Matthies, et al., 2014).

Respecto a la atención profesional, los profesionales de Servicios Sociales Especializados como el prestado por la entidad de acogimiento evaluada, presentan unas condiciones laborales menos estables y menos recursos que si trabajasen en Servicios Sociales Comunitarios, siendo uno de los sistemas de protección más perjudicados por la crisis (Asociación Estatal de Directores y Gerentes de Servicios Sociales, 2014). De ahí a que tengan que esforzarse más si cabe en sus habilidades personales y profesionales (Pacheco Mangas y Palma García, 2014) para proporcionar una atención excelente, ya que las prácticas de intervención tradicionales impiden hacer frente a las nuevas situaciones de vulnerabilidad social (Rucabado y Heras, 2010; Sotomayor et al.,2013). Del mismo modo, en otros Servicios Sociales Especializados se requiere una atención integral centrada en la persona como señal de calidad (Martínez Fuentes, y Martínez Hernández, 2013) por parte de profesionales con las suficientes competencias técnicas y humanas, y que muestre la disponibilidad de los profesionales. Los resultados muestran que tanto los 
líderes como los profesionales dan mucha importancia a la calidad técnica de la atención prestada, en especial sobresale la dimensión de la calidad técnica que se refiere a la relación interpersonal entre quien presta el servicio y quien lo recibe (Velasco, 2011). Esta relación terapéutica hace que el profesional se adentre en los significados y comprenda a la persona que tiene delante, aspectos clave para la intervención con menores. Además este nexo de unión es un recurso en sí mismo (García Roca, 2006) que tiene una gran repercusión en la calidad del servicio (Ministerio de Sanidad, Política Social e Igualdad e IOK Laboratorio de Trabajo Social, 2012).

En este sentido, todos los participantes convergen en la conveniencia de la figura del profesional de referencia, generalmente un Trabajador Social. Esta figura goza de gran aceptación en Servicios Sociales (Brezmes, 2009; Ministerio de Sanidad, Política Social e Igualdad e IOK Laboratorio de Trabajo Social, 2012; Ministerio de Sanidad, Servicios Sociales e Igualdad, 2013), al igual que en los Servicios para la Protección de Menores. En otros estudios de Servicios Sociales, los usuarios muestran el temor a perder a este profesional y manifiestan su deseo a no tener que comenzar de nuevo (Dómenech y Giménez Bertomeu, 2012). Es decir, se valora la continuidad en la intervención.

Relacionado con lo anterior, los servicios de acogimiento familiar, al igual que el resto de Servicios Especializados, deben coordinarse con otros servicios externos. Esta situación ocasiona habitualmente problemas de coordinación, siendo necesario avanzar en establecer unos criterios homogéneos de relación y evaluación para el conjunto de Servicios Sociales Especializados, de manera que el proceso sea más provechoso para todos. En esta entidad, al depender de un servicio público, los líderes y profesionales tienen que realizar numerosas gestiones para la rendición de cuentas y para la prestación del servicio en sí, ya que los procesos realizados por la entidad son supervisados y continuados por el Servicio de Protección de Menores. Sin embargo, los problemas relacionados con la burocracia y la gestión de los tiempos, ocasionan violencia para los menores (Crespo y Moretón, 2012) que precisan de compromisos y vías de coordinación que se ajusten a la realidad.

Si centramos el análisis en las herramientas de evaluación utilizadas, la utilización de las dimensiones de SERVQUAL en los grupos de discusión, ha favorecido la aparición de bastantes atributos de calidad del servicio, así como la satisfacción de los participantes con las distintas dimensiones. Además se ha podido comprobar que las dimensiones que recoge dicha herramienta son muy apropiadas, puesto que hacen referencia a las cuestiones más significativas de cualquier servicio. Asimismo también ha resultado muy útil la aplicación más abierta de la herramienta. 
Por otro lado, la autoevaluación de la calidad sí que ha presentado una serie de inconvenientes. El modelo EFQM utilizado, pese a ser una adaptación para el sector público y las organizaciones de voluntariado, no capta todos los aspectos intrínsecos del servicio de acogimiento y es difícil de comprender. Esto coincide con la opinión de otros profesionales de Servicios Sociales Especializados que han tenido experiencias de evaluación a través del Modelo Europeo (Equipo Investigador Proyecto Gesquality, 2010). Pese a ello, la utilización de la parte de formulario de la herramienta sí que ha favorecido la valoración de las áreas de mejora y los puntos fuertes por parte de los participantes, clarificando el posterior análisis de la información. Esto coincide con otros valoraciones positivas sobre el formulario en la evaluación de la calidad (Ministerio de Administraciones Públicas, 2006).

Los resultados muestran dos puntos clave. En primer lugar, que los modelos de calidad genéricos para todo tipo de servicios presentan dificultades para ajustarse a las características de Servicios Sociales como el del acogimiento familiar. Es decir, necesitan adaptaciones para resultar más efectivos y útiles. De ahí que sea importante conocer los atributos de calidad necesarios, con el fin de avanzar en la posterior delimitación de indicadores de calidad. Relacionado con esto, en segundo lugar, la evaluación de calidad realizada ha puesto en valor las coincidencias que presentan todos los Servicios Sociales Especializados en cuanto a orientación al cliente, importancia de la calidad técnica de la atención y sobre la coordinación externa. Además ha visibilizado algunas de las condiciones laborales y la importancia de la motivación profesional en la satisfacción.

Todos estos factores nos indican que no es necesario elaborar una serie de indicadores exclusivos para el acogimiento familiar, sino que más bien conviene establecer indicadores genéricos aplicables al conjunto de servicios públicos y privados que componen los Servicios Sociales Especializados en Andalucía. Esto favorecería no sólo la comparación sino también la coordinación y evaluación de los mismos. Además, no estarían basados en las categorías habituales de atención, que no ayudan a la consolidación de los Servicios Sociales Especializados ni a la integración social de los propios usuarios. No obstante, dichos indicadores podrían complementarse con otros indicadores adicionales si se considera necesario para el servicio.

En cualquier caso, la evaluación que se ha hecho en el servicio de acogimiento familiar ha sido muy satisfactoria. El realizar la investigación en una entidad de pequeño tamaño igualmente ha servicio para evidenciar el esfuerzo que hacen los profesionales por garantizar la atención, pese a la escasez de recursos. Igualmente, la evaluación realizada ha mostrado la importancia de 
implantar la calidad en este servicio y ha favorecido el conocimiento desde las perspectivas de quienes prestan el servicio: los directivos y los profesionales. No obstante, conviene avanzar también en la evaluación de la calidad desde el punto de vista de los usuarios del servicio, ya que las nuevas necesidades sociales y las demandas de participación así lo requieren.

Las particularidades de los Servicios Sociales Especializados en cuanto a la heterogeneidad de población y formas de prestación de los servicios, hace imprescindible una mayor homogeneización en los servicios que facilite el acceso y proporcione la calidad que desde las políticas públicas se enuncia. Por este motivo, es urgente desarrollar estándares de calidad para Servicios Sociales Especializados que dignifiquen la protección social. Hagamos pues de la calidad nuestro mejor instrumento para avanzar hacia el bienestar y la justicia social de quienes más lo necesitan.

\section{Bibliografía}

AEVAL (2014). Calidad de los servicios públicos en tiempos de austeridad. Madrid: Ministerio de Hacienda y Administraciones Públicas, Agencia Estatal de Evaluación de las Políticas Públicas y la Calidad de los Servicios.

Arenas Martínez, M. (2015). Calidad percibida en los servicios sociales de inclusión. Una aproximación desde el caso de Avilés (Asturias). Cuadernos de Trabajo Social, 28-1, 113-123.

Asociación Estatal de Directores Gerentes en Servicios Sociales (2014). Índice de Desarrollo de los Servicios Sociales 2014. Asociación Estatal de Directores Gerentes en Servicios Sociales.

BARRANCO EXPÓSITO C. (2011). Buenas prácticas de calidad y Trabajo Social. Alternativas. Cuadernos de Trabajo Social, 18, 57-74.

BREZMES Nieto M.J. (2009). Propuesta para la configuración de un modelo actualizado de Servicios Sociales Municipales. Zamora: Federación Española de Municipios y Provincias.

Consejo General de Trabajo Social (2014) I Informe sobre los Servicios Sociales en España. Madrid: Consejo General de Trabajo Social.

Crespo Garrido, M., Moretón SAnZ, F. (2012). La nueva Ley de Servicios Sociales en Castilla La Mancha: la figura del Trabajador Social como protección de la calidad de vida del menor. Revista de Estudios de Juventud, 97, 207-222.

Cruz Roja Española (2010). Manual de buena práctica en acogimiento familiar. Madrid: Cruz Roja Española.

Del VAlLE, J.F., BRAVO, A., y LÓPEZ, M. (2009). El acogimiento familiar en España: implantación y retos actuales. Papeles del Psicólogo, 30-1, 33-41.

Dirección General de Administración Electrónica y Calidad de los Servicios (2004a). 
Cuestionario de Autoevaluación. Sevilla: Consejería de Justicia y Administración Pública.

Dirección General de Administración Electrónica y Calidad de los Servicios (2004b). Modelo EFQM de Excelencia en la Junta de Andalucía. Sevilla: Consejería de Justicia y Administración Pública.

Dómenech López, Y., Giménez Bertomeu, V. (2012). Percepciones sobre la calidad de los Servicios Sociales de las personas jóvenes usuarias: utilidades para el diseño de estándares de calidad. Revista de Estudios de Juventud, 97, 123-146.

Equipo Investigador Proyecto GESQUALITY (2010). Aplicación del modelo europeo EFQM de excelencia en centros residenciales y en el servicio de ayuda a domicilio: Diseño de procesos y cuadro de mando integral. Memoria de investigación. Barcelona: Fundación SAR.

European Commission (2013). Social Policies. Social Europe guide. Volume 5. Belgium: European Commission.

Fundación Edad y Vida (2008). Calidad y acreditación para las entidades prestadoras de servicios de atención a las personas mayores en situación de dependencia. Madrid: IMSERSO.

GARCÍA RoCA, J. (2006). Memorias silenciadas en la construcción de los servicios sociales. Cuadernos de Trabajo Social, 19, 197-212.

Kvist, T., Voutilainen, A., MÄntynen, R. y VeHViläInEn-Julkunen, K. (2014). The relationship between patients' perceptions of care quality and three factors: nursing staff job satisfaction, organizational characteristics and patient age. BMC Health Services Research 14, 466.

Martínez Fuentes, M. T., Martínez Hernández, L. (2013). Promoción del desarrollo infantil y atención temprana: calidad de los servicios. Azarbe. Revista Internacional de Trabajo Social y Bienestar, 2, 49-67.

Matthies Baraibar, C., Arcelay Salazar, A., Cantero González, D., Colina Alonso, A., García Urbaneja, M., GonzÁlez llinares, M., et. al. (2014). Is organizational progress in the EFQM model related to employee satisfaction?. BMC Health Services Research, 14, 468.

Medina Tornero, M. E. (2006). La implantación de la calidad en Servicios Sociales. Desafío a la tradición. En Gobierno de la Rioja (Ed.), III Jornadas sobre la Calidad en Centros de Servicios Sociales (pp.121-137). Logroño: Gobierno de La Rioja.

Ministerio de Administraciones Públicas (2006). Guía de orientación para la realización de estudios de análisis de la demanda y de encuestas de satisfacción. Madrid: Ministerio de Administraciones Públicas.

Ministerio de Sanidad, Política Social e Igualdad, IOK Laboratorio de Trabajo Social (2012). Calidad en los Servicios Sociales de Atención Primaria. Madrid: Ministerio de Sanidad, Política Social e Igualdad. 
Ministerio de Sanidad, Servicios Sociales e Igualdad (2013). Catálogo de referencia de Servicios Sociales. Madrid: Ministerio de Sanidad, Servicios Sociales e Igualdad.

Miranda González, F., Chamorro Mera, A. y Rubio lacoba, S. (2007). Introducción a la gestión de la calidad. Madrid: Delta Publicaciones Universitarias.

Pacheco Mangas, J. y Palma García, M. (2014). El discurso profesional en Servicios Sociales Comunitarios: una aproximación desde la identificación de repertorios interpretativos. Alternativas. Cuadernos de Trabajo Social, 21, 9-28.

Parlamento Europeo (2011). Informe sobre el futuro de los servicios sociales de interés general (Informe no. 2009/2222 INI). Bruselas: Parlamento Europeo.

Rucabado Sala, A., Heras Robles, I. (2010). La atención a los grupos vulnerables en Jaén. Jaén: Universidad de Jaén.

Sotomayor Morales, E., De la Fuente Robles, Y., García Domingo, M., Grande Gascón, M. y Alberich Nistal, T. (2013). Calidad en los servicios de bienestar en un contexto de crisis económica internacional. Comunitania. Revista internacional de Trabajo Social y Ciencias Sociales, 5, 153-179.

The Social Protection Comitee (2010). A Voluntary European Quality Framework for Social Services. (Report SPC/2010/10/8 final, 8 October). Luxemburg: The Social Protection Comitee.

Tyssen, R., Palmer, K., Solberg, I., Voltmer, E. y Frank, E. (2013). Physicians' perceptions of quality of care, professional autonomy, and job satisfaction in Canada, Norway, and the United States. BMC Health Services Research, 13, 516.

Velasco SÁnCHEZ, J. (2011). Gestión de la calidad. Mejora continua y sistemas de gestión. Teoría y práctica. Madrid: Ediciones Pirámide.

Zeithaml, V., Parasuraman, A. y Berry, L. (1992). Calidad Total en la Gestión de Servicios. Madrid: Díaz de Santos S. A. 



\title{
¿CÓMO AFECTA LA CRISIS ECONÓMICA AL CONTEXTO DE LA PROSTITUCIÓN DE CALLE? ${ }^{1}$
}

\author{
How does the economic crisis affect the context of street prostitution? \\ CARMEn MENESES FALCÓN² y LAURa GuindeO AGUERRI ${ }^{3}$
}

\section{Resumen}

Este estudio tiene la finalidad de describir las repercusiones que la crisis económica ha supuesto en las poblaciones más vulnerables, en concreto en las mujeres que ejercen la prostitución en la calle, así como en las entidades que les prestan apoyo. Para desarrollar los objetivos se ha realizado trabajo etnográfico (observación participante y entrevistas) en una zona de prostitución de calle de la ciudad de Madrid. Así mismo se ha realizado entrevistas semiestructuradas a las entidades principales que trabajan con estas mujeres que ejerce la prostitución en la misma ciudad para poder triangular la información y complementarla. Entre las consecuencias destacan una reducción de los clientes y por tanto de los ingresos, con más largas horas de presencia en la calle, aceptando servicios o prácticas de riesgo a cambio de un incremento económico y la inaccesibilidad a los servicios sanitarios básicos. Los resultados nos llevan a concluir que la reducción de asistencia social y sanitaria en los colectivos más vulnerables conlleva la transformación de los mismos en grupos en exclusión social, así como posibles repercusiones en salud pública al no poder detectar y prevenir muchas de las infecciones que puedan producirse.

Palabras clave: Prostitución, exclusión social.

\begin{abstract}
This study aims to describe the impact of the economic crisis on the most vulnerable populations, particularly female street prostitutes and the institutions that support them. To obtain these goals, the study was done through fieldwork (participant observation and interviews) in a characteristic area of prostitution located in Madrid. The study was also conducted through semi-structured interviews with key organizations that work with these women engaged in prostitution in the same city, to triangulate the information to complement the study. Principal consequences include: reduced customers and therefore less revenue, longer hours on the streets, acceptance of unsafe practices to make more money, and inaccessibility of basic healthcare services. These results lead us to conclude that the reduction of health and social care in the most vulnerable population transforms them into groups of social exclusion, which may affect also the public health system, by failing to detect and prevent many possible derivate infections.
\end{abstract}

Keywords: Prostitution, social exclusion.

Recibido: 16/09/2015

Aceptado: 16/11/2015

Publicado: 03/12/2015

1. Este proyecto se ha realizado en el marco del Proyecto Nacional de I+D+I con referencia CSO201455209-P, «Visibilizando a las víctimas de trata: actuando contra la trata de mujeres con fines de explotación sexual», y ha sido aprobado por el Comité de Ética de la Universidad Pontificia Comillas.

2. Departamento de Sociología y Trabajo social. Universidad Pontificia Comillas. c/ Universidad Comillas, 3. 28049. Telf.917343950. email: cmeneses@comillas.edu

3. Instituto de Innovación Social de la Universidad de ESADE 


\section{Introducción}

La prostitución es una actividad de baja cualificación, predominantemente femenina, y en las que las mujeres pueden ganar más dinero que los hombres en su mismo nivel (Edlund y Korn, 2002). La prostitución puede ofrecer mucho dinero en pocas horas y por eso se ha asociado con una actividad de «dinero rápido» (Willman, 2010). Los riesgos de tipo físico, psicológico y social que conlleva, hace que no sea la más deseada para las mujeres entre sus alternativas de sustento (Meneses, 2007). El alto nivel de ingresos económicos, el grado de autonomía y capacidad de decisión, cuando la actividad es voluntaria, llevan a muchas mujeres a tenerla en cuenta como una importante opción para su subsistencia. Muchos estudios han puesto de manifiesto que la principal razón para ejercer la prostitución es la necesidad económica y de supervivencia, especialmente entre las capas populares (Vanwessenbeeck, 2001; Meneses et al, 2003; Monroe, 2005), pero también hay otras razones que están detrás de ésta elección: la adicción a drogas, el abuso sexual en la infancia o la violencia de género (Cobina y Oselin, 2011). Se ha planteado que en momentos de crisis económica aquellas actividades más informales, marginales o precarias, por las condiciones que conllevan su realización, aumentan considerablemente. Este puede ser el caso de algunas modalidades del mercado servicios sexuales, ya que la prostitución puede realizarse de forma permanente, ocasional o de manera puntual, dependiendo de las circunstancias de las personas que las efectúan. En momentos donde la tasa de paro nacional supera el 26\% en España (INE, 2013), con pocas ofertas de empleo, la prostitución resulta una alternativa, o un recurso complementario, a los escasos ingresos que se puedan obtener desde actividades formales para satisfacer las necesidades básicas. De hecho, en épocas de mayor bonanza la prostitución ha supuesto no solo una forma de subsistencia sino una buena opción para obtener importantes beneficios en los proyectos personales.

Pero también se ha realizado una distinción entre las mujeres que realizan estos intercambios de forma voluntaria de aquellas que son explotadas o coaccionadas para ejercer la prostitución. En estos casos las condiciones son muy diferentes y cambia radicalmente las ventajas que la actividad pueda tener para las mujeres. La distinción de estas dos realidades en muchas ocasiones no es fácil, pues la amenaza y el maltrato impiden que se reconozcan y se declaren las situaciones de prostitución coactiva, aunque en muchas ocasiones se pueda producir posteriormente un tránsito al ejercicio de la prostitución voluntaria.

Encontramos claras diferencias de género en la ocupación de esta actividad. Mayoritariamente la oferta de servicios sexuales se concentra en las mujeres mientras que la demanda de estos servicios se produce por parte de 
los varones en la mayoría de los casos. Se ha planteado que las actividades económicas precarias, estigmatizadas, infravaloradas o poco reconocidas socialmente suelen ser ocupadas en mayor medida por las mujeres que por los varones (Vanwessenbeeck, 2001).

Podemos apreciar diversas formas de ejercer la prostitución, o maneras de contactar con los clientes, destacando tres modalidades (Meneses, 2008): la que contacta en la calle, la que se produce en los clubs de alterne, ya sean urbanos o de carretera, y la oferta de servicios sexuales en los pisos o casas de cita. Podríamos añadir una cuarta forma de contacto, aquella que surge mediante internet, pero en muchas ocasiones las modalidades anteriores se anuncian por esta vía, además de por la prensa escrita. La prostitución callejera suele ser la más minoritaria, en torno al $5 \%$, y la que más se ha descrito por los riesgos que conlleva, principalmente de agresión o violencia (Raphael y Shapiro, 2004). Sin embargo, se trata de la modalidad que menos comisiones tiene, es decir, las ganancias obtenidas por los servicios sexuales son en exclusividad para las personas que ejercen la prostitución. Aunque en la última década habría que añadir el riesgo punitivo, o a ser multada por utilizar la vía pública y, en este sentido, a compartir sus ganancias con los ayuntamientos correspondientes. En el nuevo siglo han proliferado las ordenanzas municipales prohibiendo la prostitución de calle con importantes repercusiones para las mujeres (Villacampa y Torres, 2013). La prostitución de calle es la más visible y por tanto la más estigmatizada y discriminada.

El objetivo de este estudio es describir los cambios y repercusiones que se han producido en las personas que ejercen la prostitución en la calle, en su contexto más inmediato y en las entidades que les presta algún tipo de apoyo como resultado de la reducción o eliminación de servicios sociales y sanitarios en Madrid. Estas medidas se enmarcan en políticas sociales aplicadas en la Comunidad de Madrid por la crisis económica acontecida entre los años 2011 y 2013 ante la demanda de reducir el déficit público del Estado.

\section{Material y métodos}

La investigación presentada es descriptiva, exploratoria y cualitativa. Se utilizaron dos técnicas de investigación: la observación participante (OP) y la entrevista abierta. La primera técnica se realizó en una zona tradicional de prostitución nocturna de calle, de cierto nivel adquisitivo ${ }^{4}$. En dicha zona existían

4. Comprende un par de manzanas entre las calles Capitán Haya y la Castellana. Se trata de una zona tradicional de alterne tanto en clubs, locales y apartamentos. Es una de las zonas de negocios de Madrid, a pocos metros de la torre Picasso. 
cuatro o cinco establecimientos de alterne que facilitaba la afluencia de clientes de servicios sexuales a la zona. La presencia de las personas que ejercían la prostitución comenzaba sobre las 11:30 hasta las 5:00 de la madrugada. Se realizó entre una y dos horas a la semana de observación, desde septiembre del 2012 a junio del 2013, suponiendo un total de unas 75 horas de observación aproximadamente. Las dos autoras de este trabajo llevaron un diario de campo de forma separada que permitía, posteriormente, triangular la información, suponiendo un elemento de rigor y calidad en la investigación cualitativa (Whittemore y otros, 2001; Pyett, 2003). Se trataba de una zona en declive a nivel de oferta de prostitución callejera, puesto que las autoridades locales y los propios vecinos de la zona habían intentado eliminar la presencia de esta prostitución nocturna. A través de la observación realizada, y desde las entrevistas conseguidas con las personas que desarrollaban esta actividad en la zona, calculamos una presencia de alrededor de 40 personas $^{5}$ que frecuentaban la calle ejerciendo esta actividad, aunque a distintas horas y en distintos días. La saturación de contenidos nos permitió dar por finalizada la $\mathrm{OP}$ en aquellos aspectos que eran fundamentales para cumplir con los objetivos de investigación planteados.

La segunda técnica de investigación utilizada fue la entrevista abierta, aplicada con dos tipos de sujetos-participantes: las mujeres que ejercían la prostitución, contactadas en la calle desde la técnica anterior; y los/as coordinadores/as o responsables de instituciones que estaban trabajando con estas personas en Madrid en ese momento. Las entrevistas llevadas a cabo con las mujeres fueron cortas, por término general, aproximadamente 15 o 20 minutos cada vez que acudíamos a la zona, planteando la misma pregunta a todas las que ese día estaban ejerciendo la prostitución. A todas las mujeres se les informó cuál era nuestro objetivo en la zona, la voluntariedad de responder a nuestras preguntas y nuestro compromiso de mantener la confidencialidad, tal y como se ha planteado para esta técnica (Kawulich, 2005). En solo dos casos se pudo efectuar una entrevista en mayor profundidad, en torno a una hora. Respecto a las entrevistas realizadas a las instituciones que trabajaban con personas que ejercían la prostitución, se planteó inicialmente llevarlas a cabo en ocho instituciones, pero solo se consiguieron cinco entrevistas en cinco organizaciones ${ }^{6}$. Tres entrevistas no se acometieron debido a diferentes causas (falta de tiempo de las entidades, negación a realizarla...). La duración

5. De estas personas cuatro mujeres eran ya conocidas por una de las autores al realizar en esta misma zona trabajo etnográfico en la década de los noventa (1993 a 1995).

6. Nuestro profundo agradecimiento a APRAMP, Cáritas, Fundación Cruz Blanca, Fundación Triángulo, y Colectivo Hetaira por facilitarlos la entrevista y la información requerida para esta investigación. 
Tabla 1. Guión de entrevista semiestructurada

\section{Guión entrevistas a entidades}

1. características de las personas atendidas, diferenciando en mujeres, varones y transexuales;

2. cuántas provienen de Trata; denuncias que se establecen; si la entidad asume la denuncia y lleva los casos.

3. Organización de la actividad y maneras y modos de intervenir. Recursos que proporciona a las personas que ejercen la prostitución

4. Acceso de los usuarios y usuarias a los recursos ofertados, cómo los perciben, necesidades no cubiertas y cubiertas.

5. Coordinación con otras entidades

6. Posicionamiento ideológico en la prostitución

7. Apoyos institucionales, administración, colectivos, asociaciones, etc.

8. ¿Qué recursos harían falta? ¿Por qué? ¿Mecanismos puestos en marcha para tratar de conseguirlos?

9. Impacto de la crisis en las personas que ejercen la prostitución y en la entidad.

Grafico 1. Categorías analíticas utilizadas

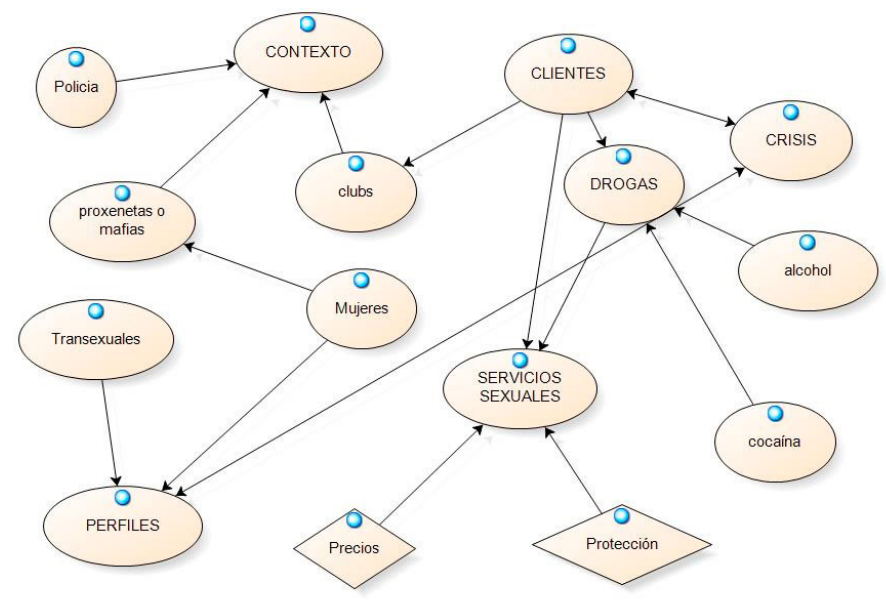

de las mismas fue entre 30 a 45 minutos y se efectuaron en la sede de las entidades. En la tabla 1 se presenta el guión de entrevista realizada. A pesar de que fueron cinco entrevistas, se consiguió la saturación de contenidos en las respuestas obtenidas al objetivo principal.

Se abordó un análisis categórico interpretativo de las notas de los diarios de campo y de las entrevistas realizadas. Se utilizaron distintas estrategias analíticas para los datos cualitativos (Leech y Onwuegbuzie, 2007): análisis de comparación constante; palabras clave usadas por los informantes en el contexto de estudio; análisis de contenido con categorías de análisis y codificación de los discursos y las notas; análisis de dominio o de los significados culturales. En el gráfico 1, se muestra las categorías analíticas 
utilizadas. Se utilizó el programa informático NVIVO v.10, en los procedimientos analíticos.

\section{Consideraciones éticas}

Todos los participantes fueron informados del objetivo del estudio, la participación fue voluntaria y se garantizó el mantenimiento del anonimato en los discursos y contenido obtenidos.

\section{Resultados}

Los datos recogidos nos llevan a señalar que las medidas de reducción de costes en servicios básicos como fruto de la crisis económica en los años mencionados afectaron a las personas que ejercían la prostitución, así como a las organizaciones que trabajaban con ellas. Mostraremos este impacto de forma separada, en las protagonistas y en las instituciones, pues los efectos fueron diferentes.

Impacto de la crisis en las personas que ejercen la prostitución

La gran mayoría de las mujeres contactadas en el trabajo etnográfico estaba ejerciendo la prostitución como medio de subsistencia. No obstante, para algunas de las mujeres jóvenes de Europa del este la entrada en la prostitución fue como consecuencia de una situación de coacción, engaño y explotación sexual, siendo menores de edad cuando sucedió esto. Este fue el caso de una de nuestras entrevistadas, con la que establecimos mayor relación. Una vez superada esta fase se había instalado en esta actividad como un medio de vida, y su juventud le proporcionaba importantes beneficios, siendo una de las pocas mujeres que la prostitución le proporcionaba en ese momento unos ingresos constantes y suficientes para sus necesidades. Pero no todas las mujeres que ejercían la prostitución en la calle conseguían mantenerse con esta actividad, ya que dependía de una serie de variables: si era autóctona o inmigrante, o la edad que tuviese. La juventud y la imagen física, o un cuerpo escultural, eran requisitos imprescindibles para atraer a los clientes y, por tanto, para disponer de un número diario de servicios y precios elevados en los mismos. En la zona estudiada la mayoría de las mujeres era joven y de Europa del este, especialmente de Rumanía. Las mujeres mayores, entre 38 a 50 años, conformaban un grupo destacado de españolas y extranjeras (brasileñas, italianas, colombianas, etc.). Muchas de estas mujeres habían disfrutado de prestaciones sociales o ayudas para ellas o sus hijos, complementando los ingresos de la prostitución, pero en ese momento se las habían suprimido 
(becas de comedor, becas para libros...). Por tanto, las percepciones sobre las consecuencias de la eliminación de servicios eran diferentes para cada una de ellas, porque partían de situaciones vitales distintas. En todo el tiempo que se realizó el trabajo etnográfico se recogió continuamente la queja sobre la escasez de clientes, si lo comparaban con otros momentos anteriores a este periodo. Los clientes eran su única fuente de ingresos.

«Ana está junto a la marquesina informativa del Ayuntamiento, junto a la acera. Se la nota muy enfadada. Parece que no hay clientes, según nos dice, lleva varios días aguantando largas horas y se marcha sin hacerse nada.» (Diario de campo, 13 diciembre, 2012)

«Nadine nos vuelve a comentar, como siempre, que no hay clientes, que ha estado bajando durante todo el mes de febrero y que no se ha hecho nada, que hay muy pocos clientes y que los que vienen no tienen dinero» (Diario de campo, 7 marzo 2013)

Se había producido una reducción de demanda de servicios sexuales, y esta era una consecuencia que ellas atribuían a la crisis económica. Las mujeres se acoplaban a las horas y días que encontraban mayor afluencia de clientes, alejados del fin de semana, o vísperas de fiestas. Por otra parte, al encontrarse la zona de prostitución muy cerca de un conocido estadio de fútbol, los días de partido entre semana eran días de gran ocupación. Esta zona de prostitución de calle, como sucede en otros lugares, estaba segmentada por edad. Las calles más visibles, transitadas, con afluencia de coches, y cercano a los dos grandes y prestigiosos hoteles, estaban reservadas para las chicas más jóvenes, fundamentalmente rumanas que eran las de mayor número. Las calles más oscuras y con menos tránsito eran el espacio de contacto de las mujeres más mayores. Dicha organización se mantenía desde la década de los ochenta y noventa, cuya presencia de mujeres en la zona cada noche fue más elevada que en ese momento.

La prostitución no conseguía ser la única fuente de ingresos para muchas de las mujeres, especialmente las más mayores, ya que la baja frecuencia de clientes demandando servicios sexuales les impedía que se mantuviera como su único medio de vida. Ello llevaba a que muchas de ellas articularan distintas estrategias para aumentar los servicios sexuales.

«Ana: Le he dicho al del bar qué cuanto me paga si me hago tarjetera, y me ha dicho que ya hablaremos. Claro, el tiempo que estoy aquí, esperando clientes, pues me dedico a repartir tarjetas del bar y me llevo unas pelas, que esto está mu, mal» (Entrevista, Ana, 40 años, española, 11 abril 2013)

Una manera de captación de clientes surgía aprovechando las nuevas tecnologías, dándose a conocer en páginas web de internet. Se buscaba maneras 
alternativas de captar clientes que permitiera aumentar los ingresos y poder satisfacer sus necesidades básicas.

«Nos habla de una colega rubia, que estaba con ella cuando nos acercamos a saludarla y que se ha marchado porque la han llamado por teléfono. Se anuncia en Internet, en una página web específica. Pero nos dice que ella no puede, que tiene un hijo de 21 años que no sabe a qué se dedica. Nos comenta que en las páginas web aunque pongas la cara de refilón suele haber fotografías del cuerpo, para que los clientes te vean y seleccionen, y que ella no puede porque tiene varios tatuajes que sería reconocidos rápidamente por su hijo, sus amigos o sus familiares.» (Diario de campo, 14 marzo, 2013)

Otra manera era el trasiego de las mujeres hacia el club y desde éste hacia la calle, aspecto que ha sido comentado en otras ocasiones y estudios (Day, 2007) y que se agudizaba en ese momento. La trayectoria solía ser del club a la calle, pues los ingresos que las mujeres obtenían, si no había proxeneta o mafia detrás que controlasen sus recursos, eran exclusivamente para ellas. Sus discursos también señalaban una baja demanda de servicios sexuales en los clubs de alterne, cuando venían de estos locales a ocupar espacios en la calle. Así nos lo contaba una de las mujeres.

« $i$ Te has planteado trabajar en un club?

No, porque tienes que ir al $50 \%$ con el dueño, en copas y en todo. No me interesa.» (Diario de campo, 8 noviembre 2012)

Era posible que la salida de club estuviera motivada por diferentes circunstancias, como el consumo de drogas, la mayor edad, etc. La edad era muy importante. Las mujeres mayores, a partir de los 40 años aproximadamente, difícilmente eran admitidas en los clubs o locales de alterne de la zona, ya que eran considerados como alto standing y eso significaba disponer de mujeres con muy buena presencia. Existía alguna excepción en ciertos pisos o apartamentos $^{7}$, tolerándose la presencia de mujeres de mediana edad junto con las mujeres más jóvenes.

«Esta noche conocemos a Nadia, es colombiana, pero lleva residiendo más de 20 años en España. Ha trabajado siempre en un club de alto standing de Madrid, pero ahora está en la calle. Aunque ella justifica su presencia en la calle de otra forma, el hecho es que a pesar de tener una apariencia e imagen estupenda, tiene 50 años, aunque aparente diez años menos. Si siguiese en el

7. Alrededor de la zona de prostitución de calle se encuentran una serie de pisos o apartamentos que son previamente concertados con las mujeres que están en la calle para poder realizar los servicios. También los tres grandes hoteles son otra opción, principalmente si son clientes de estos alojamientos. Por último, también es una zona de muchos apartamentos destinados a la venta de servicios sexuales. 
club la demanda de clientes hacia ella sería muy escasa» (Diario de campo, 17 septiembre 2012)

Solo se justificaba salir de la calle a un club, desde sus propias perspectivas en estos momentos de crisis económica y escasez de recursos, por dos motivos: las agresiones o violencia a la que se exponían en la calle o por las condiciones meteorológicas. Fue el caso de Catalina, una joven rusa, que se marchó de la zona porque había sido sujeto de agresión por parte de un cliente que iba bebido.

Por último, donde más afectaba la situación de crisis era a los servicios sexuales, especialmente en el precio y en el tipo de servicio. El sexo oral era la practica más demandada a las mujeres que contactaban en la calle, ya que dicho servicio era rápido y el más económico, pudiéndose realizar en el mismo coche del cliente. Un sector de los clientes que compraban estos servicios sexuales los solicitaba sin protección y se recorría la zona comparando precios y buscando la persona que se los ofreciese sin preservativo.

«Cuando llegamos Ana está negociando en un coche. Esperamos un momento por si no se lleva a efecto la negociación. Efectivamente se marcha. Nos acercamos a ella y nos dice que el cliente le pedía sexo oral sin preservativo. Hoy ha venido pronto, sobre las 22:00 y son 00:40, a.m y no se ha ocupado con nadie... Vemos a Nadia, se queja de lo mismo que Ana, ningún cliente y el único que se le ha acercado quería sexo oral sin preservativo. Parece que es el mismo, está buscando quién le oferta lo que quiere. Además, quiere el servicio por 20 euros». (Diario de campo, 21 febrero, 2013)

No hemos podido constatar que alguna de las mujeres ofertase los servicios sin protección, pero referencias a que siempre había alguna de ellas que rompía las normas y ejercía una competencia desleal estaba en sus discursos. Especialmente llamativo resultaba dicha acusación de las españolas y de mayor edad hacía las mujeres extranjeras, -rumana o albanesa-. Una de nuestras informantes de la calle nos decía:

«Mira, yo cuando me piden los servicios sin preservativo, les digo que son 500 euros, para quitármelo de encima. Una vez le dije a uno que cuando me trajera los análisis y me mostrara que no tenía ninguna enfermedad. Y el cliente vino otro día con las analíticas. Nos estuvimos riendo un rato de él». (Entrevista Adriana, 23 años. Rumana).

Por último, otro de los servicios demandados fue el consumo de drogas con el cliente, especialmente cocaína. En este caso no parecía que el precio hubiera variado, aunque la demanda del mismo sí.

«Tengo un cliente fijo, que es profesor de la Universidad como tú, que se pone coca y quiere que consuma con él. Tengo muchos clientes que consumen coca, o te viene puestos de coca, o te quieren pagar en coca porque no tengan 
pelas pero tengan coca, pero yo nunca lo acepto». (Entrevista Adriana, 23 años, Rumana).

En la zona estudiada tenían presencia puntual dos organizaciones, que antiguamente prestaban los servicios todas las semanas. Sin embargo, solo coincidimos con una de ellas y solo un día. La reducción de subvenciones por parte de la administración pública madrileña, como veremos a continuación, hizo que estas organizaciones tuviesen que disminuir su presencia en esta zona de prostitución. Por otra parte, durante gran parte del tiempo del trabajo de campo realizado se observaron controles policiales, a veces de alcoholemia y otras de cualquier tipo, que mermaban la presencia de mujeres y de clientes. Como ya hemos mencionado, la zona disponía de varios clubs de alterne que generaba una afluencia de clientes potenciales por la calle y que hacía muy difícil erradicar totalmente la prostitución en la vía pública.

Impacto de la crisis económica en las Organizaciones de apoyo

Las cinco entidades entrevistadas tenían presencia en las principales zonas de prostitución del Municipio de Madrid, y todas ellas confirmaban la información que habíamos recogido previamente: se había producido una disminución de la demanda de servicios sexuales y las mujeres que ejercían la prostitución no lograban obtener los recursos económicos que necesitaban para vivir.

«La crisis ha afectado en gran medida al mundo de la prostitución. Hay menos actividad, menos clientes... las mujeres que viven en el propio club donde ejercen la prostitución, vale... pero las que viven por su cuenta tienen serias dificultades para sufragar los gastos» (ONG, religiosa)

Por tanto, las entidades entrevistadas triangulaban la información que había sido recogida en el trabajo de campo etnográfico, y podía ser extrapolada a todas las zonas y sectores donde trabajaban. Esta escasez de clientes y de ingresos estaba generando una serie de consecuencias y repercusiones para las mujeres:

En primer lugar, si la prostitución para un sector de mujeres era una actividad temporal, hasta que la crisis económica remitiera, se estaba convirtiendo en algo más prolongado y no previsto inicialmente, además de pasar más horas intentando contactar con los clientes.

«Anteriormente las mujeres que venían a España a ejercer la prostitución lo consideraban como una «etapa provisional» o "proyecto de vida», como un medio para poder tener suficientes ingresos y luego emprender una vida independiente. Estos proyectos vitales se han visto destrozados, sus 
posibilidades son muy restringidas...dejar esto es prácticamente imposible» (ONG Religiosa)

«Las personas prostituidas trabajan muchas más horas que antes» (ONG, Religiosa)

En segundo lugar, la disminución de clientes, o de demanda de servicios sexuales, se producía en un momento de aumento de la oferta de estos servicios; es decir, más mujeres recurrían a la prostitución para sobrevivir. Incluso era el caso de muchas mujeres que hacía tiempo habían abandonado la prostitución, y entre las que predominan españolas. Por tanto, no solo había en la zona mujeres extranjeras.

«...de alguna manera tienen que satisfacer sus necesidades básicas...y en la prostitución tienen experiencia y contactos» (ONG Religiosa)

«Antes la mayoría provenían de Brasil, el Magreb, Europa del Este o Latinoamérica. Ahora muchos son españoles. Se nota en este sector también lo mucho que está sufriendo la población española en relación al empleo». (ONG laica, desde 1996)

En tercer lugar, ese aumento de oferta, con una disminución de la demanda, conducía al aumento de la competitividad entre ellas y a la reducción de la solidaridad o ayuda mutua.

«Esto supone mayores tensiones y conflictos entre ellas, y una reducción de la red de apoyo inmediata que allí tienen». (ONG, Laica, desde 1995)

En cuarto lugar, la escasez de ingresos había influido en la aceptación de algunas prácticas de riesgo. Solo se podía asumir una desprotección, o no usar preservativos, en los servicios sexuales si el precio de los mismos se triplicaba.

«Algunas se someten incluso a prácticas de alto riesgo, y antes nunca lo harían» (ONG laica, desde 2011)

En quinto lugar, otro servicio que podía incrementar los ingresos era el consumo de drogas. Los clientes, que acudían a la zona y las consumían, deseaban que las personas con las que se ocupaban y a las que le demandaban servicios sexuales las consumieran con ellos. Habitualmente las mujeres no ofrecían este tipo de servicio, pero muchos de ellas comenzaron a admitirlo.

Las drogas que se consumen ahora son principalmente cocaína y alcohol. Lo hacen para aguantar más. Un día se dan cuenta de que su compañera aguanta más que ellas, y lo prueban. Empiezan queriendo aguantar más y acaban volviéndose adictas. A veces son ellas mismas las que compran cocaína, pero otras muchas son los propios hombres quien se las facilitan. (ONG laica, desde 2011).

El sexto lugar, todas las entidades habían sufrido recortes en las subvenciones que recibían de la administración y que les permitían realizar su trabajo 
con las mujeres en los contextos de prostitución. Esta merma de ingresos había supuesto la reducción de su presencia en los contextos de calle y de su intervención.

Hemos perdido muchas subvenciones de nuestros proyectos de prostitución, si ya de por si es un sector muy excluido ahora lo está más. Los proyectos de prostitución sobreviven fundamentalmente por los fondos propios que aporta XXX por propia convicción, por aportaciones particulares, y por el apoyo tanto humano como material de las Adoratrices (Proyecto Esperanza) y las Oblatas. (ONG, religiosa)

Por último, una crítica importante recogida de todas las organizaciones fue las reducciones en materia de salud. La normativa aplicada en la Comunidad de Madrid en esos años impedía que los inmigrantes no regularizados pudieran ser atendidos en los servicios sanitarios, salvo en caso de urgencia. Esto suponía que la gran mayoría de las mujeres que ejercía la prostitución en esta zona no tenía acceso a los servicios sanitarios, pues estas mujeres eran extranjeras y en situación irregular. Por último, el material sanitario ofrecido a estas personas, especialmente los preservativos, también se había reducido e incluso mermado en calidad.

Esto es un gran problema, en el sexo anal es necesario tanto preservativo como lubricante, si no se rompe, y se contagia el Sida. Ahora ya no recibimos ni lubricante, y no podemos hacernos casi cargo de ese gasto...Es un problema de salud pública, un problema muy serio. (ONG, laica desde 1996)

Es muy importante el acceso a la atención sanitaria, y no solo para atender la salud sexual, sino porque el personal sanitario hacía una importante labor de detección de casos de $\operatorname{Trata}^{8}$, prostitución o malos tratos». «Esto las deja todavía más aisladas, todavía más fuera de la red normalizada de recursos. (ONG, religiosa).

Las instituciones públicas delegaban en las ONGs ciertos servicios sociales y de información sanitaria para las personas que ejercían la prostitución. Si estas organizaciones no podían seguir cumpliendo esta tarea como venían haciendo hasta el surgimiento de los recortes económicos el resultado era la

8. Trata hace referencia a la explotación de la prostitución forzada, más en concreto nos referimos a casos de Trata cuando se produce «la captación, el transporte, el traslado, la acogida o la recepción de personas, recurriendo a la amenaza o al uso de la fuerza u otras formas de coacción, al rapto, al fraude, al engaño, al abuso de poder o de una situación de vulnerabilidad o a la concesión o recepción de pagos o beneficios para obtener el consentimiento de una persona que tenga autoridad sobre otra, con fines de explotación. Esa explotación incluirá, como mínimo, la explotación de la prostitución ajena $\mathrm{u}$ otras formas de explotación sexual, los trabajos o servicios forzados, la esclavitud o las prácticas análogas a la esclavitud, la servidumbre o la extracción de órganos»(ONU, 2004:44-45).La Trata puede ser con fines de explotación sexual, laboral o de órganos. 
desatención básica a colectivos sociales vulnerables, incrementando la exclusión social.

\section{Discusión}

Como en otros estudios (Meneses et al, 2003; Cobbina y Oselin, 2011), las personas que ejercían la prostitución en la calle presentaban distintas trayectorias de entrada en la actividad, que se enmarcaban en los dos tipos de prostitución: la prostitución voluntaria y la prostitución coactiva. En ambas la crisis económica tenía importantes repercusiones para su bienestar social y su salud, afectado negativamente en estos dos aspectos a los colectivos más vulnerables. Nuestros resultados son acordes con otros trabajos donde se señalaba que la principal motivación para ejercer la prostitución en el colectivo de calle era la necesidad económica (McKeganey y Barnard, 1996). De hecho, algunas mujeres que habían dejado la prostitución recurrían de nuevo a ella para poder sobrevivir, especialmente las autóctonas y las más mayores de la zona (más de 40 años).

Además de la crisis económica, las medidas represivas, que pretendían erradicar o invisibilizar a ciertos colectivos sociales de la vía pública, generaban consecuencias más negativas que positivas, principalmente en materia de salud pública. En este sentido, tanto los escasos recursos económicos como los excesivos controles y sanciones administrativas podían producir una mala negociación de los servicios sexuales entre las personas que ejercían la prostitución y sus clientes, con importantes repercusiones en la protección contra las infecciones de transmisión sexual. Los servicios sexuales sin preservativos han sido demandados siempre por cierto sector de clientes y aunque la gran mayoría de las mujeres lo ha rechazado, en situaciones de crisis económica pueden considerarse como una opción para obtener ingresos (Cusick, 1998).

Nuestros resultados concuerdan con lo planteado por Adriaenssens y Hendrickx (2012), en donde el segmento de mercado de la prostitución más bajo, la de calle, la mayor edad de las personas que ejercían la prostitución y el menor atractivo físico estaban detrás de la aceptación de prácticas sexuales sin protección. El incremento del riesgo -vivido como algo lejano- era compensado por la obtención de ingresos económicos que les permitía subsistir a corto plazo.

También nuestros resultados apuntan a lo encontrado en otros trabajos (McKeganey y Barnard, 1996, Gossop et al, 1994, Meneses, 2007b y 2010), esto es, las conexiones entre el consumo de drogas y el consumo de servicios sexuales por parte principalmente de los clientes y secundariamente de las personas que prestan estos servicios, con las consecuencias que generan para 
la salud y el bienestar. Existen pocos y escasos programas de prevención del consumo de drogas en los contextos de prostitución, y los riesgos de adicción a cocaína y alcohol, como sustancias principales de consumo en estos contextos, pueden producirse en ambos actores sociales.

En ese momento la gran mayoría de las prestaciones sociales (alimentos, pago de libros, ropa, becas de guardería, comedor, etc.) que recibía la población que se dedicaba a la prostitución de calle eran ofrecidas por las organizaciones no gubernamentales, no existiendo recursos públicos para este sector. Si estas organizaciones que vienen desarrollando una tarea de atención y prevención a estos colectivos, desde los recursos que recibían del Estado, dejan de hacerlo queda al descubierto la atención social a un colectivo vulnerable y necesitado.

Las repercusiones de la inaccesibilidad a los servicios sanitarios por parte de las personas inmigrantes que ejercen la prostitución puede generar secuelas importantes tanto en esta población como en el trabajo que realizan las ONGs. En primer lugar, porque para muchas mujeres que ejercían la prostitución el mantenimiento del contacto con estas organizaciones se realizaba por la información sanitaria y el reparto de preservativos que les ofrecían, siendo una herramienta fundamental de trabajo. Desde esta tarea las organizaciones podían detectar aquellas mujeres que estaban explotadas o eran víctimas de Trata, y esta tarea se ponía en peligro. En segundo lugar, siendo un colectivo que necesitaba cuidar su salud se estaba poniendo en riesgo no solo su salud sino la de su familia y el resto de la población. Aunque fuera de forma egoísta debería replantearse que la falta de atención a los colectivos inmigrantes repercute en la falta de control de enfermedades e infecciones para el resto de la población. La atención sanitaria básica es una cuestión de derechos humanos y derechos de ciudadanía y España, como otros países de la Unión Europea, debería ser modelo en esta materia, ya que ha firmado y se ha vinculado a los tratados internacionales en materia de derechos humanos y de erradicación de la Trata, como el Protocolo de Palermo (2000),

Algunas limitaciones hacen que no podamos generalizar los resultados obtenidos, ya que no han sido explorados todos los contextos de prostitución de calle en Madrid, sino solo uno de ellos. Por otra parte, la presencia de varones y transexuales fue muy reducida, lo que imposibilita también extender los resultados a estos colectivos.

De los resultados obtenidos podríamos concluir con dos recomendaciones tanto para la intervención como para la investigación social. En primer lugar, evitar la reducción de recursos económicos en las entidades que trabajan con las personas que ejercen la prostitución en la calle, pues repercute en 
la oferta de atención y de servicios que pueden ofrecer, a la vez que se reduce considerablemente su labor de detección, información y prevención en los aspectos socio-sanitarios. En muchos pisos, locales de alterne e incluso carreteras o vías públicas donde se ejerce la prostitución el único contacto que tienen estas personas fuera del contexto de la prostitución son los profesionales que trabajan en las ONGs. La ausencia de las entidades de estos contextos de prostitución puede impedir la detección de la prostitución coactiva, y más en concreto la Trata con fines de explotación sexual en mujeres y niñas, fenómeno que ha ido creciendo en España en los últimos años (EUROTAT, 2013). En segundo lugar, se debe facilitar el acceso de estos colectivos vulnerables a la salud universal, pues el que solo puedan ser atendidos desde urgencias hospitalarias supone un gran desconocimiento de la epidemiología y la salud pública por parte de los políticos madrileños (como de hecho posteriormente se ha revocado). Estas medidas impiden tratar a tiempo enfermedades infecciosas y disminuyen el bienestar y calidad de vida de las personas, algo que atenta contra los derechos humanos y resulta increíble en sociedades democráticas y solidarias como las europeas.

\section{Bibliografía}

AdriaensSens, S., y Hendrickx, J. (2012).Sex, Price and preferences: accounting for unsafe sexual practices in prostitution markets. Sociology of health \& Illness, 34(5), 665-680.

CoBbiNA, J.E., y OSELIN S.S. (2011). It's Not only for the money: an analysis of adolescent versus adult entry into Street prostitution. Sociological Inquiry, 82(3), 310-332.

Cusick, L. (1998). Female Prostitution in Glasgow: Drug Use and Occupational Sector. Addiction Research, 6(2), 15-30.

FLICK, U. (2004). Introducción a la investigación cualitativa. Madrid: Morata.

Gossop, M. Powis, M. GrifFithS, P. y StranG, J. (1994) Sexual Behaviour and Its Relationship to Drug-Taking among Prostitutes in South London. Addiction, 89(8), 961-70.

KAWULICH, B.B. (2005). La observación participante como método de recolección de datos. Qualitative Social Research, 6(2),1-32

LeECH, N.L., y OnwUeGbuZIE, A.J. (2007). An Array of Qualitative Data Analysis Tools:bA Call for Data Analysis Triangulation. School Psychology Quarterly, 22(4), 557-584.

McKeganey y Barnard, (1996). Sex Work on The Streets. Prostitutes and Their Clients. Buckingham: Open University Press. 
Meneses, C., Rubio, E., Labrador, J., Huesca, A., y Charro, B. (2003).Perfil de la prostitución callejera. Análisis de una muestra de personas atendidas por APRAMP. Madrid: Universidad P. Comillas.

MENESES, C. (2007). Riesgo, vulnerabilidad y prostitución. Documentación Social, 144, 11-35.

MENESES, C. (2007b). Consecuencias del uso de cocaína en las personas que ejercen la prostitución. Gaceta Sanitaria, 21(3), 191-196.

MenEses C. (2008). Prostitución y salud mental, en Achotegui J. (Ed). Exclusión social y salud mental. Curso acreditado de formación continua para atención primaria. Barcelona, Ediciones Mayo. Pp.82-90.

Meneses, C. (2010). Usos y abusos de drogas en contextos de prostitución. Revista Española de Drogodependencias, 35(3), 329-344.

Monroe, J. (2005). Women in Street Prostitution: The Result of Poverty and the Brunt of Inequity. Journal of Poverty, 9(3), 69-88.

ONU. (2004). Convención de las Naciones Unidas contra la delincuencia organizada transnacional y sus protocolos. 44-45. http://www.unodc.org/documents/treaties/UNTOC/Publications/TOC\%20Convention/TOCebook-s.pdf (Consulta, 11 nov 2015)

PyetT, P. (2003). Validation of Qualitative Research in the «Real Word». Qualitative Health Research, 13(8), 1170-1179.

RAPHAEL, J. y SHAPIRO, D. (2004) Violence in Indoor and Outdoor Prostitution Venues.» Violence Against Women, 10(2), 126-39.

Whittemore, R., Chase, S., y Mandle, CL. (2001). Validity in Qualitative Research. Qualitative Health Research, 11 (4), 522-537.

Willman, A. (2010). Let's talk about money. En M. Hope, A. Levy y A. Willman (Eds.). Sex Work Matters. London: Zed Books.

VANWESSENBEECK,I. (2001). Another Decade of Social Scientific Work on Sex Work: a review of research 1990-2000. Annu Rev Sex Res, 12:242-89.

VillacAmpa, C., Y TORRES, N. (2013). Políticas criminalizadoras de la prostitución en España. Revista Electrónica de Ciencia Penal y Criminología. 15-06:1-40. 


\title{
DIEZ PROPUESTAS PARA CUIDARSE Y CUIDAR EN LAS PROFESIONES SOCIALES. HACIA LA CONSTRUCCIÓN DE UNA CULTURA DEL CUIDADO EN LOS PROFESIONALES
}

\author{
Ten proposals to care for oneself and others in the social professions. \\ Towards the construction of a culture of care for professionals
}

Carmina Puig CRUElls ${ }^{1}$

\section{Resumen}

Los profesionales son el recurso más valioso del sistema de servicios sociales y deben de cuidarse para poder cuidar. Cada día se enfrentan con historias de superación, pero también de dolor y de frustración, que los confrontan con ellos mismos.

El artículo quiere contribuir a la generación de consciencia sobre los efectos que produce en los profesionales trabajar con situaciones de riesgo psicosocial y promover la atención y la proactividad en lugar de instalarse en el malestar. De lo contrario, este malestar se traslada al interior de los equipos y también, en última instancia, a las personas atendidas.

Para ello, se fundamentan diez propuestas teórico- prácticas: la interdependencia, la inteligencia colectiva, el doble cuidado, atender la subjetividad, dotarse de una mirada molecular sobre las situaciones, la confianza, el volver a la palabra, la creatividad y el cuidado, investigar para cuidar y cuidarse y, por último, la supervisión social como forma de atención y autocuidado. Todas ellas son las reflexiones que resultan de una práctica sistematizada y del estudio realizado durante el ejercicio de supervisiones con diez equipos y sesenta profesionales del ámbito psicosocial, con el propósito de contribuir a la construcción de una mirada colectiva y así fundar una cultura del cuidado profesional.

Palabras clave: cuidados profesionales, supervisión, profesionales.

\begin{abstract}
Professionals are the most valuable resource of the social service system and they must take care of themselves to be able to care for others. Every day professionals have to deal with stories of overcoming obstacles, but also with stories of pain and frustration, which make them question themselves.

The article aims to generate awareness about the effects on professionals working with psycho-social risk situations and promote attention to these issues and pro-activeness rather than settling in the discomfort zone. If this is not done, this discomfort is transferred to the work teams and, finally, to the people they have to help.

To this end, ten theoretical-practical proposals are presented: interdependence, collective intelligence, dual care, address subjectivity, acquire a molecular perspective of situations, trust, return to words, creativity and care, research to care for others and care for oneself, and finally social supervision as a way to help others and oneself. These reflections are the results of a systematic practice and of a study done during the supervision of ten teams and sixty professionals in the psychosocial field. We will contribute to generate ideas, strategies and set aside resources to propose a care culture in global sense: towards the people we care for, towards teammates and towards oneself.
\end{abstract}

Keywords: professional care, supervision, professional.

Recibido: 04/08/2015

Aceptado: 20/11/2015

Publicado: 03/12/2015

1. Universidad Rovira i Virgili. Facultad de Ciencias jurídicas. CAMPUS CATALUNYA Despacho 20, edificio D1, $2^{\text {a }}$ planta. Av. Cataluña, 3543002 Tarragona. Departamento de Antropología, Filosofía y Trabajo Social. http://dafits.urv.cat. Correo electrónico: carmina.puig@urv.cat 


\section{Introducción}

Los profesionales sociales hablan sobre el cansancio que sienten, especulan sobre el malestar que sienten. Es muy comentado pero a menudo no se traspasa la barrera del comentario sin una verdadera toma de consciencia. «Si lo tenemos que hacer», dicen unos, o «haré lo que pueda» dicen otros, pero en la práctica se considera que tener cuidado de uno mismo está relacionado con mantener una buena salud y hacer ejercicio físico.

Este artículo huye del enfoque fisiológico y es una primera contribución a una nueva perspectiva, una nueva mirada fruto de la experiencia supervisora que pretende generar estrategias concretas para favorecer la salud mental de los profesionales, al mismo tiempo que maximiza su competencia con las personas atendidas. También aborda los problemas y propuestas que se hacen desde una perspectiva psicosocial, fundamentada principalmente en los autores Bleichmar (2009), Dejours (2006), Leal (2003-2006) i Molinier (20132015), orientados desde el psicoanálisis. El tratamiento de los problemas se relega desde una orientación de la fatiga por compasión o por el trauma vicario planteado por Rothschild (2006) en su obra Ayuda para el profesional que ayuda, así como por los planteamientos psicofisiológicos planteados por Figley, Adams \& Boscarino (2008) y Figley (2014).

Son antiguas las discusiones sobre el estrés y sus efectos en las profesiones sociales y como el compromiso y la responsabilidad pueden conducir a cambios en su bienestar psicológico, físico y espiritual. En el ámbito del trabajo social, quizás el autor más tratado y clásico sea Herbert Freudenberger (1974), quien se ha transformado en un referente cardinal para el abordaje del cansancio en el ámbito social. Justamente en Puig (2005) se analizan estos fenómenos y su expresión profesional.

Las propuestas de cuidado se fundamentan en la idea de que los síntomas de agotamiento profesional, propuesto por Freudenberger, son un problema acuciante y de que es posible la ayuda cuando los profesionales expanden su consciencia y practican activamente algunas de las propuestas psicosociales señaladas. Para ello se crean y delimitan diferentes procesos y propuestas prácticas, fundamentadas principalmente en los autores mencionados.

También se ha problematizado sobre los efectos que tiene sobre los profesionales trabajar con personas y situaciones de violencia, vulnerabilidad y pobreza, así como no poner atención a la idea expuesta por Dejours: «se han desatendido los sufrimientos del trabajo y en general el de las relaciones entre subjetividad y trabajo» (Dejours, 2006: 35).

Otro eje que fundamenta el trabajo multidisciplinario e integrador que se presenta es la participación en procesos de supervisión desde finales de 
los años 80 y la trayectoria de investigación realizada sobre este tema. Esta se sitúa en la intersección de diferentes marcos teóricos: trabajo social, teoría sistémica, teoría psicoanalítica, la ética del cuidado que propone Gilligan, (1985) y las capacidades transformativas descritas por Sharmer, (2007) y Kofman, (2007), que integran artes, prácticas y ciencias que ayudan a evolucionar competencias individuales y colectivas desde diversos ejes: uno desde «el ser» (más interno) y el otro «el hacer» (más externo).

Todo ello se realiza a través de la sistematización de la práctica de las sesiones de supervisión. Esta es entendida como la reconstrucción teórica de una experiencia práctica concreta y realizada (Gagneten, 1987; Aguayo, 1992; Ayllón, 1995). Precisamente a través de la sistematización práctica de las sesiones y de los contenidos de las supervisiones se ha analizado la experiencia como supervisora y de los supervisados, y se han elaborado las diferentes propuestas que se desarrollan en este artículo. Este proceso se ha desarrollado durante los años 2013 y 2014 dialogando con más de diez equipos conformados por sesenta profesionales.

Por último, se exponen las reflexiones que han acontecido como resultado de esta sistematización de supervisiones con profesionales del ámbito psicosocial. Ellos y ellas, sus aportaciones, han guiado las directrices de las propuestas que se formulan, que no tienen otro objetivo que el de amplificar la toma de conciencia sobre las necesidades profesionales y especialmente de los efectos que produce trabajar con situaciones de crisis social y así generar, dentro de lo posible, nuevas prácticas e instrumentos para estar atentos hacia los otros y hacia uno mismo con el objetivo de evitar y prevenir instalarse en el malestar personal, en el malestar en los encuentros con el otro o en el interior de los equipos.

Con ello se intenta favorecer la construcción de una mirada más colectiva y así generar ideas, estrategias y destinar recursos a fundar una cultura del cuidado en sentido global: hacia las personas atendidas, hacia los compañeros y hacia uno mismo.

A continuación se desarrollaran diez propuestas para cuidarse y cuidar en las profesiones sociales. A partir de una instancia de reflexión individual como supervisora y otra colectiva por parte de los supervisados, se ordenará lo acontecido en la experiencia generando conocimientos.

\section{Diez propuestas para cuidarse y cuidar en las profesiones sociales}

Las propuestas se fundamentan en tres ejes: el derecho a cuidar, cuidarte y que te cuiden. Partiendo de la inferencia de que los profesionales son el recurso más valioso del sistema de servicios sociales, educativos y sanitarios, y de que 
se enfrentan cada día a historias de superación, pero también de dolor y de frustración, que son duras de soportar y que los confrontan con ellos mismos.

La primera propuesta se plantea bajo el epígrafe de la interdependencia. Las personas somos interdependientes, nos necesitamos los unos a los otros para sobrevivir. Continuamente estamos intercambiando e interactuando y es precisamente en este intercambio donde surgen los efectos más brillantes y los más miserables de las relaciones. Todos formamos parte de este entramado de dependencias puesto que todos ayudamos.

La ética del cuidado nacida en Estados Unidos, de la mano de Carol Gilligan, reconoce la vulnerabilidad como una condición común de la humanidad. En su obra destaca que somos seres vulnerable extraordinariamente frágiles y dependientes a lo largo de las diversas etapas de la vida y que es necesario aceptar que somos vulnerables, que nos necesitamos los unos a los otros (Gilligan, 1985). Estas afirmaciones se oponen al valor neoliberal de la autonomía total y la independencia de la necesidad del otro. Guilligan afirma que somos interdependientes.

Con los planteamientos neoliberales imperantes y las políticas públicas menguando, las garantías del estado del bienestar están en peligro. En contrapartida el uso de métodos de gestión del mundo industrial, basados en los retos de la competencia económica, están más presentes que nunca en los sectores públicos a través de la gestión del caso en servicios sociales, la gestión sanitaria y también la gestión universitaria. Todos están regidos por las reglas de las buena gestión que si bien son imprescindibles para la administración de los recursos no toma en cuenta el trabajo real de tener cuidado de las personas. Esta situación hace que se tenga que retomar y poner en valor la cultura del cuidado, en el sentido de preocuparse por la atención, por el trato de los otros. No es suficiente con tratar bien técnicamente. Las personas «quieren estar informadas, sentirse seguras, que se ocupen de sus problemas y sus preocupaciones» (Molinier, 2015:2). Esto es más necesario que nunca. Todos lo necesitamos para estar-bien, para dar y darnos bien-estar.

El bienestar atraviesa a los profesionales que trabajan juntos, a los equipos de diferentes instituciones que trabajan desconectados y con poca comunicación. Intercambiar siempre ha sido importante. Ahora acontece como imprescindible porque los espacios de intercambio de atención, de conocimiento consciente y compartido, transforman nuestra manera de vivir y son saludables, curan y hacen bien.

Una segunda premisa es la inteligencia colectiva. Ni todo depende de mí, ni todo depende de los otros. Los acontecimientos y el insuficiente desarrollo del estado del bienestar se han ido tragando una gran cantidad de inteligencia 
colectiva de los profesionales, que ahora se encuentra desperdigada y no encuentra caminos para volver a re-pensar las situaciones. «La sensación de derrota es tan grande que ha dejado a los profesionales, a los intelectuales rendidos no sólo políticamente, sino a nivel de pensamiento. Es como si no se pudieran pensar nuevas opciones. Se ha impuesto una realidad, no la realidad» (Bleichmar, 2009:30).

Ni todo depende de mí ni todo depende de los otros, así es. Esta actitud se refiere a las iniciativas y a las nuevas formas que pueden ejercerse sobre uno mismo y el entorno para que sea más equilibrado. La idea es que no todo viene dado por las condiciones externas. Poder cuidar bien a los demás empieza por uno mismo y por el entorno inmediato. Esto requiere poder preguntarse ¿con quién? ¿Dónde? ¿De qué manera y de qué forma quieres y quieren ser cuidados? ¿Cómo establecer relaciones, debates, construcción conjunta de ideas? ¿En qué tiempos quieres y puedes hacerlo? No todo depende del otro.

La ética del cuidado nos aporta la necesidad de mantener un doble cuidado, hacia nosotros y hacia las personas atendidas. Profesionalmente se está abocado a trabajar muy atentamente en un doble cuidado: por un lado se supone a los profesionales una experiencia y un saber que actúa como resorte de confianza en las personas atendidas, como facilitadores de acciones sociales en beneficio de las personas. Pero cómo escribe Tronto (2013), la atención se estructura como una continuidad con lo que cada uno necesita y nunca como una dicotomía entre los que son atendidos y los cuidadores. Los profesionales necesitan poder reconocer su vulnerabilidad e interdependencia y así quizás poder pensar de nuevo sobre su rol y responsabilidad. «El cuidado no es una moral de los buenos sentimientos, es un proyecto social» (Tronto, 2013:44).

Mantener una atención hacia uno mismo es completamente necesario para no causar daños, para atender a lo que se está sintiendo y no traspasarlo (dentro de lo posible) a las personas atendidas (mal humor, frustración). Igualmente es necesario para controlar las expectativas profesionales y deshacerse de la idea de que trabajar con los otros, o posibilitar el acceso a los servicios, satisface plenamente el espacio personal-profesional. A menudo se exige a los profesionales tomar distancia y separar de forma artificial la vida del trabajo, pero este mandato es contraproducente porque niega la realidad y el riesgo. Los profesionales, siempre subjetivos en tanto que sujetos, sufren, sienten, tienen esperanzas e ilusiones. Es desde el sujeto encarnado en el profesional que se crea empatía y se puede atender al otro. La conciencia del riesgo y de los límites es lo que permite escuchar y aproximarse al otro, y comporta la necesidad de pensar y generar recursos protectores. 
Las transformaciones sociales son tan rápidas que requieren atender a la subjetividad, de lo contrario no es posible asumirlas. No se pueden subjetivar, ni hacerlas nuestras tan deprisa (Leon y Zemelman, 1997). Se quieren superar los problemas y resolver de forma muy rápida. Se quiere todo para ahora mismo.

A menudo la respuesta profesional es actuar, hacer, obteniendo (en parte) gran satisfacción del trabajo realizado, a pesar de saber que cuidar de las personas no es tan solo actuar, dar prestaciones, hacer informes o gestionar.

Para atender a la subjetividad hay que recuperar la espera, que no es la pasividad. Sostener la espera implica que se moviliza un proceso psíquico de reflexión y anticipación en el profesional, que puede resultar útil para elaborar la propia irritación que se produce cuando se trata de no hacer, de no ofrecer un recurso o de respetar otro ritmo profesional (Cancrini, 1991). Atender cuidadosamente nuestra subjetividad es no danzar al ritmo de lo urgente, de lo que es noticia. Estar informado no es conformarse con reunir mucha información sobre las personas. Sabemos que estar enterados, tener sobre o infrainformación, a veces, puede disparar intervenciones y decisiones sin tomar la suficiente distancia que permita que fluya la reflexividad y la calma.

El contexto individualista, basado en la búsqueda de la satisfacción de uno mismo, y que a menudo evita el encuentro con el otro, pudo hacer creer en un estado del bienestar que suplía la propia responsabilidad. Quizás en el imaginario social no nos hacía falta el otro y hoy es posible descubrir que las posiciones del cuidador y de la persona cuidada no son fijas y ambos tienen algo que ofrecerse. Se basan en la relación y no son reducibles a una actividad ni a una actitud de una sola persona sino que se apoya en el trabajo en común.

Se necesita volver a lo colectivo, a creer y sentir que la vida no sólo depende de uno mismo, sino de todos los que nos rodean. El trabajo, el desarrollo profesional, la familia, los amigos, las personas con las que poder actuar. Dependemos de lo colectivo, de aquello que es común, de saber poner en valor nuestro potencial colectivo. Una alternativa seria realizar un trabajo basado en la cooperación, en la atención compartida a las pequeñas cosas.

Dotarse de una mirada molecular es una propuesta proactiva. La atención social está necesitada de una mirada más molecular, más atenta a las transformaciones mínimas que acontecen en los procesos subjetivos de las personas. Precisa concentrarse, detenerse y apoyar la intervención en los procesos minúsculos que acontecen a las personas, también en los momentos de crisis. En términos de cuidado hay que prestar mucha atención a las relaciones, a las conexiones, y a las redes entre personas. 
Por otra parte, se pide más calidad en los servicios y de manera simultánea aumenta la lógica de la gestión y de la evaluación a partir de criterios objetivables. Sin duda es natural que tratemos de tener buena atención y cuidado a la vez que gestionamos de manera óptima los recursos de los ciudadanos. Pero la objetividad evaluadora no siempre es compatible con la realidad del trabajo de cuidar.

La cultura del cuidado implica habilidades discretas, encaje emocional y atención a las pequeñas cosas inefables. Comporta una conversación, entrelazada en la cotidianidad o en la textura de la vida cotidiana, como nos remarca Oury (2007). A veces resulta difícil evaluar este trabajo que a menudo sólo tiene sentido a largo plazo o de manera inesperada. El tiempo de la gestión no siempre coincide con el tiempo del cuidado, más flexible y discontinuo.

La sexta propuesta se fundamenta en la confianza hacia las personas que atendemos y hacia nosotros mismos. La confianza es un factor básico en las personas, tanto para la autoestima como para la convivencia. Se necesita recuperar la confianza en nuestros representantes, pero también la confianza en los compañeros, en las familias, en los jóvenes con los que trabajamos. La desconfianza es un tóxico que deteriora y debilita.

Poder recuperar la confianza en las personas está en relación con la espera atenta del otro, sostenida por el profesional. Consiste en realidad en construir un espacio de umbral (González, 2013) ${ }^{2}$, normalmente entre dos puertas, pero simbólicamente un espacio de tránsito donde las personas atendidas no están ni integradas (dentro del sistema) ni excluidas (fuera del servicio). Están en un espacio evolutivo intermedio, de difícil evaluación debido a su invisibilidad, pero que les ayuda a construir su confianza, su capacidad de superación, y sus acciones o reacciones a lo que les está sucediendo. Es un espacio de valor incalculable pero que no se puede medir bajo las leyes de la economía de mercado.

Ahora bien, también hace falta confianza en uno mismo como profesional para poder decir no, poder decir basta, para poder poner límites. Cuidarse implica esfuerzo, conocimientos, preguntarse cómo se conoce y se trata al otro, cooperando y reflexionando conjuntamente. Son precisamente este conjunto de prácticas de cuidado las que están llenas de decisiones donde no hay reglas fijas sino contextuales, que implican reflexión y tiempo improductivo (Molinier, 2013).

2. Conferencia pronunciada 12/3/2013 por Itziar González. Arquitecta, con motivo de la entrega de la medalla de oro del Colegio profesional del Trabajo Social. Catalunya. Recuperado el 1 de junio de 2015 https://youtu.be/xV1IHuRVSAk. 
Para todo ello hay que poder hacerse confiable. Ser más claro y riguroso, si cabe, en las narraciones sobre la realidad que se trabaja. Explicarse mejor en los entornos de influencia; exponer con transparencia los marcos desde donde se puede trabajar y manifestar posicionamientos. Todo ello otorga mayor credibilidad a los sistemas desde donde se actúa y hace más confiables a los profesionales.

Abandonar lo que Bleichmar (2009) denomina como una autocensura, que no sólo está condicionada por ser funcionario o pertenecer a una determinada empresa, sino por algo menos tangible, que tiene que ver con la falta de una perspectiva compartida respecto a la posibilidad de esbozar o diseñar algún tipo de propuesta nueva. Ella lo atribuye al malestar sobrante, en el sentido de que este malestar viene dado por la falta de un proyecto, por el sometimiento a la idea de que las cosas son así y siempre serán así, y que lo único que podemos hacer es amoldarnos a lo que hay (Bleichmar, 2009). De este modo, como dice Muraro (2012), nos reducimos a una existencia disminuida.

Es necesario recuperar el pensamiento de las cosas, sobre lo que pasa y sucede en el entorno, más allá de la inmediatez, sin asumir paradigmas insostenibles de atención que alejan del conocimiento de la realidad y colocan en una repetición ritualitzada (PIRMIS, ayudas económicas...) que abocan al desaliento y a la parálisis intelectual.

Quizás nos sobran imágenes, actos. Para ello hay que volver a la palabra. Faltan palabras, conversaciones, diálogos para generar alternativas o soluciones. Se necesita volver a la palabra, nombrar lo que pasa desde uno mismo y no desde la agenda de los otros (políticos, responsables de servicios...).

También la priorización durante las últimas décadas de un trabajo individualizado, masivo e invasivo, ha generado pérdida de palabras, experiencias y saber que otras generaciones profesionales tenían sobre el trabajo con grupos y colectividades.

El regreso a la palabra abre nuevas posibilidades, ya que «el lenguaje es generador, da orden y sentido a nuestra vida y a nuestro mundo y opera como una forma de participación social» (Anderson, 2000:22). El regreso a la palabra significa también recuperar el diálogo intergeneracional, el diálogo intercultural, y sobre todo el diálogo entre profesionales. Tan solo el diálogo, la palabra y el trabajo colaborativo puede conducir a una mayor creatividad. Se necesita creatividad para generar alternativas de trabajo, de acción social, alternativas que tienen que recuperar aquello que sabíamos hacer cuando existían menos recursos económicos. La innovación social necesita de la 
capacidad para impulsar prácticas concretas y sostener la impotencia, y así generar alternativas. ${ }^{3}$

La conciliación entre la creatividad y el cuidado profesional son imprescindibles. La creatividad es necesaria para reconocer y participar en las iniciativas sociales que acontecen en territorios concretos o en los servicios y requiere interés para saber lo que saben los otros, las personas que se atienden, los compañeros de profesión u otros servicios del territorio. Hay que resaltar la importancia de incorporar la perspectiva del usuario en los modelos de intervención y evitar dentro de lo posible las rutinas cotidianas acríticas.

Cuidar conlleva disponer de creatividad técnica para dotar a los recursos y las prestaciones de un nuevo significado. Los recursos no pueden cubrir de manera total lo que las personas esperan de los servicios. Los profesionales pueden acompañar procesos, mostrar posibilidades o distribuir prestaciones, pero el grado de satisfacción de las personas atendidas y el de los profesionales es limitado. Es recomendable no caer en un sobre exceso de valoración del poder transformador del recursos (Puig, 2008a).

Se necesita re- significar los recursos, en el sentido de dotarlos de nuevos significados. Estos se deben utilizar en su justa medida porque en caso contrario se devalúa su valor y el poder de cambio que tiene un recurso bien indicado y orientado (Puig, 2008b).

Es importante prestar atención al modelo de gestión imperante: primero el recurso y después la persona. A menudo los profesionales son presionados para resolver rápidamente los problemas o las listas de espera, cuando todo ello es muy complejo, y se sabe que algunos problemas solo pueden desaparecer a largo plazo y algunos no tienen solución. No creer en la validez del recurso significa descuidarse profesionalmente, ya que como indica Leal (2006),» lo que genera más incomodidad en el profesional no es la necesidad que le expresa el usuario sino la posición que éste adopta ante la misma. Quizás la necesidad sea objetivable [...] pero el sujeto necesitado, el que expresa yo necesito... me hace falta..., apela a la subjetividad y apunta a la subjetividad del que escucha» (Leal, 2006:37). Hay que avanzar hacia una re-significación de los recursos materiales. Con este propósito, planteé en algunos artículos de 2008 diferentes maneras de aproximación a las prestaciones y a los recursos, y a las que denominé micro-intervenciones para la mediación de los recursos, y que ahora denominaría prácticas de cuidado. Estas se refieren a orientaciones que sitúan al recurso en su capacidad real de apoyo. Respetando los

3. Enrique Sacanell (2009). Curso sobre calidad servicios sociales. Recuperado el 27 de mayo 2015 http://es.slideshare.net/sacanell/curso-calidad-servicios-sociales-2009-eudel-ivap. 
requisitos de una prestación sin usarla como reparación de lo que no existe en el sistema. De lo contrario, como expone Leal, las personas no pueden aceptar las prestaciones como funciones neutrales y es el vínculo y la implicación lo que fatiga y agota a los profesionales. Es necesario reconocer que aunque las instituciones han hecho un esfuerzo para dotarse de protocolos estandarizados, con ellos se afrontan las necesidades pero no los efectos vinculados los mismos.

Investigar para cuidar y cuidarse. La investigación es una manera de autocuidado. Esta se puede hacer investigando sobre la práctica y la acción profesional a través de la sistematización. Son necesarias investigaciones que aporten construcciones teóricas desde la experiencia práctica concreta. Se trataría de partir de la experiencia profesional como unidad sometida a un proceso de análisis (Aguayo, 1992).

Pero ¿cómo cuida la investigación a los profesionales? La investigación nos da conocimiento sobre aquello que se ha hecho y ha resultado útil y ha generado bienestar en las personas y ayuda a identificar aquellas actuaciones profesionales sin sentido y que no se tendrían que repetir. Permite identificar formas alternativas de hacer acción social que superen las estructuras rígidas de algunos encargos institucionales. Para realizar investigación y docencia debemos que proponer marcos, pedir tiempo reconocido y recursos en nuestras instituciones y así poder repensarse como profesionales y hacerlo colectivamente.

La supervisión social es una forma de atención y autocuidado. La supervisión es por excelencia una forma de atención, de cuidado de los profesionales ${ }^{4}$. La supervisión, como espacio de renovación durante el ejercicio profesional, se caracteriza por ser un ámbito de reflexión sistemática sobre la acción profesional sin cumplir funciones de control. Es un espacio para preguntar, para exponer dudas, para canalizar la no solución y debatir conflictos. El grupo y el supervisor escuchan y permiten que fluya la subjetividad de los participantes (Puig, 2014; Hernández, 2000).

La supervisión se basa en la experiencia y la práctica profesional, con el fin de mejorarla. Su función es pensar sobre lo que se hace, sobre el trabajo, para devolverlo a las personas atendidas. Este es su gran potencial formativo. Permite que puedan ser reconocidos problemas y experiencias dolorosas que se sufren en el trabajo, y tiene efectos terapéuticos en la medida que contiene, trata y posibilita, la elaboración de dificultades de forma cooperativa. El

4. Entrevista Carmina Puig. «Los profesionales somos el recurso más valioso del sistema de atención a las personas y debemos cuidarnos para cuidar» Obtenida 4 de junio 2015. http://www.social.cat/entrevistes 
supervisor no tiene funciones de control, ni de coordinación, ni de dirección. Por este motivo es una condición indispensable que el supervisor sea independiente y foráneo a la institución contratante. Es justamente esta posición del supervisor, distante de la tarea y de la institución, la que se convierte en una oportunidad para el supervisado de descubrir fortalezas personales y profesionales.

En las sesiones de supervisión se pueden tratar casos o los efectos de las situaciones institucionales en la intervención profesional. Aquello que permite intervenir al supervisor es el acuerdo de los participantes de mantener un espacio en el cual estén garantizadas la escucha, la palabra, la participación y la confidencialidad. Para los equipos, la supervisión resulta muy conveniente y aconsejable, a veces imprescindible y siempre útil (Puig, 2009).

En Cataluña diferentes instituciones han hecho suya esta práctica. Concretamente, existen experiencias de convenios entre colegios profesionales y diputaciones, o entre universidades y administraciones locales o comarcales, que han contratado servicios de supervisión externa y de este modo han apoyado a sus profesionales. ${ }^{5}$

La supervisión es una herramienta que, después de décadas de prácticas, es muy útil en la lectura de la complejidad actual (Puig, 2011:23) y en la construcción de una cultura de autocuidado profesional.

\section{Referencias bibliográficas}

Aguayo, C. (1992). Fundamentos teóricos de la sistematización. Revista de Trabajo Social de la Universidad Católica de Chile, 61, 31-16.

ANDERSON, H. (2000). Conversación, lenguaje y posibilidades: Un enfoque posmoderno de la terapia. Buenos Aires: Amorrortu.

AYLlón, M. R. (1995). La sistematización de la práctica. Apuntes desde una experiencia docente. Revista de Trabajo Social de la Universidad Católica de Chile, $61,2-28$.

Bleichmar, S. (2009). Superar la inmediatez: Un modo de pensar nuestro tiempo. Buenos Aires: Ediciones del CCC (Centro Cultural de la Cooperativa F. Gorini).

Dejours, C. (2006). La banalización de la injusticia social. Buenos Aires: Topia editorial.

Gilligan, C. (1985). In a Different Voice: Psychological Theory and Women's Development. Cambridge, Massachussets: Harvard University Press, 1982.

5. Col.legi Oficial de Treball Social de Cataluña. Obtenido el 4 junio 2015. http://www. tscat.cat/ 
Traducción: La moral y la teoría. Psicología del desarrollo femenino. México: Fondo de Cultura Económica.

CANCRINI, L. (1991). La psicoterapia, gramática y sintaxis. Barcelona: Paidós.

Gagneten, M. (1987). Hacia una metodología de sistematización de la práctica. Buenos Aires: Humanitas.

HERNANDEZ, J. (2000). La supervisión. Un sistema de asesoramiento y orientación para la formación y el trabajo. Valencia: Nau LLibres.

Kofman, F. (2007). Metamanagement. LHospitalet del Llobregat: Granica.

LEAL. J. (2003). Motivació i desencant profesional. Fórum. Revista del Centre d'Estudis Jurídics i Formació especialitzada. 1. Generalitat de Catalunya.

LEAL, J. (2006). La continuidad de cuidados y trabajo en red en salud mental. Madrid: Asociación Española de Neuropsiquiatría.

LeÓn, E., Zemelman, H. (1997). Subjetividad: umbrales del pensamiento social. México: Ed. Anthropos.

Molinier, P. (2013). Le Travail du care. París: La disopute / Snédit.

Molinier, P. (2015). Salud y trabajo en trabajadores hospitalarios: cultura de la gestión, cultura del cuidado, ¿Una condición imposible? Revista Topia. Recuperado de http://www.topia.com.ar/articulos/salud-y-trabajotrabajadores-hospitalarios-cultura-gestioncultura-del-cuidado-\%C2\%BFuna

Muraro, L. (2012). El poder y la política no son lo mismo. Revista Duoda, 39. Universidad de Barcelona, 37, 47-59.

OuRY, J. (2007). Psychothérapie institutionnelle, histoire et actualité. Paris: Éditions du Champ Social.

PUIG, C. (2005). El agotamiento de los profesionales. La importancia de la supervisión. Revista Trabajo social y salud, 50, 11-25.

PuIG, C. (2008a). La intervención social: más allá del recurso más cerca del vínculo. Servicios sociales y política social, 82, 9-27.

PUIG, C. (2008b). Las posiciones institucionales y profesionales que se imbrican en la atención a la demanda de las personas en los servicios sociales: la mediación entre la demanda y los recursos ofertados. Documentos Trabajo social, 40, 195-208.

PUIG, C. (2009). El equipo, las coordinación y la supervisión: construyendo la red. Sistemas de trabajo que contribuyen al trabajo en red. Aportación singular de la supervisión. VII Jornadas de servicios sociales de Atención Primaria. Colegio de educadoras y educadores sociales de Cataluña, 157-168.

PUIG, C. (2011). La supervisión en los equipos de Servicios Sociales: una oportunidad para la reflexión, el pensamiento y el cuidado de los profesionales. Cuadernos de Trabajo Social, 24, 123-133. Universidad Complutense de Madrid. 
PUIG, C. (2014). Supervision of child social care teams: a method to ensure quality services. Revista de cercetare [i interven] ie social 4 . The online version: www.scopus.com

SHARMER, O. (2007). Theory U: Leadingfrom the future as it Emerges. Cambridge. MA: Society for organizational Learning.

Tronto, J.C. (2013). Caring Democracy. Markets, equality and justice. New York: University Press. 



\title{
VOCES MIGRANTES FRENTE A LA VIOLENCIA DE GÉNERO': UNA INVESTIGACIÓN PARA LA ACCIÓN EN SAN FRANCISCO (EEUU) ${ }^{2}$
}

\author{
Migrant Voices Confronting Gender-based Violence: A Research for Action \\ in San Francisco (USA)
}

MARÍA PILAR TUdela-VÁZQUEZ ${ }^{3}$

\begin{abstract}
Resumen
Introducción: La intersección entre la violencia de género y el hecho migratorio, produce situaciones de vulnerabilidad concretas que dificultan el acceso de muchas mujeres a los recursos disponibles. Objetivos:1) Partir de las redes asociativas para atender a los procesos de formulación de necesidades y recomendaciones comunitarias. 2) Proponer la Investigación Acción Participativa (IAP), donde la trabajadora social desarrolle un papel de dinamización, como herramienta metodológica de enriquecimiento de la intervención social. Material, Métodos y Resultados: IAP que la autora desarrolló en la organización Mujeres Unidas y Activas, California (EEUU). Participaron 148 mujeres que incorporaron sus experiencias, necesidades y recomendaciones para la mejora de la calidad de los servicios sociales disponibles. La investigación se estructuró en 3 partes. A) Fase preinvestigación, B) Fase de Diagnostico Comunitario, y C) Fase de Herramientas para la Acción. Resultados: Esta investigación permitió visibilizar el potencial de los espacios comunitarios como ámbitos de intervención en donde las mujeres sobrevivientes se insertan como agentes de cambio. Discusión: La IAP nos permite, como profesionales de la intervención social, implicarnos en espacios de convergencia que permitan generar nuevas respuestas y/o mejorar las existentes.
\end{abstract}

Palabras Clave: Violencia de Género, Migraciones, Intervención Social Comunitaria, Investigación Acción Participativa.

\begin{abstract}
Introduction: The intersection between genderbased violence and migration produces specific situations of vulnerability that hinder the access of women to available social services. Objectives: 1) To take associative networks as the starting point to address the processes of needs assessment and community recommendations regarding violence against women. 2) To propose Participatory Action Research (PAR), where the social worker develops a facilitator role, as a methodological tool to enrich social intervention. Materials, Methods and Results: PAR developed by the author at the organization of Mujeres Unidas y Activas, California (USA). 148 women participated by incorporating their personal experiences, needs and recommendations to improve the quality of the social services available for assistance in cases of intimate partner violence against women. The research was structured in three phases. Phase A: Pre- research, Phase B: Community Diagnosis and Phase C: Tools for Action. Results: This research highlighted the potential of community spaces as areas of intervention where women survivors are inserted as agents of change. Discussion: PAR allows us, as social intervention professionals, to get involved in areas of convergence which are critical to generate new answers and / or improve existing ones.
\end{abstract}

Keywords: Gender-based violence, Migrations, Community Social Intervention, Participatory Action Research.

1. Como veremos más adelante, la organización define el problema de la violencia de género o machista, como violencia doméstica. Por coherencia con el proceso metodológico que aquí se presenta, la denominación de tan amplia problemática como «violencia doméstica» se mantendrá a través del texto, una vez presentada la definición que se desarrolló.

2. Los datos que aquí se presentan corresponden al trabajo de campo desarrollado en San Francisco y Oakland, entre 2006 y 2010 para la tesis doctoral «La Organización de Nosotras: Procesos de ciudadanía a partir de experiencias de 'ilegalidad' en Estados Unidos. Aprendizajes con Mujeres Unidas y Activas» dirigida por Prof. Carmen Gregorio Gil. Dpto. Antropología Social. Universidad de Granada.

3. Universidad de Granada. Dpto. Antropología Social. Facultad de Filosofía y Letras. Campus Universitario de Cartuja. 18071, Granada. E-mail: mtudela@ugr.es 


\section{Introducción}

La presente investigación se inserta en el marco de los trabajos que cuestionan la premisa de la violencia de género como un problema expresado de manera uniforme en la vida de las mujeres independientemente de la sociedad en la que vivan, orientación sexual, cultura, clase social o nivel educativo. Partimos de que las formas que adopta esta violencia y sus significados dependen de las relaciones sociales y contextos culturales en donde toma forma (Merry, 2009; Yoshihama, 1999), y por lo tanto, del papel que determinados ejes estructurales desarrollan a la hora de situar a las mujeres en espacios de vulnerabilidad localizados (Menjívar y Salcido, 2002).

Estas aportaciones abogan por incorporar en el estudio para la intervención y prevención de la violencia de género una perspectiva estructural que atienda a la diversidad de experiencias de las mujeres, partiendo de un análisis interseccional del papel que juegan la clase social, la nacionalidad, el género y la raza (Sokoloff y Dupont, 2005; Rivera, 1994; Crenshaw, 1991). Desde una perspectiva estructural, el problema de la violencia de género expresada en la vida de las mujeres migrantes no puede ser analizada como una cuestión únicamente relacionada con la distribución diferenciada y desigual de poder entre hombres y mujeres (Bhuyan y Senturia, 2005). Debemos complejizar los niveles de desigualdad y adoptar una visión integrada del papel que desempeñan otros ejes, como el racismo, el etnocentrismo, los privilegios de clase o el heterosexismo en su intersección con el género (Villalon, 2010). Esta forma de análisis nos permite explicar las razones de muchos de los factores identificados como relevantes en la vida de mujeres migrantes en relaciones violentas. Así, el estatus migratorio, la falta de redes sociales de apoyo, la precariedad laboral, y/o la falta de medios económicos (Alencar-Rodrigues, Cantera, y Strey, 2013; Fundación Cepaim, 2013; Montañez y Moyano, 2006), dejan de ser realidades estáticas e inamovibles, y se presentan como posibles ejes de intervención social en donde el Trabajo Social desarrolla un papel clave en el impulso de procesos organizativos comunitarios.

La prevalencia de la intervención individualizada en el problema de la violencia contra las mujeres, en detrimento de actuaciones a nivel grupal y comunitario, ha sido identificada como uno de los obstáculos para poder apoyar a las mujeres que buscan transformar su situación de subordinación (AlcazarCampos, 2013). La atención individualizada como única respuesta, contradice aquellas propuestas que desde el Trabajo Social, presentan la construcción de relaciones de apoyo mutuo y el trabajo grupal, como elementos clave para la adquisición de herramientas vitales de empoderamiento, como son la auto percepción y definición positiva y el desarrollo de habilidades y nuevos 
conocimientos (Wood y Middleman, 1992). Otro de los obstáculos señalados corresponde a la excesiva confianza depositada en los sistemas de intervención legal, como la principal puerta de entrada para adquirir asistencia. Importantes trabajos desarrollados en relación a mujeres pobres que pertenecen a comunidades definidas por nociones de exclusión y criminalidad, basadas en estereotipos de raza, etnicidad y/ o experiencias de ilegalidad ${ }^{4}$, muestran la ambivalencia de estas mujeres a la hora de recurrir a la policía en un caso de violencia de género (Bhuyan y Senturia, 2005; Menjívar y Salcido, 2002; Rivera, 1994). La posibilidad de que las intervenciones estatales reproduzcan las vivencias de maltrato y desempoderamiento que están viviendo en sus relaciones de pareja, previene a muchas mujeres de acudir a estos servicios en primer lugar (Coker, 2006; Strang y Braithwaite, 2002).

Los espacios comunitarios han sido identificados como lugares clave desde los que poder llegar a mujeres reticentes a utilizar aquellos servicios sociales que implican a la policía y priorizan la separación familiar (Sokoloff y Dupont, 2005). La construcción y promoción de respuestas comunitarias orientadas al fortalecimiento del tejido social supone una importante contribución para el trabajo preventivo y de apoyo en casos de violencia contra las mujeres (Lee, 2013). Concretamente, Wood y Middleman (1992) han definido dos formas de intervención claves que en Trabajo Social podemos desarrollar en este contexto. Partiendo del trabajo en grupo, ambas autoras resaltan la promoción y desarrollo de oportunidades de aprendizaje que permitan a las participantes conectar sus experiencias individuales con condiciones estructurales. Este tipo de procesos permite construir sentimientos de colectividad, a la vez que potencia formulas positivas de redefinición subjetivas. En segundo lugar consideran como intervención clave, facilitar oportunidades para que las mujeres tomen la iniciativa en el uso de recursos propios y comunitarios para promover cambios vitales, "participando y construyendo redes comunitarias, enfrentando obstáculos organizativos, y comprometiéndose en acciones políticas» (Pinderhuges en Wood y Middleman, 1992, p. 88).

Un objetivo de este artículo es abogar por respuestas de prevención y atención en materia de violencia contra la mujer en la pareja que partan de intervenciones comunitarias promovidas por organizaciones de base (Minkler, 2005), en donde la trabajadora social desarrolle un papel de facilitación. Como profesionales de la intervención social, esta investigación supone un ejemplo del potencial dinamizador que tiene el situarnos en aquellos procesos

4. La ilegalidad se define como el espacio de reproducción social producido a partir de la desconexión entre la presencia física en un espacio dado y el reconocimiento del derecho a permanecer en dicho espacio (De Genova, 2005) 
en donde la participación viene promovida por propuestas organizativas como las que destacan Wood y Middleman.

Un segundo objetivo es incidir, a través de una experiencia práctica, en la aplicación de la Investigación Acción Participativa (IAP) como herramienta metodológica necesaria para el enriquecimiento de la intervención social y en general, para la construcción de conocimiento y práctica científica en Ciencias Sociales (Humphries, 2008; Greenwood y Levin, 2006; Ander-Egg, 2003).

En el contexto de intervención en salud pública y comunitaria, la IAP viene siendo reconocida como herramienta para la promoción de cambios a nivel comunitario y estructural (Minkler y Wallerstein, 2011; Minkler, 2005; Wallerstein, 2000). En el área de la violencia de género, y concretamente la violencia en la relación de pareja, existen algunos trabajos publicados que muestran el potencial de la IAP a la hora de acercarnos, desde diferentes puntos de vista, a las realidades de las mujeres migrantes (Sullivan, Bhuyan, Senturia, Shiu-Thornton, y Ciske, 2005). Así encontramos investigaciones que recogen: 1) percepciones de la violencia en la pareja de mujeres refugiadas procedentes de países en guerra (Bhuyan, Mell, Senturia, Sullivan, y ShiuThornton, 2005; Shiu-Thornton, Senturia, y Sullivan, 2005); 2) experiencias de mujeres migrantes indocumentadas a la hora de solicitar recursos legales para casos específicos de violencia en la pareja (Ingram et al., 2010); 3) evaluación y recomendaciones en relación a los programas y servicios sociales disponibles (Bhuyan y Senturia, 2005). La mayor parte de estos trabajos inciden en la IAP en tanto que herramienta de acercamiento y problematización de perspectivas unidimensionales a la hora de atender las experiencias concretas de mujeres migrantes. Al mismo tiempo, es necesario continuar profundizando en el objetivo de la acción misma de la investigación. Es decir, plantear desde dónde parte la necesidad de investigar, y qué consecuencias tiene el proceso de la IAP para las comunidades que se involucran en dicho proceso.

En la investigación aquí presentada, se entiende la participación como un proceso guiado de reflexión colectiva y de búsqueda conjunta de propuestas para el cambio, por parte de los grupos afectados por la problemática social en la que se quiere incidir, atendiendo al grado de implicación de las partes interesadas (Villasante y Montañés Serrano, 2000; Greenwood, Whyte, y Harkavy, 1993). Por lo tanto, involucra a las personas afectadas, entendidas como agentes de cambio, en todas las fases de la investigación, incluyendo el diseño, la implementación, análisis y divulgación de los resultados. La propuesta consiste en que el papel de los trabajadores sociales sea proveer de 
las herramientas metodológicas necesarias para abrir procesos colectivos de reflexión y búsqueda de propuestas para el cambio (Ioé, 1993).

El presente artículo dedica una parte importante al proceso de la investigación con el objetivo de reflejar la relevancia de las metodologías utilizadas. Estas permiten asegurar un alto nivel de implicación a lo largo de su implementación y se encuentran articuladas desde el compromiso de situar en el centro del problema de la violencia de género vivida por mujeres migrantes, las necesidades y propuestas elaboradas por las propias protagonistas. Así mismo, a través de la propuesta metodológica presentada se incide en la necesidad de que el motor del proceso esté conformado por una visión y definición de cambio compartida, que trascienda las necesidades individuales y promuevan una mayor capacidad para la prevención y respuesta al problema de la violencia contra la mujeres en el ámbito de las relaciones de pareja.

\section{Métodos y Materiales}

Este estudio se desarrolla en Estados Unidos, concretamente en las ciudades de San Francisco y Oakland, California, en donde trabajé durante seis años como trabajadora social y educadora en el Dpto.de Educación para la Salud Comunitaria (Casa CHE) de La Clínica de la Raza. Este trabajo me permitió conocer de primera mano tanto las limitaciones como las potencialidades de un sistema de servicios sociales diverso y descentralizado. Este contexto dista mucho del español en cuanto al papel social del Estado y desarrollo de provisiones públicas de protección social. Caracterizado por una larga tradición de provisión de servicios sociales y aplicación de programas de intervención social por parte de un complejo y diverso entramado de agentes privados con y sin ánimo de lucro. Estos entran en contacto con las instituciones gubernamentales a través de financiación de programas de ayuda específicos y/o de convocatorias para proyectos de intervención social.

Siendo el fortalecimiento del tejido asociativo uno de los objetivos de la promoción de la salud comunitaria, entré en contacto con numerosas organizaciones trabajando en el área. Una de estas organizaciones fue Mujeres Unidas y Activas (MUA), con más de veinte años de historia y que cuenta con la participación de más de 200 mujeres en Oakland y San Francisco.

El proceso de la Investigación Acción Participativa se desarrolló como se muestra en la tabla presentada a continuación: 
Tabla 1: Fases de la Investigación-Acción

\begin{tabular}{|l|}
\hline A) Fase Pre-investigación/Acción \\
\hline - Demanda que guía la intervención. \\
- Definición de objetivos generales \\
- Constitución de Grupo motor. \\
- Diseño de la Investigación y Proceso \\
\hline B) Fase del Diagnostico Comunitario y Resultados \\
\hline 1) Definición del Problema: ¿qué es la violencia doméstica? \\
2) Encuesta. \\
3) Análisis grupal de los resultados de la encuesta. \\
4) Compilación de primeros resultados. \\
5) Grupos de enfoque. \\
\hline C) Fase de Herramientas para la Acción \\
\hline 1) Elaboración de Recomendaciones \\
2) Plan de Acción: Definición y puesta en marcha. \\
- Identificación de agentes políticos y sociales (Directorio). \\
- Herramienta de Difusión. Informe \\
- Capacitación para presentaciones en público \\
- Equipos para dar presentaciones \\
- Priorización de interlocutores (listado) \\
3) Implementación- Evaluación-Devolución. \\
- Presentaciones y reuniones \\
- Recoger devolución \\
- Valorar su incorporación \\
- Definir próximos pasos \\
\hline
\end{tabular}

Fuente: Elaboración propia en base a IAP. San Francisco, California 2009

\section{A) Fase Pre-investigación/Acción. Identificación de Objetivos}

En el año de 2008, el Departamento del Estatus de la Mujer de San Francisco $^{5}$ financió programas locales en materia de violencia de género, para ser implementados a través de organizaciones sin ánimo de lucro, que proveyeran servicios en las siguientes áreas: teléfonos de asistencia, atención y

5. En 1998, San Francisco fue la primera ciudad de EEUU que adoptó los principios recogidos en UN Convention on the Elimination of All forms of Discrimination Against Women (CEDAW), a través del Dpto. del Estatus de la Mujer y, la ya existente, Comisión del Estatus de la Mujer. Ambos organismos, Comisión y Departamento, tomaron como referencia este marco legal transnacional de Derechos Humanos de las Mujeres, para el desarrollo de políticas y programas dirigidos a la mejora de la calidad de vida de mujeres y niñas residentes en la ciudad y Condado de San Francisco. En mi artículo «Levantando Nuestra Voz»: Traducciones Locales de los Derechos Humanos de las Mujeres» se describe el contexto político en el que se inscribe esta investigación (Tudela-Vázquez, 2013). 
acompañamiento, servicios legales, prevención y educación, casas de acogida y pisos tutelados. Una de las organizaciones beneficiarias fue MUA, la cual inició una campaña comunitaria cuyo objetivo era visibilizar los obstáculos a los que muchas de las mujeres de la organización se enfrentaban cuando buscaban ayuda para salir de una relación violenta. Siendo este el objetivo general, me invitaron a colaborar en el proceso de la campaña, aportando apoyo técnico en el desarrollo de una investigación participativa, cuya finalidad era conocer y recopilar las experiencias de Mujeres Latinas Inmigrantes ${ }^{6}$ en relación a la violencia de género, así como evaluar con ellas los dispositivos y servicios de atención disponibles. Una vez finalizada esta etapa elaboraríamos un informe con recomendaciones que sirviera de herramienta para entablar diálogo, tanto con organismos institucionales como con organizaciones sociales. Dadas las características de la intervención en la que este estudio se insertaba, esta campaña se llamó «Campaña de Derechos en Violencia Doméstica».

Además de los objetivos generales presentados, el grupo motor, formado por dos educadoras, dos coordinadoras de la organización, y yo como facilitadora técnica, identificamos tres objetivos adicionales: 1) Incorporar la evaluación de los propios programas de la organización durante el proceso de investigación; 2) Capacitar a las participantes en temáticas relacionadas con la investigación y 3) Fortalecer las relaciones de la organización con otras organizaciones. Así mismo, diseñamos las fases de la investigación, las técnicas a utilizar y un cronograma.

Las técnicas utilizadas fueron una combinación de tipo cuantitativo, fundamentalmente la encuesta, y de tipo cualitativo, como grupos de discusión y de enfoque. También llevamos a cabo la aplicación de la observación participante, y técnicas participativas orientadas a la promoción de la reflexión y desarrollo de propuestas colectivas, aportando al estudio una perspectiva dialéctica, la cual incorpora una noción de sujeto participante como productor de conocimiento colectivo e implica presentar claves dinamizadoras que provoquen la reflexión (Alberich Nistal, 2008; Villasante \& Montañés Serrano, 2000).

El principal criterio de selección de las participantes fue su pertenencia a algunos de los grupos de trabajo de la organización, como los grupos abiertos de reunión semanal y los comités de trabajo dedicados al área de intervención en violencia de género y al desarrollo de liderazgo comunitario. A partir de

6. Con estas tres palabras se autodefine la organización, de manera que situar «in» delante de migración es parte de la autodenominación de la asociación y de las mujeres que la conforman. Así será presentado cuando sea el caso, de lo contrario mi opción preferente es el término «migrante» 
este criterio, el número de participantes en cada una de las actividades que comprenden esta investigación, se determinó en base a la disponibilidad y voluntad de las propias mujeres.

En total participaron 148 mujeres, con edades comprendidas entre los 18 y los 55 años, procedentes en su mayoría de México, y en menor medida de El Salvador, Nicaragua, Guatemala, Perú y Uruguay. Residentes en el Área de la Bahía de San Francisco, concretamente en las ciudades de San Francisco, Oakland, Richmond, San Leandro y Hayward.

\section{B) Fase del Diagnóstico Comunitario}

El proceso de Diagnóstico Comunitario se construye sobre la base dialéctica de la propia Investigación-Acción. Cada una de las fases de la investigación se encuentra delimitada por los resultados que se hayan obtenido en la fase anterior, por las reflexiones colectivas derivadas del análisis de estos resultados, así como por las preguntas que hayan surgido y que definen la metodología a seguir en la siguiente fase.

1) Definición del problema: ¿qué es la violencia doméstica? A través de dos grupos de discusión, elaboramos la definición de «violencia doméstica» de

Tabla 2. Definición de Violencia doméstica. Mujeres Unidas y Activas, 2008

Mujeres Unidas y Activas define la Violencia Doméstica como una forma de conducta ejercida por una persona para mantener el poder y el control sobre otra persona. Incluye las siguientes características:

- La violencia doméstica ocurre dentro de la familia, es silenciosa, está escondida, y es mantenida por normas sociales y culturales, tales como el machismo.

- La violencia doméstica no es la única forma de abuso. Existe también el abuso emocional, sexual y financiero, incluyendo insultos, intimidación, amenazas y violación, los cuales forman parte de una relación abusiva.

- La violencia doméstica impacta y es impactada por otras formas de violencia, tales como la violencia política (p.e, el encarcelamiento de inmigrantes indocumentados); violencia comunitaria, (p.e. vecindarios con altos índices de criminalidad y escasos recursos), violencia económica (p.e, explotación de los trabajadores inmigrantes)

- Para las mujeres inmigrantes, las amenazas acerca del estatus migratorio son a menudo usadas por sus compañeros como una forma de ejercer poder y control.

- La violencia doméstica ocurre entre esposos, novios, parejas LGBTQ, adultos mayores y sus cuidadores, padres e hijos o familiares, prostitutas y sus clientes o tratantes, así como víctimas de persecución y tráfico humano.

- Aunque la violencia doméstica puede impactar a cualquiera, la mayoría de las víctimas son mujeres y niños.

Fuente: Elaboración propia en base a IAP. San Francisco (California), 2009

Alternativas. Cuadernos de Trabajo Social, 22, 2015, pp. 185-206 - ISSN 1133-0473 
Mujeres Unidas y Activas. Se desarrollaron dos sesiones, con un total de 16 participantes; cada sesión fue facilitada por dos personas del grupo motor y se desarrollaron de igual manera. Las preguntas guía para la facilitación fueron: ¿Que tipos o formas de violencia se dan en la violencia doméstica? ¿Cuáles son las diferencias entre la violencia doméstica y otras formas de violencia? ¿A quién/quienes afecta la violencia doméstica? ¿Cuáles son las raíces de la violencia doméstica? La Tabla 2 muestra la definición resultante de esta dinámica.

2) Encuesta: Se implementó una encuesta de 22 preguntas cerradas de respuesta múltiple, diseñada por el grupo motor, que se aplicó a las 148 mujeres participantes. Esta herramienta permitió adquirir información acerca de la problemática identificada, pero sobre todo fue un ejercicio exploratorio para el diseño de las técnicas cualitativas que se aplicarían posteriormente. Los objetivos de la encuesta fueron, entre otros, saber cuántas de las participantes habían vivido experiencias de violencia doméstica y de qué tipo, de acuerdo a la definición elaborada, a qué servicios habían acudido, si habían obtenido servicios en español y cómo valoraban su experiencia en la búsqueda de ayuda. Sistematizamos y agrupamos los datos obtenidos en base a las siguientes categorías: 1) Incidencia de violencia en la pareja, 2) Obstáculos que impiden buscar ayuda, 3) Acceso y Experiencias en relación a los Servicios Disponibles 4) Factores que promueven buscar ayuda.

3) Análisis grupal de los resultados de la encuesta. El objetivo fue analizar a través de grupos de discusión los datos de la encuesta. La sesión se desarrolló de manera paralela en ambas sedes de la organización. En Oakland participaron un total de 27 mujeres y en San Francisco, 37. Cada sesión duró dos horas y media aproximadamente.

4) Compilación de primeros resultados del Diagnóstico Comunitario. A continuación se presentan los datos cuantitativos obtenidos en combinación con algunas de las aportaciones que surgieron durante las sesiones de análisis grupal.

- Incidencia de violencia en la pareja. Los resultados mostraron que 8 de cada 10 mujeres (81\%) habían experimentado alguna forma de violencia. De aquellas mujeres que habían experimentado alguna forma de violencia, la violencia física y verbal fueron las más frecuentes. Ochenta y cinco por ciento (85\%) indicaron haber experimentado violencia verbal y casi las tres cuartas partes $(73 \%)$ experimentaron violencia física. Una de cada cuatro (26\%) experimentó violencia sexual. Una participante describió cómo la violencia se expresa de 
Figura 1. Porcentaje de mujeres que encontraron cada uno de los obstáculos para salir de la relación de violencia

\section{Obstáculos Identificados}

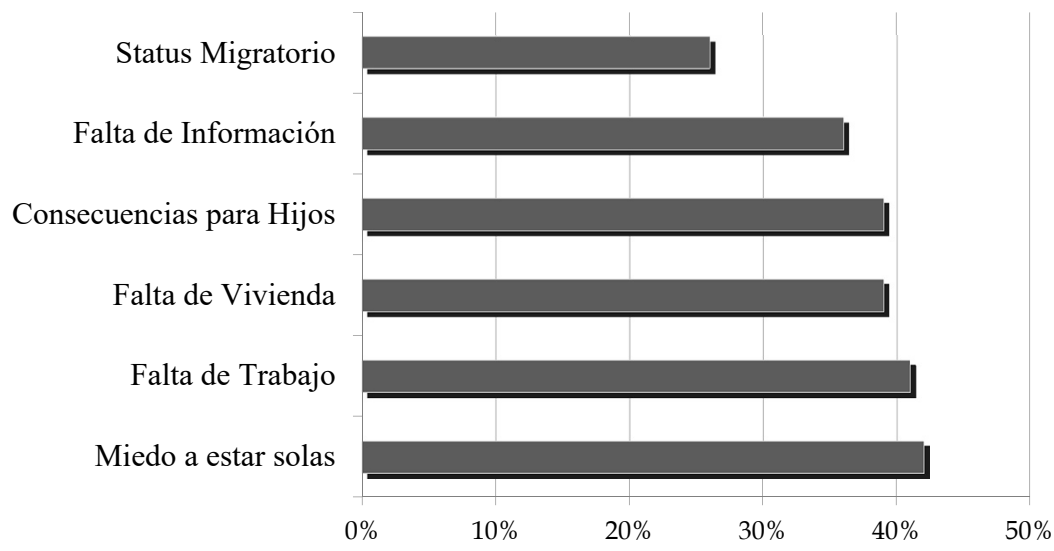

Fuente: MUA Encuesta. San Fancisco, 2009.

diferentes formas: «la violencia sexual es tanto el ser forzada a hacer el acto sexual como la humillación de tener que escuchar que una huele a esto o al otro».

- Obstáculos que impiden buscar ayuda. La Figura 1 presenta un resumen de los obstáculos identificados.

Como puede verse, los efectos negativos en los hijos fue una preocupación manifestada por muchas (39\%), y de manera particular en el caso de las casas de acogida. Una de las participantes (P1), en los grupos de análisis de la encuesta compartía su propia experiencia:

Tengo un niño de 17 años y una niña de 14, y por las edades que tienen te frenan porque no te los puedes llevar contigo. Entonces los exponen a otro trauma más grande porque estamos saliendo de un problema y pasar otro problema de que tienes que separarte de ellos. Muchas veces no sales de la situación por esto, o te vas a buscar ayuda en otro lado.

Como compartió otra participante (P2) otro obstáculo identificado está relacionado con el status migratorio: «muchas veces, una mujer es amenazada por su propio marido a ser denunciada a Inmigración, o a perder sus hijos si ella habla y él hace que la deporten». Una de cada 
Tabla 3: Experiencias de Servicios Contra la Violencia Doméstica

\begin{tabular}{|l|c|}
\hline \multicolumn{2}{|c|}{$\begin{array}{c}\text { Servicios de Violencia Doméstica } \\
\text { No Accedidos }\end{array}$} \\
\hline No acudieron a ningún servicio & $18 \%$ \\
\hline No fueron a una casa de acogida & $69 \%$ \\
\hline \multicolumn{2}{|c|}{ Experiencia en Servicios } \\
\hline La experiencia fue buena & $79 \%$ \\
\hline No fueron bien atendidas & $21 \%$ \\
\hline \multicolumn{2}{|c|}{ Acceso a traducción al español } \\
\hline Recibió traducción siempre & $54 \%$ \\
\hline $\begin{array}{l}\text { Recibió traducción usualmente o } \\
\text { Varias veces }\end{array}$ & $44 \%$ \\
\hline Nunca recibió el servicio & $2 \%$ \\
\hline \multicolumn{2}{|c|}{ Sentimiento de discriminación } \\
\hline No percibió discriminación & $67 \%$ \\
\hline Percibió discriminación & $33 \%$ \\
\hline \multicolumn{2}{|c|}{ Si experimento discriminación, que tipo } \\
\hline Por no hablar Ingles & $64 \%$ \\
\hline Por ser Latina & $48 \%$ \\
\hline
\end{tabular}

Fuente: MUA Encuesta. San Fancisco,2009.

4 mujeres (26\%) expresó que su status migratorio es un obstáculo para escapar de la violencia.

- Acceso y Experiencias en relación a los Servicios Disponibles. En la Tabla 3 pueden verse los principales resultados.

Casi la mitad de las participantes (44\%) recibieron servicios de traducción algunas veces o casi siempre. La otra mitad (54\%) dijeron haber recibido servicios de traducción en todo momento. Sin embargo, una participante (P3) comenta: «Hay lugares donde te ayudan por teléfono, donde sí hay traductor pero a veces cambian lo que tú estás diciendo. Lo que tú estás diciendo no es exactamente lo que ellos están traduciendo»

La atención psicológica (terapia), Grupos de Apoyo y Teléfonos de Asistencia fueron los servicios más utilizados. Más de la mitad (51\%) de las mujeres encuestadas eligió la terapia como recurso, y 
cuarenta y ocho por ciento (48\%) escogió grupos de apoyo. Una de cada cuatro (25\%) manifestó haber usado los teléfonos de asistencia. Una educadora (E1) explicaba: «reciben con más frecuencia servicios en español cuando acuden a servicios de terapia o grupos de apoyo. Además, estos servicios no incluyen separación familiar o llamar a la policía»

5) Grupos de Enfoque: Un resultado de la encuesta fue la infrautilización de los servicios legales e institucionales disponibles, y en especial las Casas de Acogida. Al mismo tiempo, la falta de vivienda fue identificada como uno de los obstáculos principales para salir de la violencia. Siete de cada 10 mujeres encuestadas no optaron por ir a una casa de acogida. De las mujeres que sí lo hicieron, cuarenta por ciento (41\%) definió la experiencia como «normal», quince por ciento (15\%) identificó la experiencia como «mala». Casi un cuarenta por ciento (39\%) abandonaron el programa manifestando que si estuvieran en la misma situación, no volverían a la casa de acogida.

Dinámica Grupo de Enfoque 1: En este grupo se exploraron, a partir de un guión de preguntas abiertas, las experiencias de mujeres que habían residido en casas de acogida. Participaron 10 mujeres, la mayoría procedentes de México, todas con un número de hijos entre 3 y 7 . Residieron en casas de acogida entre el 2003 y el 2007, y todas menos una completaron el programa de la casa de acogida.

Una de las preguntas fue en relación a los obstáculos que pueden intervenir a la hora de decidir ir a una Casa de Acogida. Las participantes identificaron las siguientes razones por las que consideraban que muchas mujeres no acuden a una Casa de Acogida.

- Preocupación por las consecuencias que tiene en los hijos e hijas salir de su casa y tener que ir a una casa de acogida.

- El aislamiento en el que la mujer se encuentra, sobre todo cuando acaba de llegar a Estados Unidos.

- La falta de información sobre los recursos disponibles y sobre sus derechos.

- Las malas experiencias de mujeres en Casas de Acogida, previene a otras de acudir a este recurso.

Además se compartieron las siguientes características que una casa de acogida debería de tener: 
- Personal que Hable Español en todo momento. Todas las participantes compartieron la barrera del idioma como un gran obstáculo.

- Atención para jóvenes, niñas y niños, en las casas de acogidas. Las participantes expresaron la necesidad de servicios psicológicos, programas educativos y espacios y normas que les permitan jugar.

- Apoyo para prevenir el maltrato entre las residentes y del personal a las residentes. Varias participantes reconocían que hay personal atento y dedicado a su labor. Al mismo tiempo compartían que no hay mecanismos para denunciar al personal que impone las reglas de forma desigual, y emplean el favoritismo.

- Apoyo para transitar los sistemas legales y de servicios sociales. Varias participantes expresaron no haber contado con toda la información que necesitaban para poder tener un plan de salida de la Casa de Acogida adecuado.

Casi todas las participantes recomendarían a una amiga y/o familiar ir a una casa de acogida en caso de violencia doméstica. Además de proveer un alojamiento, comida y seguridad, varias compartieron haber tenido el apoyo y la solidaridad que necesitaban, especialmente cuando las trabajadoras sociales las habían derivado a Mujeres Unidas y Activas.

Todas las participantes reconocían que ir a una casa de acogida puede ayudar a mejorar la vida, ofreciendo la oportunidad de buscar trabajo y ahorrar. Insistieron en la necesidad de que las Casas de Acogida estén en contacto con asociaciones comunitarias para asegurar que las mujeres se sientan seguras, apoyadas y con la información necesaria para poder tomar decisiones que las ayuden a salir adelante.

Dinámica Grupo de Enfoque 2: El objetivo fue explorar las causas por las que un número importante de encuestadas no acudieron a una casa de acogida. Participaron un total de 18 mujeres, la mayoría procedentes de México con un rango de edad entre los 20 y los 50 años, que no acudieron a una casa de acogida y eligieron buscar apoyo en sus redes cercanas o grupos de apoyo comunitarios. Casi el cuarenta por ciento (39\%) indicó que todavía vivían violencia con sus parejas cuando el grupo de enfoque se estaba desarrollando.

Al preguntar al grupo por qué no acudirían a una casa de acogida, las participantes identificaron los siguientes obstáculos:

- Las largas listas de espera para poder entrar a una casa de acogida.

- No tener suficiente apoyo en su idioma en el momento en que deciden dar el paso. 
- Tener hijos en edad adolescente que no pueden entrar en la casa de acogida

- No tener hijos, y por tanto menos posibilidades de entrar en una casa de acogida.

- Presentar casos de maltrato psicológico, los cuáles son considerados de menor riesgo que la violencia física y/o sexual.

Muchas mujeres identificaron la falta de información y de apoyo para utilizar los servicios de atención disponibles, el aislamiento, y las malas experiencias de otras mujeres en casas de acogida, como las razones principales por las que no eligieron este servicio. Este grupo también habló acerca de las ventajas y desventajas de buscar apoyo en redes cercanas y/o intentar salir sola de la relación violenta. Señalaron al grupo de apoyo de Mujeres Unidas y Activas como el lugar en donde estaban aprendiendo información útil para poder identificar «lo que no es normal» en una relación. Además en este grupo se compartió lo siguiente:

- Acudir a una casa de acogida y/o a la policía ayuda a que el caso legal de una mujer tenga más fuerza. El grupo discutió acerca de las ventajas que tiene hacer denuncias a la policía como tramite para fortalecer sus casos legales y acceder a otros recursos. También expresaron las dificultades por no hablar inglés, no tener papeles, el miedo a que te deporten y separen de los hijos e hijas, o no tener la información y estar aislada.

- Tener que irse de casa y cambiar el ritmo de vida de los hijos e hijas es una gran desventaja. Varias participantes reconocieron que, independientemente de a donde vayas, casa de acogida o a casa de familiares/amigos, tener que salir de tu casa junto con los hijos y ser la persona que tiene que cambiar de vida, es en sí un gran obstáculo. No tener trabajo y las consecuencias en la vida de los hijos e hijas, son los factores que más influyen a la hora de tomar esta decisión.

- Las redes familiares y/ amigos ayudan mucho cuando las relaciones familiares son saludables, pero también pueden ser un gran obstáculo. Las participantes reconocieron que si encuentran apoyo en las redes más cercanas, prefieren acudir a estas en primer lugar. La gran mayoría había llegado al grupo de apoyo de MUA de la mano de alguien que conocían. Al mismo tiempo, se compartieron experiencias de aislamiento y violencia fomentadas por el miedo y el chantaje en el ámbito de las redes familiares. 


\section{C) Fase de Herramientas para la Acción}

1. Elaboración de Recomendaciones. Concluido el diagnóstico comunitario, en el grupo motor preparamos la metodología con la que desarrollar las recomendaciones de la organización. Estas se desarrollaron en dos fases, protagonizadas por un total de 30 mujeres.

Definición de Recomendaciones: Recopilamos la información recogida y la repartimos entre las participantes para agrupar las recomendaciones que habían ido surgiendo en el Grupo de Enfoque 1. Se identificaron las siguientes categorías: 1) Idioma/Acceso a recursos, 2) Jóvenes y niños, 3) Empleados: Formación y Atención al usuario, 4) Calidad general de servicio, 5) Apoyo de la organización. A partir del análisis de los resultados del Grupo 2, se añadieron las siguientes categorías 6) Fortalecer los espacios comunitarios 7) Respetar los diferentes procesos de sanación. Criterios utilizados en la definición de recomendaciones: que fueran «posibles», es decir, que fueran alcanzables, potencialmente sostenibles, y que respondieran a cambios que beneficiaran a «grupos diferentes».

En total se desarrollaron 6 recomendaciones principales, que se presentan tal y como vienen recogidas en el informe:

- Fortalecer Redes de Apoyo Comunitarias. Las mujeres Latinas inmigrantes que están en una relación de violencia y maltrato necesitan encontrar información de servicios de apoyo en los lugares en donde ellas desarrollan su día a día y en su idioma.

- Incorporar a Mujeres acompañantes en los Servicios de apoyo y asistencia en Violencia Doméstica. MUA cuenta con sesenta mujeres que participan activamente en la organización y que han recibido el curso de capacitación para detección y asistencia de casos de violencia doméstica aprobado por el Estado de California (EC 1037.1). Los servicios sociales específicos para esta problemática enriquecerían y aumentarían su competencia cultural si incluyeran en sus programas a mujeres hispanohablantes capacitadas para dar servicios y responder a las necesidades de las mujeres inmigrantes.

- Construir y Ampliar Colaboraciones. MUA considera prioritario que se formalicen colaboraciones entre servicios comunitarios formados y dirigidos desde la comunidad inmigrante, con otros servicios como casas de acogida, servicios legales y jurídicos.

- Mejorar la Atención Profesional. Es necesario que los profesionales que trabajan en esta problemática estén capacitados, a nivel humano 
y profesional. Es importante que acompañen a las mujeres a lo largo de todo el proceso, ayudando a transitar complejos sistemas legales y de ayudas públicas, presentando en todo momento a la mujer cuáles son sus opciones y posibilidades.

- Respetar y Apoyar Diferentes Procesos de Sanación. Mujeres Unidas y Activas promueve a través de su modelo de trabajo respuestas colectivas para romper el aislamiento que la persona en violencia doméstica está viviendo, respetando en todo momento su proceso personal. Apoyar a mujeres que están pasando por experiencias por las que otras mujeres de la organización también han vivido, promueve la sanación de todas. Es en las respuestas colectivas y de solidaridad donde está la fuerza de sanación individual y comunitaria.

- Priorizar Fondos Económicos para Servicios y Organizaciones Comunitarias. En el momento de crisis económica actual, las familias con pocos recursos económicos están viviendo grandes dificultades que ponen en riesgo su calidad de vida. Ahora más que nunca es necesario fortalecer los servicios básicos y de asistencia.

2. Plan de Acción: Definición y puesta en marcha: Una vez desarrolladas las recomendaciones, diseñamos un Plan de Acción para su presentación a agentes políticos y sociales, interesados en adscribirse a las recomendaciones y trabajar en colaboración. Se desarrollaron las siguientes actividades:

- Identificación de agentes políticos y sociales. Elaboramos un directorio de instituciones públicas y privadas con capacidad de influencia política para incorporar dichas recomendaciones.

- Herramienta de Difusión. Redactamos y se publicó, con el apoyo de la organización «Data Center. Research for Justice», un informe que recogiera las motivaciones y resultados del diagnóstico comunitario y los resultados del mismo (Mujeres Unidas y Activas, 2009).

- Capacitación para dar presentaciones. Realizamos dos talleres para aquellas mujeres que habiendo participado en el proceso, quisieran formar parte de los comités de presentación de las recomendaciones.

- Comités de presentación de Informe. Se estableció un grupo de 10 mujeres que formaron dos equipos, uno para trabajar en la ciudad de Oakland, y otro para trabajar en San Francisco. Los grupos estuvieron formados por mujeres voluntarias y educadoras que habían sido parte del grupo motor.

- Priorización de interlocutores. Cada grupo elaboró un listado de organizaciones en las que presentar las recomendaciones en base a una 
serie de criterios: a) Non- profits y grupos comunitarios afines, para buscar formas de trabajo conjunto y preguntar por otras organizaciones (institucionales y comunitarias) que pudieran estar interesadas. b) Organizaciones comunitarias afines no conocidas, derivadas del grupo anterior c) instituciones o servicios específicos d) administraciones públicas y fundaciones privadas.

3. Implementación-Evaluación-Devolución. Mujeres Unidas y Activas inició el Plan de Acción, con una rueda de prensa en su sede de San Francisco a la que acudieron dos medios de comunicación local de habla hispana. A continuación comenzaron las reuniones con directores de Casas de Acogida, redes de colaboración entre servicios sociales y organizaciones comunitarias. En total se desarrollaron 40 presentaciones, destacando la realizada al Departamento del Estatus de la Mujer del Ayuntamiento de San Francisco, durante la cual Mujeres Unidas y Activas se vio reconocida por la importante labor de visibilización y promoción de los derechos del colectivo al que representa. En reacción a esto, algunas organizaciones, dedicadas a la provisión de servicios sociales en esta área, cuestionaron la identificación de la organización como un servicio propiamente de "violencia doméstica» partiendo de una definición asistencial. Durante estas reuniones MUA reivindicó su papel y trabajo por la mejora de la calidad de vida de muchas mujeres que, tal y como mostraba la investigación llevada a cabo, no se sienten identificadas en un gran número de servicios. Además incorporó muchas de las impresiones derivadas de las conversaciones establecidas en el diálogo interno de la propia organización, como por ejemplo, incorporar psicólogos infantiles y crear grupos de jóvenes, así como establecer protocolos de emergencia con servicios específicos.

\section{Resultados}

Esta investigación pone de manifiesto el potencial de procesos de IAP, no como un fin en sí mismo, sino como herramienta para el impulso de cambios que parten de la propia experiencia de quienes se involucran en el proceso. El alto nivel de compromiso con la intervención por parte de las mujeres de MUA estuvo promovido por su enfoque hacia el impulso de cambios concretos basados en sus necesidades y propuestas. Las herramientas metodológicas aplicadas sirvieron para facilitar la reflexión colectiva y definición de los pasos siguientes, incorporando la construcción de conocimiento junto con objetivos para la transformación de los dispositivos institucionales disponibles. Estos resultados contienen un impacto aún mayor si atendemos 
a tres niveles de diálogo interrelacionados. En primer lugar, encontramos un nivel de dialogo entre la mujer y el grupo de acogida. El proceso descrito permitió que aquellas necesidades identificadas por las participantes como individuales a través de, por ejemplo, la encuesta fueran trasladadas al ámbito grupal, a través de los grupos de discusión, permitiendo romper sensaciones de aislamiento a la vez que construir un análisis de problemáticas y necesidades que les afectaban como grupo. En segundo lugar, encontramos un nivel de diálogo dentro de propio grupo de Mujeres Unidas y Activas. La prevalencia de la atención individualizada, la falta de servicios de traducción en momentos clave y la asunción de la separación familiar como la «mejor»solución, fueron identificadas, entre otras cuestiones, por las participantes como formulas institucionales generalizadas que sin embargo no consiguen responder a sus necesidades y experiencias como mujeres migrantes, que no hablan inglés y que por las razones presentadas prefieren acudir a servicios comunitarios. Un tercer nivel de dialogo se desarrolló entre la organización y otros servicios trabajando en el mismo área de intervención, como grupos comunitarios y servicios institucionales específicos. De esta manera, la organización inició y afianzó relaciones con servicios sociales específicos estableciendo programas conjuntos de colaboración, como por ejemplo el acceso de mujeres capacitadas para el acompañamiento en Casas de Acogida. Así mismo, la presencia de Mujeres Unidas y Activas en espacios institucionales, como interlocutoras expertas, contribuyó a la promoción de servicios y programas basados en el empoderamiento y liderazgo en tanto que servicios de prevención y atención de violencia contra las mujeres.

\section{Discusión}

A menudo las mujeres que abogan por los derechos de quienes viven violencia de género se encuentran insertas en lógicas de victimización y desempoderamiento cuando buscan compromisos de cambio desde espacios institucionales (Coll, 2010). Sin embargo, a nivel local, estos pueden servir para impulsar procesos organizativos que incorporen las necesidades sentidas de la personas destinatarias de intervención (Pastor Seller, 2004, 2001). También pueden convertirse en escenarios de articulación ciudadana promovidos por quienes ponen en marcha definiciones de derechos propios orientados a la mejora de la calidad de vida colectiva. Para ello son necesarias herramientas de análisis estructural que nos permitan cambiar el enfoque institucional de victimización de las mujeres e incorporar intervenciones basadas en la capacidad resiliente de las personas, que potencien la autonomía en la toma de decisiones 
y reproduzca modelos de atención y acompañamiento (Fundación Cepaim, 2013; Wood \& Middleman, 1992). Como trabajadoras y trabajadores sociales la perspectiva estructural nos propone nuevas formas de intervención social a medida que la realidad se complejiza y surgen propuestas que impulsan políticas públicas de impacto más amplio y profundo (Sokoloff \& Dupont, 2005). Finalmente, abandonar la perspectiva de la violencia de género como un problema unidimensional, nos permite mejorar las respuestas al problema en la medida en que podamos desarrollar intervenciones adaptadas a las necesidades y realidades, culturales, políticas y económicas, de las mujeres con las que trabajamos.

Como trabajadoras y trabajadores sociales, casos como el que aquí se presentan nos ofrecen oportunidades para potenciar prácticas de Trabajo Social Comunitario vertebradas por organizaciones comunitarias. Este posicionamiento nos permite ser agentes activos en espacios de convergencia para incidir en problemas sociales, facilitando la incorporación de voces que a menudo están situadas en los márgenes de los espacios de toma de decisión.

Agradecimientos: La investigación aquí presentada no hubiera sido posible sin el trabajo y apoyo de las mujeres de la organización Mujeres Unidas y Activas: María de Jesús Jiménez, Juana Flores, Claudia Reyes, María Guadalupe Carrillo, Mari Chuy Hernández, Andrea Cristina Mercado, Carmen Denís, Andrea Lee y Ariana Gil Nafarrate. Así mismo, quiero hacer explícito mi agradecimiento a las mujeres participantes en los Comités Corazón y Clínicas del Alma de Oakland y San Francisco y a quienes dedicaron su tiempo, fuerza e historias de vida a la «Campaña de Derechos en Violencia Doméstica».

\section{Bibliografía}

Alberich NistAL, T. (2008). IAP, Redes y Mapas Sociales: Desde la investigación a la intervención social. Portularia, 8 (1), 131-151.

AlCAZAR-CAmpos, A. (2013). Social Work with Female Victims of Gender Violence: Analysis of an Experience in Southern Spain from a Feminist Perspective. Affilia, 28 (4), 366-378.

Alencar-Rodrigues, R. D, Cantera, L. M, y Strey, M. N. (2013). Violencia de género en la pareja contra mujeres inmigrantes: un estado del arte. Revista de Estudios de Género. LA VENTANA, 4 (37), 41-69.

ANDER-EGG, E. (2003). Repensando la investigación-acción-participativa. Lumen-Humanitas. 
Bhuyan, R., Mell, M., Senturia, K., Sullivan, M., y Shiu-Thornton, S. (2005). «Women Must Endure According to Their Karma» Cambodian Immigrant Women Talk About Domestic Violence. Journal of Interpersonal Violence, 20 (8), 902-921.

Bhuyan, R., y SEnturia, K. (2005). Understanding Domestic Violence Resource Utilization and Survivor Solutions among Immigrant and Refugee Women. Introduction to the Special Issue. Journal of Interpersonal Violence, 20 (8), 895-901.

COKER, D. (2006). Restorative justice, Navajo Peacemaking and domestic violence. Theoretical Criminology, 10 (1), 67-85.

Coll, K. (2010). Remaking Citizenship: Latina Immigrants and New American Politics. Stanford University Press.

CREnSHAW, K. W. (1991). Mapping the Margins: Intersectionality, Identity Politics, and Violence against Women of Color. Standford Law Review, 46 (6), 1241-1299.

FUNDACIÓN CEPAIM. (2013). Informe sobre Violencia de Género en Mujeres Inmigrantes. Grupo de análisis y trabajo sobre violencia de género en mujeres inmigrantes. Recuperado a partir de http://cepaim.org/th_gallery/ informe-sobre-violencia-de-genero-en-mujeres-inmigrantes/

De Genova, N. D. (2005). Working the Boundaries: Race, Space, and «Illegality» in Mexican Chicago. Duke University Press.

Greenwood, D. J., y Levin, M. (2006). Introduction to Action Research: Social Research for Social Change. SAGE Publications.

Greenwood, D. J., Whyte, W. F., y Harkavy, I. (1993). Participatory Action Research as a Process and as a Goal. Human Relations, 46 (2), 175-192.

Humphries, B. (2008). Social Work Research for Social Justice. Palgrave Macmillan. ingram, M., McClelland, D. J., Martin, J., Caballero, M. F., Mayorga, M. T., y GiLlespie, K. (2010). Experiences of Immigrant Women Who Self-Petition Under the Violence Against Women Act. Violence Against Women, 16 (8), 858-880.

IOÉ, C. (1993). Investigación-acción participativa. Introducción en España. Documentación social, 92, 59-70.

LEE, J. A. B. (2013). The Empowerment Approach to Social Work Practice. Columbia University Press.

Menjívar, C., y Salcido, O. (2002). Immigrant Women and Domestic Violence. Common Experiences in Different Countries. Gender \& Society, 16 (6), 898-920.

Merry, S. E. (2009). Human Rights and Gender Violence: Translating International Law into Local Justice. University of Chicago Press.

Minkler, M. (2005). Community Organizing and Community Building for Health. Rutgers University Press. 
Minkler, M., y Wallerstein, N. (2011). Community-Based Participatory Research for Health: From Process to Outcomes. John Wiley \& Sons.

Montañez, P., y Moyano, M. (2006). Violencia de género sobre inmigrantes en España. Un análisis psicosocial. Pensamiento psicológico, 2 (6), 21-32.

MUJERES UNIDAS Y ACTIVAS. (2009). Ecos del Silencio, Levantando Nuestra Voz. San Francisco, Oakland. Recuperado a partir de http://www.datacenter. org/wp-content/uploads/Mua-English-report.pdf

PAStor Seller, E. (2001). Iniciativa social y trabajo social comunitario. Alternativas. Cuadernos de Trabajo Social, 9, 169-191.

PASTOR SEller, E. (2004). La participación ciudadana en el ámbito local, eje transversal del trabajo social comunitario. Alternativas. Cuadernos de Trabajo Social, 12, 103-137.

RiverA, J. (1994). Doméstic Violence Against Latinas by Latino Males: An Analysis of Race, National origin, and Gender Differentials. Boston College Third World Law Journal, 14 (2), 231-258.

Shiu-Thornton, S., Senturia, K., y Sullivan, M. (2005). «Like a Bird in a Cage» Vietnamese Women Survivors Talk About Domestic Violence. Journal of Interpersonal Violence, 20 (8), 959-976.

Sokoloff, N. J., y Dupont, I. (2005). Domestic Violence at the Intersections of Race, Class, and Gender Challenges and Contributions to Understanding Violence Against Marginalized Women in Diverse Communities. Violence Against Women, 11 (1), 38-64.

Strang, H., y BraithWAite, J. (2002). Restorative Justice and Family Violence. Cambridge University Press.

Sullivan, M., Bhuyan, R., Senturia, K., Shiu-Thornton, S., y Ciske, S. (2005). Participatory Action Research in Practice A Case Study in Addressing Domestic Violence in Nine Cultural Communities. Journal of Interpersonal Violence, 20 (8), 977-995.

Tudela-VÁzquez, M. P. (2013). «Ecos del Silencio, Levantando Nuestra Voz»: traducciones locales de los Derechos Humanos de las Mujeres. Trabajo Social Global-Global Social Work, 3 (4), 113-132.

Villalon, R. (2010). Violence Against Latina Immigrants: Citizenship, Inequality, and Community. NYU Press.

Villasante, T., y Montañés Serrano, M. (2000). Algunos cambios de enfoque en las ciencias sociales. La investigación social participativa. En T. Villasante, M. Montañés Serrano, y J. Martí, La investigación social participativa. Construyendo Ciudadanía. (2002. ${ }^{a}$ ed.). Vol. 1, 14-60. Madrid: El Viejo Topo.

WAllerstein, N. (2000). A participatory evaluation model for Healthier Communities: developing indicators for New Mexico. Public Health Reports, 115 (2-3), 199-204. 
Wood, G. G., y Middleman, R. R. (1992). Groups to Empower Battered Women. Affilia, 7 (4), 82-95.

Yoshinama, M. (1999). Domestic Violence Against Women of Japanese Descent in Los Angeles: Two Methods of Estimating Prevalence. Violence Against Women, 5 (8), 869-897.

\section{ANTECEDENTES DE DIFUSIÓN}

Investigación basada en el trabajo de campo desarrollado para la tesis doctoral «La Organización de Nosotras: Procesos de ciudadanía a partir de experiencias de 'ilegalidad' en Estados Unidos. Aprendizajes con Mujeres Unidas y Activas»

Alternativas. Cuadernos de Trabajo Social, 22, 2015, pp. 185-206 - ISSN 1133-0473 


\section{RESEÑAS}

Título: El Trabajo Social ante el reto de la crisis y la educación superior. Autor(es): Enrique Pastor Seller, María Teresa Martínez Fuentes, Manuela Avilés Hernández y Yolanda Domenech López (Coords.)

Edita: Editorial Universitas, S.A. Madrid, 2014

ISBN:978-84-7991-424-0

Cada vez que un trabajo se hace de forma colaborativa, desde el compromiso y la convicción de sus autores, el resultado obtenido alcanza grandes dosis de interés y calidad. Esto es lo que encuentran las lectoras y lectores de la obra titulada El Trabajo Social ante el reto de la Crisis y la Educación Superior, en la que confluyen las reflexiones, análisis y propuestas compartidas en el I Congreso Internacional de Facultades y Escuelas de Trabajo Social celebrado en Murcia durante los días 23, 24 y 25 de abril de 2014.

En este congreso, a partir del trabajo en red de docentes, investigadores, estudiantes, profesionales y otros muchos agentes relacionados con el Trabajo Social, se ha construido un proceso reflexivo bajo el modelo inputs-outputs, del que ha surgido el producto colectivo que recoge este libro. Los inputs, aportados por 850 congresistas procedentes de 80 universidades y 15 países, han recogido a modo de proceso de entrada los conocimientos, investigaciones y buenas prácticas desarrollados por todos ellos en sus realidades de referencia. Un proceso de entrada que ha permitido identificar, describir y diagnosticar la situación actual del Trabajo Social y sus respuestas a las necesidades tanto académicas como sociales con las que convive. Los outputs, como proceso de salida, se reflejan en la riqueza de las contribuciones aportadas a dicho congreso. Estas contribuciones se estructuran en cinco conferencias plenarias y 34 grupos de trabajo organizados en torno a las siguientes líneas temáticas: Innovación Docente; Investigación en Trabajo Social y Transferencia de Resultados; Prácticas y supervisión; Trabajos fin de Grado; Seguimiento 
y evaluación de los Títulos de Grado en Trabajo Social y su vinculación con las competencias y salidas profesionales; Estudios de Posgrado y Doctorado; Internacionalización del Trabajo Social; El Trabajo Social en tiempos de crisis; y Ciudadanía y Trabajo Social.

Desde todas estas áreas los autores muestran la actualidad del Trabajo Social en el plano nacional e internacional, y lo hacen de una forma muy pegada a la realidad. Las más de 250 comunicaciones escritas que encuentra el lector en esta obra, ofrecen un claro repertorio de iniciativas, ensayos, análisis y propuestas que parten del conocimiento y práctica real de sus autores y, pueden por ello, orientar con gran valor la agenda futura de la formación y la profesión. En este sentido, adquieren especial centralidad las aportaciones relacionadas con las metodologías docentes aplicadas en las que destacan textos de gran relevancia respecto a aprendizajes colaborativos, interdisciplinariedad y otras expresiones artísticas en la formación, procesos de evaluación, funciones y percepciones del profesorado, de estudiantes, etc.

Se suman a estas propuestas para la innovación docente los trabajos recogidos sobre investigación y transferencia de resultados en Trabajo Social. Bajo este marco, la obra se erige en punta de iceberg de la experiencia empírica desarrollada, mostrando trabajos de investigación que cualifican la metodologías desde las que llevarla a cabo, y exploran a su vez, todo el espectro de la realidad social: desigualdades sociales, enfoque de género, nuevas formas familiares, protección a la infancia, a los mayores, investigación novel, dimensiones éticas de la investigación, resiliencia, etc.

Continúa el libro recogiendo las aportaciones de diferentes autores respecto a Prácticas y Supervisión, Trabajos Fin de Grado, Posgrados y Doctorados, y Seguimientos de los títulos. En todas estas áreas el lector puede encontrar sugerencias y respuestas ante los desafíos que desde ellas se plantean, con el valor añadido de que se aportan desde el compromiso diario de sus autores en la búsqueda de la mejora de la calidad en estos procesos.

Los últimos textos de esta obra se organizan para introducir al lector ante los interrogantes que los cambios sociales están dirigiendo al Trabajo Social contemporáneo. Para ello, desde las aportaciones relacionadas con la Internacionalización, con los Tiempos de crisis y con los derechos de Ciudadanía, y más allá de las exigencias derivadas de la intervención propia del trabajador social, se apuesta por fortalecer su papel de agente de promoción de los derechos sociales y de procesos que, en general, favorezcan el bienestar de la ciudadanía.

En resumen, el escenario de actualidad y oportunidad que se dibuja desde todas estas áreas, hace que los textos recogidos en el presente libro sean de 
referencia obligada tanto para docentes, como estudiantes y profesionales del Trabajo Social. Su consulta va a permitir al lector encontrar elementos suficientes, desde la perspectiva micro y macro, para elaborar respuestas propias y colectivas ante los retos y desafíos que la sociedad y la universidad del silo XXI proponen al Trabajo Social. Estas respuestas, a modo de cascada, hacen de esta obra un instrumento dinámico, abierto, en el que a partir del intercambio de conocimientos y experiencias que ofrece, impulse la generación de nuevas reflexiones e investigaciones. Los ouputs se convierten en inputs de un nuevo proyecto. Conseguir que una obra se mantenga viva, abierta, es sin duda el objetivo final de cualquier trabajo, y es esto lo que ocurre en esta ocasión.

María de las Olas Palma García

Dpto. de Psicología Social, Antropología Social, Trabajo Social y Servicios Sociales

Universidad de Málaga 

Título: Las Prácticas curriculares en el Grado de Trabajo Social. Supervisión y construcción del conocimiento desde la práctica profesional.

Autor: Enrique Pastor Seller (editor).

Editorial Universitas, S.A. Madrid, 2014, 289 pp.

ISBN: 978-84-7991-433-2

La obra que aquí se presenta, recoge las aportaciones de diversos autores acerca de un tema central en los estudios de Trabajo Social como es el de las prácticas curriculares en el Grado de la titulación. En efecto, desde los inicios de la disciplina, su carácter fuertemente práctico ha sido un sello distintivo de la misma, por cuanto el Trabajo Social es una profesión basada en la práctica y una disciplina académica que promueve el cambio social, la cohesión social y el empoderamiento de las personas.

Supuestos estos planteamientos, es evidente la importancia de las prácticas en la formación de los futuros profesionales para lograr un desarrollo efectivo de su desempeño profesional que no es más que ayudar a las personas y/o colectivos más desfavorecidos. Esto incluye armonizar conocimientos y habilidades, actitudes y compromiso ético. Todas estas cuestiones están claramente reflejadas en esta obra que aúna aspectos relativos a las prácticas externas y los contextos donde se desarrollan esas prácticas y a la metodología y habilidades precisas para desarrollarlas.

El libro está dividido en nueve capítulos, desarrollados por diferentes profesionales del mundo académico y profesional, lo que proporciona una variedad y riqueza de puntos de vista y, sobre todo refuta una vieja discusión sobre el «divorcio» entre la teoría y la práctica.

El primer capítulo, a cargo de las profesoras de la Universidad del País Vasco, Charo Ovejas y Ainhoa Berasaluce, ofrece una completa visión de las prácticas externas de la carrera de Trabajo Social y su vinculación con otras asignaturas del Grado, aportando una visión histórica de la evolución del concepto de la práctica pre-profesional y su situación actual en los estudios. 
El capítulo segundo, de la profesora de la Universidad de Barcelona, Irene de Vicente aborda un tema central en la formación para el Trabajo Social como es la supervisión de las prácticas de los estudiantes. El tercer capítulo, de los profesores Enrique Pastor y Blas Gallardo, de la Universidad de Murcia, ofrece un interesante análisis de los contextos, instituciones y organizaciones en la práctica profesional.

En el siguiente capítulo, Ana Lima, presidenta del Consejo General de Trabajo Social y la docente de la Universidad de Vigo, Carmen Verde nos introducen en el perfil y las funciones profesionales y las personas usuarias de los Servicios Sociales, así como los espacios profesionales, clarificando conceptos básicos referidos a esas cuestiones.

El quinto capítulo, de la profesora de la Universidad de Alicante, Asunción Lillo está orientado a clarificar una metodología de intervención del trabajo social con Personas y Familias desde una óptica ecológico-sistémica. El siguiente capítulo de la profesora de la UNED Sagrario Salgado y del profesor de la Universidad Complutense de Madrid, aborda la metodología y habilidades para la práctica del Trabajo Social con Grupos. El capítulo siete, a cargo de los profesores de la Universidad de Murcia, Enrique Pastor y Raquel Torralba introduce la metodología para la intervención con Comunidades.

El capítulo ocho, a cargo de los miembros del Grupo Efimec-Departamento de Trabajo Social de la Universidad Pública de Navarra, Alberto Ballestero, Francisco Iradeta, María Jesús Uriz, Juan Jesús Viscarret y Gabriela Díez aborda de forma muy sugestiva los dilemas éticos en la práctica del Trabajo Social. Y por último, el capítulo nueve, desarrollado por la docente de la Universidad de Valencia, Esther Escoda y por Nuria Baeza, de Cáritas Valencia, ilustra sobre las habilidades sociales y técnicas de comunicación para el Trabajo social.

En definitiva, se trata de un libro sugerente que ofrece numerosas claves para conocer e interpretar las prácticas curriculares en el Grado de Trabajo Social y que será sin duda muy útil, no sólo para los estudiantes, sino también para profesores y colaboradores de las instituciones sociales de prácticas y todos aquellos interesados en conocer algo más acerca del Trabajo Social.

M. ${ }^{a}$ José Escartín Caparrós

Departamento de Trabajo Social y Servicios Sociales

Universidad de Alicante 
Título: Trabajo Social con Comunidades.

Autor: Pastor Seller, E. (2015).

Edita: Editorial Universitas, S.A. Madrid, 2015. 257 pp.

ISBN: 978-84-7991-451-6

La publicación del libro Trabajo Social con Comunidades de Enrique Pastor Seller, Doctor en Sociología y Profesor Titular de Universidad adscrito al Departamento de Sociología y Trabajo Social de la Universidad de Murcia, supone a nivel académico una referencia imprescindible dada su riqueza temática, metodológica y bibliográfica en el ámbito de la intervención con comunidades. Es un manual con contenido teórico-práctico dirigido al alumnado, docentes e investigadores vinculados a la intervención comunitaria. Las lectoras y lectores que se aproximen a este manual van a conocer los modelos teóricos, estrategias de intervención, método, proceso metodológico y técnicas para realizar una intervención en contextos comunitarios. Así mismo el texto ofrece un análisis detallado y actualizado de los ámbitos y prácticas de intervención comunitaria desde el Trabajo Social.

El libro se estructura en siete capítulos en los que se analiza de manera precisa los principales retos y futuro del trabajo social con comunidades. En el capítulo primero se analizan y comparan detenidamente los contextos de intervención comunitaria en Trabajo Social ante los retos de las nuevas ciudades y en el medio rural. El autor presenta una ruptura de los modelos dicotómicos clásicos (rural vs. urbano, local vs. global, etc.) para llevar a cabo un análisis e intervención en comunidades. Se fundamenta la importancia de la intervención en, para y con la comunidad local como ámbito más adecuado de análisis e intervención. En el capítulo dos se investiga el objeto del trabajo social con comunidades y se profundiza en la comunidad bajo el término de redes sociales. Como señala el autor, el concepto de red social sitúa al individuo en el centro de la intervención, superando la contradicción existente entre el nivel individual y el comunitario considerando la comunidad como red social. 
A continuación, en el capítulo tres se analizan las competencias teóricosmetodológicas imprescindibles para llevar a cabo una intervención a nivel comunitario desde la perspectiva de la integración de los distintos modelos teóricos, y se hace especial énfasis en la importancia del acercamiento ecológico que supone una reconceptualización de la práctica en contextos comunitarios. En el capítulo cuatro se presentan los modelos de intervención definidos desde el Trabajo Social con comunidades articulando el análisis en torno a una propuesta de construcción de estrategias de intervención comunitaria desde un enfoque multimodal (planificación social, acción social y desarrollo local o de la comunidad) que concibe a la comunidad como contexto, sistema y proceso para el cambio social. En un acertado análisis, en el capítulo cinco, se desarrolla el compromiso del trabajo social con el desarrollo social local integral a escala humana. El trabajo social comunitario es preciso compatibilizarlo con un desarrollo local postmoderno y en clave estratégica. Se destaca la importancia de la participación y democratización de las políticas sociales locales. Además, se profundiza en la participación ciudadana en el ámbito local como eje transversal del trabajo social comunitario y se presenta un mapa detallado de mecanismos de participación en la política social en España como resultado del análisis de las últimas leyes autonómicas de servicios sociales desde 2003. En el capítulo seis el autor ahonda en las competencias metodológicas y en las técnicas necesarias utilizadas para llevar a cabo una intervención comunitaria y se centra en el modelo de desarrollo local estratégico, integral y sostenible aportando estrategias metodológicas para dar respuesta a los retos de la actual sociedad postmoderna. El autor profundiza en la necesidad de la integración de diferentes enfoques teóricos y metodológicos como la teoría ecosistémica, enfoque de potenciación, defensa e influencia social, enfoque educativo socializante, etc. Se plantea un proceso metodológico a partir de objetivos centrados en la tarea y en el proceso. Además, se introduce un proceso metodológico novedoso e integrador mediante cinco fases: caracterización y enlace con la comunidad, análisis estratégico, formulación y formalización de la intervención, implementación de la propuesta de intervención comunitaria y evaluación, validación y/o reformulación del modelo de intervención. En el último capítulo se analizan en profundidad los ámbitos de intervención comunitaria: sistemas de servicios sociales, sistema de salud, sistema educativo, justicia, vivienda-hábitat, sistema de la dependencia y mediación comunitaria. Para finalizar se describe una tipología de experiencias comunitarias en España y se reflexiona en la necesidad de sistematizar y definir buenas prácticas comunitarias. 
En síntesis, ésta obra supone un manual innovador basado en la experiencia académica y profesional de su autor. Su lectura es muy recomendable para todos aquellos actores interesados en el conocimiento del trabajo social con comunidades e identifica los desafíos de futuro en contextos comunitarios. Este manual detallado y riguroso ofrece una oportunidad para reflexionar sobre la situación actual del trabajo social con comunidades y aporta estrategias e instrumentos para afrontar con éxito la intervención con comunidades en la sociedad postmoderna.

Blas José Martínez Gallardo

Facultad de Trabajo Social

Universidad de Murcia 



\section{INSTRUCCIONES PARA LOS AUTORES ${ }^{1}$}

\section{Información general}

La Revista Alternativas. Cuadernos de Trabajo Social con ISSN 1133-0473 es una publicación de Departamento de Trabajo Social y Servicios Sociales de la Universidad de Alicante. Fundada con el mismo título en 1992 por la Escuela Universitaria de Trabajo Social de la Universidad de Alicante, se publica desde el 2009 por el Departamento de Trabajo Social y Servicios Sociales de dicha universidad. Su periodicidad es anual. Se edita en el mes de diciembre.

Se trata de una revista arbitrada que utiliza el sistema de revisión externa por expertos (peer-review) en el conocimiento de los objetos investigados y en las metodologías utilizadas en las investigaciones. Adopta y se adhiere a las normas de publicación establecidas en el Manual de la $\mathrm{APA}^{2}$. Es preciso recordar que el cumplimiento de los requisitos del Manual de la APA facilita la indización de la revista en las principales bases de datos de la especialidad, con lo que ello supone de beneficio para los autores y sus centros por la mayor difusión que alcanzan los trabajos publicados.

Cada uno de sus números se edita tanto en versión impresa como en versión electrónica, ésta disponible en el Repositorio Institucional de la Universidad de Alicante (http://rua.ua.es/dspace/handle/10045/5269).

Alternativas. Cuadernos de Trabajo Social está abierta a intercambios con otras publicaciones.

1. De acuerdo con lo elaborado para FECYT por Rafael Ruiz-Pérez, Emilio Delgado LópezCózar, Evaristo Jiménez Contreras. Grupo de Investigación EC3, Universidad de Granada, http://ec3.ugr.es/.

2. American Psychological Association, [en línea], http://books.apa.org/books.cfm?id= 4200061 \& toc=yes). 


\section{Alcance y Cobertura}

Alternativas. Cuadernos de Trabajo Social tiene como objeto fundamental contribuir a la difusión de investigaciones, experiencias, trabajos teóricos y metodológicos, tanto de carácter académico como profesional, que se realizan en nuestro país y en el ámbito internacional, relativos al Trabajo Social, a la política social y a los Servicios Sociales, así como a otras disciplinas y profesiones que, desde un punto de vista multi e interdisciplinar, enriquecen y complementan la disciplina y la acción profesional del Trabajo Social en el ámbito de las Ciencias Sociales.

Los trabajos deben ser originales, no publicados ni estar siendo considerados en otra revista para su publicación, escritos en español, inglés, francés o portugués. El autor es el único responsable de las afirmaciones sostenidas en su artículo. De manera excepcional, los artículos que no sean inéditos se publicarán bajo la valoración del Comité Editorial y en función de: que su difusión haya sido en algún medio de difícil acceso y de que se consideren de particular relevancia e interés científico profesional.

Serán considerados para su publicación los siguientes tipos de trabajos: investigaciones originales, trabajos teóricos, experiencias prácticas y notas técnicas.

Investigaciones originales: estarán estructuradas de la siguiente manera: resumen, palabras clave, texto (introducción, material y métodos, resultados y discusión), agradecimientos y bibliografía. La extensión máxima del texto será de 6.000 palabras (en formato Word), escritas a doble espacio, cuerpo de letra 12, tipo Times New Roman, admitiéndose 4 figuras y 6 tablas. Las tablas y figuras deberán presentarse en hoja aparte, numerándose correlativamente e indicando el lugar de colocación en el artículo. Si se utilizan, han de ser aquellas que, por su relevancia, sean necesarias para apoyar los argumentos recogidos en el texto. Es aconsejable que el número de autores no sobrepase los seis.

Trabajos teóricos y experiencias prácticas: los trabajos teóricos consistirán en un análisis crítico de temáticas relevantes para el Trabajo Social, la política social y los servicios sociales. Las experiencias prácticas consistirán en una sistematización rigurosa del proceso y resultados de las mismas. Ambas, revisiones y experiencias, deberán incluir un apartado con aportaciones o propuesta de aplicación o transferencia al Trabajo Social, la política social, los servicios sociales o la intervención social. Los textos tendrán una extensión máxima de 4.000 palabras en formato Word, escritas a doble espacio, cuerpo de letra 12 y tipo Times New Roman. Opcionalmente el trabajo podrá incluir tablas y figuras. 
Notas técnicas: describirán de forma resumida normativas o políticas, investigaciones en curso, así como crónicas de congresos, seminarios o jornadas relevantes para el Trabajo Social, la política social y los servicios sociales. Tendrán una extensión máxima de 1.000 palabras (en formato Word), escritas a doble espacio, cuerpo de letra 12 y tipo Times New Roman.

\section{Presentación y estructura de los trabajos}

Las siguientes normas de publicación están basadas en Manual de la APA:

a) Los manuscritos deben ser enviados por correo electrónico a la Redacción de la revista Alternativas. Cuadernos de Trabajo Social del Departamento de Trabajo Social y Servicios Sociales, a la dirección dtsss@ua.es con copia a masun.martinez@ua.es, a doble espacio, márgenes amplios y con sus páginas numeradas correlativamente en el ángulo superior derecho. Deberán ir acompañados de una carta de presentación (ver modelo facilitado por la revista) pidiendo la consideración del manuscrito, en la que además el autor explicará en 4-5 líneas cuál es la aportación original del trabajo que presenta y sus novedades, la declaración de que no ha sido publicado anteriormente y que no se ha enviado simultáneamente a otras revistas, así como la confirmación de las autorías firmantes. En esta carta también figurará la cesión de derechos al editor. El autor debe conservar una copia del original para evitar irreparables pérdidas o daños del material.

b) Las citas bibliográficas deben reseñarse en forma de referencias a continuación de la discusión o de los agradecimientos, si los hubiere. Las citas bibliográficas, cuyo número ha de ser el suficiente y necesario, se presentarán según el orden de aparición en el texto con la correspondiente numeración correlativa y serán identificadas por autor y año entre paréntesis y separados por una coma (ejemplo: Coob, 1989), con inclusión del número de página o páginas en el caso de citas textuales (ejemplo: Coob, 1989: 25-27).

\section{Los manuscritos se presentarán según el siguiente orden y estructura}

Página de título. Primera página del manuscrito

A modo de portada del manuscrito, esta primera página contendrá:

a) Título del artículo (conciso pero informativo), en español e inglés, conformado con el mayor número de términos significativos posibles (a ser posible tomados de un vocabulario controlado de la especialidad). Si es 
necesario, se añadirá un subtítulo no superior a 40 letras y espacios, en español e inglés.

b) Nombre y dos apellidos de cada uno de los autores teniendo en cuenta la forma de firma para indexación en bases de datos internacionales (véanse en la sección "¿Sabes qué tienes que hacer para identificar tus publicaciones científicas?" las recomendaciones formuladas en http://www.accesowok.fecyt.es/).

c) Nombre completo del centro de trabajo de cada uno de los autores, el cual tendrá su referencia al lado del nombre del autor con números arábigos entre paréntesis (o en superíndice).

d) Nombre y dirección completa del responsable del trabajo o del primer autor como responsable de correspondencia, incluyendo número de teléfono y del telefax en su caso, así como dirección de correo electrónico si se dispone de ella.

e) Información sobre becas, ayudas o soporte financiero con el que se ha contado (Proyectos de Investigación) para la subvención del trabajo y otras especificaciones, cuando sea el caso.

Para una mejor elaboración de esta página, véase modelo adjunto a estas instrucciones sobre cómo elaborar la hoja de identificación del manuscrito

Páginas de resumen y palabras-clave. Segunda página del manuscrito

Una segunda página independiente deberá contener los nombres y apellidos de los autores, el título del artículo y de la revista, un resumen del contenido del artículo en español y el listado de palabras clave. Tanto el resumen como las palabras clave tendrán una versión en inglés.

a) El resumen del trabajo tendrá una extensión de 150-250 palabras. En el caso de los artículos originales, el contenido del mismo se dividirá en cuatro apartados (resumen estructurado): introducción, material y métodos, resultados y discusión. En cada uno de ellos se describirá, de forma concisa, respectivamente, el motivo y el objetivo de la investigación, la metodología empleada, los resultados más destacados y las principales conclusiones. Se enfatizarán los aspectos novedosos y relevantes del trabajo. En el caso de las colaboraciones especiales, se resumirá el trabajo sin dividirlo en estos cuatro apartados.

b) Palabras clave: a continuación del resumen se especificarán cinco palabras clave o frases cortas que identifiquen el contenido del trabajo para su inclusión en los repertorios y bases de datos nacionales e internacionales. 
Se procurará poner el mayor número posible hasta un máximo de cinco.

Deberán utilizarse términos controlados de referencia.

Texto del manuscrito. Tercera página, que será la del arranque del texto del manuscrito

La tercera página y siguientes serán las que se dediquen al texto del manuscrito, que se ajustará a las especificaciones de las instrucciones indicadas para cada tipo de trabajo. En el caso de los Trabajos teóricos y Notas técnicas podrá figurar el manuscrito estructurado en los apartados convenientes para facilitar así su compresión. Sin embargo, los trabajos originales deben ajustarse en la medida de lo posible a los siguientes apartados: introducción, materiales y métodos, resultados y discusión:

Introducción: debe incluir los fundamentos y el propósito del estudio, utilizando las citas bibliográficas estrictamente necesarias. No incluirá datos o conclusiones del trabajo presentado. No debe realizarse una revisión bibliográfica detallada.

Material y métodos: será presentado con la precisión que sea conveniente para que el lector comprenda y confirme el desarrollo de la investigación. Fuentes y métodos previamente publicados deben describirse solo brevemente y aportar las correspondientes citas, excepto si se han realizado modificaciones en los mismos. Se describirá el cálculo del tamaño de la muestra y la forma de muestreo utilizada en cada caso. Se hará referencia al tipo de análisis documental, crítico, estadístico, etc. empleado. Si se trata de una metodología original, será necesario exponer las razones que han conducido a su empleo y describir sus posibles limitaciones.

Cuando se trate de trabajos experimentales en los que se hayan utilizado grupos humanos, se indicará si se han tenido en cuenta los criterios éticos correspondientes. No deben utilizarse los nombres ni las iniciales de las personas que hayan participado formando parte de la muestra estudiada.

Resultados: aparecerán en una secuencia lógica en el texto, tablas o figuras, no debiendo repetirse en todas ellas los mismos datos. Se procurará resaltar las observaciones importantes. Se describirán, sin interpretar ni hacer juicios de valor, las observaciones efectuadas con el material y métodos empleados.

Discusión: resumirán los hallazgos, relacionando las propias observaciones con otros estudios de interés y señalando las aportaciones y limitaciones de unos y otros. No deben repetirse con detalle los datos u otro material ya comentado en otros apartados. Se mencionarán las inferencias de los hallazgos y sus limitaciones, incluyendo las deducciones para una investigación 
futura. Se enlazarán las conclusiones con los objetivos del estudio, evitando las afirmaciones gratuitas y las conclusiones no apoyadas completamente por los datos del trabajo.

Agradecimientos: únicamente se agradecerá su colaboración a aquellas personas que hayan hecho contribuciones sustanciales al estudio pero sin llegar a merecer la calificación de autor, debiendo disponer el autor de su consentimiento por escrito. Asimismo, el Council Science Editors (CSE) recomienda a los autores, en su caso, una declaración explícita de la fuente de financiación de la investigación, y que ésta se encuentre en los agradecimientos (CSE, 2000) (Conflicts of Interest and the Peer Review Process. Draft for CSE member review, del 03/31/00. http://www.cbe.org/services_DraftPolicies. shtml).

Bibliografía: la bibliografía debe reseñarse a continuación de la discusión o de los agradecimientos si los hubiere, y en la forma antes indicada según el orden alfabético de autores.

Para las referencias bibliográficas se recomienda seguir el estilo que se detallará más adelante como ejemplo, basado en las normas de la APA.

- Los nombres de las revistas deben abreviarse según consenso existente en el área de conocimiento, y siempre que exista una lista de referencia.

- Se mencionarán todos los autores hasta seis, o los seis primeros, y et al. cuando sean siete o más.

La bibliografía debe ser corregida por el autor, comparándola con la copia en su poder. Se evitará utilizar frases imprecisas como citas bibliográficas. No pueden emplearse como tales las que precisen de aclaraciones del tipo "observaciones no publicadas", ni "comunicación personal", aunque sí podrán citarse dentro del texto entre paréntesis. Los trabajos aceptados, pero aún no publicados, se incluirán en las citas bibliográficas especificando el nombre de la revista, seguido por la expresión "en prensa".

Las citas bibliográficas deberán extraerse de los documentos originales, indicando siempre la página inicial y final del trabajo del que proceden. A fin de asegurar la coherencia, en cualquier momento del proceso editorial, la dirección de la revista podrá requerir a los autores el envío de la primera página (fotocopia) de cada uno de los artículos citados en la bibliografía.

Para las revistas, dada su trascendencia para los índices de citas y los cálculos de los factores de impacto, se citarán: a) autor(es), con su(s) apellido(s) e inicial(es) de nombre(s), separando los apellidos del nombre con una coma. Si hay más de un autor, entre ellos se pondrá una coma. Todos hasta un máximo de seis, y cuando sean más de seis se pondrán sólo los seis primeros y se añadirá et al. Tras el último autor se pondrá el año entre paréntesis y un 
punto; b) título del artículo en su lengua original, y con su grafía y acentos propios. Tras el título se pondrá un punto; c) nombre correcto de la revista; d) número de volumen $\left(\mathrm{n}^{\circ}\right)$ (la separación entre este apartado y el siguiente se hará con coma); y e) páginas primera y última, separadas por un guión.

A continuación se dan ejemplos de citas bibliográficas correctamente referenciadas.

\section{Publicaciones periódicas}

Artículo de revista, un autor

Bekerian, D. A. (1992). In search of the typical eyewitness. American Psychologist, 48, 574-576.

Artículo de revista, dos autores

Klimowski, R., Palmer, S. (1993). The ADA and the hiring process in organizations. Consulting Psychology Journal: Practice and Research, 45(2), $10-36$.

Artículo de revista, de tres a cinco autores

Borman, W. C., Hanson, M. A., Oppler, S. H., Pulakos, E. D., y White, L. A. (1993). Role of early supervisory experience in supervisor performance. Journal of Applied Psychology, 78, 443-449.

Artículo de revista, seis autores

Kneip, R. C., Delamater, A. M., Ismond, T., Milford, C., Salvia, L., y Schwartz, D. (1992). Self- and spouse ratings of anger and hostility as predictors of coronary heart disease. Health Psychology, 12, 301-307.

Artículo de revista, en prensa

Bekerian, D. A. (en prensa). In search of the typical eyewitness. American Psychologist.

Bekerian, D. A. (en prensa-a). Role of early supervisory experience in supervisor performance. American Psychologist.

Bekerian, D. A. (en prensa-b). Self- and spouse ratings of anger and hostility as predictors of coronary heart disease. American Psychologist.

Artículo de revista no inglesa, con el título traducido al inglés

Zajonc, R. B. (1992). Bischofs gefühlvolle Verwirrunggen über die Gefühlle [Bischof's emotional fluster over the emotions]. Psychologische Rundschau, 40, 574-576. 


\section{Libros y capítulos de libro}

Referencias a libros completos

Bekerian, D. A. (1992). People in organizations: An introduction to organizational behavior ( $3^{a}$ ed.). New York: McGraw-Hill.

Libro, autor en grupo (agencia gubernamental) como editor

Australian Bureau of Statistics (1992). Estimated resident population by age and sex in statistical local areas, New South Wales, June 1990 ( $\mathrm{N}^{\circ}$ 3209.1). Australian Capital Territory: ABS

Libro editado

Bekerian, D. A. (Ed.). (1992). People in organizations: An introduction to organizational behavior. New York: McGraw-Hill.

Libro sin autor o editor

Merriam-Webster's Collegiate Dictionary $\left(10^{\mathrm{a}}\right.$ ed.). Springfield, MA: Merriam-Webster.

Enciclopedia o diccionario

Bekerian, D. A. (1992). The new Grove dictionary of music and musicians (3 ed., Vols. 1-20). New York: McGraw-Hill.

Traducción inglesa de un libro

Laplace, P. -S. (1951). A philosophical essay on probabilities (Trads., F. W. Truscott y F. L. Emory). New York: McGraw-Hill. (Trabajo original publicado en 1814).

Capítulo en un volumen de una serie

Maccoby, E. E. (1992). Socialization in the context of the family. En P. M. Musen (Ed. Serie) y M. J. Martin (Ed. Vol.). Handbook of child psychology: Vol. 4. Socialization, personality, and social development ( $3^{\mathrm{a}}$ ed., pp. 1-101). New York: McGraw-Hill.

\section{Informes técnicos y de investigación}

Informe disponible en la GPO (Government Printing Office), instituto gubernamental como autor 
National Institute of Mental Health (1992). Clinical training in serious mental illnes (Publicación DHHS No ADM 90-1679). Washington, DC: Government Printing Office.

Reuniones científicas (congresos, simposios, etc.)

Actas de congreso publicadas, contribución publicada a un simposio, artículo o capítulo en libro editado

Bekerian, D. A. (1992). A motivational approach to the self. En R. DeMaier (Ed.), Nebraska Symposium of Motivation: Vol. 38. Perspectives on motivation (pp. 574-596). Lincoln: University of Nebraska Press.

Actas publicadas regularmente

Bekerian, D. A. (1992). In search of the typical eyewitness. Proceedings of the National Academy of Sciences, USA, 89, 574-576.

Trabajo no publicado presentado a un congreso

Bekerian, D. A. (1992, Enero). Early data on the Trauma Symptom Checklist for Children (TSC-C). Comunicación presentada al Congreso de la American Professional Society on the Abuse of Children, San Diego, CA.

\section{Tesis doctorales y de máster}

Tesis doctoral no publicada

Bower, D. L. (1993). Employee assistant programs supervisory referrals: Characteristics of referring and nonreferring supervisors. Tesis doctoral no publicada. University of Missouri, Columbia.

Tesis de máster no publicada, universidad no estadounidense

Saldaña, P. (1992). Actitudes de los padres hacia la integración escolar. Tesis de master no publicada, Universidad de Salamanca, Salamanca, España.

\section{Revisiones}

Revisión de un libro

Baumeister, R. F. (1993). Exposing the self-knowledge myth [Revision del libro The self-knower: A hero under control]. Contemporary Psychology, $38,466-467$. 


\section{Medios audiovisuales}

Película, circulación limitada

Bekerian, D. A. (Productor), y Smith, J. N. (Director). (1992). Changing our minds [Película]. (Disponible en Changing Our Minds, Inc., 170 West End Avenue, Suite 35R, New York, NY 10023).

\section{Medios electrónicos}

Artículo de revista on-line, acceso limitado a suscriptores

Central Vein Occlusion Study Group. (1993, 2 Octubre). Central vein occlusion study of photocoagulation: Manual of operations [675 párrafos]. Online Journal of Current Clinical Trials [Serie on-line]. Disponible en: Doc. $\mathrm{N}^{\circ} 92$.

\section{Referencias de fuentes electrónicas (internet)}

Sitios web

Tilton, J. (1995). Composing good HTML (Vers. 2.0.6). http://www.cs.cmu. edu/ tilt/cgh/ (13 Jan. 1997).

Tablas: deben presentarse en hojas independientes numeradas según su orden de aparición en el texto con números arábigos. Se emplearán para clarificar puntos importantes no aceptándose la doble documentación bajo la forma de tablas y figuras. Los títulos o pies que las acompañen deben explicar perfectamente el contenido de las mismas.

Figuras: serán consideradas figuras todo tipo de fotografías, gráficas o dibujos. Se les asignará un número arábigo según orden de aparición en el texto, siendo identificadas por el término abreviado fig.(s). Los pies o leyendas de cada una deberán ir mecanografiados y con el número correspondiente en una hoja aparte. El texto en las figuras irá en mayúsculas. Deben ser diseñadas presentando un buen contraste, de forma que no pierdan calidad con la reducción. Las microfotografías presentarán también un buen contraste de forma que puedan ser publicadas sin reducción.

La publicación con figuras a color debe especificarse previamente, corriendo los gastos de fotomecánica a cargo del autor.

Las figuras deben clarificar de forma importante el texto y su número estará reducido al mínimo necesario.

Abreviaturas: solo deberán ser empleadas abreviaturas estándar universalmente aceptadas (consultar Units Symbols and Abbreviations). Cuando se pretenda acortar un término empleado frecuentemente en el texto, su abreviatura, entre paréntesis, deberá acompañarse la primera vez que aparezca. No 
serán usados los números romanos en el texto, empleándose para los decimales el punto a la derecha del cero en lugar de la coma. Los nombres comerciales no serán utilizados salvo necesidad, en cuyo caso la primera vez que se empleen irán acompañados del símbolo.

\section{Proceso editorial}

Los trabajos se remitirán acompañados de una carta de presentación, en la que se solicitará la evaluación de los mismos para su publicación en alguna de las secciones de la revista, con indicación expresa de tratarse de un trabajo que no ha sido difundido ni publicado anteriormente, ser enviado únicamente a la revista Alternativas. Cuadernos de Trabajo Social para su evaluación y publicación si procede, así como las aportaciones en cuanto a originalidad y novedad que, a juicio de los autores, plantea el trabajo.

La carta de presentación deberá ir firmada por todos los autores. Es responsabilidad de los autores el cumplimiento de los principios éticos, incluyendo, en su caso, la autorización escrita de todas las personas que aparezcan en los agradecimientos o de aquellas que hayan sido estudiadas durante la investigación y cuya identificación sea esencial para presentar los resultados. Asimismo, se declarará aceptar, si procede, la introducción de cambios en el manuscrito por parte de la Redacción de la revista.

La Redacción de la revista acusará recibo a los autores de los trabajos que le lleguen y, posteriormente, informará de su aceptación o rechazo.

La Redacción pasará a considerar el trabajo para su publicación por el Comité Editorial, comprobando si se adecua a la cobertura de la revista y cumple las normas de publicación. En tal caso, se procederá a su revisión externa.

Los manuscritos serán revisados de forma anónima (ciego o doble ciego) por dos expertos en el objeto de estudio y/o metodología empleada. La Redacción de la revista, a la vista de los informes externos, se reserva el derecho de aceptar/rechazar los artículos para su publicación, así como el de introducir modificaciones de estilo y/o acortar los textos que sobrepasen la extensión permitida, comprometiéndose a respetar el contenido del original. El protocolo utilizado por los revisores de la revista se hace público como anexo a estas normas y está publicado en la web de la Revista en el Departamento de Trabajo Social y Servicios Sociales (http://dtsss.ua.es/es/alternativascuadernostrabajosocial/normas-de-edicion.html).

En el caso de juicios dispares entre los dos evaluadores, los trabajos se remitirán a un tercer evaluador. Serán sometidos a revisión pareada externa las investigaciones, los trabajos teóricos y las experiencias. Los trabajos que sean revisados y pudieran ser considerados para publicación previa modificación, 
deberán ser devueltos en el plazo de 30 días tanto si se solicitan correcciones menores como mayores. Cuando sea necesario, la nueva versión del texto será enviada otra vez a los revisores externos, procedimiento que se seguirá hasta la aceptación definitiva del trabajo por la revista. Los autores recibirán los informes de evaluación de los revisores (de acuerdo con el protocolo de evaluación de la revista) de forma anónima, para que éstos puedan realizar (en su caso) las correcciones o réplicas oportunas.

En general, una vez vistos los informes externos, los factores en los que se funda la decisión sobre la aceptación-rechazo de los trabajos por parte de la Redacción de la revista son los siguientes: a) originalidad: totalmente original, información valiosa, repetición de resultados conocidos; b) actualidad y novedad; c) relevancia: aplicabilidad de los resultados para la resolución de problemas concretos; d) significación: avance del conocimiento científico; e) fiabilidad y validez científica: calidad metodológica contrastada; y f) presentación: buena redacción, organización (coherencia lógica y presentación material).

Los autores/as de artículos aceptados recibirán las pruebas de imprenta para su corrección por correo electrónico en formato PDF. Deberán devolverlas corregidas a la Redacción de la revista mediante fax o PDF dentro de las 72 horas siguientes a su recepción. Únicamente se pueden realizar mínimas correcciones sobre el contenido del manuscrito original sin incurrir en un coste extra.

En su caso, el autor o primer firmante recibirá un ejemplar de la revista en papel después de su publicación.

\section{Responsabilidades éticas}

Es responsabilidad y deber de la Redacción de la revista Alternativas. Cuadernos de Trabajo Social recordar a sus colaboradores los siguientes extremos:

- Cuando se describen experimentos realizados en seres humanos debe indicarse si los procedimientos seguidos son conformes a las normas éticas del comité de experimentación humana responsable (institucional o regional) y a la Declaración de Helsinki de 1975 revisada en el 2000. No se deben utilizar nombres, iniciales u otros datos de identificación de los centros donde se ha realizado.

- Contar con permiso de publicación por parte de la institución financiadora de la investigación, cuando proceda.

- La revista no acepta material previamente publicado. Los autores son responsables de obtener los oportunos permisos para reproducir parcialmente material (texto, tablas o figuras) de otras publicaciones y de citar su procedencia correctamente. 
Conflicto de Intereses: la revista espera que los autores declaren cualquier asociación comercial que pueda suponer un conflicto de intereses en conexión con el artículo remitido.

Autoría: en la lista de autores firmantes deben figurar únicamente aquellas personas que han contribuido intelectualmente al desarrollo del trabajo. Haber ayudado en la colección de datos o haber participado en alguna técnica no son, por sí mismos, criterios suficientes para figurar como autor. En general, para figurar como autor deben cumplirse los siguientes requisitos: a) haber participado en la concepción y realización del trabajo que ha dado como resultado el artículo en cuestión, b) haber participado en la redacción del texto y en las posibles revisiones del mismo y c) haber aprobado la versión que finalmente va a ser publicada.

La revista declina cualquier responsabilidad sobre posibles conflictos derivados de la autoría de los trabajos a publicar.

Consentimiento informado: los autores deben mencionar, en la sección de métodos, que los procedimientos utilizados con los participantes han sido realizados tras obtención de un consentimiento informado.

Transmisión de derechos de autor: se incluirá junto al manuscrito, o formando parte de la carta de presentación, una Hoja de Identificación y Cesión de Derechos (facilitada por la revista) firmada por todos los autores.

\section{Información Adicional}

La revista acusa recepción de todos los trámites realizados para tener informados a los autores de la situación en la que se encuentra su manuscrito.

Los juicios y opiniones expresados en los artículos y comunicaciones publicados en la revista son del autor(es) y no necesariamente del Comité Editorial.

Tanto el Comité Editorial como la empresa editora declinan cualquier responsabilidad sobre el material publicado. Ni el Comité Editorial ni la empresa editora garantizan o apoyan ningún producto que se anuncie en la revista, ni garantizan las afirmaciones realizadas por el fabricante sobre dicho producto o servicio. 


\section{Protocolos destinados a los autores ${ }^{3}$}

\section{Listado de comprobaciones}

Tiene por objeto el exigir al autor una revisión final del manuscrito en cuanto a sus aspectos fundamentales de carácter formal y metodológico.

\section{Listado de comprobaciones}

Para facilitar la labor del Comité de Lectura, la entrada en proceso de su manuscrito y la rapidez en su posible publicación, se exige que el autor realice una revisión final del manuscrito, comprobando las cuestiones enumeradas en la presente lista que, una vez marcadas, será remitida junto al manuscrito. Se recuerda que el incumplimiento de alguno de los ítems puede ser motivo de devolución del manuscrito.

1. Se envía el manuscrito vía correo electrónico, en ficheros en formato Word, escritos a doble espacio, incluidas las citas bibliográficas, tablas y figuras.

2. Se incluye el título completo del manuscrito en español e inglés.

3. Se incluye el resumen del manuscrito y las palabras clave, en español e inglés.

4. El resumen se ajusta a las normas de publicación en cuanto a número de palabras, y en él constan objetivos, diseño o material y métodos, resultados, conclusiones y/o discusión.

5. Se envía el resumen y las palabras clave traducidos al inglés y, a ser posible, revisados por un experto en este idioma.

6. Se incluyen las filiaciones institucionales y/o profesionales de cada uno de los autores.

7. Se incluye la dirección del autor principal o responsable de correspondencia, número de teléfono, fax y dirección de correo electrónico.

8. En su caso, se declaran becas, ayudas o soporte financiero y su procedencia.

9. El manuscrito responde a la estructura exigida en las normas de publicación y a las especificaciones de la sección a la que se dirige.

10. El manuscrito describe todas las fuentes, materiales, equipo y elementos usados, tanto en términos de grupos investigados como la globalidad del estudio.

11. Un experto en el contenido del manuscrito podría reproducir su estudio, experimento, análisis, etc., a partir de la metodología descrita.

12. Las conclusiones se apoyan en los resultados obtenidos.

13. En su caso, se han utilizado análisis estadísticos, y estos han sido revisados por un experto en la materia.

14. Se han revisado las referencias bibliográficas, y se ajustan en su estilo y formato a las normas internacionales exigidas por la revista.

15. En su caso, las figuras y tablas aportan información adicional y no repetida en el texto.

16. En su caso, se ha revisado el sistema de unidades empleado.

3. De acuerdo con lo elaborado para FECYT por Rafael Ruiz-Pérez, Emilio Delgado LópezCózar y Evaristo Jiménez Contreras. Grupo de Investigación EC3, Universidad de Granada (http://ec3.ugr.es/). 


\begin{tabular}{|l|c|}
\hline 1. Listado de comprobaciones \\
\hline 17. Se detallan las abreviaturas tras su primera cita en el texto. & $\bullet$ \\
\hline 18. En su caso, se citan las normas éticas utilizadas. & $\bullet$ \\
\hline $\begin{array}{l}\text { 19. En su caso, se adjuntan o se da fe en el manuscrito del consentimiento de } \\
\text { los informados de experimentación con personas, así como de los permisos de } \\
\text { reproducción. }\end{array}$ & $\bullet$ \\
\hline $\begin{array}{l}\text { 20. Se adjunta lista de comprobación y carta de presentación indicando } \\
\text { originalidad, novedad del trabajo y sección de la revista a la que se dirige. }\end{array}$ & $\bullet$ \\
\hline $\begin{array}{l}\text { 21. La carta de presentación debe incluir un anexo firmado por los autores } \\
\text { responsabilizándose de la autoría y cediendo los derechos de autor al editor. }\end{array}$ & $\bullet$ \\
\hline
\end{tabular}

\section{Cómo confeccionar la primera página del manuscrito}

También llamada hoja de identificación o página de título. Este protocolo tiene la intención de facilitar al autor el formato adecuado para la elaboración de los datos de identificación del manuscrito. Estos datos no solo son importantes para la propia versión del manuscrito que finalmente será publicada, sino también para la indexación en las bases de datos.

\section{Cómo confeccionar una hoja de identificación}

Dada la importancia de los datos de identificación del manuscrito (primera página del manuscrito o página de título), debe seguirse la estructura del siguiente modelo:

TÍTULO:

COMPETENCIA PROFESIONAL EN TRABAJO SOCIAL...

PROFESSIONAL COMPETENCE IN SOCIAL WORK...

\section{AUTORES:}

Roberto A. XXXX-XXXX ${ }^{1}$, Luis A. DE XXX-XXXX², José XXXXX-XXXX

FILIACIÓN PROFESIONAL/INSTITUCIONAL

1. Universidad XXXXX, Dpto. de XXXXXXX, Madrid, España

2. Consejo Superior de Investigaciones Científicas, Instituto de XXX, Granada, España

3. Hospital XXX, Servicio de XXX, Unidad de XXX, Madrid, España

(No hacer referencia a la condición de «residente», «profesor», «catedrático», etc.)

\section{RESPONSABLE CORRESPONDENCIA}

Roberto A. XXXX-XXXX

Universidad XXXXX, Dpto. de XXXXXXX, Madrid, España

Av. MMMMMMM, 273

28007 Madrid, España

E-mail: xxx@internet.com

INSTITUCIÓN RESPONSABLE QUE SOPORTA LA INVESTIGACIÓN Y/O SOPOR-

TE FINANCIERO (en su caso)

Instituto Oftalmológico XXX, Universidad de XXXXXXXX, Madrid, España

Proyecto subvencionado FIS-78/2-1993 del Ministerio de Sanidad

ANTECEDENTES DE DIFUSIÓN (en su caso)

Presentado parcialmente como comunicación al «XX Congreso XXXXXXXX»,

Helsinki, Finlandia, celebrado el XXXXXXXX 
2. Cómo confeccionar una hoja de identificación

SECCIÓN A LA QUE SE DIRIGE EL ARTÍCULO

(especificar)

3. Carta de presentación, de cesión de derechos y de declaración de conflicto de intereses

La carta de presentación tiene la finalidad de ayudar a que el proceso de revisión del manuscrito y la toma de decisiones sobre el mismo sea más rápida y eficiente, y ello en la medida en que informa y adelanta aquellos aspectos y detalles más importantes requeridos por la revista para la toma en consideración de un trabajo, tales como justificación de la elección de la revista, aportaciones del trabajo, declaración de autoría y originalidad, responsabilidades éticas y conflictos de interés, etc.

\begin{tabular}{l}
\hline 3. Carta de presentación y transferencia de derechos de copyright \\
\hline Sr./Sra. director/a de la Revista Alternativas. Cuadernos de Trabajo Social \\
Leídas atentamente las instrucciones a autores, y analizada la cobertura de la revista, \\
considero que la publicación que Vd. dirige es la adecuada para la difusión de nuestro \\
trabajo, por lo que le ruego someta a la consideración de su posible publicación en la \\
sección de \\
el manuscrito que adjunto le remito titulado \\
cuyos autores son \\
de los cuales \\
será el encargado de correspondencia. \\
Las aportaciones originales y novedades que en nuestra opinión el referido manuscrito \\
aporta al estudio de \\
son, en síntesis, las siguientes: \\
\hline \\
\hline Los autores certifican que este trabajo no ha sido publicado ni en todo ni en parte por \\
cualquier otro medio, ni está en vías de consideración para publicación en otra revista. \\
Los autores se responsabilizan de su contenido y de haber contribuido a la concepción, \\
diseño y realización del trabajo, análisis e interpretación de datos, y de haber participado \\
en la redacción del texto y sus revisiones así como en la aprobación de la versión que \\
finalmente se remite. \\
Asimismo, aceptamos la introducción de cambios en el contenido si hubiere lugar tras la \\
revisión y de cambios en el estilo del manuscrito por parte de la redacción de la revista.
\end{tabular}

Alternativas. Cuadernos de Trabajo Social, 22, 2015, pp. 217-233 - ISSN 1133-0473 
3. Carta de presentación y transferencia de derechos de copyright

Cesión de derechos y declaración de conflicto de intereses

Los autores abajo firmantes transfieren los derechos de propiedad (copyright) del presente trabajo al Servicio de Publicaciones de la Universidad de Alicante, como organización editora patrocinadora de la revista Alternativas. Cuadernos de Trabajo Social. Declaramos además estar libres de cualquier asociación personal o comercial que pueda suponer un conflicto de intereses en conexión con el artículo remitido, así como el haber respetado los principios éticos de investigación.

Firmado:

Roberto A. XXX-XXX Luís A. de XXX

José XXX-XXX

Alternativas. Cuadernos de Trabajo Social, 22, 2015, pp. 217-233 - ISSN 1133-0473 



\section{INSTRUCTIONS FOR THE AUTHORS ${ }^{1}$}

\section{General Information}

The Journal Alternativas. Cuadernos de Trabajo Social, ISSN 1133-0473, is a publication of the Department of Social Work and Social Services at the University of Alicante. Originally founded under the same title in 1992 by the University School of Social Work at the University of Alicante, since 2009 the journal has been published by the Department of Social Work and Social Services at the same University. The journal is published annually.

It is a refereed journal, using the peer-review system for external revision by experts in the field and methodology of the research. The publication standards adopted and applied are those detailed in the APA Publication Manual $^{2}$.

It should be noted that indexing of the journal in the leading social work databases is facilitated by compliance with the requirements of the APA Manual; such compliance is therefore of benefit to authors and their centers as it ensures widespread dissemination of the research published.

Each issue of the journal is published in both a printed version and an electronic version; the latter is available on RUA at the University of Alicante (http://rua.ua.es/dspace/handle/10045/5269)

The journal is open to collaboration with other publications.

\section{Scope and Policy}

The primary objective of the Journal Alternativas. Cuadernos de Trabajo Social is to contribute towards the dissemination of research, experiences, and theoretical and methodological studies, of both an academic and professional

1. FECYT Rafael Ruiz-Pérez, Emilio Delgado López-Cózar, Evaristo Jiménez Contreras. Granada University. http://ec3.ugr.es/t.

2. APA (American Psychological Association http://books.apa.org/books.cfm?id= $4200061 \&$ toc $=$ yes $)$ 
practice nature, carried out in Spain or internationally. Such studies may deal specifically with social work, social policies and the social services or come from other disciplines and professions in the area of the Social Sciences, which from a multi- or interdisciplinary perspective serve to enrich and complement the discipline and professional practice of social work.

Submissions must represent original, previously unpublished work which is not being considered for publication in another journal, written in Spanish, English, French or Portuguese. The author bears sole responsibility for the claims made in the article. Under special circumstances, previously published research may be published following consideration by the Editorial Board, when the following condition applies: publication has been through channels which are not easy to access, and the article is of particular professional relevance or scientific interest.

The following are considered for publication: original research, concept papers, practical experience and technical notes.

Original. They must have the following structure: summary, key words, text (introduction, material and methods, results and discussion), thanks and bibliography. The maximum length of the text will be 6.000 words, (in Word format), double-spaced, font size 12, font Times New Roman, with a maximum of 4 figures and 6 tables. Tables and Figures must be submitted on a separate page, numbered sequentially and indicating where they are to be inserted in the article. Only those Tables and Figures necessary to support the arguments presented in the text should be included. It is recommended that the number of authors does not exceed six.

Concept papers and practical experience. Concept papers should comprise a critical analysis of subjects relevant to social work, social policy and the social services. Practical experiences should consist of a rigorous systemization of the process and corresponding results. Both concept papers and practical experiences should include a section detailing the contribution made, or a proposal for application or transfer to social work, social policy the social services or social intervention. Texts will be no longer than 4.000 words in Word format, and should be double spaced in Times New Roman font size 12. Optionally, the text may include Tables and Figures.

Technical notes: These should comprise a brief description of regulations or policies, research in progress, or reports of conferences, seminars or study days of relevance to social work, social policy or the social services. They will be no longer than 1.000 words in Word format, and should be double spaced in Times New Roman font size 12. 


\section{Paper presentation and structure}

The following publication standards are based on APA http://books.apa.org/ books.cfm?id=4200061\&toc=yes

a) The manuscripts must be sent to the Department of Social Work and Social Services (dtsss@ua.es) with a copy to masun.martinez@ua.es, double-spaced, wide margins and with the pages numbered sequentially in the upper right-hand corner. The manuscript shall be accompanied by a cover letter (use the template provided by the journal) asking for the manuscript to be taken into consideration, with the author explaining in 4-5 lines what the original contribution of the work presented is and its new developments, a statement of non-simultaneous submission to other journals and confirmation of the undersigned authors. This letter must also transfer the copyright to the publisher. The author must keep a copy of the original to avoid irreparable loss or damage to the material.

b) Bibliographic quotations must be marked as references following the discussion or thanks, if any. An adequate number of relevant references should be used, and these should be listed in order of appearance in the text, with the corresponding reference number. References should be given as author and year between brackets, separated by a comma (for example, Coob, 1989). Page number or numbers should be included for textual quotes (for example, Coob, 1989: 25-27).

The manuscripts must be presented according to the following order and structure:

Title Page. First page of the manuscript

As the cover of the manuscript, this first must contain:

a) Title of the article (concise, yet informative), in Spanish and English, made up of the greatest number of significant terms possible (taken when possible from a controlled specialty glossary). If necessary, a subtitle may be added, not to exceed 40 letters and spaces, in Spanish and English.

b) First name and two last names of each of the authors, taking into account the signature format for indexing in international databases (see section "Do you know how to reference scientific publications?" the recommendations provided in http://www.accesowok.fecyt.es/)

c) Full name of the work center of each of the authors, which is referenced beside the name of the author with Arabic numerals in parentheses (or superscript). 
d) Name and full address of the person responsible for the work of the lead author as responsible for correspondence, including the phone number and fax number, when appropriate, as well as the e-mail address, if any.

e) Information on grants, aid or financial support provided (Research Projects) to subsidize the work and other specifications, when applicable.

To better prepare this page, see the template (provided by the journal) attached to these instructions on how to prepare the manuscript identification sheet.

Abstract and Key-Word Pages. Second page of the manuscript

A second, separate page must contain the first and last names of the authors, the title of the article and the abbreviated title of the journal, article content summary in Spanish and the list of key words. Both the abstract and the key words must have an English version.

- The Abstract of the work must be between 150 and 250 words. In case of the original articles, the content shall be divided into four sections (structured abstract): Introduction, Material and Methods, Results and Discussion. Each of them must describe, concisely, the purpose and objective of the research, the methodology used, the most important results and the main conclusions, respectively. The innovative and relevant aspects of the work must be emphasized. In the case of Special Collaborations, the work will be summarized, without dividing it into these four sections.

- Key words: Below the abstract, 5 key words or short phrases shall be specified to indicate the content of the work, for inclusion in collections of national and international databases. As many as possible should be provided, up to a maximum of five. The controlled reference terms must be used.

Manuscript text. Third page, which is where the manuscript text begins

The third and following pages are dedicated to the manuscript text, which will comply with the specifications detailed in the instructions above for all submissions. In the case of concept papers and notes, the structured manuscript may be included in the appropriate sections to facilitate comprehension. However, the Original papers must include, to the extent possible, the following sections: Introduction, Material and Methods, Results and Discussion. 
Introduction: You must include the foundation and purpose of the study, using the bibliographic citations that are strictly necessary. Do not include data or conclusions of the work presented. Do not provide a detailed bibliographic review.

Material and Methods: It must presented with sufficient precision so that the reader can understand and confirm the development of the research. Sources and methods published previously should be described just briefly, providing the corresponding quotes, except when they have been modified. The sample size calculation and the sampling method used must be described, when appropriate. Reference must be made to the type of documentary, critical and statistical analysis, etc. used. If it is an original methodology, the reasons for using it must be explained, describing any possible limitations.

When dealing with experimental papers in which groups of humans have been used, indicate whether the ethical criteria has been approved. Neither the names nor the initials of the people participating in the study sample must be used.

Results: These shall appear in a logic sequence in the text, tables or figures, without repeating the same data included in each of them. Try to highlight the important observations. Describe, without interpreting or judging, the observations made with the material and methods used.

Discussion: Summarize the findings, relating the observations of this study with those of other studies of interest, highlighting the contributions and limitations of each. Do not repeat the data or other material already commented in other sections in detail. Mention the inferences from the findings and their limitations, including the deductions for future research. Link the conclusions to the study objectives, avoiding gratuitous affirmations and conclusions that are not fully supported by the study data.

Thanks: Thank only those who have made substantial contributions to the study, but who do not warrant the status of author; the author must obtain their consent in writing. Likewise, the Council Science Editors (CSE) recommend that authors, when appropriate, provide an explicit statement of the source of their research funding, placing it among the thanks (CSE 2000) (Conflicts of Interest and the Peer Review Process. Draft for CSE member review, posted 3/31/00. http://www.cbe.org/services_DraftPolicies.shtml).

Bibliography: The bibliography must be placed after the discussion or the thanks, if any, in the format indicated above, based on the alphabetical order of authors.

The recommended style for the references is indicated below in the examples; it is based on the APA standards. 
- The names of the journals must be abbreviated in accordance with the consensus reached in the area of knowledge, whenever there is a reference list.

- All authors must be mentioned, up to six, or the first six plus "et al" when there are seven or more.

The bibliography must be corrected by the author, correcting it with the copy in his or her possession. Avoid using vague phrases as bibliographical quotations. Do not use those that require clarifications such as "unpublished observations" or "personnel correspondence", although they may be cited in the text in parentheses. Papers that have been accepted, but not yet published, shall be included in the bibliography, specifying the name of the journal, followed by the expression "pending publication".

The bibliographic quotes must be taken from the original documents, always indicating the starting and ending page number of the work from which they are taken. To ensure consistency, at any time during the publishing process, the journal editors may require authors to send the first page (photocopy) of each of the articles quoted in the bibliography.

For journals, given the importance for quotation indexes and Impact Factor calculations, the following shall be cited: a) author(s), with their last name(s) and first name(s). If there is more than one author, they must be separated by a comma. All of them, up to a maximum of six; if there are more than six, the first six shall be indicated, followed by "et al". Place the year, in parentheses and a period after the final author; b) title of the article in the original language, with the appropriate spelling and accents. Place a period after the title; c) correct name of the journal; d) issue number (no.). A comma shall be used to separate this section and section f; and e) first and last pages, separated by a hyphen.

The following are examples of properly referenced bibliographic quotations:

\section{Periodical Publications}

Journal article, one author

Bekerian, D. A. (1992). In search of the typical eyewitness. American Psychologist, 48, 574-576.

Journal article, two authors

Klimowski, R., Palmer, S. (1993). The ADA and the hiring process in organizations. Consulting Psychology Journal: Practice and Research, 45(2), 10-36.

Journal article, three to five authors 
Borman, W. C., Hanson, M. A., Oppler, S. H., Pulakos, E. D., and White, L. A. (1993). Role of early supervisory experience in supervisor performance. Journal of Applied Psychology, 78, 443-449.

Journal article, six authors

Kneip, R. C., Delamater, A. M., Ismond, T., Milford, C., Salvia, L., and Schwartz, D. (1992). Self- and spouse ratings of anger and hostility as predictors of coronary heart disease. Health Psychology, 12, 301-307.

Journal article, pending publication

Bekerian, D. A. (pending publication). In search of the typical eyewitness. American Psychologist.

Bekerian, D. A. (pending publication-a). Role of early supervisory experience in supervisor performance. American Psychologist.

Bekerian, D. A. (pending publication-b). Self- and spouse ratings of anger and hostility as predictors of coronary heart disease. American Psychologist.

Non-English journal article, with the title translated into English

Zajonc, R. B. (1992). Bischofs gefühlvolle Verwirrunggen über die Gefühlle [Bischof's emotional fluster over the emotions]. Psychologische Rundschau, 40, 574-576.

\section{Books and Book Chapters}

References to entire books

Bekerian, D. A. (1992). People in organizations: An introduction to organizational behavior (3rd ed.). New York: McGraw-Hill.

Book, group authorship (governmental agency) as publisher

Australian Bureau of Statistics (1992). Estimated resident population by age and sex in statistical local areas, New South Wales, June 1990 (No. 3209.1). Australian Capital Territory: ABS

Published book

Bekerian, D. A. (Ed.). (1992). People in organizations: An introduction to organizational behavior. New York: McGraw-Hill.

Book without author or publisher

Merriam-Webster's Collegiate Dictionary (10th ed.). Springfield, MA: Merriam-Webster. 
Encyclopedia or dictionary

Bekerian, D. A. (1992). The new Grove dictionary of music and musicians (3rd ed., Vols. 1-20). New York: McGraw-Hill.

English translation of a book

Laplace, P. -S. (1951). A philosophical essay on probabilities (Trans., F. W. Truscott and F. L. Emory). New York: McGraw-Hill. (Original work published in 1814).

Chapter in one volume of a series

Maccoby, E. E. (1992). Socialization in the context of the family. En P. M. Musen (Ed. Serie) and M. J. Martin (Ed. Vol.). Handbook of child psychology: Vol. 4. Socialization, personality, and social development (3rd ed., pgs. 1-101). New York: McGraw-Hill.

\section{Technical and Research Reports}

Report available in the GPO (Government Printing Office), governmental institution as author

National Institute of Mental Health (1992). Clinical training in serious mental illness (Publication DHHS No. ADM 90-1679). Washington, DC: Government Printing Office.

Scientific Meetings (Congresses, symposiums, etc.)

Published congress minutes, contribution published in a symposium, article or chapter in published book

Bekerian, D. A. (1992). A motivational approach to the self. En R. DeMaier (Ed.), Nebraska Symposium of Motivation: Vol. 38. Perspectives on motivation (pgs. 574-596). Lincoln: University of Nebraska Press.

Regularly published minutes

Bekerian, D. A. (1992). In search of the typical eyewitness. Proceedings of the National Academy of Sciences, USA, 89, 574-576.

Unpublished work presented at a congress

Bekerian, D. A. (1992, January). Early data on the Trauma Symptom Checklist for Children (TSC-C). Presentation given at the Congress of the American Professional Society on the Abuse of Children, San Diego, CA. 


\section{Doctoral and Master's Theses}

Unpublished doctoral thesis

Bower, D. L. (1993). Employee assistant programs supervisory referrals: Characteristics of referring and nonreferring supervisors. Unpublished doctoral thesis. University of Missouri, Columbia.

Unpublished Master's thesis, non-American university

Saldaña, P. (1992). Actitudes de los padres hacia la integración escolar. Unpublished Master's thesis, Universidad de Salamanca, Salamanca, Spain.

\section{Reviews}

Review of a book

Baumeister, R. F. (1993). Exposing the self-knowledge myth [Review of the book The self-knower: A hero under control]. Contemporary Psychology, $38,466-467$.

\section{Audiovisual Media}

Film, limited distribution

Bekerian, D. A. (Producer), and Smith, J. N. (Director). (1992). Changing our minds [Film]. (Available from Changing Our Minds, Inc., 170 West End Avenue, Suite 35R, New York, NY 10023).

\section{Electronic Media}

Online journal article, access limited to subscribers

Central Vein Occlusion Study Group. (1993, 2 October). Central vein occlusion study of photocoagulation: Manual of operations [675 paragraphs]. Online Journal of Current Clinical Trials [Online series]. Available in: Doc. No. 92.

\section{References to electronic sources (INTERNET)}

WWW sites

Tilton, J. (1995). Composing good HTML (Vers. 2.0.6). http://www.cs.cmu. edu/ tilt/cgh/ (13 Jan. 1997).

Tables: These must be presented on separate pages, numbered according to their order of appearance in the text with Arabic numerals. They are used to clarify important points; double documentation by means of tables and 
figures shall not be accepted. The titles or footers that accompany them must perfectly explain their content.

Figures: All types of photographs, graphs or drawings are considered figures. They are assigned an Arabic numeral according to their order of appearance in the text, identified by the abbreviated term fig.(s). The legend of each one must be typed, with the corresponding number on a separate sheet. The text in the figures must be in uppercase. They must be designed and presented with good contrast so that quality is not lost in the reduction. Micro-photographs will be accepted in these proportions for publication without reduction.

The publication of figures in color must be specified in advance. The author shall be responsible for the photomechanical expenses.

The figures must clarify the text in a major way, and they must be used in the minimum amount necessary.

Abbreviation: Only standard, universally accepted abbreviations shall be used. See Units, Symbols and Abbreviations. When a term that is used frequently in the text is to be shortened, the corresponding abbreviation must accompany it (in parentheses) the first time it appears. No Roman numerals shall be used in the text; periods shall be used to the right of the zero for decimals, not commas. Trademarks shall not be used except as needed, in which case the first time they are used they shall be accompanied by the symbol.

\section{Editorial process}

Papers shall be submitted together with a cover letter which requests evaluation of the same for publication in one of the sections of the Journal, expressly indicating that it is a work that has not been disseminated or published previously, sent only to the Journal Alternativas. Cuadernos de Trabajo Social for evaluation and publication, if appropriate, as well as the contributions regarding originality and novelty that, according to the authors, the paper contains.

The cover letter must be signed by all authors. The authors are responsible for and must comply with ethical principles, including (if it is the case), authorization from all people appearing in the section of thanks or from those studied during the research whose identification is essential in presenting the results. It shall also include a statement, when appropriate, accepting the introduction of changes to the manuscript by the journal editors.

The Journal's editorial staff shall acknowledge receipt to the authors of the articles they receive, subsequently notifying them of their acceptance or rejection. 
The editorial staff shall pass the work under consideration for publication to the Editorial Board, verifying that it suits the journal's coverage and complies with the publication standards. If it does, it will be reviewed externally.

The manuscripts shall be reviewed anonymously (blind or double blind) by two experts in the study subject and/or methodology used. Based on the external reports, the Journal's editorial staff reserves the right to accept / reject the articles for publication, as well as to make style modifications and/or shorten texts that surpass the established limit, respecting the original content. The protocol used by the journal reviewers shall be made public as annexes to these standards published on the journal's website: http://dtsss.ua.es/ en/alternativascuadernostrabajosocial/editing-rules.html

In the event of differences of opinion between the two evaluators, the article shall be sent to a third evaluator. External paired review will be applied to research, concept papers, and practical experiences. Papers that are reviewed and considered for publication following modification shall be returned within a period of 30 days regardless of whether minor or major corrections are requested. Where necessary, the new version of the text will be submitted again for an external review, and this process will be repeated until the text is definitively accepted by the Journal. The authors will receive the evaluation reports from the reviewers, anonymously, so that they may make (when appropriate) any necessary corrections or replies.

In general, once the external reports have been seen, the factors on which the Journal's editorial staff bases its decision on accepting/rejecting the paper are the following: a) originality: completely original, valuable information, repetition of known results; b) timeliness and novelty; c) relevance: applicability of the results in resolving specific problems; d) significance: advancement of scientific knowledge; e) reliability and scientific validity: verified methodological quality; f) presentation: good writing, organization (logical coherence and material presentation).

The author(s) of accepted articles will receive printing proofs for correction by e-mail in PDF format. These must be returned corrected to the editorial staff of the journal by fax or PDF within 72 hours of receipt. Only minimal corrections may be made to the content of the original manuscript without an extra charge applying.

The author or the lead signatory will receive 1 copy of the Journal after it has been published. 


\section{Ethical responsibility}

It is the responsibility and duty of the editorial staff of the Journal Alternativas. Cuadernos de Trabajo Social to remind its collaborators of the following:

- When describing the experiments carried out on human beings, indicate whether the procedures followed are in compliance with the ethical standards of the responsible human experimentation committee (institutional or regional) and the 1975 Declaration of Helsinki, revised in 2000. No names, initials or other information should identify the centers where the research was conducted.

- The institution financing the research must grant permission for publication.

- The journal does not accept previously published material. The authors are responsible for obtaining the appropriate permission for partially reproducing material (text, tables or figures) from other publications and for citing their source correctly.

Conflict of Interest. The Journal expects the authors to declare any commercial association that may represent a conflict of interest as regards the article submitted.

Authorship. The list of signing authors must include only those who have contributed intellectually to the development of the work. Having assisted in the collection of data or participated in a technique are not in and of themselves sufficient criteria for listing as an author. In general, being listed as an author requires fulfilling the following requirements: a) Participation in the conception and drafting of the work leading to the article in question, b) Participation in drafting the text and in any revisions, c) Having approved the final version to be published.

The Journal waives any liability due to possible conflicts derived from the authorship of the works published in the Journal.

Informed Consent. The authors must mention, in the methods section, that the procedures and controls used with participants were carried out after obtaining an informed consent form.

Copyright Transfer. The manuscript or the cover letter shall include a Rights Identification and Transfer Sheet (provided by the journal) signed by all authors. 


\section{Additional Information}

The Journal confirms receipt all formalities carried out to keep the authors abreast of the status of their manuscript.

The judgments and opinions expressed in the articles and notices published in the Journal are those of the authors and not necessarily of the Editorial Board.

Both the Editorial Board and the publishing company waive all liability for the material published. Neither the Editorial Board nor the publishing company guarantee or support any product advertised in the Journal, nor do they guarantee the claims made by the manufacturer of said product or service.

\section{Protocols for the authors ${ }^{3}$}

\section{Checklist}

(Its purpose is to require the author(s) to review the manuscript one last time as regards its fundamental formal and methodological aspects.)

\section{CHECKLIST}

To facilitate the Reading Committee's work, acceptance of the manuscript for processing and speeding up its possible publication, the author(s) must carry out a final review of the manuscript, verifying the issues included on this list. Once completed, the list must be submitted together with the manuscript. Remember that failure to complete any of the items may be cause for the manuscript to be returned.

1. Attached is a complete copy of the manuscript by e-mail files, in word format, double-spaced, including the bibliographic quotations, and figures.

2. The full title of the manuscript is included in Spanish and English.

3. The abbreviated title of the manuscript and the key words are included in Spanish and English.

4. The summary complies with the publication standards as regards the number of words, and it includes objectives, design or material and methods, results, conclusions and/or discussion.

5. The summary and key words has been translated into English or Spanish and, when possible, reviewed by an expert in that language.

6. The institutional and/or professional affiliations of each author are included

7. The address, telephone number, fax number and e-mail address of the main author or the person responsible for correspondence are included.

8. When applicable, grants, aid or financial support have been stated. Source.

3. (C) Drafted for FECYT by Rafael Ruiz-Pérez, Emilio Delgado López-Cózar, Evaristo Jiménez Contreras. EC3 Research Group. University of Granada. http://ec3.ugr.es/ 


\begin{tabular}{|l|l|}
\hline 1. CHECKLIST \\
\hline $\begin{array}{l}\text { 9. The manuscript follows the structured required in the publication standards and } \\
\text { the specifications from the section to which it is addressed. }\end{array}$ & $\bullet$ \\
\hline $\begin{array}{l}\text { 10. The manuscript describes all sources, materials, equipment and elements used, } \\
\text { both in terms of research groups and in the whole of the study. }\end{array}$ & $\bullet$ \\
\hline $\begin{array}{l}\text { 11. An expert in the subject matter covered by the manuscript could reproduce the } \\
\text { study, experiment, analysis, etc. based on the methodology described. }\end{array}$ & $\bullet$ \\
\hline 12. The conclusions are based on the results obtained. & $\bullet$ \\
\hline 13. When appropriate, statistical analyses were used, reviewed by an expert. & $\bullet$ \\
\hline $\begin{array}{l}\text { 14. The Bibliographic References have been reviewed and they comply with the style } \\
\text { and format in the international standards required by the journal. }\end{array}$ & $\bullet$ \\
\hline $\begin{array}{l}\text { 15. When applicable, the figures and tables provide additional information, not } \\
\text { repeated in the text. Their graphical quality has been verified. }\end{array}$ & $\bullet$ \\
\hline $\begin{array}{l}\text { 16. When appropriate, the units system used has been reviewed. } \\
\text { 17. Abbreviations are detailed the first time they are mentioned in the text. }\end{array}$ & $\bullet$ \\
\hline 18. When appropriate, the ethical standards used are cited. & $\bullet$ \\
\hline $\begin{array}{l}\text { 19. When appropriate, the informed consent forms for experimentation with humans } \\
\text { or animals, as well as reproduction permission, are attached to the manuscript. }\end{array}$ & $\bullet$ \\
\hline $\begin{array}{l}\text { 20. The checklist and cover letter are attached, indicating originality, novelty of the } \\
\text { work and the section of the journal to which it is addressed. }\end{array}$ & $\bullet$ \\
\hline $\begin{array}{l}\text { 21. The cover letter includes an annex signed by the authors, taking responsibility } \\
\text { for authorship and transferring the copyright to the publisher. }\end{array}$ & $\bullet$ \\
\hline
\end{tabular}

\section{Writing the first page of the manuscript}

Also known as the Identification Sheet or Title Page, this protocol provides the author with the appropriate format for providing the manuscript identification data. These data are important not only for the final version of the manuscript that is to be published, but also for indexing in the databases.

\section{PREPARING AN IDENTIFICATION SHEET}

Given the importance of the identification data for the manuscript (First page of the manuscript or Title Page), follow the structure in the following template.

TITLE: spanish and english

COMPETENCIA PROFESIONAL EN TRABAJO SOCIAL...

PROFESSIONAL COMPETENCE IN SOCIAL WORK...

AUTHORS:

Roberto A. XXX-XXX'1, Luís A. de XXX-XXX², José XXX-XXX ${ }^{3}$

PROFESSIONAL/INSTITUTIONAL AFFILIATION

1. XXX University. XXX Dept., Madrid, Spain

2. Higher Council for Scientific Research. Institute of XXX, Granada, Spain

3. XXX Hospital. XXX Service. XXX Unit, Madrid, Spain

(Do not reference status as «resident», «professor», «department head», etc.) 


\begin{tabular}{|l|}
\hline 2. PREPARING AN IDENTIFICATION SHEET \\
\hline CORRESPONDENCE COORDINATOR \\
Roberto A. XXX-XXX \\
XXX University. XXX Dept., Madrid, Spain \\
Av. MMMMMMM 273 \\
28007 Madrid, Spain \\
$\quad$ E-mail: xxx@internet.com \\
\hline INSTITUTION RESPONSIBLE FOR RESEARCH SUPPORT AND/OR FINANCIAL \\
SUPPORT (when applicable) \\
XXX Ophthalmology Institute, XXX University, Madrid, Spain. \\
Subsidized project FIS-78/2-1993 by the Ministry of Health \\
\hline DISSEMINATION HISTORY (when applicable) \\
Presented in part as a speech to the "20th XXXXXXX Congress", Helsinki, Finland, held \\
on XXX \\
\hline SECTION TO WHICH THE ARTICLE IS ADDRESSED \\
Original Articles \\
\hline
\end{tabular}

\section{Cover letter, rights transfer and conflict of interests statement}

The purpose of the Cover Letter is to help make the manuscript review and decision-making process as quick and efficient as possible, in that it provides information and summarizes the most important aspects and details, required by the journal to take the work into consideration, such as justification for choosing the journal, work contributions, authorship and originality statement, ethical and conflict of interest responsibilities, etc. 


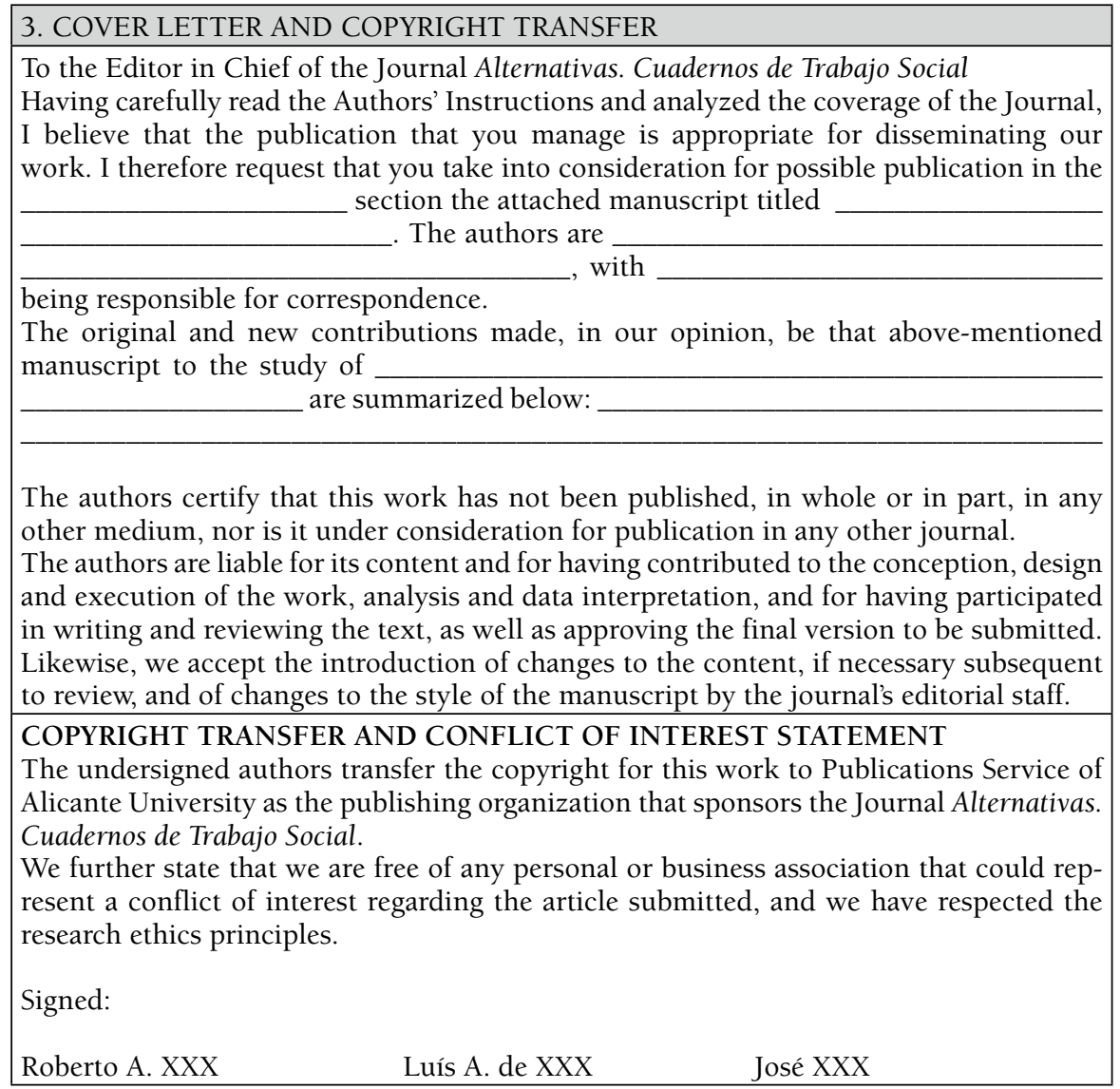




\section{PROTOCOLO REVISORES EXTERNOS}

Estimado revisor:

El modelo que se adjunta pretende ser una ayuda orientada para la realización de su valoración, y no una limitación a la misma. A este protocolo el evaluador puede añadir aquellos aspectos que considere oportunos, a ser posible, en la línea de uno de los fundamentos del Peer Review (revisión por pares), esto es, mejorar la presentación formal y los contenidos científicos del manuscrito cuando éste le merezca una valoración favorable.

Junto a este protocolo, se le remiten las instrucciones para los autores de la revista, si bien, también podrá localizarlas en http://www.ua.es/dpto/dtsss/ publicaciones.htm.

Una vez realizada la evaluación, remitir vía e-mail a Yolanda Doménech López (dtsss@ua.es), con copia a masun.martinez@ua.es.

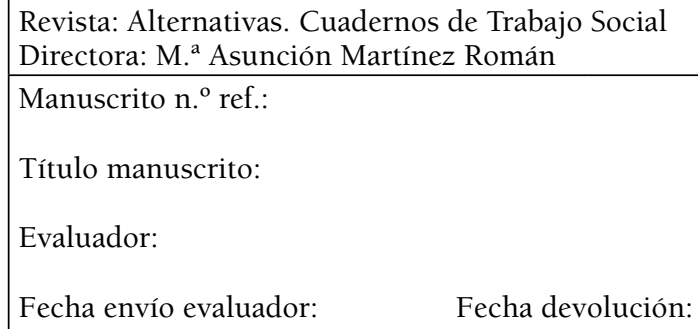




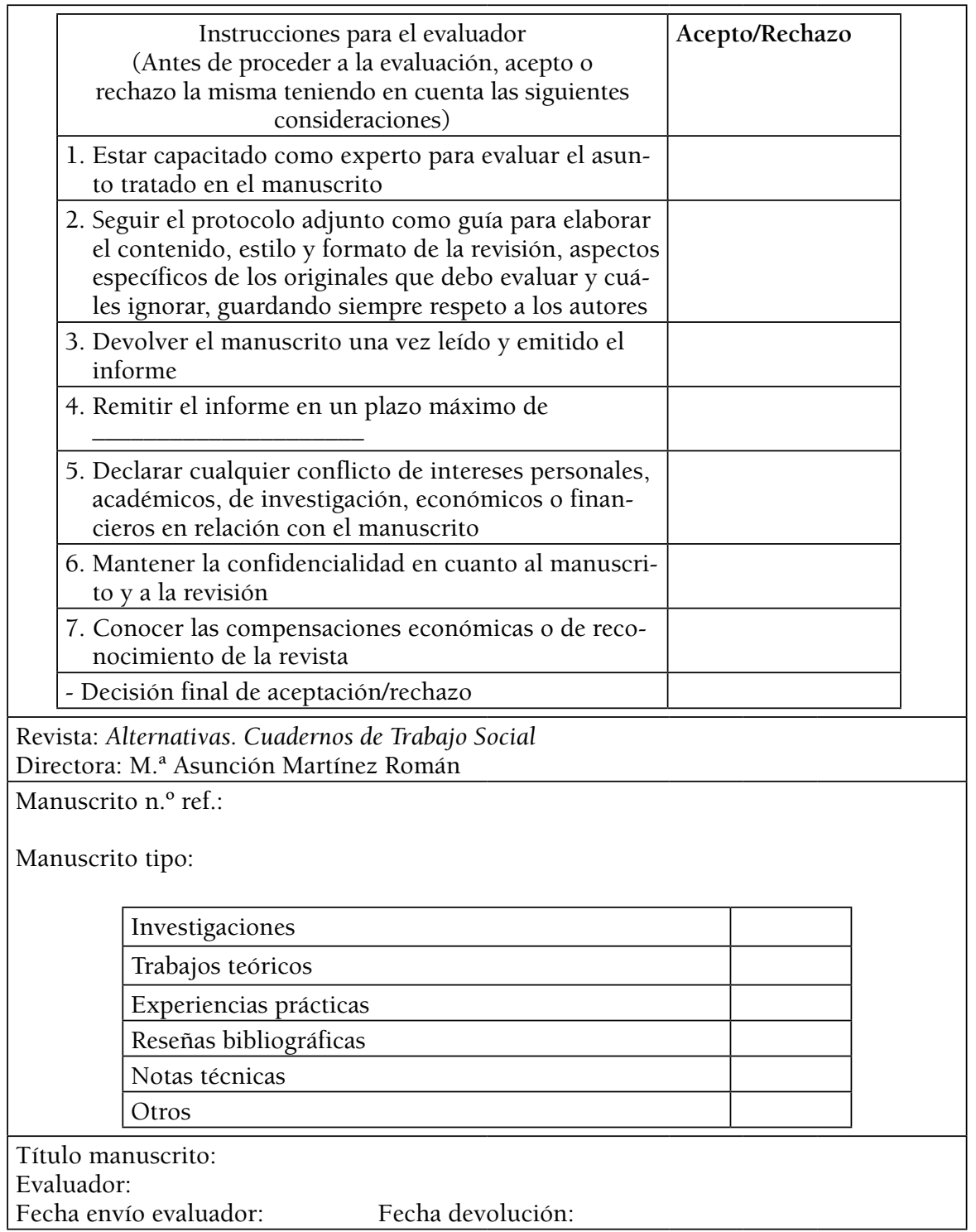




\section{Cumplimentar como conclusión final de la evaluación}

1. Recomendación:

\begin{tabular}{|l|l|}
\hline Aceptar & \\
\hline Aceptar con correcciones menores & \\
\hline $\begin{array}{l}\text { Aceptar con correcciones mayores } \\
\text { (Nuevo proceso de revisión) }\end{array}$ & \\
\hline Rechazar & \\
\hline Prioridad de publicación & \\
\hline
\end{tabular}

2. Valoración global de la calidad del trabajo

\begin{tabular}{|l|l|}
\hline Máxima & \\
\hline Buena & \\
\hline Media & \\
\hline Baja & \\
\hline
\end{tabular}

3. Valoración de originalidad y relevancia (respecto de la información científica que contiene el artículo: a) nueva y valiosa, b) resultados ya conocidos, c) irrelevante)

\begin{tabular}{|l|l|}
\hline Máxima & \\
\hline Media & \\
\hline Baja & \\
\hline
\end{tabular}

4. Aspectos técnicos y científicos:

\begin{tabular}{|l|l|l|l|}
\hline 4.1. Estructura y estilo: & Sí & No & $\begin{array}{c}\text { Mejorar o } \\
\text { cambiar }\end{array}$ \\
\hline 4.1.1. Título adecuado (claro, conciso e informativo) & & & \\
\hline Español & & & \\
\hline Inglés & & & \\
\hline $\begin{array}{l}\text { 4.1.2. Resumen correcto (es claro e incluye los objetivos, } \\
\text { el diseño, los métodos, las variables consideradas, } \\
\text { los principales resultados y las conclusiones más } \\
\text { relevantes) }\end{array}$ & & & \\
\hline Español & & & \\
\hline Inglés & & No & $\begin{array}{c}\text { Mejorar o } \\
\text { cambiar }\end{array}$ \\
\hline $\begin{array}{l}\text { 4.1.3. La estructura del discurso es adecuada } \\
\text { 4.1.4. El estilo es apropiado (claro, conciso y sigue una se- } \\
\text { cuencia lógica) }\end{array}$ & & & \\
\hline $\begin{array}{l}\text { 4.2. Fundamentación, metodología, } \\
\text { resultados y discusión }\end{array}$ & & & \\
\hline $\begin{array}{l}\text { 4.2.1. El tema, asunto o problema general ise identifica de } \\
\text { forma inmediata y clara? }\end{array}$ & & & \\
\hline $\begin{array}{l}\text { 4.2.2. El tema(s), asunto o problema específico ise delimita } \\
\text { y define con claridad? }\end{array}$ & & & \\
\hline
\end{tabular}




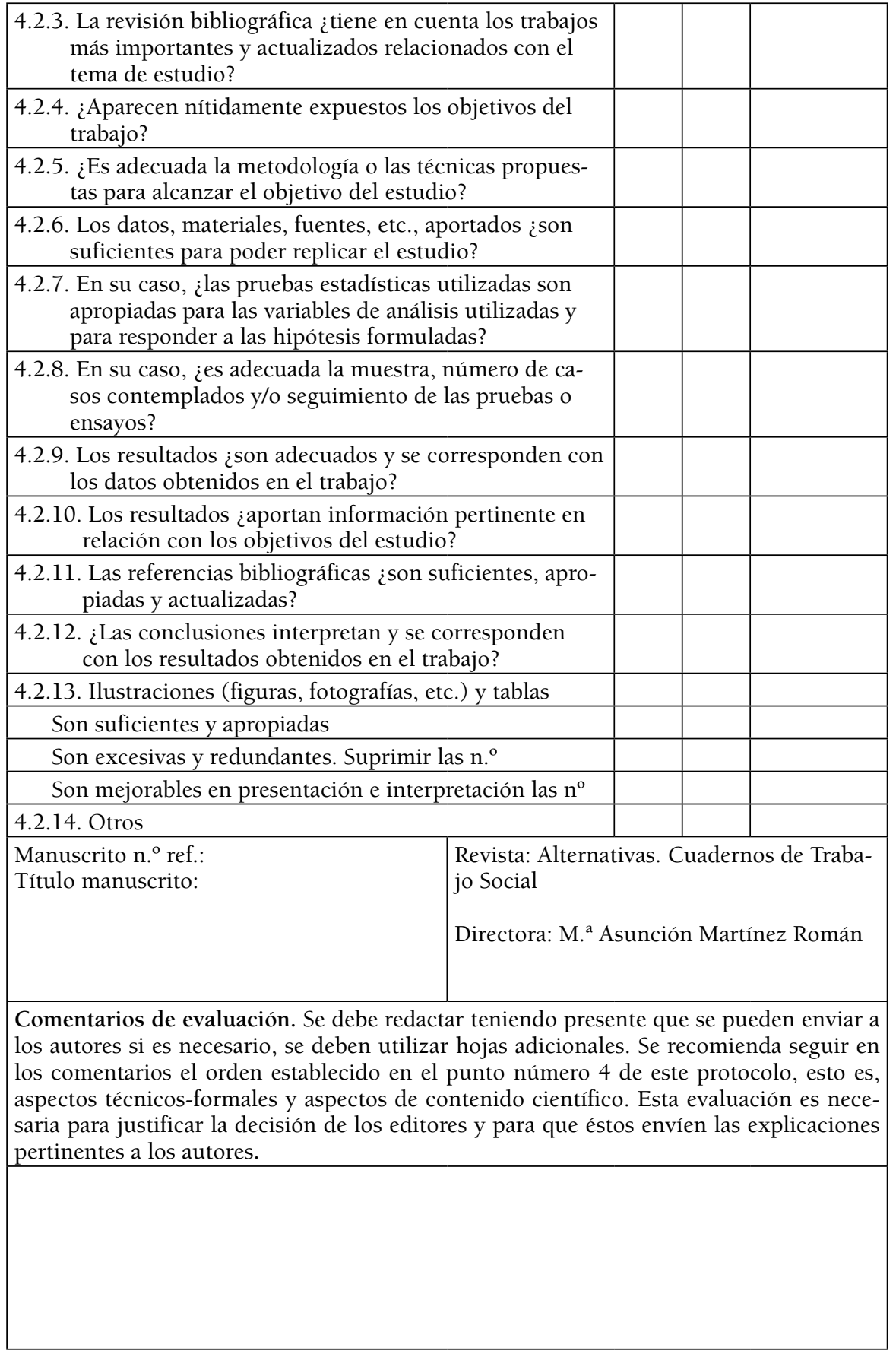




\begin{tabular}{|l|l|}
\hline $\begin{array}{l}\text { Manuscrito } \mathrm{n}^{\circ}: \\
\text { Manuscrito Título: }\end{array}$ & $\begin{array}{l}\text { Revista: Alternativas. Cuadernos de Traba- } \\
\text { jo Social }\end{array}$ \\
\hline Evaluador: & Directora: Ma Asunción Martínez Román \\
\hline $\begin{array}{l}\text { Comentarios confidenciales (Comentarios sólo con respecto a la aceptabilidad del ma- } \\
\text { nuscrito, sólo para el editor) }\end{array}$ & \\
\hline
\end{tabular}

Tras revisar el artículo, declaro: Que no tengo interés financiero ni intelectual, ni personal en relación con el mismo y que no difundiré la información obtenida a través de su revisión previamente a su publicación

Nombre y apellidos:

Lugar y fecha:

Firmado:

Alternativas. Cuadernos de Trabajo Social, 22, 2015, pp. 251-255 - ISSN 1133-0473 



\section{EXTERNAL REVIEWERS' PROTOCOL}

Dear reviewer, The attached template is intended as a guideline for conducting the assessment, but not a limitation to the same. The evaluator may add any aspects to this protocol deemed to be appropriate, in line, when possible, with one of the principles of the Peer Review; that is, to improve the formal presentation and scientific content of the manuscript when it is worthy of a favorable assessment.

The Instructions for the Authors for the journal are also included, although they can also be found on the website http://www.ua.es/dpto/dtsss/ publicaciones.htm

Once completed, send the evaluation by e-mail to Yolanda Domenech López(dtsss@ua.es),with copy to masun.martinez@ua.es

Journal: Alternativas. Cuadernos de Trabajo Social

Editor in Chief: M. ${ }^{a}$ Asunción Martínez Román

Manuscript Ref. No.:

Manuscript Title:

Evaluator:

Date sent to evaluator: Date returned: 


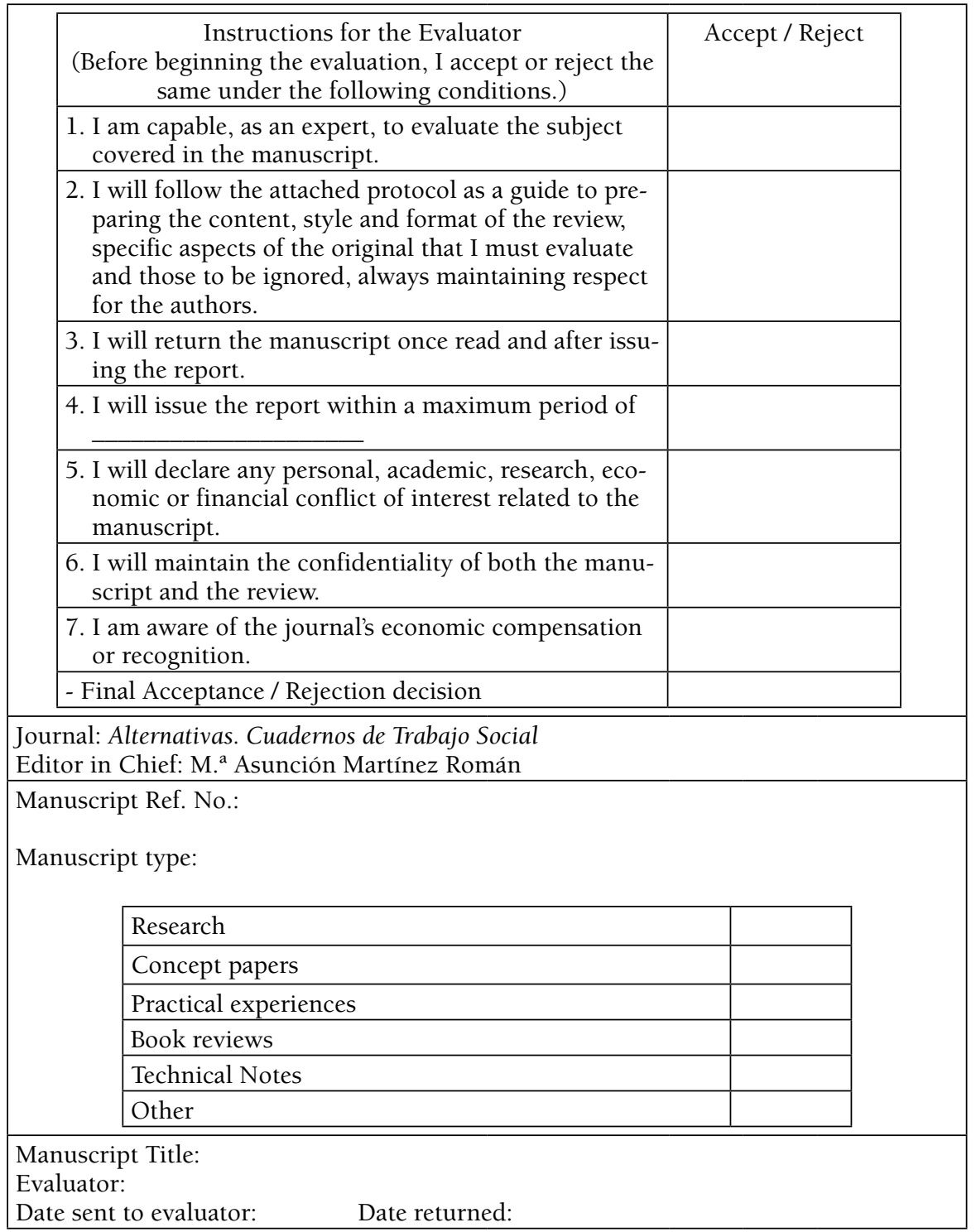




\section{Complete as final evaluation conclusion}

1. Recommendation:

\begin{tabular}{|l|l|}
\hline Accept & \\
\hline Accept with minor corrections & \\
\hline $\begin{array}{l}\text { Accept with major corrections } \\
\text { (New review process) }\end{array}$ & \\
\hline Reject & \\
\hline Publication priority & \\
\hline
\end{tabular}

2. Overall assessment of the quality of the work:

\begin{tabular}{|l|l|}
\hline Highest & \\
\hline Good & \\
\hline Average & \\
\hline Low & \\
\hline
\end{tabular}

3. Originality and relevance assessment (regarding the scientific information contained in the article: -new and valuable, -results already known, - irrelevant):

\begin{tabular}{|l|l|}
\hline Highest & \\
\hline Average & \\
\hline Low & \\
\hline
\end{tabular}

4. Technical and scientific aspects:

\begin{tabular}{|c|c|c|c|}
\hline 4.1. Structure and style & Yes & No & $\begin{array}{c}\text { Improve or } \\
\text { Change }\end{array}$ \\
\hline \multicolumn{4}{|l|}{ 4.1.1. Appropriate title (clear, concise and informative) } \\
\hline \multicolumn{4}{|l|}{ Spanish } \\
\hline \multicolumn{4}{|l|}{ English } \\
\hline \multicolumn{4}{|l|}{$\begin{array}{l}\text { 4.1.2. Correct summary (it is clear and includes the objec- } \\
\text { tives, design, methods, variables considered, primary } \\
\text { results and most relevant conclusions) }\end{array}$} \\
\hline \multicolumn{4}{|l|}{ Spanish } \\
\hline \multicolumn{4}{|l|}{ English } \\
\hline \multicolumn{4}{|l|}{ 4.1.3. The structure of the discussion is appropriate } \\
\hline \multicolumn{4}{|l|}{$\begin{array}{l}\text { 4.1.4. The style is appropriate (clear, concise and following } \\
\text { a logical sequence) }\end{array}$} \\
\hline 4.2. Foundation, methodology, results and discussion & Yes & No & $\begin{array}{c}\text { Improve or } \\
\text { Change }\end{array}$ \\
\hline \multicolumn{4}{|l|}{$\begin{array}{l}\text { 4.2.1. Is the theme, subject or general problem identified } \\
\text { immediately and clearly? }\end{array}$} \\
\hline \multicolumn{4}{|l|}{$\begin{array}{l}\text { 4.2.2. Are the theme(s), subject or specific problem } \\
\text { outlined and defined clearly? }\end{array}$} \\
\hline $\begin{array}{l}\text { 4.2.3. Does the bibliographic review take into consideration } \\
\text { the most important and up-to-date works related to } \\
\text { the study theme? }\end{array}$ & & & \\
\hline
\end{tabular}

Alternativas. Cuadernos de Trabajo Social, 22, 2015, pp. 257-261 - ISSN 1133-0473 


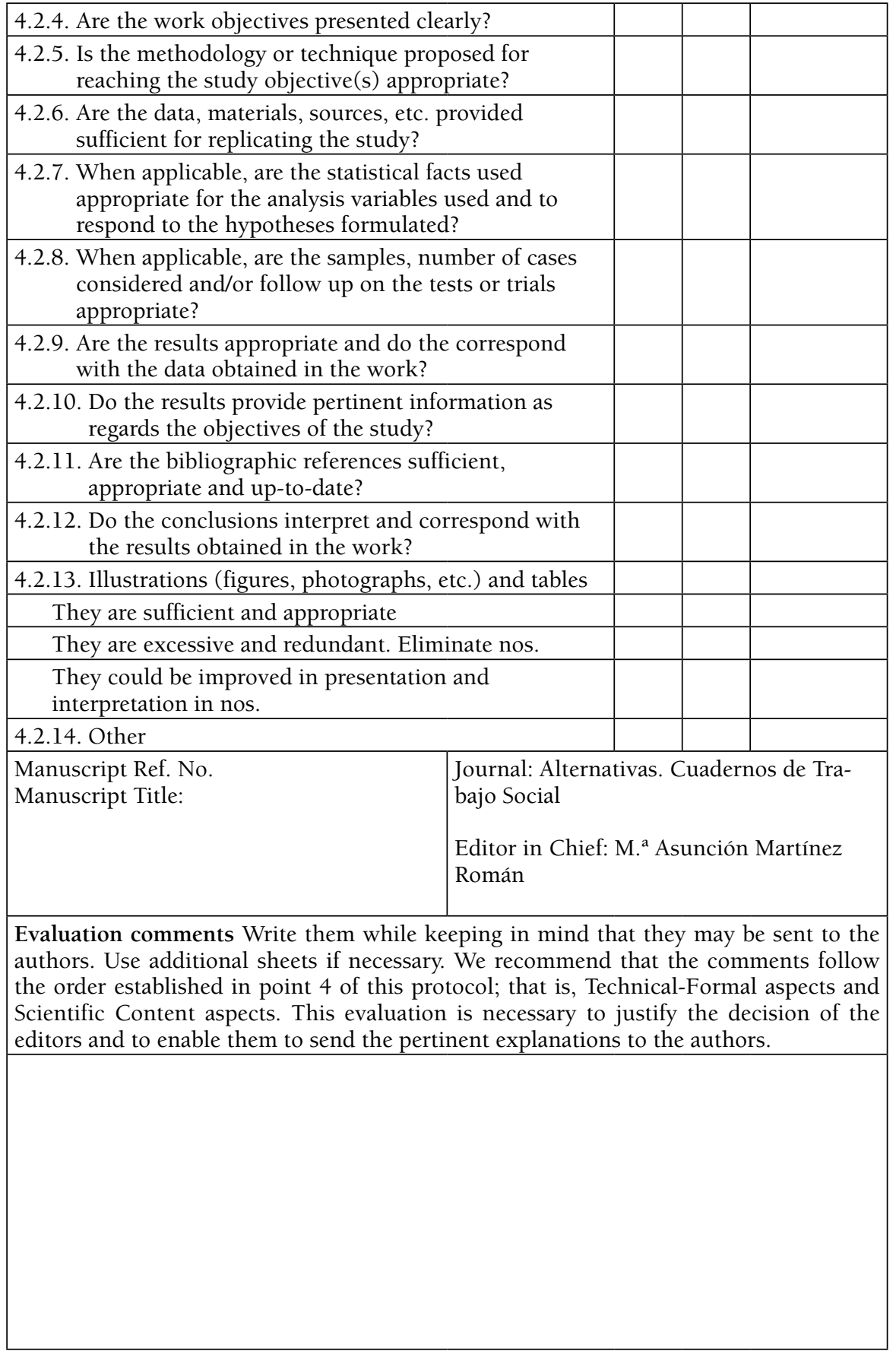




\begin{tabular}{|l|l|}
\hline $\begin{array}{l}\text { Manuscript } \mathrm{N}^{\circ} .: \\
\text { Manuscript Title: }\end{array}$ & $\begin{array}{l}\text { Journal: Alternativas. Cuadernos de Tra- } \\
\text { bajo Social } \\
\text { Editor in Chief: M. }{ }^{a} \text { Asunción Martínez } \\
\text { Román }\end{array}$ \\
\hline Evaluator: & C (Comments on the acceptability of the manuscript only; for the Editor only). \\
\hline
\end{tabular}

I have reviewed the article and hereby declare: that I have no financial, intellectual or personal interest in this article and that I will not disseminate the information obtained through the review of the article prior to its publication.

Name:

Location and date:

Signed.

Alternativas. Cuadernos de Trabajo Social, 22, 2015, pp. 257-261 - ISSN 1133-0473 



\section{LISTADO DE EVALUADORES 2014-2015}

Belén Agrela Romero

Manuel Aguilar Hendrickson

Ma José Aguilar Idáñez

Javier Arza Porras

Tomasa Bañez Tello

José Manuel Barbero García

Carmen Barranco Expósito

Evaristo Barrera Algarín

Mercedes Botija Yagüe

José Francisco Campos Vidal

Andrea Capilla Pérez

Josefa Cardona Cardona

Julia del Carmen Chávez Carapia

Yolanda de la Fuente Robles

Natividad De la Red Vega

Pablo De la Rosa Gimeno

$\mathrm{M}^{\mathrm{a}}$ José Escartín Caparrós

Eva Espinar Ruiz

Teresa Facal Fondo

Fernando Fantova

Josefina Fernández Barrera

Jorge Ferreira

Rosario Isabel Ferrer Cascales

Josefa Fombuena Valero

Francisco Francés García

$\mathrm{M}^{\mathrm{a}}$ del Castillo Gallardo Fernández

Aranzazu Gallego Molinero
Universidad de Jaén

Universitat de Barcelona

Universidad de Castilla-La Mancha

Universidad Pública de Navarra

Universitat de Barcelona

Universitat de Girona

Universidad de la Laguna

Universidad Pablo de Olavide

Universidad de Valencia

Universidad de las Islas Baleares

Unviersidad de Huelva

Universitat de Les Illes Balears

Universidad Nacional Autónoma de

México

Universidad Internacional de Andalucía

Universidad de Valladolid

Universidad de Valladolid

Universidad de Alicante

Universidad de Alicante

Universidad de Santiago de Compostela

Consultor Social

Universitat de Barcelona

ISCTE - Instituto Universitario de

Lisboa

Universidad de Alicante

Universitat de València

Universidad de Alicante

Universidad Pablo de Olavide

Universidad de Granada 
Silvia García Dauder

María Paz García-Longoria Serrano

María Teresa Gijón Sánchez

Diana Gil González

Manuel Gil Parejo

Josefa Gómez Moya

Antonio Gorri Goñi

Pilar Hilarión Madariaga

Izaskun Ibabe Erostarbe

Marta Llobet Estany

Trinidad López Espigares

Carmen Mañas Viejo

Emilia Martínez Brawley

Miguel Angel Mateo Pérez

Óscar Mateos Martín

Manuel Enrique Medina Tornero

Roberto Mohedano Menéndez

Amalia Morales Villena

Rosalía Mota López

$\mathrm{M}^{\mathrm{a}}$ de las Olas Palma García

Belén Parra Ramajo

Enrique Pastor Seller

$\mathrm{M}^{\mathrm{a}}$ Carmen Pérez Belda

José Vicente Pérez Cosín

Begoña Pérez Eransus

Laura Ponce de León Romero

Juan María Prieto Lobato

Carmina Puig Cruells

Ángela María Quintero Velásquez

Clarisa Ramos Feijóo

Esther Raya Díez

Vicenta Rodríguez Martín

Luis Miguel Rondón García

Isabel Royo Ruíz

Jordi Sancho Salido

Juana Dolores Santana Hernández

$\mathrm{M}^{\mathrm{a}}$ Luisa Setién Santamaría

Emma Sobremonte Mendicuti
Universidad Rey Juan Carlos

Universidad de Murcia

Universidad de Málaga

Universidad de Alicante

Universidad Pontificia de Comillas

Universidad de Valencia

Universidad Pública de Navarra

Universitat Autónoma de Barcelona

Universidad del País Vasco

Universitat de Barcelona

Universidad de Málaga

Universidad de Alicante

Arizona State University

Universidad de Alicante

Universitat Ramon Llull

Universidad de Murcia

Universidad de Alicante

Universidad de Granada

Universidad de Comillas

Universidad de Málaga

Universitat de Barcelona

Universidad de Murcia

Universidad de Alicante

Unviersidad de Valencia

Universidad Pública de Navarra

Universidad Nacional de Educación a

Distancia

Universidad de Valladolid

Universitat Rovira i Virgili

Universidad de Antioquia

Universidad de Alicante

Universidad de La Rioja

Universidad de Castilla-La Mancha

Universidad de Málaga

Universidad de Valencia

Universitat de Barcelona

Universidad de la Laguna

Universidad de Deusto

Universidad de Deusto 
Eva Sotomayor Morales

Graciela Tonon

José María Tortosa Blasco

Natalia Ixchel Vázquez

Octavio Vázquez Aguado

Carmen Verde Diego

Cristina Villalba Quesada

$\mathrm{M}^{\mathrm{a}}$ Teresa Yeves Bou
Universidad de Jaén

Universidad Nacional de la Matanza

Universidad de Alicante

Universidad Autónoma del Estado de

México

Universidad de Huelva

Universidad de Vigo

Universidad Pablo de Olavide

Universidad de Valencia 
